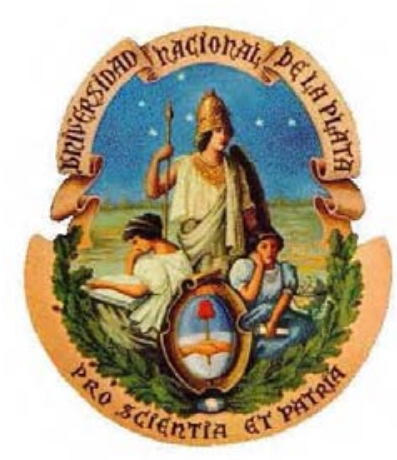

ALGORITMOS MATEMÁTICOS Y COMPUTACIONALES PARA LA DETECCIÓN AUTOMÁTICA DE SEÑALES SÍSMICAS

\author{
por \\ Juan Ignacio Sabbione \\ Geofísico, Universidad Nacional de La Plata, Argentina
}

Director:

Dr. Danilo R. Velis

TESIS DE DOCTORADO EN GEOFÍSICA

Facultad de Ciencias Astronómicas y Geofísicas

Universidad Nacional de La Plata

Marzo de 2012 



\title{
ALGORITMOS MATEMÁTICOS Y COMPUTACIONALES PARA LA DETECCIÓN AUTOMÁTICA DE SEÑALES SÍSMICAS
}

\author{
TESIS PRESENTADA EN CUMPLIMIENTO DE LOS REQUISITOS \\ PARA OBTENER EL GRADO DE \\ Doctor EN GEOFísicA \\ en la \\ Facultad de Ciencias Astronómicas y Geofísicas \\ Universidad NaCIONAL DE LA Plata
}

Por: Juan Ignacio Sabbione

Director: Dr. Danilo R. Velis

Jurado: Dr. Mauricio D. Sacchi

Dra. Claudia L. Ravazzoli

Dra. Patricia M. Gauzellino

Facultad de Ciencias Astronómicas y Geofísicas

Universidad Nacional de La Plata

Paseo del Bosque s/n

(1900) La Plata

Argentina

Marzo de 2012

(C) Juan Ignacio Sabbione, 2012 



\section{Resumen}

Este trabajo de Tesis tiene por objetivo general dar soluciones a diferentes problemas relacionados con la detección automática de señales sísmicas. Dichos problemas incluyen (1) el picado de los tiempos de los primeros arribos en exploración sísmica, (2) la detección y determinación de los tiempos de llegada de fases de terremotos en registros de estaciones sismológicas, y (3) la declaración y picado de los arribos de eventos en registros de microsismicidad. Para ello, se estudian diversos atributos sísmicos convencionales y no convencionales diseñados para realzar la llegada de las señales de interés por sobre el ruido de fondo de los datos. A partir de estos atributos se proponen nuevos algoritmos, estrategias y métodos para detectar las señales buscadas de forma eficiente, automática y precisa. En particular, se analiza la dimensión fractal de la traza sísmica, se aclaran algunas suposiciones teóricas e hipótesis que deben realizarse al considerar una traza sísmica como una curva fractal, y se evalúan distintas estrategias para estimar su dimensión. A partir de ejemplos con datos sintéticos y reales, se prueba que la dimensión fractal obtenida a través del método del variograma es un atributo que evidencia claramente la transición entre el ruido y la señal con ruido. Se desarrollan también tres nuevos métodos para detectar los tiempos de los primeros arribos en registros sísmicos complejos de forma automática. Los atributos en los que se basan estos nuevos algoritmos están dados por un cociente de energías, por la entropía de la traza sísmica, y por su dimensión fractal, aprovechando en este último caso los resultados del análisis previo. Los cambios detectados en los atributos son realzados mediante la aplicación de un filtro de suavizado que preserva los saltos bruscos. Estos algoritmos determinan los primeros arribos analizando las trazas sísmicas individualmente. Se introduce luego un novedoso proceso de corrección de picados erróneos que considera simultáneamente todo el conjunto de las trazas pertenecientes a un mismo registro de disparo común teniendo en cuenta la alineación aproximada de los primeros arribos dada por el modelo de refracción. Este procedimiento permite además descartar las trazas malas de forma automática. Los métodos propuestos son luego mejorados y aplicados a un gran volumen de datos reales provistos por la industria que presentan distintos desafíos y dificultades. Para estudiar la detección de señales en sismología, se realiza un análisis comparativo entre ocho métodos 
de detección automática de fases de terremotos. El conjunto de ocho métodos analizado está formado por la adaptación de los tres algoritmos desarrollados para picar primeros arribos, por tres métodos tradicionales, y por dos métodos obtenidos a partir de modificaciones a dos de los métodos tradicionales. El estudio es llevado a cabo utilizando registros obtenidos en la Estación Sismológica de La Plata (LPA). Como resultado, se realiza una valoración relativa de los ocho métodos de detección en la que algunos de ellos se destacan por sobre otros, y se obtienen así herramientas computacionales para realizar la detección automática de fases de terremotos en estaciones sismológicas. Por último, se seleccionan tres de estos ocho métodos y a partir de ellos se genera una nueva metodología para detectar microsismos de forma automática que consta de dos pasos. En el primer paso se detectan y determinan todos los tiempos de aquellos eventos que representan un potencial arribo de un microsismo, traza por traza en todo el registro. En el segundo paso, se utiliza un criterio que analiza todo el registro en su conjunto para declarar la presencia de microsismos. Como resultado se obtienen el número de microsismos declarados, un indicador de confianza asociado a cada uno de ellos, y los tiempos de llegada para aquellas trazas en las que el evento es detectado. 


\section{Índice}

Resumen $\quad$ v

Listado de tablas $\quad x$

Listado de figuras $\quad$ xii

Agradecimientos $\quad$ xvii

1 Introducción general $\quad 1$

1.1 Atributos sísmicos y detección de eventos . . . . . . . . . . . . . 2

1.2 Detección de señales en exploración sísmica . . . . . . . . . . . 4

1.3 Detección de señales en sismología . . . . . . . . . . . . . 6

1.4 Detección de señales en estudios de microsismicidad . . . . . . . . . 8

1.5 Descripción de los contenidos y objetivos . . . . . . . . . . . . . . 11

1.6 Aportes originales . . . . . . . . . . . . . . . . . 14

2 La dimensión fractal de la traza sísmica $\quad 17$

2.1 Dimensión fractal, curvas auto-similares, curvas auto-afines, y su uso en ciencias de la Tierra . . . . . . . . . . . . . . . . . . 19

2.2 El método del compás $(\mathrm{CM}) \ldots \ldots \ldots . \ldots . \ldots . \ldots 21$

2.3 El método del variograma $(\mathrm{VM}) \ldots \ldots . \ldots . \ldots . . \ldots . . \ldots 23$

2.4 Algoritmos implementados para analizar la señal sísmica . . . . . . . . 25

2.5 Ejemplos y resultados . . . . . . . . . . . . . . . . 27

2.5.1 Aplicación en datos sintéticos . . . . . . . . . . . . 27

2.5.2 Aplicación en datos reales . . . . . . . . . . . . . . 35

2.6 Conclusiones del capítulo . . . . . . . . . . . . . . . . 36

3 Nuevos algoritmos y técnicas para detectar primeros arribos sísmicos 38

3.1 Análisis por traza . . . . . . . . . . . . . . . . 40

3.1 .1 Método de Coppens modificado (MCM) . . . . . . . . . . 41

3.1 .2 Método de la entropía $(\mathrm{EM}) \ldots \ldots . \ldots . \ldots 44$ 
3.1.3 Método de la dimensión fractal (FDM) . . . . . . . . . . . 46

3.1.4 Selección de parámetros ................... 50

3.2 Análisis por registro . . . . . . . . . . . . . . . . 51

3.2 .1 Corrección de picados erróneos . . . . . . . . . . . 51

3.2 .2 Algoritmo final . . . . . . . . . . . . . . . . . 54

3.3 Resultados con datos reales . . . . . . . . . . . . . . . 55

3.3 .1 Análisis de sensibilidad . . . . . . . . . . . . . . . . . 59

3.4 Mejoras y aplicación en datos de proyectos sísmicos 2D y 3D . . . . 60

3.4 .1 Ajuste de los picados . . . . . . . . . . . . . . . 61

3.4.2 Restricción según el offset . . . . . . . . . . . . . 62

3.4.3 Restricción en tiempo por un modelo inicial de refracción . . . . . 63

3.4 .4 Corrección estática por elevación . . . . . . . . . . . 67

3.4.5 Ejemplos de los resultados obtenidos con las mejoras incorporadas 67

3.5 Conclusiones del capítulo . . . . . . . . . . . . . . . . . . 71

4 Detección automática de fases de terremotos $\quad \mathbf{7 4}$

4.1 Métodos utilizados . . . . . . . . . . . . . . . . 76

4.1 .1 Método de Allen (RAM) . . . . . . . . . . . . 77

4.1.2 Método de Baer y Kradolfer (MBK) . . . . . . . . . . . 78

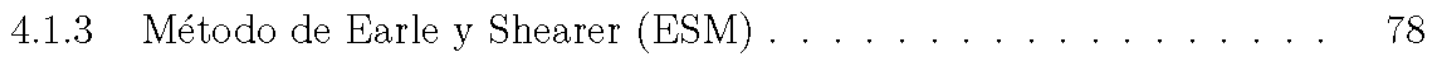

4.1.4 Método de Coppens modificado adaptado (MCM) . . . . . . . . . 79

4.1 .5 Método de la entropía adaptado (EM) . . . . . . . . . . . 80

4.1.6 Método de la dimensión fractal adaptado (FDM) . . . . . . . . 80

4.1 .7 Método de Allen modificado (MAM) . . . . . . . . . . 82

4.1.8 Método de Baer y Kradolfer modificado (MBKM) . . . . . . . . . 82

4.1 .9 Selección de parámetros . . . . . . . . . . . . . . 83

4.2 Datos de la Estación Sismológica de La Plata (LPA) . . . . . . . . . 85

4.3 Análisis comparativo de los métodos . . . . . . . . . . . . . . . 89

4.4 Conclusiones del capítulo . . . . . . . . . . . . . . . . . 94

5 Detección automática de eventos microsísmicos $\quad 97$

5.1 Datos . . . . . . . . . . . . . . . . . . . . . . . 99

5.2 Metodología propuesta y resultados . . . . . . . . . . . . . 104

5.2.1 Detección de eventos traza por traza . . . . . . . . . . . . . 104 
5.2.2 Declaración de microsismos mediante un criterio multitraza . . . 108

5.2 .3 Indicador de confianza para los microsismos declarados . . . . . . 111

5.3 Análisis global de los resultados . . . . . . . . . . . . . . . . 113

5.4 Conclusiones del capítulo . . . . . . . . . . . . . . . . . 119

6 Conclusiones generales y trabajos futuros $\quad 122$

$\begin{array}{lr}\text { Apéndice } & 128\end{array}$

$\begin{array}{lr}\text { A El filtro EPS } & 128\end{array}$

$\begin{array}{lr}\text { Referencias } & 130\end{array}$ 


\section{Listado de tablas}

3.1 Los tres conjuntos de datos de campo utilizados para ilustrar los métodos de picado y los parámetros seleccionados para cada método. El intervalo de muestreo $\Delta t$ está dado en milisegundos. Todas las cantidades, excepto $\beta$ y $S N R$, están dadas en muestras. En el caso en que $n_{p e r}$ sea impar, redondeamos $1.5 n_{\text {per }}$ al entero siguiente. . . . . . . . . . .

3.2 Rangos de variación de los parámetros de los diferentes métodos para realizar el análisis de sensibilidad. Todas las cantidades están dadas en muestras. En el caso en que $n_{p e r}$ sea impar, redondeamos $0.5 n_{p e r}, 1.5 n_{p e r}$ o $2.5 n_{\text {per }}$ al entero siguiente. . . . . . . . . . . . . . .

3.3 Desviación estándar media (en ms) de los picados por registro calculadas para el análisis de sensibilidad. . . . . . . . . . . . . . . .

4.1 Parámetros utilizados en la detección automática de fases. Las longitudes de las ventanas y de los filtros están dadas en segundos. El resto de los parámetros, incluyendo los valores de los umbrales para declarar los eventos, son adimensionales. . . . . . . . . . . . . . .

4.2 Datos de los terremotos seleccionados y los tiempos observados (o calculados) de las 30 fases utilizadas para analizar los métodos. La distancia epicentral $\Delta$ y la profundidad de foco $Z_{f}$ están en $\mathrm{Km}$, la magnitud momento $M_{w}$ es adimensional y los tiempos están en hh:mm:ss. Las 5 fases que se muestran en cursiva son aquellas sólo detectadas por algunos de los métodos, y cuyos arribos teóricos fueron calculados mediante el modelo IASP91. . . . . . . . . . . . . . . . . . . . .

5.1 Parámetros utilizados en la detección automática de eventos de microsismos en el análisis traza por traza. Las longitudes de las ventanas y de los filtros están dadas en milisegundos. El resto de los parámetros, incluyendo los valores de los umbrales para declarar los eventos, son adimensionales. 
5.2 Picado "preliminar": cantidad de eventos picados por traza y por registro para cada método. . . . . . . . . . . . . . . . 107

5.3 Indicadores de confianza de los microsismos detectados por los métodos para los tres registros utilizados. . . . . . . . . . . . . . . . . . . 114 


\section{Listado de figuras}

2.1 Una curva fractal (azul) es aproximada usando una abertura de compás constante en $N$ pasos (rojo). El último paso es más corto ("resto"). . . .

2.2 Gráfico de Mandelbrot-Richardson para obtener la pendiente en el dominio bilogarítmico. Las muestras de la curva en azul son aproximadas por mínimos cuadrados por la recta en rojo.

2.3 Ventana móvil usada para el cálculo de la dimensión fractal en los dos métodos presentados. En este ejemplo, la ventana sólo abarca ruido. . . . 26

2.4 Modelo de velocidades de los datos sintéticamente generados. . . . . . . . 28

2.5 Registro sintético generado $(S N R=10)$. (a) Con ruido de alta frecuencia. (b) Con ruido de "baja" frecuencia. Las líneas verdes indican los arribos verdaderos de la señal. . . . . . . . . . . . . . . . . . .

2.6 Traza sísmica sintéticamente generada con ruido agregado con $S N R=10$ (azul), dimensión fractal del compás calculada (rojo) y arribo real de la señal (verde). (a) El ruido adicionado es de alta frecuencia. (b) El ruido adicionado es de baja frecuencia. . . . . . . . . . . . . . . . . .

2.7 Traza sísmica sintéticamente generada con ruido agregado con $S N R=7$ (azul), dimensión fractal del variograma calculada (rojo) y arribo real de la señal (verde). (a) El ruido adicionado es de alta frecuencia. (b) El ruido adicionado es de baja frecuencia. . . . . . . . . . . . . . .

2.8 Dimensión fractal del compás correspondiente al registro mostrado en la Figura $2.5(S N R=10)$. (a) El ruido adicionado es de alta frecuencia. (b) El ruido adicionado es de baja frecuencia. . . . . . . . . . . . . .

2.9 Dimensión fractal del variograma correspondiente al registro mostrado en la Figura $2.5(S N R=10)$. (a) El ruido adicionado es de alta frecuencia. (b) El ruido adicionado es de baja frecuencia. . . . . . . . . . . .

2.10 Registro sintético generado $(S N R=7)$. (a) Con ruido de alta frecuencia. (b) Con ruido de "baja" frecuencia. Las líneas verdes indican los arribos verdaderos de la señal. 
2.11 Dimensión fractal del variograma correspondiente al registro mostrado en la Figura $2.10(S N R=7)$. (a) El ruido adicionado es de alta frecuencia. (b) El ruido adicionado es de baja frecuencia. . . . . . . . . . . . .

2.12 (a) Registro sísmico marino (registro de disparo común número 39 de Yilmaz [75]). (b) Dimensión fractal obtenida mediante el método del variograma $(\mathrm{VM}) \ldots \ldots \ldots \ldots \ldots$

3.1 Esquema de ventanas utilizado en el MCM. . . . . . . . . . . . .

3.2 (a) Traza sísmica (azul) y primer arribo picado por el COP (triángulo verde) y por el MCM (cuadrado rojo). (b) Atributo del cociente de energías (verde) y el mismo atributo filtrado por EPS (rojo). (c) Derivada del atributo filtrado. Su máximo indica el primer arribo.

3.3 (a) Traza sísmica (azul) y primer arribo picado por el EM (cuadrado rojo).

(b) Atributo de la entropía (verde) y el mismo atributo filtrado por EPS (rojo). (c) Derivada del atributo filtrado. Su máximo indica el primer arribo.

3.4 (a) Traza sísmica (azul) y primer arribo picado por el FDM (cuadrado rojo). (b) Atributo de la dimensión fractal (verde) y el mismo atributo filtrado por EPS (rojo). (c) Derivada del atributo filtrado. Su mínimo indica el primer arribo. . . . . . . . . . . . . . . . . . .

3.5 Procedimiento de corrección de picados errados. Los resultados corresponden al FDM aplicado a los datos de campo que se muestran en la Figura 3.7. (a) Picados traza por traza correspondientes al paso 1 (en rojo) y rectas ajustadas (azul) correspondientes al modelo de refracción preliminar (paso 2). (b) Picados corregidos (paso 3) y rectas ajustadas correspondientes al modelo de refracción final (paso 4). Los picados de las trazas 12 y 13 se asociaron con trazas malas o nulas y fueron rechazados

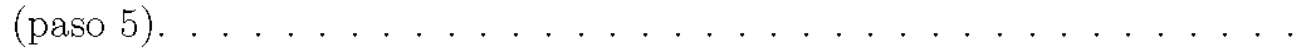

3.6 Resultado de los métodos de picado automático de primeros arribos aplicados al registro de disparo común con fuente dinamita (Registro 1 en la Tabla 3.1). En rojo los picados obtenidos mediante el MCM, en verde mediante el EM, y en azul mediante el FDM. . . . . . . . . . . . . 
3.7 Resultado de los métodos de picado automático de primeros arribos aplicados al primero de los ejemplos de registro de disparo común con fuente Vibroseis (Registro 2 en la Tabla 3.1). En rojo los picados obtenidos mediante el MCM, en verde mediante el EM, y en azul mediante el FDM.

3.8 Resultado de los métodos de picado automático de primeros arribos aplicados al segundo de los ejemplos de registro de disparo común con fuente Vibroseis (Registro 3 en la Tabla 3.1). En rojo los picados obtenidos mediante el MCM, en verde mediante el EM, y en azul mediante el FDM. .

3.9 Modelo inicial de refracción. Las coordenadas geográficas $\left(S_{x}, S_{y}\right)$ fueron trasladadas al origen. (a) Fuentes utilizadas en el proyecto de sísmica 3D. En rojo se destacan las fuentes para las que se midieron los parámetros de entrada $(a, b)$. (b) Velocidad de la capa 2 según el modelo inicial de refracción . . . . . . . . . . . . . . . . . . . .

3.10 Ejemplo de la nueva ventana de trabajo para un registro de proyecto de sísmica 3D con las restricciones dadas para el offset y para el tiempo. La fuente se encuentra fuera de la línea de receptores. La ventana se aplana hacia offsets chicos para evitar los efectos de borde al calcular los atributos. 66

3.11 Ejemplo de los resultados obtenidos para uno de los registros de la línea sísmica 2D. Primeros arribos determinados mediante (a) MCM, (b) EM y (c) FDM.

3.12 Ejemplo de los resultados obtenidos para una línea en uno de los registros del proyecto de sísmica 3D. Primeros arribos determinados mediante (a) MCM, (b) EM y (c) FDM. . . . . . . . . . . . . . . . . . .

4.1 Método de Allen modificado (MAM). (a) Registro de la componente vertical de LPA. Los picados automáticos obtenidos mediante el MAM se muestran con líneas verticales negras. (b) Función característica $C F$ y esquema de ventanas para $S T A$ y $L T A$ del MAM. (c) $S T A / L T A$ suavizado por una ventana de Hanning y umbral THR (línea horizontal gris) utilizado para detectar las fases picadas (líneas verticales negras). . . . . . . 
4.2 Método de Baer y Kradolfer modificado (MBKM). (a) Registro de la componente vertical de LPA. Los picados automáticos obtenidos mediante el MBKM se muestran con líneas verticales negras. (b) Función característica $C F$ del MBKM. (c) $C F$ suavizada por una ventana de Hanning y umbral $T H R$ (línea horizontal gris) utilizado para detectar las fases picadas (líneas verticales negras). . . . . . . . . . . . . . . . .

4.3 Registros de la componente vertical de LPA de los 6 primeros terremotos utilizados para analizar los métodos. En las abscisas se muestra el tiempo (UTC) y en las ordenadas la amplitud normalizada a $(-1,1) \ldots . .$. . .

4.4 Registros de la componente vertical de LPA de los otros 5 terremotos utilizados para analizar los métodos. En las abscisas se muestra el tiempo (UTC) y en las ordenadas la amplitud normalizada a $(-1,1) \ldots . .$. .

4.5 Eficiencia de los métodos. Las barras negras muestran el porcentaje de detecciones correctas y las barras grises el porcentaje de picados falsos

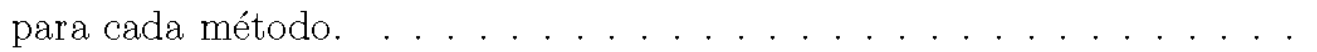

4.6 Errores de los diferentes métodos. Los cuadrados negros representan las medias de los errores: los valores positivos son retrasos en el picado y los negativos adelantos. Las barras representan las magnitudes de las respectivas dispersiones. . . . . . . . . . . . . . . . .

5.1 Registro de microsísmica número 1. La relación señal-ruido del evento es buena. (a) Componente $x$. (b) Componente $y$. (c) Componente z. . . . . 101

5.2 Registro de microsísmica número 2. La relación señal-ruido del evento es regular. (a) Componente $x$. (b) Componente $y$. (c) Componente $z$. . . . 102

5.3 Registro de microsísmica número 3. La relación señal-ruido del evento es mala. (a) Componente $x$. (b) Componente y. (c) Componente z. . . . . . 103

5.4 Ventana móvil utilizada para detectar los microsismos (en verde). La ventana avanza en tiempo muestra a muestra y cuenta el número de eventos contenidos en ella. Los datos corresponden a la Figura 5.1 y los picados corresponden a los obtenidos mediante el MAM. . . . . . . . . . . 109 
5.5 Estrategia para determinar la mínima ventana que contiene el microsismo. (a) La primera y la última de las ventanas que detectan un microsismo (en verde). (b) La unión de todas las ventanas móviles contiguas que detectan un microsismo forma una ventana grande (en verde). La ventana grande se acorta todo lo posible para definir una ventana final más pequeña que delimita el microsismo (en rojo). Al igual que en la Figura 5.4, los datos corresponden al registro 1 y los picados corresponden a los obtenidos mediante el MAM. . . . . . . . . . . . . . . . 112

5.6 Ventana final con el microsismo detectado y los eventos picados para el registro 1. (a) ESM, (b) MAM y (c) MBKM. . . . . . . . . . . . . . 115

5.7 Ventana final con el microsismo detectado y los eventos picados para el registro 2. (a) ESM, (b) MAM y (c) MBKM. . . . . . . . . . . . . . 116

5.8 Ventana final con el microsismo detectado y los eventos picados para el registro 3. (a) ESM, (b) MAM y (c) MBKM. . . . . . . . . . . . . . 118

A.1 (a) Función escalón (negro) y función escalón contaminada con ruido (azul). (b) Valor absoluto de la derivada de la función escalón contaminada con ruido. (c) Función escalón con ruido luego de ser suavizada por promediación móvil (verde) y por EPS (rojo) utilizando un operador de 25 muestras. (d) Valor absoluto de la derivada la función filtrada por EPS

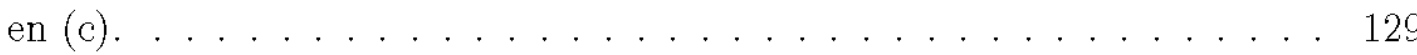




\section{Agradecimientos}

En primer lugar, le agradezco especialmente a Danilo por todos estos años en los que me ha guiado y ayudado. Gracias por atender a todas y cada una de mis dudas y consultas, siempre con buena predisposición, incluso con premura. Valoro enormemente esos gestos. Más de una vez he escuchado que es inevitable que la relación con el director acabe algo desgastada. Lejos de eso, pienso que en este tiempo he ganado un buen amigo.

También quiero agradecer a Daniel Lorenzo, por su constante generosidad para compartir desinteresadamente su vasta experiencia y conocimiento en exploración sísmica. Muchas de sus sugerencias me han ayudado a desarrollar esta Tesis. A Ricardo Rebollo, por sus comentarios sobre el picado de primeros arribos, a Fabio Zyserman, por haberme prestado ayudado con diversas consultas, especialmente sobre Linux, y a Claudio Brunini, por la discusión acerca de cómo automatizar el ajuste de las rectas de los primeros arribos.

Al Departamento de Sismología de la Facultad y en particular a María Laura Rosa y a mi tía Nora Sabbione: un capítulo de esta Tesis surgió de una interesante trabajo en colaboración.

A Data Seismic, por haber confiado en nosotros para desarrollar un trabajo de vinculación tecnológica que enriqueció tanto la Tesis como mi formación profesional.

A la Facultad de Ciencias Astronómicas y Geofísicas de la Universidad Nacional de La Plata, que me ha brindado un lugar de trabajo tan ameno y al CONICET, por subsidiar mis estudios de doctorado,

A mis compañeros y amigos de oficina, que hacen de mi lugar de trabajo un ambiente agradable. En especial a Andrés, cuya amistad me acompaña y enorgullece hace ya tantos años, y también a Leonardo, uno de los tantos amigos que me llevo de esta etapa, y que algunas veces tanto me ha hecho reir destinando instantes de su capacidad para hacer humor.

A mi familia, por su afecto y apoyo. En especial a mi tío Carlos, por hacerme sentir que siempre puedo contar con él, con su ayuda y sus consejos. Y también por saber contagiarme su sentido del humor y alegría.

A mi hermana Irene, por su compañía y amor constante e incondicional, que siempre 
me ha hecho sentir cuidado y contenido.

Finalmente a Mariana, por saber valorar mis virtudes por sobre mis defectos. Gracias por acompañarme, tenerme paciencia, quererme y cuidarme. Con su compañía todo se hizo más fácil y más lindo.

Juan I. 


\section{Capítulo 1}

\section{Introducción general}

Uno de los principales objetivos de la geofísica es el estudio de la propagación de perturbaciones elásticas a través del subsuelo. Estas perturbaciones, denominadas ondas sísmicas, viajan de un punto a otro a través del medio y brindan información del mismo. Las ondas sísmicas pueden generarse naturalmente, como ocurre cuando acontece un terremoto, o ser intencionalmente provocadas por el hombre para estudiar el subsuelo en busca de recursos naturales, como sucede en exploración sísmica. Cualquiera sea el caso, las ondas sísmicas son luego registradas en superficie, o cerca de la superficie, mediante algún tipo de receptores (sismógrafos, geófonos, hidrófonos, etc.). La información sísmica que recolectan estos receptores, denominada traza sísmica o sismograma, conforma el dato de interés que se examina en esta Tesis.

La información sísmica puede analizarse desde diferentes enfoques. Desde el punto de vista del análisis de señales, una traza sísmica, o un sismograma, representa una serie de tiempo. Por tanto, es posible estudiar el dato sísmico utilizando las herramientas disponibles para el análisis de series temporales digitales. De esta manera, a partir de la teoría del análisis de las señales digitales, se pueden extraer distintas características de los datos, dependiendo de cuál sea el objetivo del análisis. Los desarrollos llevados a cabo a lo largo de este trabajo de Tesis se centran en el procesamiento de los datos sísmicos con el fin de detectar los tiempos de llegada de ciertas señales que, lamentablemente, se encuentran usualmente contaminadas por ruidos indeseados, lo que dificulta esta tarea. Para ello, resulta primordial definir y calcular diferentes atributos sísmicos que tienen por objeto resaltar las señales de interés presentes en los datos. Las señales que se busca detectar mediante las diferentes metodologías propuestas están dadas por los primeros arribos en sísmica de exploración, las fases de terremotos en registros sismológicos, y los eventos generados por microfracturas en registros de microsísmica. 


\subsection{Atributos sísmicos y detección de eventos}

En general, el concepto de atributo sísmico hace alusión a cualquier cantidad obtenida a partir de la información sísmica, la que a su vez está usualmente basada en medidas de tiempo, amplitud, frecuencia y/o atenuación $[59,17]$. Esta definición nos permite afirmar que el concepto de atributo sísmico es bien amplio, y puede aplicarse a un gran número de magnitudes. Por ejemplo, cantidades tales como el valor absoluto o la energía de la traza sísmica, que son obtenidas mediante operaciones sencillas, son algunos casos simples de atributos sísmicos. En la actualidad, el concepto se ha ampliado más aún e involucra una inmensa cantidad de magnitudes extraídas de las trazas sísmicas mediante diversas operaciones matemáticas. Desde un enfoque más moderno y práctico, un atributo sísmico es definido como cualquier medida que ayuda a mejorar o cuantificar características del dato que interesan para su interpretación [17].

Durante la década del 70 se introdujo la idea de presentar la información sísmica mediante el coloreo de los gráficos convencionales de área variable. El trabajo presentado por Balch [11] representa la primera publicación en Geophysics en la que se muestran datos sísmicos utilizando colores. Paralelamente, Nigel Anstey y su equipo comenzaron a trabajar en algunas técnicas innovadoras para la época para exhibir los datos sísmicos, introduciendo los colores en las secciones sísmicas, según lo apunta el propio Anstey años más tarde [8]. Esta es hoy día una práctica no sólo habitual, sino también imprescindible en la interpretación sísmica. Algunos años después, dos colegas de Anstey, Turham Taner y Fulton Koehler, continuaron su trabajo y desarrollaron el marco matemático necesario para poder calcular computacionalmente ciertos atributos a partir del análisis complejo de la traza sísmica $[64,63]$. A partir de aquel momento, el concepto de atributo sísmico comienza a ser ampliamente difundido. Los atributos desarrollados en estos trabajos, que fueron derivados mediante dicho análisis complejo y presentados novedosamente en gráficos con colores, incluyen la amplitud de la función envolvente, la fase instantánea, la frecuencia instantánea y la polaridad aparente. Asimismo, otro atributo que es frecuentemente considerado entre los primeros desarrollados es la impedancia acústica [59]. La impedancia acústica representa la propiedad del subsuelo responsable de que se produzcan las refracciones y/o reflexiones de la ondas que lo atraviesan, y se puede obtener a partir de la inversión sísmica de los datos [65]. Así, a partir de la inclusión de colores para exhibir la información sísmica, el análisis complejo de la traza y el desarrollo de las 
técnicas de inversión geofísica, los atributos proliferaron dando lugar a un gran número de nuevas aplicaciones.

En esta Tesis vamos a analizar y proponer algunos atributos que resultan adecuados para la detección de señales. Cuando las operaciones matemáticas involucradas en el cálculo de un dado atributo pertenezcan al análisis de señales digitales tradicional, diremos que dicho atributo es convencional. Por el contrario, si las operaciones matemáticas llevadas a cabo incorporan conceptos relativos a otras ramas de la matemática, o incluso a otras teorías, diremos que el atributo es no convencional.

Es importante remarcar que cualquier operación matemática legítima realizada utilizando los datos sísmicos puede derivar en un atributo que resulte provechoso para resaltar alguna característica de los datos y que sea útil de acuerdo al objetivo de estudio. En todo caso, la dificultad reside en elegir las operaciones apropiadas para extraer las características buscadas de forma eficiente. En este contexto, vamos a estudiar y analizar diversos atributos sísmicos, convencionales y no convencionales, con un objetivo concreto: detectar los tiempos de llegada de las señales inmersas en el inevitable ruido de fondo de los datos.

El éxito en la detección de señales está estrechamente ligado con la capacidad del atributo seleccionado de responder matemáticamente en forma diferenciada ante la llegada de los eventos a detectar. Por otro lado, las características de las trazas sísmicas están determinadas, entre otros motivos, por el tipo de fuente con el que se generó la señal (sea artificial como en una campaña de prospección sísmica o natural como en el caso de un terremoto), el medio por el que viajó la onda, el instrumento con el que se registró, y el ruido de fondo de la estación o receptor. Todos estos factores deberán entonces considerarse al momento de elegir qué atributo utilizar para la detección, puesto que influyen directamente sobre los datos registrados.

El objetivo que se persigue a lo largo de esta Tesis es generar algoritmos que calculen un atributo determinado, y a partir de éste, diseñar estrategias matemáticas y computacionales que detecten los tiempos de llegada de las señales de interés de forma precisa y automática. Para ello, la selección y cálculo del atributo representa simplemente el primer paso del procedimiento, puesto que los métodos de detección automática se suelen implementar mediante diversos pasos de procesamiento que involucran operaciones de filtrado, criterios estadísticos, criterios de coherencia, etc. No obstante, dicha selección es fundamental en cualquier método de detección utilizado. 


\subsection{Detección de señales en exploración sísmica}

En la exploración sísmica, el picado de primeros arribos (first-breaks) es la tarea que consiste en determinar, dado un conjunto de trazas sísmicas, los tiempos de la llegada de la señal en cada traza con la mayor precisión posible. En general, estos arribos están asociados con la energía de las ondas refractadas en la base de la capa no consolidada (capa de weathering) o con la energía de la onda que viaja directamente desde la fuente hasta el receptor.

La determinación precisa de los tiempos de los primeros arribos es necesaria para el cálculo de las correcciones estáticas, una etapa fundamental en el procesamiento de los datos sísmicos. La eficacia de las correcciones estáticas basadas en los métodos de reflexión y refracción depende de la fiabilidad del proceso de picado [75, p. 374]. Además, aplicaciones tales como correcciones estáticas por tomografía sísmica (tomostatics), requieren de una detección automática rápida y precisa de los primeros arribos de la señal [78].

En general, la calidad del primer arribo está relacionada con el tipo de fuente, con la estructura del subsuelo más cercano a la superficie, y con la relación señal-ruido de los datos. Como consecuencia de ello, el picado automático de los primeros arribos puede ser una tarea muy difícil si los datos se adquieren en un área con estructura subsuperficial somera compleja, o si la relación señal-ruido es baja. Por otra parte, si la onda de origen es de fase cero, como ocurre cuando se utilizan fuentes de Vibroseis, la correlación con el barrido a menudo produce lóbulos laterales que llegan antes que el primer arribo, con lo que el proceso de detección se vuelve aún más difícil.

Tradicionalmente, la determinación de la llegada de la señal era llevada a cabo mediante la inspección visual de las amplitudes y los cambios de forma de onda de los datos ("picado manual"). Además de consumir demasiado tiempo, esta estrategia puede generar picados sesgados e inconsistentes, ya que recae en la subjetividad del operador que realice la tarea. Con el desarrollo de los equipos modernos, el uso de software específico para realizar el picado de forma interactiva facilita el proceso, pero en general, todo el procedimiento es todavía muy costoso e involucra mucha subjetividad. Por lo tanto, la implementación de sistemas automatizados basados en algoritmos computacionales es crucial para una detección rápida de los primeros arribos de forma coherente y objetiva. Hoy en día, la estrategia más común es usar un método de picado automático 
o semi-automático como primer paso, y corregir los resultados de forma interactiva mediante la inspección visual en segunda instancia. En ciertos casos, este proceso debe ser repetido varias veces, en especial en áreas particularmente complejas. Como resultado, cuando el volumen de datos es grande y la calidad de los datos es pobre, picado puede involucrar hasta $30 \%$ del tiempo total de procesamiento.

Durante las últimas décadas se han desarrollado numerosas técnicas para la determinación de los primeros arribos de forma automática o semi-automática. Los primeros intentos se basaron en la correlación cruzada de trazas adyacentes para encontrar el tiempo de retardo entre los primeros arribos [47]. Estas técnicas tienden a fallar cuando cambia la forma de la señal de llegada de una traza a otra y cuando aparecen trazas malas o nulas. Hatherly [25] propuso un método que determina la llegada de los primeros arribos basado en la realización de algunas pruebas estadísticas algo engorrosas, mientras que Gelchinsky y Shtivelman [23] presentaron una técnica basada en una combinación de las propiedades de correlación de la señal y un criterio estadístico. Otros enfoques, usualmente incluidos en distintos paquetes de software comerciales, se han centrado en la detección de un aumento repentino en la energía de la señal [19]. Como ha sido apuntado por Coppens [19], este método es muy robusto cuando la relación señal-ruido de los datos es suficientemente alta. Como primera aproximación a la ubicación de los primeros arribos, Spagnolini [61] basó su método adaptativo de picado en la detección de cambios bruscos en la energía de la señal. Se han publicado también nuevos métodos que se basan en variaciones de los criterios recién mencionados [42].

Por otro lado, entre los métodos no convencionales, muchos algoritmos diseñados para la detección semi-automática de primeros arribos están basados en el uso de redes neuronales. Estos enfoques han demostrado ser muy útiles para esta tarea y cuentan con amplia aceptación [44]. No obstante, se necesita de un adecuado entrenamiento de la red neuronal para que estos métodos funcionen correctamente, lo que a menudo requiere invertir una cantidad considerable de tiempo del operador (y experiencia). Sin un buen entrenamiento previo de la red neuronal, los resultados pueden requerir de varios ajustes manuales de los picados, que llevan mucho tiempo, especialmente cuando la calidad de los datos es baja. Otros métodos no convencionales implican el uso de covarianzas de tercer orden [76], con limitaciones similares a las de los enfoques basados en la correlación cruzada, pero más robustos en condiciones de baja relación señal-ruido. Otros, se basan en la transformada wavelet [66]. Por desgracia, cuando el ruido de fondo 
es alto y la calidad de los datos es pobre, estas técnicas tienden a fallar. La obtención de picados consistentes y fiables de forma automatizada sigue sin resolverse, y representa un problema de gran interés e impacto entre los actuales temas de investigación en prospección geofísica para la obtención de recursos naturales.

Algunos métodos no convencionales basados en el análisis de la dimensión fractal de los datos merecen especial atención. Los fractales han sido en las últimas décadas ampliamente estudiados en diversos problemas pertenecientes a las ciencias de la Tierra [69, 30]. Si bien la formalidad matemática de los fractales es aún motivo de discusión, existe indudablemente un gran número de aplicaciones de la teoría de los fractales que ha resultado de gran utilidad $[36,22,46,30,69]$. En particular, los fractales se han aplicado con éxito en la detección de señales en datos de prospección geofísica [12, 26], y también en sismología para la detección de fases de terremotos [67]. La estrategia se basa en considerar la traza sísmica (o el sismograma) como una curva fractal y a partir de su dimensión diferenciar las señales de interés del ruido de fondo. No obstante, el análisis de series de tiempo mediante el cálculo de la dimensión fractal no es trivial, y se debe tener especial cuidado con el cumplimiento de ciertas hipótesis [51]. Durante el próximo capítulo describiremos con detalle cómo utilizar la dimensión fractal como un atributo sísmico no convencional para la detección de primeros arribos.

\subsection{Detección de señales en sismología}

Del mismo modo que el picado automático de primeros arribos es fundamental para numerosas aplicaciones en sísmica de prospección, en sismología global, la detección y picado de fases de eventos representa un paso fundamental para la localización y análisis de datos de terremotos en cualquier estación sismológica. Al igual que ocurre con los primeros arribos sísmicos, esta tarea era realizada tradicionalmente mediante la inspección visual de los datos. En este caso, la metodología clásica es la lectura de las bandas de los registros de las estaciones y la identificación manual del advenimiento de las diferentes fases asociadas a los terremotos. Actualmente, la gran mayoría de los instrumentos utilizados en las estaciones sismológicas digitalizan y almacenan los datos. Además, el monitoreo sísmico se ha multiplicado significativamente en todo el planeta, lo que genera la necesidad de analizar un inmenso volumen de datos. Esta abundancia de datos provocó que la inspección visual de los registros se vuelva una tarea muy demandante en cuanto a 
tiempo y recurso humano. Por esta razón, en las últimas décadas se han desarrollado diversos algoritmos para realizar la detección y picado de fases de terremotos de manera automática o semi-automática. Muchos de estos algoritmos están actualmente incluidos en paquetes de procesamiento utilizados por diferentes organizaciones o instituciones [5].

Sin dudas, puede trazarse una analogía entre el problema que representa la detección de fases de terremotos en sismología y el picado automático de primeros arribos en sísmica de exploración. Claramente, la semejanza entre estos dos problemas se debe principalmente a que los fundamentos físicos que subyacen en ambas teorías son muy similares. Esta semejanza queda también evidenciada en la literatura por la presencia de métodos que usan algoritmos muy similares para realizar una tarea o la otra.

Entre los artículos presentados en revistas de sismología son muy populares aquellos métodos que comparan el valor de algún atributo de la señal en dos ventanas de tiempo diferentes. Este atributo es calculado en una primera ventana de corta duración en tiempo que intenta extraer las características actuales de la señal, y en otra de mayor duración que tiene por objeto dar la referencia del ruido de fondo en el que está inmerso el evento a detectar. En 1982, Allen introduce un nuevo concepto definiendo dicho atributo como characteristic function $(C F)$ [7]. Debido a que estos métodos comparan los promedios de dicha $C F$ entre las dos ventanas de tiempo mencionadas, suelen ser denominados métodos de tipo STA/LTA (short term average/long term average). El evento se declara cuando este cociente supera un valor umbral THR (threshold). El método que fue presentado originalmente por Allen [6] ha sido ampliamente utilizado por el U.S. Geological Survey (USGS), en particular en el proyecto USGS Earthworm System [27].

Además del método de Allen, existen otros métodos de tipo STA/LTA muy difundidos. Uno de los más citados es aquel presentado por Baer y Kradolfer [9], que es actualmente utilizado como el motor del software de picado MannekenPix desarrollado por Aldersons [5]. La rutina AUTOPIC contenida en el Seismic Analysis Code (SAC) utiliza el método presentado por Ruud y Husebye [48], también de tipo STA/LTA. Por su parte, Earle y Shearer [21] definen la envolvente de la señal (calculada a partir de la función analítica) como la función característica $(C F)$ para calcular el cociente $S T A / L T A$ en el que se basa su método para hacer un estudio de sismología global a partir de la construcción de tablas de tiempos de recorrido. Todos estos métodos de tipo STA/LTA, que podríamos denominar "convencionales" por su amplia difusión y aceptación a lo largo del tiempo, guardan ciertas similitudes con el tradicional método 
para picado de primeros arribos sísmicos desarrollado por Coppens [19], en donde se introduce un criterio de comparación de energías entre dos ventanas anidadas de diferentes tamaños.

Se han desarrollado también diversos algoritmos de picado de fases no convencionales que utilizan modelos auto-regresivos (AR) junto con el Criterio de Información de Akaike (AIC) presentado por Akaike [1,2]. Los trabajos más difundidos con este enfoque son los de Sleeman y van Eck [60], Leonard y Kennett [33], Bai y Kennett [10], y Zhang et al. [77]. La teoría de los fractales fue también utilizada tanto en sismología para picar fases de terremotos [67] como en sísmica de exploración para picar primeros arribos [12, 26, 54]. Asimismo, se han realizado más recientemente algunos intentos para abordar el mismo problema a partir del uso de estadística de órdenes superiores [56, 31], en los que nuevamente se puede encontrar una correlación con métodos de exploración sísmica [76].

No obstante, se debe remarcar que existe una diferencia substancial entre el picado de primeros arribos sísmicos y el picado de fases de terremotos. Mientras que en el problema relativo a la exploración sísmica se busca detectar un único evento (el primer arribo) por cada traza sísmica para realizar luego las correcciones estáticas, en los registros de estaciones sismológicas en muchas ocasiones el interés se centra en detectar diferentes fases de terremotos. Por ello, algunos métodos intentan picar los tiempos de varias fases, que pueden ser las correspondientes a arribos de ondas P, S, y/o superficiales. Así, mientras que en los métodos sísmicos se busca un único rasgo distintivo a lo largo de toda la traza, los algoritmos utilizados en sismología tienden a detectar varias fases cuando se supera un umbral o tolerancia dada. Por esta razón, al buscar utilizar algoritmos originalmente desarrollados para picar primeros arribos sísmicos (como haremos en el Capítulo 4 de esta Tesis), se debe previamente adaptarlos para identificar fases de terremotos en registros de estaciones sismológicas.

\subsection{Detección de señales en estudios de microsismicidad}

La sísmica puede ser dividida en dos grandes ramas: la sísmica activa y la sísmica pasiva. En la primera, el hombre es quien introduce una perturbación (fuente sísmica) que se propaga a través del subsuelo para luego ser registrada en superficie o en un pozo mediante un arreglo de receptores. Este es el caso de los tradicionales métodos de refracción y de reflexión en exploración geofísica. Por otro lado, la sísmica pasiva se basa 
en "escuchar" los movimientos naturales del subsuelo sin que exista energía agregada por el hombre [59]. A modo de ejemplo, los estudios preliminares de ruido durante una campaña sísmica representan un caso de sísmica pasiva.

Los estudios de sísmica pasiva comenzaron hacia fines de la década del 60, si bien fue recién en las últimas dos décadas que una serie de operadores independientes han aplicado con éxito este tipo de estudios para dar soluciones a temas específicos [41]. En particular, el monitoreo pasivo de emisiones acústicas, o microsismos de pequeña magnitud (microsismicidad) asociados con cambios de tensión dentro y alrededor de un reservorio de hidrocarburos, puede ser utilizado para obtener una imagen sísmica de la dinámica del mismo [38].

Para realizar la recuperación secundaria en un pozo de hidrocarburos se inyectan fluidos con el objeto de generar fracturas en las inmediaciones del mismo y facilitar la extracción de hidrocarburos. Asimismo, para poder monitorear la evolución del reservorio y el propio proceso de inyección de fluidos resulta de gran interés conocer la localización y dinámica de estas fracturas. Los registros de microsísmica son obtenidos mediante una riestra de geófonos ubicados en un pozo cercano al pozo de extracción del hidrocarburo, en el que se producen las microfracturas o cambios de tensión que generan los microsismos. Generalmente, se utilizan imágenes microsísmicas para estudiar el desarrollo espacial y temporal de la creación y reactivación de fracturas, principalmente a partir de las variaciones espaciales y temporales de la ubicación hipocentral de las emisiones acústicas asociadas a la deformación sísmica [39]. De esta forma, la inyección de fluidos en los pozos posee un rol doble: (1) favorecer la extracción de los hidrocarburos (recuperación secundaria) y (2) generar fracturas que permiten monitorear la evolución del reservorio mediante estudios microsísmicos. Esta aplicación de la microsísmica ha crecido exponencialmente en los últimos años e incluso se ha convertido en una herramienta de ingeniería rutinaria en la evaluación de la geometría de las fracturas hidráulicas [40].

El rasgo distintivo de los microsismos inducidos por inyección hidráulica es que poseen magnitudes muy pequeñas [57]. A consecuencia de esto, el principal desafío que se presenta al momento de desarrollar alguna metodología que intente detectar y picar los tiempos de arribo de los eventos automáticamente está dado por la mala relación señalruido que generalmente presentan los datos. Más aún, dependiendo de la polarización de las ondas al arribar a los receptores, la presencia de la señal en algunas componentes 
puede estar parcial o totalmente enmascarada por el ruido. Con esta motivación, recientemente se han publicado algunos trabajos en los que se intenta atenuar el ruido de fondo y mejorar así la relación señal-ruido de los registros de microsísmica con diferentes enfoques. Han et al. [24] propusieron una metodología de reducción de ruido aleatorio a partir de una técnica de separación de señal y ruido desarrollada como una extensión de la promediación simple entre trazas. Por su parte, Vera Rodriguez et al. [71] desarrollaron una técnica de atenuación de ruido en registros microsísmicos utilizando una transformada tiempo-frecuencia en la que se impone la condición de que la matriz que representa la transformada sea rala. No obstante, más allá de estos avances para mejorar la relación señal-ruido en los registros de microsísmica, el desafío de la detección automática de los eventos persiste.

Como primera aproximación, para detectar eventos en estudios de microsismicidad se pueden adaptar tanto aquellos métodos y estrategias desarrollados para realizar el picado de los primeros arribos sísmicos como aquellos utilizados para la detección de fases de terremotos. Los métodos de mayor difusión para detectar fases de terremotos son los de tipo STA/LTA. Como hemos explicado en la sección anterior, en estos métodos se calcula el cociente entre los promedios de cierto atributo (función característica $C F$ ) obtenidos en dos ventanas de diferente tamaño. Luego, un evento es declarado cuando este cociente supera un dado valor de umbral. Este enfoque es también ampliamente utilizado para detectar microsismos. Por ejemplo, Munro [43] utiliza un algoritmo basado en un método de tipo STA/LTA en donde el atributo seleccionado para promediar en las ventanas es la energía. A excepción del esquema de ventanas utilizado, este método es equivalente al método que utiliza Coppens para picar primeros arribos [19]. De forma similar, Chen y Stewart [16] proponen utilizar el valor absoluto de las trazas sísmicas para la función característica que es luego promediada en las ventanas. Recientemente, Wong et al. [74] y Han et al. [24] presentaron un método que denominan "cociente de energías modificado" (MER) y que es validado a partir de su comparación con un algoritmo $S T A / L T A$ "clásico". El esquema de ventanas en el MER es similar al del método para detectar fases de terremotos de Earle y Shearer [21] (ESM), si bien los atributos elegidos y criterios en la elección de las longitudes de ventanas son diferentes. Por su parte, Vera Rodriguez [70] también propone utilizar un método de tipo STA/LTA donde la función característica elegida para generar luego el cociente STA/LTA es obtenida a partir de la transformada wavelet discreta estacionaria (SDWT) de la traza sísmica. 
Además de los métodos de tipo $S T A / L T A$, existen otro tipo de estrategias propuestas por diversos autores para abordar el problema de la detección automática de microsismos. Akram [3] presentó un método para detectar el arribo de las ondas P en las componentes verticales de los geófonos basado en el cálculo de la desviación estándar en una ventana móvil que avanza a lo largo de la traza. Por otro lado, Tselentis et al. [68] desarrollaron un método de picado automático de fases $\mathrm{P}$ de microsismos basado en el test estadístico de $\chi^{2}$. Como mencionamos durante la sección anterior, diversos autores basan sus métodos de detección y/o picado de fases de terremotos en el Criterio de Información de Akaike [60, 33, 10, 77]. Este mismo criterio es propuesto por St-Onge [62] para la detección de eventos de microsísmica.

Claramente, la detección de los eventos microsísmicos relacionados tanto con movimientos inducidos en las estructuras preexistentes como con la creación de nuevas fracturas representa una aplicación directa de los algoritmos desarrollados para detectar fases de terremotos. Más aún, dadas las características de los registros de microsísmica, que usualmente están compuestos por los datos recolectados por riestras de receptores colocados en pozos, se pueden tomar también muchos elementos de las estrategias desarrolladas para detectar primeros arribos en sísmica de exploración. Dicho de otro modo, la detección automática de microsismos puede considerarse una aplicación que se encuentra entre la detección de eventos en sísmica de prospección (picado de primeros arribos) y la detección y picado de las fases de terremotos en sismología. Estas ideas dieron lugar a los métodos propuestos en el Capítulo 5 de esta Tesis.

\subsection{Descripción de los contenidos y objetivos}

A lo largo de esta Tesis se estudian y proponen diversos atributos sísmicos, convencionales y no convencionales, para la detección automática de señales sísmicas en diferentes problemas geofísicos. Para ello, se analiza el comportamiento de los atributos frente a datos con distinta relación señal-ruido. En particular, se analizan y aclaran algunos aspectos relativos al uso de la dimensión fractal para analizar trazas sísmicas. Luego, se proponen nuevos métodos y algoritmos para detectar de forma precisa, eficiente y automática los tiempos de llegada de los primeros arribos en diversos experimentos de exploración sísmica, especialmente para los casos en los que los métodos actuales tienden a fallar. Además, se realizan aportes originales al problema de la detección automática de fases de 
terremotos en sismología. Por último, se aprovechan algunos de los resultados previos y se propone una nueva metodología para detectar eventos en estudios de microsismicidad de forma automática.

El Capítulo 2 está enfocado a analizar exhaustivamente la teoría de los fractales cuando es aplicada a las trazas sísmicas. La motivación de este capítulo está dada por trabajos recientes en los que se propone detectar las señales sísmicas utilizando la dimensión fractal de los datos como atributo. Se repasan primero conceptos fundamentales de la teoría, y las consideraciones que deben hacerse e hipótesis que debe cumplir la traza sísmica para poder ser considerada una curva fractal. Además, se consideran distintos métodos diseñados para extraer la dimensión fractal de una curva, se proponen algunas mejoras respecto de su implementación tradicional, y se evalúa su capacidad para detectar eventos enmascarados por ruido. Los métodos son evaluados utilizando datos sintéticamente generados con diferentes relaciones señal-ruido. Finalmente, aquel método que resulta ser el más eficiente y robusto ante los datos sintéticos, denominado método del variograma, es aplicado a un registro real de sísmica marina.

En el Capítulo 3 se proponen tres nuevos métodos para realizar el picado automático de los tiempos de los primeros arribos para datos que presentan alta complejidad. La descripción de los métodos está dividida en dos etapas. En una primera etapa se detallan los algoritmos utilizados para calcular los atributos en los que se basan las nuevas estrategias para una única traza. Los tres atributos están determinados por un cociente de energías por ventanas, por la entropía de la traza sísmica, y por la dimensión fractal calculada mediante el método del variograma (en este último caso, a partir de los resultados expuestos en el capítulo previo). En la segunda etapa se describe un proceso de corrección de picados erróneos que involucra simultánemente a todas las trazas de un dado registro de disparo común. Este proceso, que completa los métodos propuestos, es llevado a cabo mediante un algoritmo que consta de cinco pasos, en donde el primer paso está dado por el análisis de trazas individuales de la primera etapa. Se estudia también la dependencia de los resultados respecto de la elección de los parámetros de los métodos a partir de un análisis de sensibilidad. Los métodos son aplicados primero a tres registros de campo con diversas complejidades. Finalmente, en el marco de un convenio específico de desarrollo tecnológico en conjunto con la compañía de servicios geofísicos Data Seismic, los métodos propuestos son adaptados, mejorados y puestos a punto para llevar a cabo el picado automático de un gran volumen de datos correspondientes a proyectos de 
sísmica 2D y de sísmica 3D.

Con la motivación que representa la utilidad de contar con herramientas para realizar la detección automática de fases de terremotos en la Estación Sismológica de la Plata (LPA), con aplicación directa tanto en estudios de sismología global como para estudios de sismicidad, en el Capítulo 4 se analizan y comparan ocho algoritmos de detección automática de fases de terremotos. Este conjunto de algoritmos aquí presentado está formado por un grupo de tres métodos tradicionales, dos métodos surgidos a partir de modificaciones propuestas a los métodos tradicionales, y tres adaptaciones de los tres algoritmos desarrollados en el capítulo anterior para analizar una única traza. Los algoritmos son testeados utilizando diversos datos de terremotos registrados en la Estación Sismológica de La Plata. El capítulo se completa con un análisis comparativo de los métodos, que permite concluir que algunos de los ochos métodos estudiados sean valorados por sobre los otros.

A partir de considerar el análisis comparativo llevado a cabo entre aquellos métodos desarrollados durante el Capítulo 4 para detectar señales en registros adquiridos en estaciones sismológicas, se seleccionaron tres de los ocho algoritmos estudiados para generar una nueva metodología enfocada en la detección automática de microsismos. Durante el Capítulo 5 proponemos y desarrollamos una técnica que se basa en utilizar estos tres algoritmos para picar arribos de microsismos a los largo de todas las trazas que comprenden un registro de microsísmica. La estrategia propuesta consta de dos pasos. En el primero, se analiza un registro de microsísmica traza por traza, adaptando los parámetros de los tres algoritmos tomados del estudio llevado a cabo en el capítulo previo. De esta forma, se obtiene un conjunto de tiempos picados correspondientes a eventos que representan potenciales arribos de microsismos en cada uno de los canales de registración. En el segundo paso, se considera todo el registro, y mediante una ventana móvil se detectan automáticamente aquellos eventos que se interpretan como señales correspondientes a arribos de microsismos, con un criterio de declaración mediante. Como resultado, se obtiene el número de microsismos declarados, un indicador de confianza asociado a cada uno de ellos, y los tiempos de llegada de los microsismos para cada una de las trazas en las que son detectados.

En el Capítulo 6 se enuncian las conclusiones generales y los trabajos futuros que se derivan de los resultados de las investigaciones realizadas a lo largo de esta Tesis. Las 
conclusiones generales están compuestas por las conclusiones globales y por las conclusiones más destacadas de los diferentes análisis y estudios realizados en cada uno de los capítulos 2, 3, 4 y 5 .

Por último, se incluye un Apéndice en el que se explica el funcionamiento del filtro de suavizado con preservación de bordes (EPS, edge preserving smoothing) que es utilizado para realzar los cambios generados por el arribo de la señal en los atributos en los que se basan los métodos propuestos en el Capítulo 3 y algunos de los métodos analizados en el Capítulo 4. Aquí, el filtro es ilustrado mediante un ejemplo sintético sencillo.

\subsection{Aportes originales}

La mayor relevancia respecto de los aportes realizados mediante esta Tesis está dada por el desarrollo y generación de un conjunto de algoritmos nuevos y originales para la detección automática de señales sísmicas de forma precisa, rápida y eficiente. Los algoritmos se implementan mediante programas de computación y tienen diversas aplicaciones. Los aportes se reflejan en el ámbito científico-académico a través de presentaciones en reuniones científicas y publicados en revistas nacionales e internacionales de circulación periódica con referato, en la vinculación con otros grupos de investigación, y también en el reciente interés de alumnos de grado de la Facultad para aplicar los métodos aquí descritos para realizar sus tesis de grado. Por otro lado, en lo que respecta a la transferencia de resultados y desarrollos de tecnología, a partir del impacto generado por algunos de los temas de investigación desarrollados y los resultados obtenidos, se han creado nexos entre la industria y el grupo de investigación liderado por el Dr. Danilo Velis en el marco de trabajos y convenios de vinculación tecnológica. Este aspecto debe resaltarse, pues permite acceder a datos reales, establecer contacto con problemas cotidianos de la exploración geofísica, e interactuar con profesionales de vasta experiencia en el área.

En particular, en el estudio desarrollado en el Capítulo 2 acerca del uso de la teoría de los fractales para el procesamiento de las señales sísmicas, se aclaran una serie de aspectos teóricos y prácticos relativos a la utilización de la dimensión fractal de la traza sísmica para detectar señales. Debido a la gran diversidad de métodos para extraer la dimensión fractal de una curva, en algunas ocasiones existe cierta confusión en la literatura respecto de qué método utilizar. En este sentido, es estudiaron las hipótesis que se deben suponer para considerar a la traza sísmica como una curva fractal, y consecuentemente, qué 
métodos utilizar para obtener su dimensión. Estas consideraciones se avalaron mediante la aplicación a datos sintéticos y reales. Los principales resultados en este tema fueron expuestos y presentados como artículo completo en el simposio de geofísica del congreso del Instituto Argentino del Petróleo y Gas (IAPG) del año 2008 [51].

Por otro lado, se generó un método robusto y eficiente para abordar uno de los problemas del procesamiento de datos en exploración geofísica que presenta mayor dificultad y demanda gran cantidad de tiempo cuando la calidad de los datos es mala: el picado de los primeros arribos. Si bien existen muchas estrategias para solucionar este problema, algunas de ellas implementadas mediante diversos Software de uso comercial o académico, si los datos son complejos los métodos tienden a fallar, y el gran interés por el tema persiste. Entre los aportes más significativos de esta aplicación de los métodos propuestos debemos mencionar el uso de la entropía como atributo sísmico no convencional para detectar señales, la inclusión de un filtro de suavizado con preservación de bordes (EPS) para facilitar notablemente la determinación del tiempo de llegada de la señal, y una técnica automática para ajustar las rectas de refracción y a partir de ellas mejorar los picados y detectar, también de forma automática, la presencia de trazas malas. Todas estos estrategias se validaron mediante su aplicación a datos reales. Los resultados logrados en esta línea de investigación fueron presentadas en un congreso internacional [52] y en un workshop sobre inversión y procesamiento de señales en exploración sísmica realizado en la Facultad de Ciencias Astronómicas y Geofísicas de la Universidad Nacional de La Plata [53]. Además, se publicó un artículo en Geophysics, una revista de circulación internacional de alto impacto y de gran prestigio en el tema [54].

Hacia fines del año 2010 se ha firmado un convenio específico de vinculación tecnológica entre la Facultad y la compañía de servicios geofísicos Data Seismic. Debido al mencionado interés en la industria por el recién mencionado tema de investigación, el objetivo central del convenio se basa en reformular, intentar mejorar, e implementar los métodos de picados de primero arribos desarrollados en esta Tesis utilizando datos de proyectos de sísmica 2D y 3D provistos por la empresa, para generar así un desarrollo tecnológico en conjunto. Estas tareas, también llevadas a cabo durante esta Tesis y detalladas en el Capítulo 3, representan aportes significativos en el ámbito de la transferencia de resultados. Los objetivos planteados en el convenio están actualmente muy avanzados, y en estos momentos los resultados logrados están siendo cotejados contra aquellos obtenidos mediante el uso de Software comercial que dispone la empresa. 
Entre los aportes que tienen que ver con la aplicación de los programas computacionales en la detección automática de fases de terremotos en estaciones sismológicas, el análisis comparativo de los métodos utilizando registros adquiridos de la Estación Sismológica de La Plata que se presenta en el Capítulo 4 sirve de guía a un sismólogo o analista a la hora de seleccionar qué estrategia de picado automático utilizar. Los principales resultados obtenidos en esta línea de investigación se presentaron en primer término en una reunión de la Asociación Argentina de Geofísicos y Geodestas en el año 2009 [49], y ha sido recientemente aceptado un artículo completo para su publicación en Geoacta [50]. Además, los métodos que mejor funcionaron conforman una herramienta disponible para realizar estudios futuros, tanto en la Estación Sismológica de la Plata, como en otras estaciones de interés de la Facultad, como por ejemplo la de Río Grande, en Tierra del Fuego, donde se prevé realizar nuevas investigaciones en conjunto con el Departamento de Sismología de La Plata.

Por último, se han generado aplicaciones desarrolladas con el objetivo de detectar de forma automática microsismos para el monitoreo de los procesos de fracturación inducidos en pozos de exploración petroleros mediante inyecciones hidráulicas. Estas aplicaciones poseen gran interés local, puesto que recientemente se ha comenzado a realizar estudios de microsismicidad en Argentina. En este sentido, se planea continuar trabajando en colaboración con la industria para mejorar y complementar los métodos hasta aquí desarrollados, y evaluar también otras alternativas para abordar y dar soluciones a problemas relativos al procesamiento de los datos adquiridos para estudios de microsismicidad. Además, en lo que respecta a lo científico-académico, se continúa trabajando en esta línea que forma parte del Plan de Investigación de posdoctorado. En particular, actualmente se encuentra en preparación un trabajo que será enviado como resumen expandido al congreso anual de la Society of Exploration Geophysics (SEG) donde se mostrarán los alcances hasta aquí logrados. 


\section{Capítulo 2}

\section{La dimensión fractal de la traza sísmica}

La determinación precisa de los primeros arribos representa un paso primordial en la exploración sísmica tanto para el posterior procesamiento de los datos como para numerosas y diversas aplicaciones. Por lo general, la presencia de ruido de fondo hace que el proceso de detección de la señal sea una tarea difícil, especialmente cuando las señales a detectar son débiles o la relación señal-ruido es baja. Si bien en muchos casos la determinación del inicio de la señal es llevada a cabo mediante la inspección visual de los cambios en las amplitudes y en las formas de la onda de los datos ("picado manual"), los resultados de esta estrategia suelen ser poco consistentes, presentan el inconveniente de estar basados en la subjetividad del analista y la tarea puede demandar demasiado tiempo si el volumen de los datos a analizar es muy grande. Por lo tanto, el uso de algoritmos computacionales resulta fundamental para proporcionar estimaciones más precisas, rápidas y objetivas.

Como alternativa al picado manual, en la Introducción General enumeramos varias técnicas para atacar este problema, algunas de ellas consideradas "convencionales" y otras "no convencionales". En particular, ciertas estrategias basadas en la teoría de los fractales han demostrado ser muy útiles para la detección de señales. Estas estrategias postulan que la dimensión fractal del ruido aleatorio es significativamente mayor que la dimensión fractal de una señal coherente inmersa en el ruido de fondo de los datos. Boschetti et al. [12], por ejemplo, han analizado el comportamiento de la dimensión fractal a lo largo de trazas sísmicas con el fin de detectar la transición entre el ruido y la señal más el ruido asociando esta transición a la llegada del primer arribo. Sus resultados están basados en dos métodos para calcular la dimensión fractal de las trazas: el "método de la división" (también conocido como "método del compás") y el "método de Hurst". Por otro lado, Jiao y Moon [26] utilizaron una técnica de determinación de la dimensión fractal mediante la varianza de la señal que permite obtener transiciones más nítidas entre el ruido y la señal más el ruido. Así, los autores logran una determinación más robusta y precisa de los primeros arribos sísmicos.

Podemos entonces utilizar el análisis de la variación de la dimensión fractal de los datos 
sísmicos para discriminar la señal del ruido de fondo. La dimensión fractal representa un indicador que da cuenta de cuan compleja es la curva analizada a medida que ésta es analizada con mayor detalle (a menor escala) [36]. Como veremos en la próxima sección, las trazas sísmicas pueden ser consideradas como curvas fractales en el plano. Luego, el advenimiento de los primeros arribos en las trazas sísmicas puede determinarse semiautomáticamente analizando cómo cambia la dimensión fractal en función del tiempo. En la práctica, el valor de la dimensión fractal de una curva depende del método elegido para estimarla y de la selección de los diferentes parámetros que intervienen en cada técnica.

En general, no existe un único método aceptado para calcular la dimensión fractal de una curva [29]. Lamentablemente, es frecuente encontrar en la bibliografía cierta confusión respecto de qué método utilizar para estimar la dimensión fractal de una serie de tiempo. En este capítulo estudiamos dos métodos para calcular la dimensión fractal de la traza sísmica que utilizan diferentes enfoques: el método del compás (CM) y el método del variograma (VM). Describiremos estos dos métodos y algunas mejoras que hemos propuesto a los mismos con el fin de facilitar la determinación de los primeros arribos. Además, a partir de los conceptos de curvas auto-similares y curvas auto-afines, mostraremos que las dimensiones fractales asociadas al CM y al VM reflejan características diferentes de las curvas analizadas. En particular, veremos que el VM es un método concebido para estudiar curvas auto-afines y resulta más adecuado para analizar trazas sísmicas que el CM, que es un método concebido para analizar curvas auto-similares. Nos referiremos a las dimensiones fractales obtenidas por estos métodos como dimensión fractal del compás y dimensión fractal del variograma. En este contexto, llevamos a cabo una comparación cualitativa y cuantitativa entre el CM y el VM cuando son aplicados para la detección de primeros arribos en datos sísmicos generados sintéticamente bajo diferentes condiciones de ruido. Este análisis fue publicado en un artículo completo en el simposio de geofísica del congreso del Instituto Argentino del Petróleo y Gas (IAPG) del año 2008 [51]. Los resultados mostraron que para estimar la dimensión fractal de las trazas sísmicas la técnica del variograma (VM) es más robusta y precisa que la técnica basada en el método del compás (CM). Del mismo modo, el VM es mucho más eficiente que el CM en términos de costo computacional, y su aplicación en diferentes conjuntos de datos resulta más sencilla. En contraste, encontramos los resultados obtenidos con el CM son críticamente dependientes de una serie de parámetros 
que se deben seleccionar para utilizar el método. En consecuencia, es necesario un ajuste demasiado cuidadoso cada vez que un nuevo conjunto de datos (o incluso una sola traza sísmica) es procesada. Por último, probamos el uso del VM utilizando datos reales de campo, obteniendo muy buenos resultados.

En general, podemos afirmar que los resultados indican que el análisis de la dimensión fractal es una estrategia apropiada para resolver el problema de detección de primeros arribos si se utiliza un método adecuado para el procesamiento de los datos. Las transiciones en la dimensión fractal de las trazas sísmicas que arroja el CM se producen en forma lenta y, consecuentemente, el comienzo de la señal es difícil de detectar. Por el contrario, el VM proporciona transiciones más bruscas que facilitan la identificación de los primeros arribos con gran precisión.

\subsection{Dimensión fractal, curvas auto-similares, curvas auto-afines, y su uso en ciencias de la Tierra}

De acuerdo a Mandelbrot [36], un fractal es por definición un conjunto en un espacio métrico para el cual la dimensión de Hausdorff-Besicovitch es estrictamente mayor a su dimensión topológica. La dimensión de Hausdorff-Besicovitch generaliza la noción topológica de la dimensión de un conjunto (un número natural) a valores reales no negativos. En el caso de una curva en el plano, mientras que las curvas topológicas tienen dimensión igual a uno, una curva fractal tiene una dimensión fractal $D$ que se encuentra en el rango $1 \leq D \leq 2$. Se puede decir que la dimensión fractal cuantifica el grado de complejidad de una curva. Los fundamentos de la teoría de los fractales se pueden encontrar enunciados por Mandelbrot [36], Feder [22] y Peitgen et al. [46]. El uso de los fractales en geofísica está ampliamente discutido por Turcotte [69] y Korvin [30]. Sin embargo, su aplicación para la detección de señales, y en particular para señales sísmicas, sólo se puede encontrar en unos pocos trabajos [12, 67, 26, 54].

Las curvas fractales pueden ser clasificados como auto-similares o auto-afines. De acuerdo con Turcotte [69], una definición formal de una curva fractal auto-similar en un espacio de dos dimensiones $(x, y)$ es que la curva escalada por un factor de escala $c$, $f(c x, c y)$, sea estadísticamente similar a la curva sin escalar, $f(x, y)$. Por otro lado, una definición formal de un fractal auto-afín es que $f\left(c x, c^{H_{a}} y\right)$ sea estadísticamente similar a $f(x, y)$, donde $H_{a}$ es conocida como medida de Hausdorff. Es decir que en este caso, para mantener la similitud estadística entre las curvas a diferente escala, hay que introducir 
un factor exponencial sobre la escala en una de las dos dimensiones. Para aclarar esta diferencia, sigamos el argumento de Wilson [73]: supongamos entonces que se grafica una curva en el plano $(x, y)$. Si en dicho gráfico se tienen las mismas magnitudes y unidades en el eje $x$ y en el eje $y$ y además existe una relación exponencial entre el paso utilizado para determinar la longitud de la curva y su longitud real, entonces la curva se define como auto-similar. El método del compás (CM) es uno de los métodos teóricamente adecuados para la estimación de la dimensión fractal de curvas auto-similares. Esta estimación es independiente del intercambio de los ejes, pero sí depende fuertemente de un cambio de escala en uno de ellos. Se puede decir que la dimensión fractal del compás representa una medida del grado de complejidad de la forma de la curva. Por el contrario, si el gráfico tiene diferentes magnitudes o unidades en sus ejes, y para mantener la relación exponencial entre el paso utilizado para determinar la longitud de la curva y la longitud obtenida hay que escalar diferente ambas dimensiones, se tiene entonces que la curva es auto-afín. Funciones del tiempo o del espacio, tales como series de tiempo, son ejemplos de curvas auto-afines. Contrariamente a lo que se observa en una curva auto-similar, la dimensión fractal de una curva auto-afín depende de una rotación de ejes, pero es independiente de un cambio de escala en el eje $y$. Los métodos elegidos para determinar la dimensión fractal de curvas auto-afines claramente tienen que satisfacer estas propiedades. Carr y Benzer [15] mostraron que la dimensión fractal de las curvas auto-afines describe la naturaleza estocástica de los gráficos $y$ vs. $x$, y que no hay ninguna razón para esperar que esta dimensión fractal se correlacione con la dimensión fractal del compás. Uno de los métodos desarrollados para estimar la dimensión fractal de las curvas auto-afines es el método del variograma (VM), que describiremos más adelante.

Claramente, las trazas sísmicas consideradas como curvas fractales deben ser asumidas como auto-afines. Sin embargo, Klinkenberg [29] señala que el tratamiento de una curva como auto-similar o auto-afín puede depender del objetivo de la investigación. Además, algunas curvas que se suponen que son auto-similares, como es el caso de un perfil de topografía del fondo marino, a menudo se pueden caracterizar y tratar como auto-afines [35]. Contornos topográficos usualmente se describen como auto-similares, mientras que el relieve topográfico de un perfil vertical puede ser considerado auto-afín [69]. Por otra parte, Boschetti et al. [12] desarrolló una técnica de detección de primeros arribos sísmicos basado en un análisis fractal de los datos y encontró que el CM (mencionado como método de la división en su trabajo), que se supone que debe ser utilizado 
para analizar curvas auto-similares, es más eficaz que el método de Hurst, que se supone que es más apropiado para analizar curvas auto-afines. No obstante, como veremos en las próximas secciones, el CM no es adecuado para la detección de primeros arribos, por lo que desalentamos su uso en este tipo de análisis. Contrariamente, el uso de métodos concebidos para analizar curvas auto-afines (como una traza sísmica) arroja resultados más consistentes.

\subsection{El método del compás (CM)}

Consideremos una curva fractal en el plano. La longitud total $L$ de la curva se puede aproximar "caminando" a lo largo de la curva con pasos de longitud fija, digamos $r$. Después de $N$ pasos toda la curva podrá ser cubierta a excepción de un "resto", $f$, menor que $r$. Este proceso es análogo a usar un compás con una abertura fija $r$ para intersectar la curva en $N+1$ puntos sucesivos hasta alcanzar el final de la curva (salvo por la fracción restante $f$ ). Esta metodología se ilustra en la Figura 2.1. Luego, podemos escribir:

$$
L=r N+f .
$$

Claramente, cuanto menor es la abertura del compás $r$, mayores son los detalles de la curva que se tienen en cuenta, y por lo tanto, mayor es la longitud total $L$ que se mide. Si la curva es un fractal auto-similar, la relación entre $L$ y $r$ se puede expresar por la ley exponencial

$$
L=k r^{1-D}
$$

donde $k$ es una constante y $D$ es la dimensión fractal del compás, con $1 \leq D \leq 2$. Entonces, tomando logaritmo a ambos miembros obtenemos

$$
\log (L)=\log (k)+(1-D) \log (r)
$$

Esta es la ecuación de una recta de pendiente $S=1-D$ en un gráfico bilogarítmico. Este gráfico, denominado gráfico de Mandelbrot-Richardson, se construye fácilmente midiendo $L$ para diferentes aberturas del compás $r$. La pendiente $S$ de la recta definida por la ecuación (2.3) en el dominio bilogarítmico se obtiene mediante la solución de un problema de regresión lineal por mínimos cuadrados. En la Figura 2.2 se muestra un ejemplo 


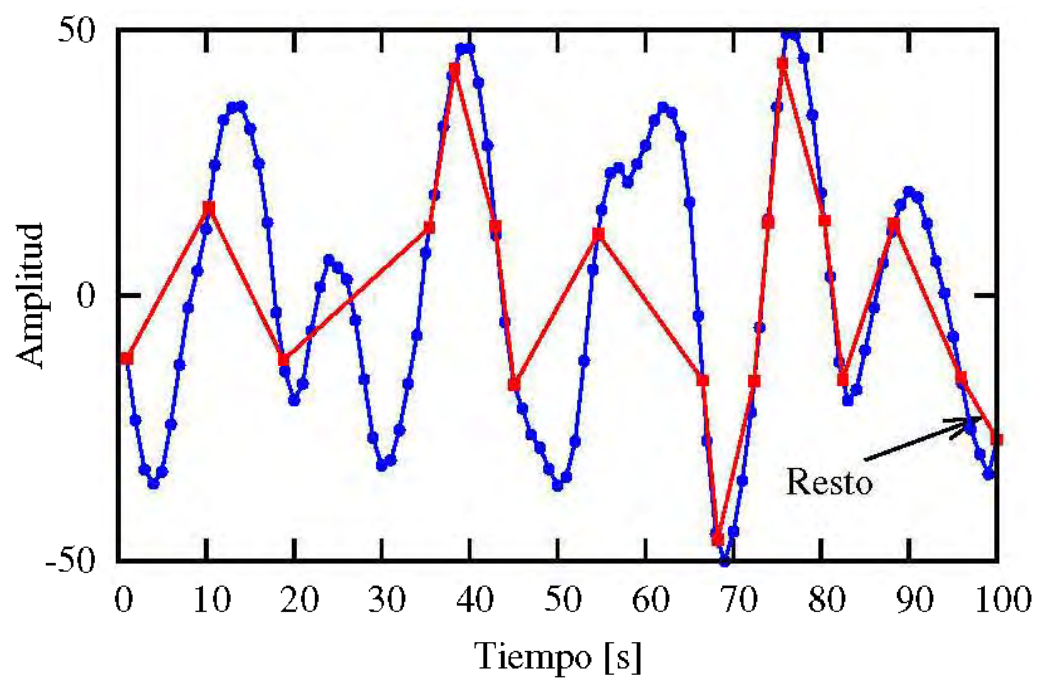

Figura 2.1: Una curva fractal (azul) es aproximada usando una abertura de compás constante en $N$ pasos (rojo). El último paso es más corto ("resto").

de un gráfico de Mandelbrot-Richardson que nos sirve para ejemplificar la idea de este procedimiento. Esta técnica es idéntica a la utilizada en el método del variograma, como veremos en la próxima sección.

Finalmente, la dimensión fractal $D$ es estimada mediante

$$
D=1-S
$$

En la práctica, este método presenta algunas dificultades que se describen brevemente a continuación (para una descripción completa y también para algunas recomendaciones útiles referirse a Klinkenberg [29]). Uno de los aspectos más importantes a considerar en este método se relaciona con el hecho que por lo general el compás intersecta a la curva en más de un punto en cada paso dado. Para solucionar este inconveniente existen dos posibilidades: (1) elegir el primer punto de intersección (el punto con el menor valor de abscisa $x \circ t$ ) o (2) considerar el último punto de intersección (el punto con el mayor valor de $x \circ t$ ). Mandelbrot [37] ha mostrado cuáles son las diferencias entre la elección de una opción u otra. Otro tema crítico tiene que ver con la escala que se utiliza para el eje $y$. Existe una fuerte dependencia entre la dimensión fractal del compás y la escala seleccionada. Dado que el método supone que el fractal es auto-similar, este parámetro de escala se debe establecer con el fin de hacer la curva lo más "auto-similar" posible. 
Es decir, lograr tener las mismas magnitudes en ambas dimensiones. Una vez que se decidió si considerar el primer o el segundo punto de intersección y se fija el valor de escala para el eje $y$, se debe decidir también qué aberturas de compás van a ser utilizadas para medir la longitud de la curva. A tal efecto, algunos parámetros adicionales deben ser seleccionados: las aberturas de compás mínima y máxima, el número de aberturas a utilizar y el paso entre diferentes aberturas. Un práctica común para elegir el paso de las aberturas del compás es utilizar una secuencia aritmética o geométrica de aberturas, y definir así el paso. Al utilizar intervalos aritméticos, se supone que se obtiene una cobertura más homogénea de los detalles de la curva. Por otro lado, utilizar intervalos geométricos es ventajoso desde el punto de vista estadístico pues de esta manera los puntos a considerar en la etapa de la regresión lineal por mínimos cuadrados resultarán equidistantes en el dominio bilogarítmico.

\subsection{El método del variograma (VM)}

El variograma $V(h)$, muy utilizado en geoestadística, caracteriza la continuidad o la "rugosidad" de un conjunto de datos. Se define como el valor esperado del cuadrado de las diferencias entre pares de valores de una función muestreada $s_{t}$ (por ejemplo, una traza sísmica) que están separados en $h$ muestras, y se puede entonces estimar a partir de:

$$
V(h)=\frac{1}{n(h)} \sum_{i=1}^{n(h)}\left[s_{i+h}-s_{i}\right]^{2},
$$

donde $n(h)$ es el número de pares de observaciones $\left(s_{i}, s_{i+h}\right)$ que están separadas por $h$ unidades de tiempo dentro de la ventana de tiempo considerada para su cálculo, y que depende, lógicamente, del tamaño de dicha ventana. De acuerdo a Burrough [14], se puede demostrar que:

$$
V(h) \propto h^{\beta}
$$

donde $\beta$ está relacionado con la dimensión fractal $D$ mediante

$$
\beta=4-2 D
$$




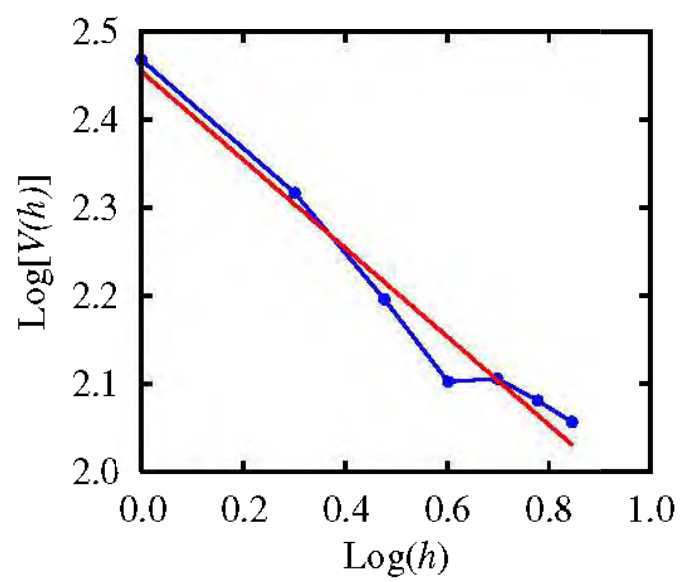

Figura 2.2: Gráfico de Mandelbrot-Richardson para obtener la pendiente en el dominio bilogarítmico. Las muestras de la curva en azul son aproximadas por mínimos cuadrados por la recta en rojo.

Análogamente al CM, si calculamos $V(h)$ para diferentes separaciones $h$, se puede utilizar la pendiente $\beta$ de la recta definida en el dominio bilogarítmico $\log (V(h))$ vs. $\log (h)$ (gráfico de Mandelbrot-Richardson) para estimar la dimensión fractal en la ventana analizada simplemente a partir de la ecuación anterior:

$$
D=2-\beta / 2
$$

En la Figura 2.2 se muestra un ejemplo de un gráfico de Mandelbrot-Richardson para el VM en donde los siete puntos de la curva azul son aproximados por la recta roja por mínimos cuadrados. Es fácil ver que este método es, contrariamente al CM, independiente de cualquier factor de escala aplicado a la componente vertical. Para ello, basta reemplazar $s_{t}$ por $c s_{t}$ en la ecuación 2.5, con $c$ constante, y observar en las ecuaciones anteriores que la pendiente $\beta$ permanece invariante. En efecto, si llamamos $V_{c}(h)$ al valor del variograma obtenido con $c s_{t}$, entonces, según la ecuación 2.5:

$$
V_{c}(h)=c^{2} V(h)
$$

y luego, de acuerdo a la ecuación 2.6:

$$
V_{c}(h) \propto c^{2} h^{\beta}
$$

Así, $V_{c}(h)$ también será proporcional a $h^{\beta}$ y su dimensión fractal será la misma que 
la de $V(h)$. En consecuencia, la implementación práctica del VM es más simple que el $\mathrm{CM}$, debido que no entra en juego el parámetro de escala del eje vertical. No obstante, hay que definir un valor mínimo y un valor máximo de las separaciones $h$ para el cálculo del variograma, de la misma manera que tienen que ser definidos a priori los valores de las aberturas del compás en el CM. Cuando la señal $s_{t}$ está contaminada con ruido blanco (cuya dimensión fractal teórica es igual a 2), para captar su naturaleza aleatoria es necesario seleccionar una separación $h$ pequeña. Si bien el ruido que suele estar presente en las trazas sísmicas no es estrictamente blanco, los valores pequeños de $h$ otorgan información relevante acerca de la dimensión fractal a calcular pues para estos valores se evidencia la presencia del ruido caracterizado por una dimensión fractal alta. En particular, estos valores serán mayores a los de la dimensión fractal de la señal. Por lo tanto, es una buena práctica considerar $h=1$ como separación mínima en todos los casos. Cabe destacar que esto es una ventaja sobre el CM, en donde la mínima abertura $r$ es un parámetro que debe ajustarse para cada curva considerada. Además, el paso que se utiliza en el VM para los distintos valores de $h$ es un número entero $(h=1,2, \times)$.

\subsection{Algoritmos implementados para analizar la señal sísmica}

En esta sección se describen brevemente los algoritmos que se han utilizado para detectar el tiempo de arribo de las señales sísmicas. En particular, se describen varias cuestiones prácticas relativas a la selección de los distintos parámetros que están involucrados tanto en el CM como en el VM.

En todos los casos, la dimensión fractal se calcula en una "ventana móvil" que se desplaza muestra por muestra a lo largo de la señal en tiempo (ver Figura 2.3). El primer problema a resolver es entonces cómo seleccionar la longitud de la ventana móvil. Si esta longitud fuera demasiado corta, la estimación de la dimensión fractal podría estar demasiado sesgada debido a la poca información que contendría la ventana en este caso. Si por el contrario fuera demasiado larga, las transiciones en la dimensión fractal serían suaves, complicando la determinación exacta de la llegada de la señal (primer arribo). Después de algunos experimentos hemos encontrado que un tamaño de ventana de 100 muestras brinda resultados razonables para trazas sísmicas muestreadas a 4 ms. Cabe destacar que Boschetti et al. [12] y Jiao y Moon [26] utilizaron valores similares. Tanto en el CM como en el VM las dimensiones fractales obtenidas para cada ventana móvil 


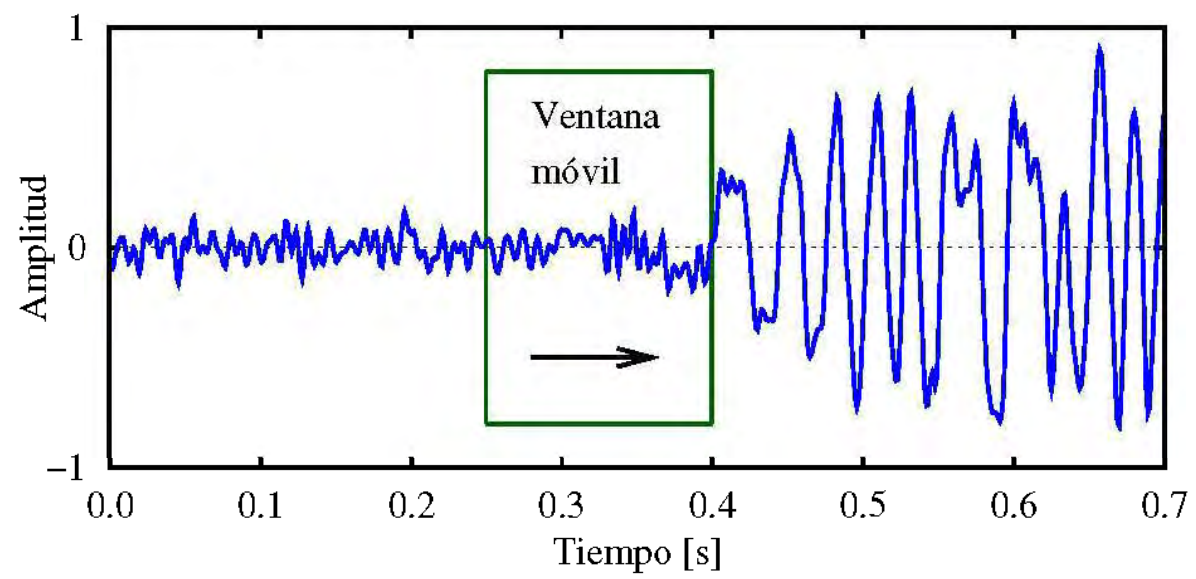

Figura 2.3: Ventana móvil usada para el cálculo de la dimensión fractal en los dos métodos presentados. En este ejemplo, la ventana sólo abarca ruido.

han sido asignadas al último punto de la ventana, ya que los algoritmos intentan detectar un rápido cambio en la dimensión fractal a lo largo de la traza ante la llegada de la señal inmersa en el ruido de fondo.

Hemos propuesto algunas mejoras al CM respecto de la implementación tradicional, descrita por Boschetti et al. [12], con el fin de mitigar algunos de los problemas que hemos discutido en las secciones anteriores en la descripción del método. Por ejemplo, encontramos que a los efectos de discriminar mejor la señal del ruido de fondo es más apropiado considerar el primer punto de intersección del compás y no el último. Por supuesto, esta intersección es geométrica y se produce en una porción de la curva que une a dos valores muestreados consecutivos $s_{i}$ y $s_{i+1}$. Una vez que identificamos estos dos puntos $\left(i, s_{i}\right)$ y $\left(i+1, s_{i+1}\right)$, realizamos una interpolación para escoger el punto de intersección. Esta interpolación es llevada a cabo mediante el clásico método de la bisección. Luego, avanzamos hacia el siguiente punto y repetimos el proceso en cada paso hasta alcanzar el final de la ventana. Por último, se agrega el "resto" $f(\operatorname{con} f<r)$.

Otra de las mejoras incorporadas se puede resumir de la siguiente manera. Para medir la longitud de la curva, no existe ningún argumento que indique si se debiera recorrerla en un sentido o el otro. Entonces, en el algoritmo implementado, este proceso de medición de la longitud de la curva para cada abertura $r$ se realiza primero hacia un sentido y luego hacia el otro, dando lugar a dos estimaciones de la dimensión fractal que son finalmente promediadas. Esta estrategia ya ha sido sugerida recientemente por Nams [45].

Como se mencionó anteriormente, los resultados del CM dependen en gran medida de 
la selección de la escala vertical, y en menor medida de la selección de los valores mínimo, máximo y del intervalo de las aberturas del compás. Por lo tanto, la selección adecuada de estos parámetros es fundamental. Hemos tratado de seguir algunas recomendaciones volcadas en la bibliografía (ver Klinkenberg [29]). Sin embargo, cada autor parece preferir un conjunto diferente de parámetros. Hemos encontrado los mejores resultados después de testear los parámetros experimentalmente para cada conjunto de datos. Como regla general, seleccionamos primero la escala vertical a fin de que cada traza sísmica sea lo más auto-similar posible. Esto se logra eligiendo dicha escala de forma tal que los cambios de la curva tengan valores comparables en ambas dimensiones. Luego, seleccionado la abertura mínima del compás aproximadamente igual a la menor distancia entre cualquier par de puntos consecutivos. Las diferentes aberturas las tomamos equidistantes aumentándolas de a una muestra y utilizamos cerca de diez aberturas diferentes; es decir, utilizamos unos diez pasos aritméticos para la regresión por mínimos cuadrados. Con estos criterios, claramente queda fija la abertura máxima del compás.

Contrariamente al caso del CM, el algoritmo para implementar el VM es muy simple. Para el cálculo del variograma usamos la ecuación 2.5. A fin de obtener la dimensión fractal de cada ventana de 100 muestras, el variograma se calculó para diferentes separaciones $h$ con el objeto de resolver luego el problema de mínimos cuadrados, como se explicó anteriormente. Al igual que en el CM, utilizamos valores de $h$ separados de a una muestra. Entonces, los valores de $h$ utilizados fueron $h=1,2, \ldots, h_{\max }$ donde $h_{\max }$ se determinó experimentalmente. Para las diferentes trazas sísmicas que hemos analizado, valores de $h_{\max }$ entre 4 y 15 han brindado buenos resultados. Vale la pena mencionar que la estimación de la dimensión fractal $D$ obtenida es mucho menos sensible respecto de la selección de este parámetro en el VM que lo que ocurre en el CM respecto de la selección de los valores de abertura del compás. Por ello, en relación a la selección de los parámetros, podemos afirmar que VM es mucho más robusto que el CM.

\subsection{Ejemplos y resultados}

\subsubsection{Aplicación en datos sintéticos}

Hemos testeado el CM y el VM con datos sísmicos sintéticamente generados con diferentes relaciones señal-ruido. Para tal fin, generamos un registro de disparo común mediante la simulación de un simple experimento de sísmica 2D de refracción y reflexión. El modelo 


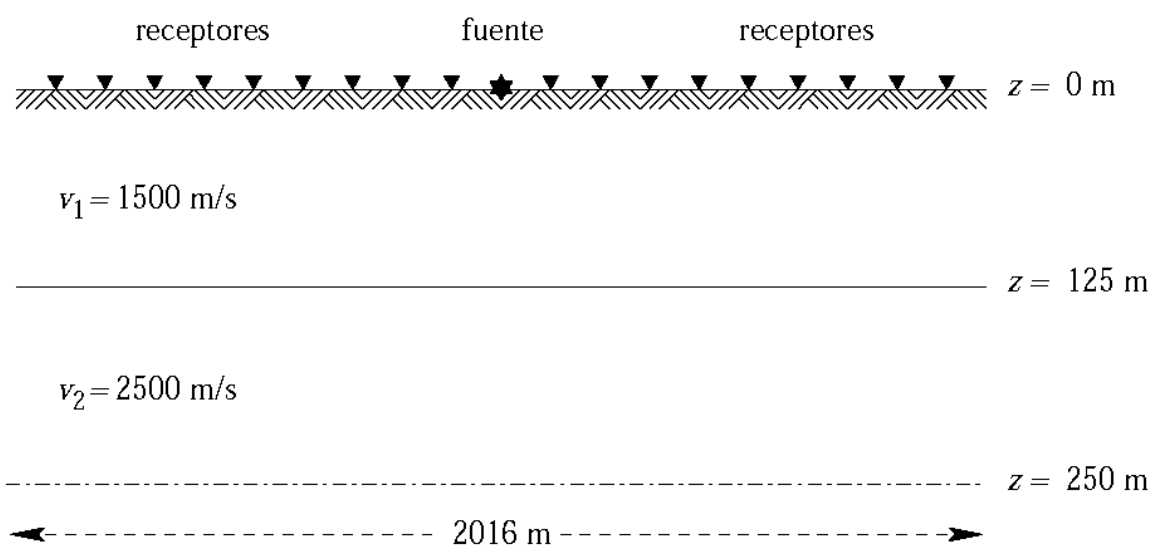

Figura 2.4: Modelo de velocidades de los datos sintéticamente generados.

de velocidades (Figura 2.4) está dado por una estructura de capas planas horizontales de $2.016 \mathrm{~m} \times 250 \mathrm{~m}$ que consta de dos medios homogéneos de densidad constante (e igual para ambos medios) separados por una interfaz ubicada $125 \mathrm{~m}$ de profundidad. La onda $\mathrm{P}$ tiene velocidades $v_{1}=1500 \mathrm{~m} / \mathrm{s}$ y $v_{2}=2500 \mathrm{~m} / \mathrm{s}$, respectivamente para cada capa. La fuente está colocada en superficie en el centro del modelo en $x=1008 \mathrm{~m}, z=0 \mathrm{~m}$.

Dado este modelo del subsuelo, calculamos los frentes de onda utilizando un paquete de modelado de la ecuación de onda acústica a través de diferencias finitas de segundo orden [18] tomando $d z=1.0 \mathrm{~m}$. La fuente que se utiliza para realizar el modelado es una ondícula de ricker con frecuencia máxima $f_{\max }$ y frecuencia central $f_{0}$ dadas por:

$$
\begin{gathered}
f_{\max }=\frac{v_{\min }}{10.0 d h} \\
f_{0}=0.5 f_{\max }
\end{gathered}
$$

donde $d h=\min \{|d x|,|d z|\}$. Reemplazando con los parámetros del modelo propuesto $v_{\min }=1500 \mathrm{~m} \mathrm{y} d h=1.0 \mathrm{~m}$ resulta $f_{\max }=150 \mathrm{~Hz}$ y $f_{0}=75 \mathrm{~Hz}$. Luego, a partir de los frentes de onda, obtenemos los registros sintéticos de disparo común colocando 145 trazas uniformemente distribuidas a lo largo de la superficie, separadas entre sí $d x=14 \mathrm{~m}$ (Figura 2.4). Para simular las frecuencias usualmente registradas en sísmica, aplicamos un filtro pasabanda trapezoidal con frecuencias de corte $(5,10,90,100) \mathrm{Hz}$. Por último, las trazas resultantes fueron contaminadas con ruido aditivo gaussiano con diferentes relaciones señal-ruido $(S N R)$ como veremos a continuación.

Con el fin de calibrar los parámetros de los algoritmos, en primer lugar testeamos los dos métodos con una sola traza extraída de los registros de disparo común generados. 

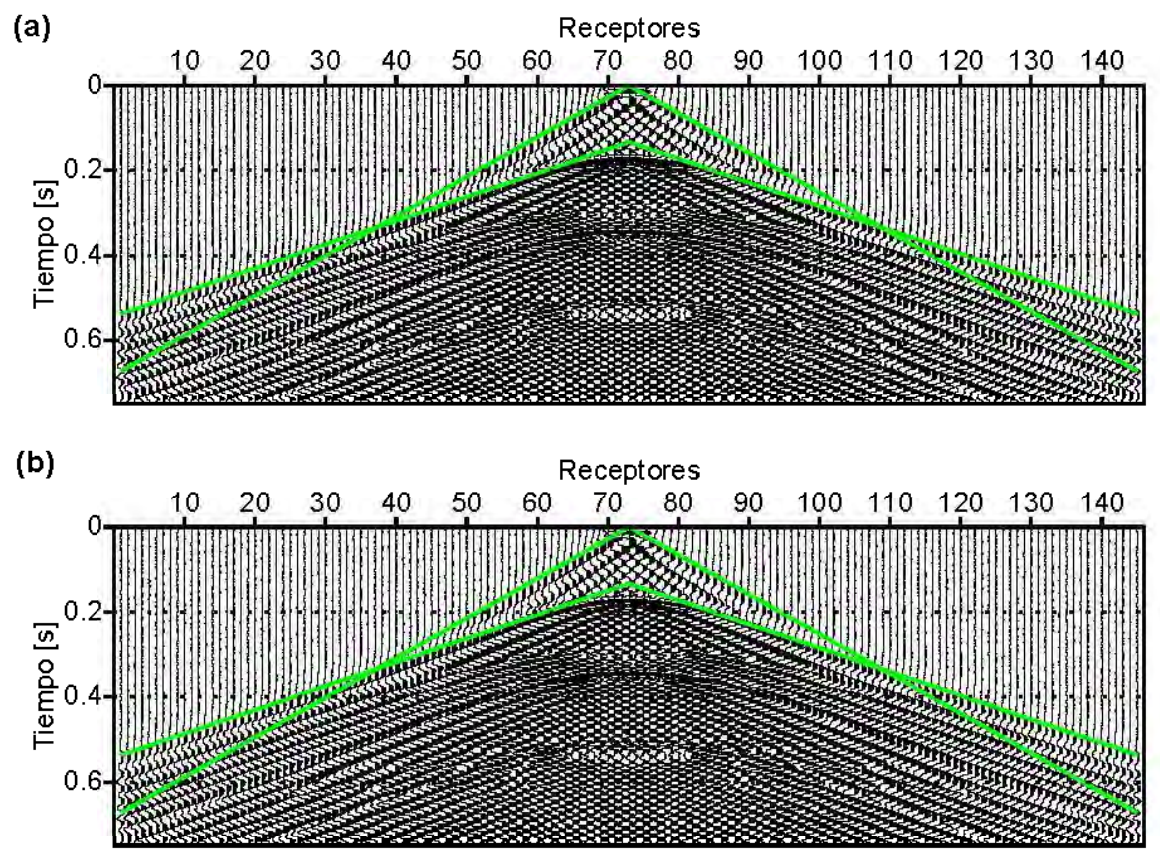

Figura 2.5: Registro sintético generado $(S N R=10)$. (a) Con ruido de alta frecuencia. (b) Con ruido de "baja" frecuencia. Las líneas verdes indican los arribos verdaderos de la señal.

Luego, hemos testeado los dos algoritmos con todo el conjunto de trazas de disparo común simulado bajo diferentes niveles de ruido. Además de utilizar diferentes valores de $S N R$, y con el objetivo de analizar la sensibilidad de los algoritmos en respuesta al ancho de banda del ruido, consideramos registros contaminados tanto con ruido de alta frecuencia $(0-160 \mathrm{~Hz})$ como con ruido de "baja" frecuencia $(0-100 \mathrm{~Hz})$. Los registros resultantes se muestran en la Figura $2.5(S N R=10)$ y en la Figura $2.10(S N R=7)$. En las figuras también se muestran los valores que corresponden a los arribos sísmicos verdaderos del rayo directo y al rayo refractado mediante líneas rectas (en verde). En el centro de los registros se observan mayores frecuencias, a excepción de algunos "blancos" de bajas frecuencias producidos por artefactos numéricos del modelado. Para los ejemplos de un sola traza que mostraremos más adelante (Figuras 2.6 y 2.7) hemos seleccionado la traza correspondiente al receptor número 120 (offset $658 \mathrm{~m}$ ) del registro con $S N R=10$ (Figura 2.5).

Hemos encontrado que ambos métodos exhiben una dependencia significativa con el contenido en frecuencia de la señal. Como se mencionó antes, debido a que el espectro de frecuencias del ruido blanco es plano, su dimensión fractal teórica es igual a 2. Sin 
(a)

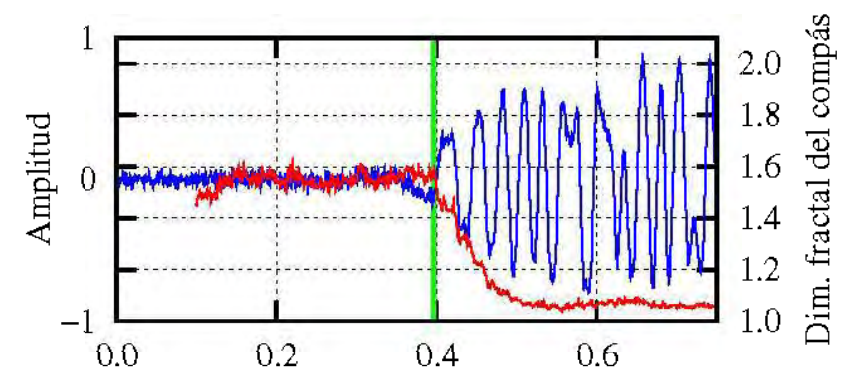

(b)

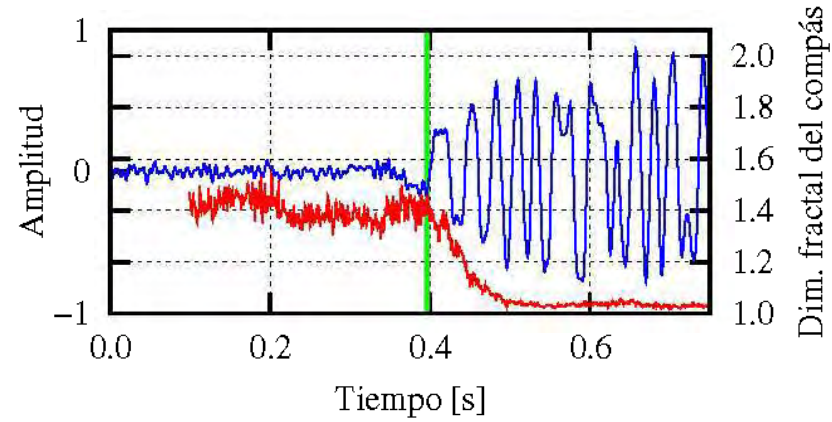

Figura 2.6: Traza sísmica sintéticamente generada con ruido agregado con $S N R=10$ (azul), dimensión fractal del compás calculada (rojo) y arribo real de la señal (verde). (a) El ruido adicionado es de alta frecuencia. (b) El ruido adicionado es de baja frecuencia.

embargo, el CM no es capaz de capturar la naturaleza fractal del ruido de forma adecuada, y en consecuencia la dimensión fractal resultante obtenida con este método cuando aún no ha arribado la señal es significativamente menor que el valor teórico de 2. Cuando el contenido en frecuencia del ruido de los datos es de un ancho de banda menor, la dimensión fractal del compás disminuye como es de esperarse. Estos conceptos se ilustran en la Figura 2.6, que muestra una traza sísmica sintética (en azul) con relación señal-ruido $S N R$ (por amplitud) de aproximadamente 10, tanto con ruido agregado de alta como de baja frecuencia, y la dimensión fractal del compás correspondiente (en rojo). El arribo efectivo de señal $(t \approx 0.4 \mathrm{~s}$ ) también es graficado en la misma figura (en verde). Las diferencias entre las dimensiones fractales en los casos del ruido de alta y baja frecuencia se aprecian con claridad, especialmente para tiempos previos al de la llegada de la señal, si bien los cambios no son bruscos. Por otro lado, el VM resulta más adecuado que el CM para extraer la dimensión fractal del ruido blanco (Figura 2.7). El acuerdo con el valor teórico en el caso con ruido agregado de alta frecuencia es muy bueno (muy cercano a 2, ver Figura 2.7a). Una vez más, cuando el ancho de banda del ruido es menor, la 
(a)

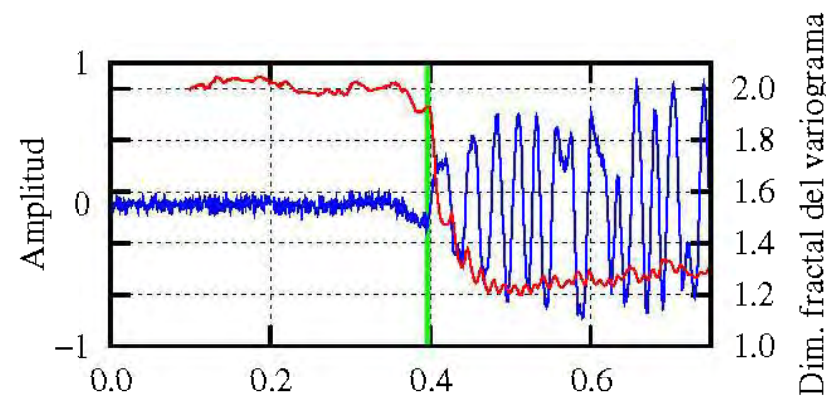

(b)

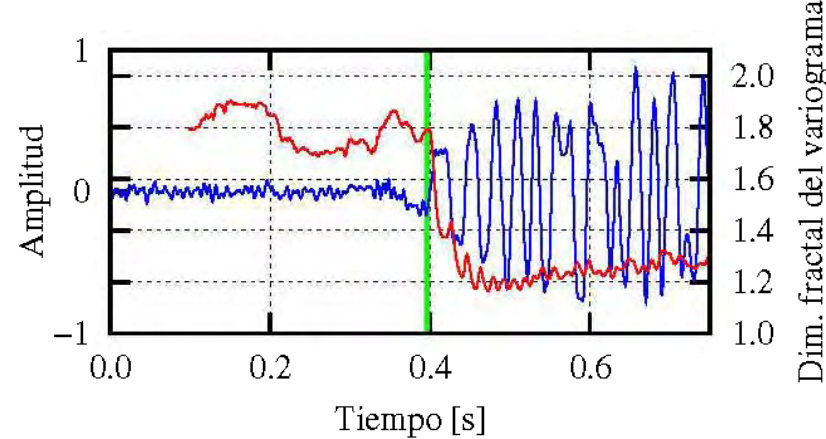

Figura 2.7: Traza sísmica sintéticamente generada con ruido agregado con $S N R=7$ (azul), dimensión fractal del variograma calculada (rojo) y arribo real de la señal (verde). (a) El ruido adicionado es de alta frecuencia. (b) El ruido adicionado es de baja frecuencia.

dimensión fractal estimada con el VM disminuye de manera significativa (Figura 2.7b), pero en menor medida que en el caso del CM.

Una conclusión que se debe destacar es que ambos métodos exhiben un decrecimiento en la dimensión fractal cuando arriba la señal. Sin embargo, la tasa de cambio es muy diferente cuando se utiliza el CM o el VM. En el CM el cambio se produce con una pendiente suave, en completo acuerdo con los resultados obtenidos por Boschetti et al. [12]. Por otra parte, en el VM el cambio es mucho más abrupto. Mientras que la estimación de la dimensión fractal del ruido es altamente afectada por el contenido en frecuencias, el efecto sobre la dimensión fractal de la señal es considerablemente menor. Por tanto, el proceso de filtrado del ruido de los datos sísmicos hace que la diferencia entre la dimensión fractal del ruido y aquella de la señal disminuya, y entonces, la detección precisa de la llegada de la señal se hace más complicada. Este comportamiento ha sido observado también por Jiao y Moon [26] quienes se basaron en él para mejorar su algoritmo de detección mediante la dimensión fractal de la varianza agregando ruido aleatorio a los datos. 
(a)

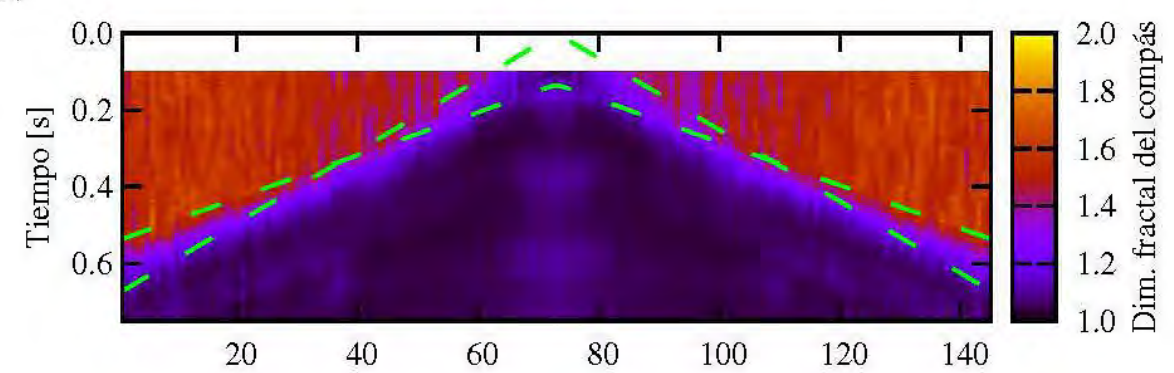

(b)

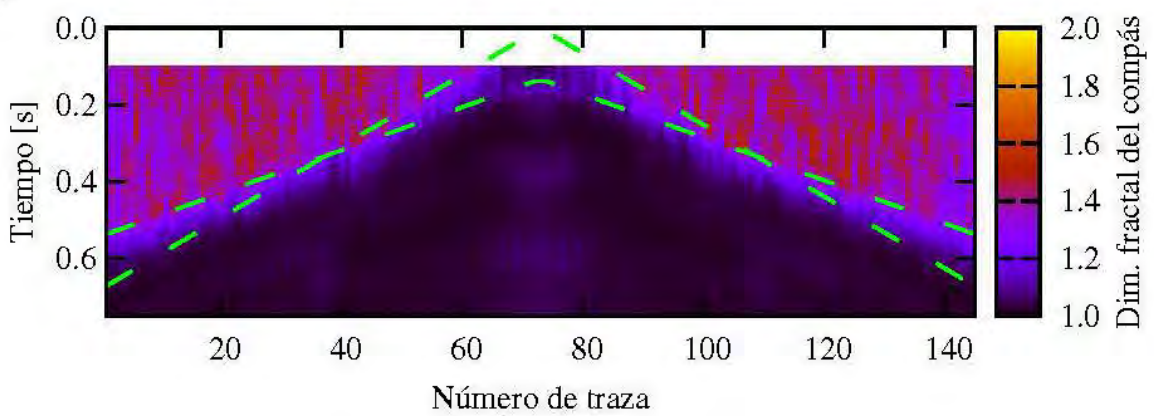

Figura 2.8: Dimensión fractal del compás correspondiente al registro mostrado en la Figura $2.5(S N R=10)$. (a) El ruido adicionado es de alta frecuencia. (b) El ruido adicionado es de baja frecuencia.

En la Figura 2.8 se muestran los resultados del CM cuando es aplicado al registro de 145 trazas que se muestra en la Figura 2.5. La brecha en los primeros $0.1 \mathrm{~s}$ se debe al hecho que el algoritmo precisa las primeras 100 muestras para el cálculo del primer valor de la dimensión fractal. Como era de esperar, según discutimos cuando analizamos el comportamientos de los algoritmos para una única traza, los resultados son mejores en los casos en que el ruido agregado es de mayor frecuencia. En esencia, el CM resulta ser poco preciso debido a la suave pendiente de la transición de la dimensión fractal del compás entre el ruido y la señal más el ruido (como ya vimos en la Figura 2.6). Por simplicidad, hemos utilizado los mismos parámetros en el algoritmo para cada traza. Es posible que un ajuste más fino de los parámetros del CM para cada traza, aunque poco práctico, podría haber mejorado los resultados de algunas trazas individuales. Sin embargo, si bien los primeros arribos se pueden identificar claramente en la Figura 2.8, la exactitud del CM en la determinación del inicio de la señal es bastante pobre.

Por el contrario, la exactitud del primer arribo cuando se utiliza el VM es mucho mayor, incluso en el caso en que el ruido adicionado es de baja frecuencia (Figura 2.9). Aquí, no sólo es mucho más abrupta la transición de la dimensión fractal (lo que permite 
(a)

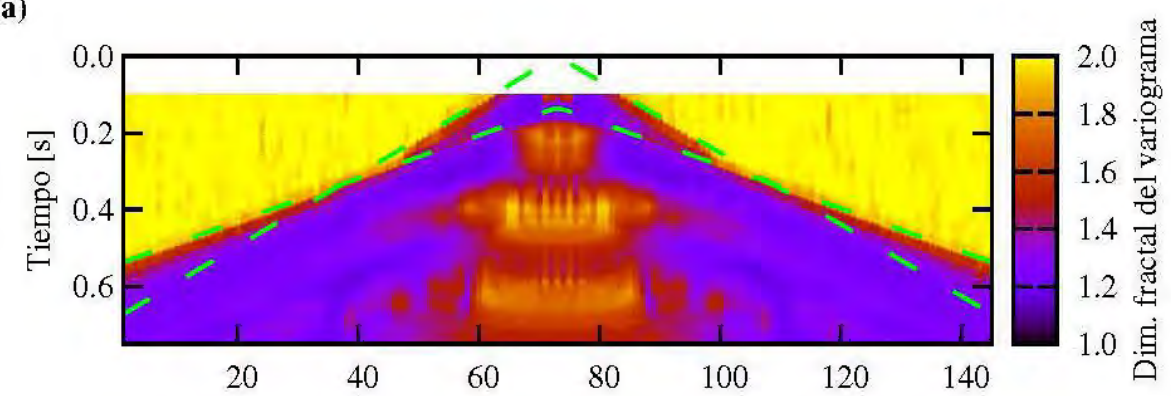

(b)

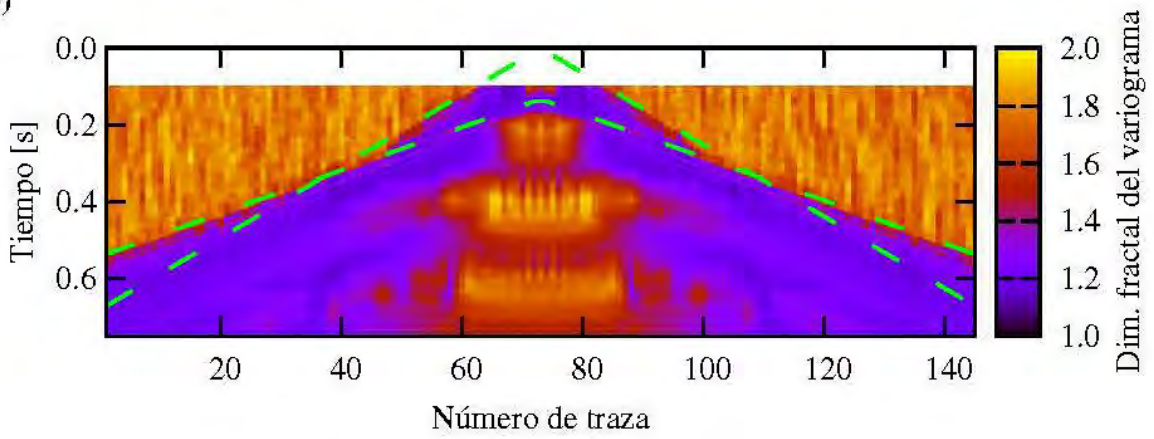

Figura 2.9: Dimensión fractal del variograma correspondiente al registro mostrado en la Figura $2.5(S N R=10)$. (a) El ruido adicionado es de alta frecuencia. (b) El ruido adicionado es de baja frecuencia.

discriminar con mayor facilidad el ruido de la señal), sino también la selección de los parámetros es mucho menos crítica, como ya hemos comentado en la descripción del método. Más aún, el VM tolera un nivel de ruido más alto sin que sus resultados sean mayormente afectados. La dimensión fractal del variograma correspondiente a los datos de disparo común generados sintéticamente con $S N R=7$ (Figura 2.10) se muestra en la Figura 2.11. A partir del gráfico, podemos ver que se puede apreciar el inicio de la señal con un alto grado de confianza. Cabe destacar que la relación $S N R$ es más baja para las trazas con mayor distancia fuente-receptor, pero el VM aún así brinda buenos resultados para estos receptores más alejados. Tanto en la Figura 2.9 como en la Figura 2.11 se observa en el centro del registro (a offsets pequeños) colores asociados a una dimensión fractal alta debido a las altas frecuencias excepto en donde aparecen los "blancos" que ya hemos comentado. 

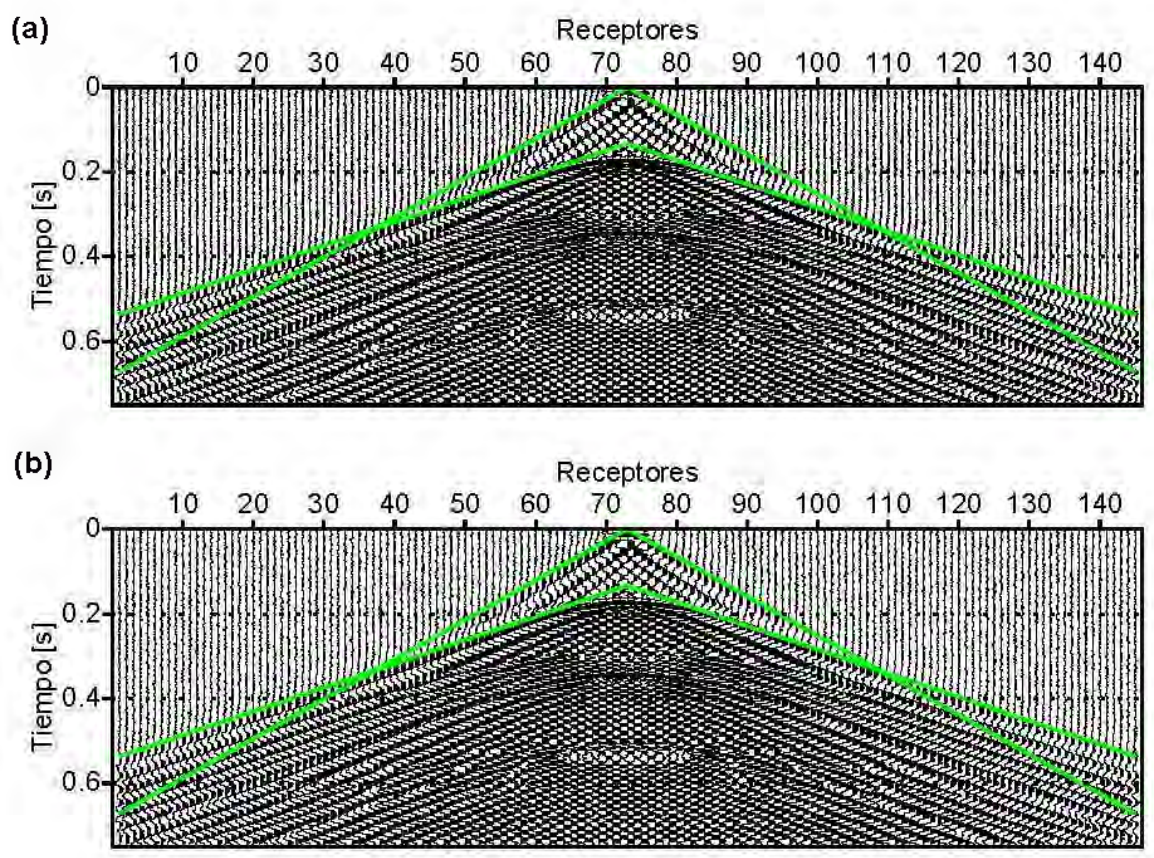

Figura 2.10: Registro sintético generado $(S N R=7)$. (a) Con ruido de alta frecuencia. (b) Con ruido de "baja" frecuencia. Las líneas verdes indican los arribos verdaderos de la señal.

(a)

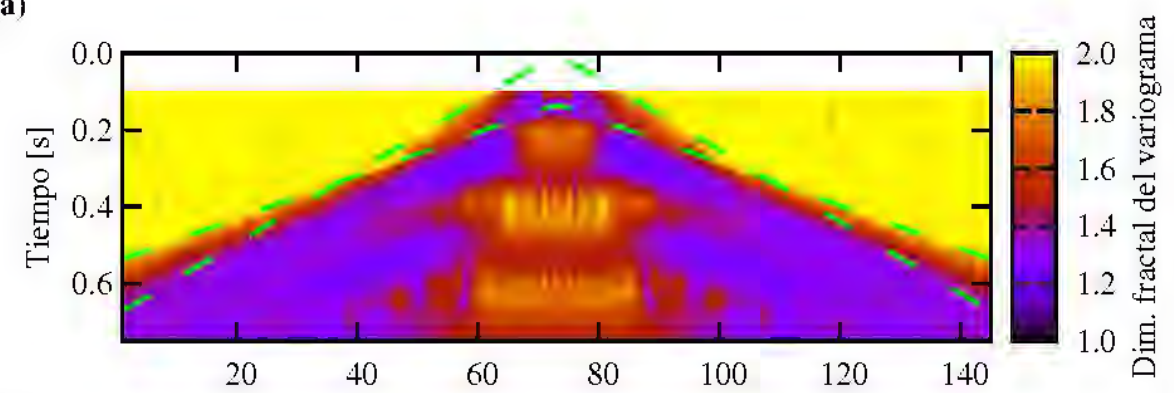

(b)

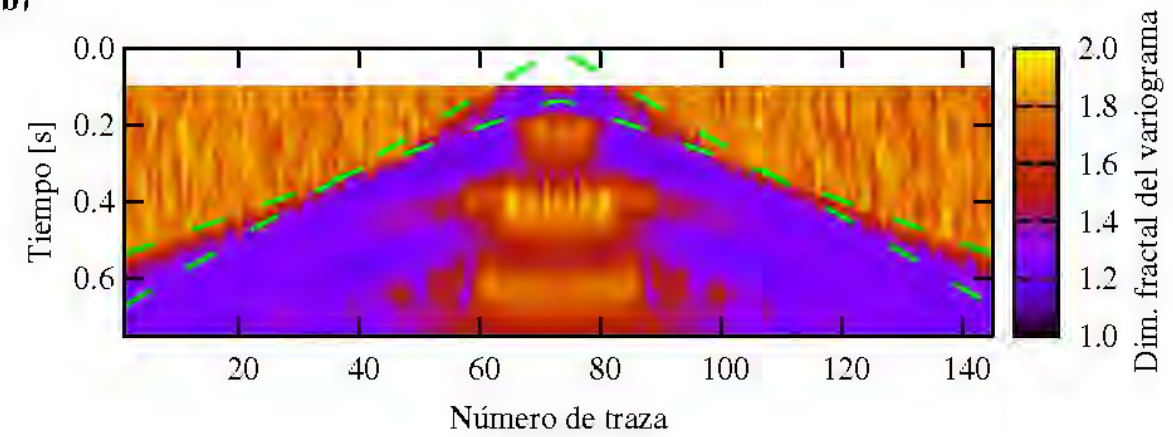

Figura 2.11: Dimensión fractal del variograma correspondiente al registro mostrado en la Figura $2.10(S N R=7)$. (a) El ruido adicionado es de alta frecuencia. (b) El ruido adicionado es de baja frecuencia. 
(a)

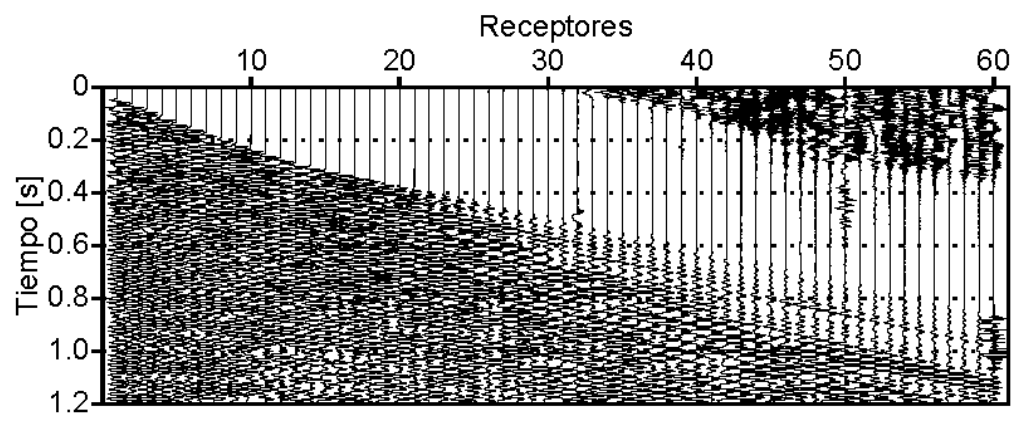

(b)

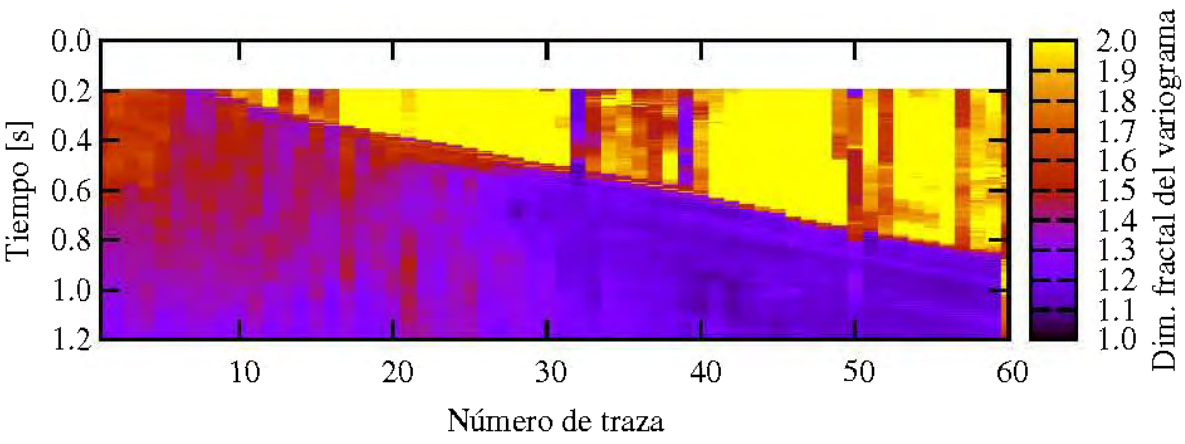

Figura 2.12: (a) Registro sísmico marino (registro de disparo común número 39 de Yilmaz [75]). (b) Dimensión fractal obtenida mediante el método del variograma (VM).

\subsubsection{Aplicación en datos reales}

Hemos seleccionado un registro real de campo de sísmica marina para testear el método que ha arrojado mejores resultados en las pruebas previas con datos sintéticos: el método del variograma (VM). Los datos de campo utilizados se muestran en la Figura 2.12. El registro corresponde a datos obtenidos en el Medio Oriente, tomados del ejemplo de disparo común número 39 de Yilmaz [75], que está disponibles en la web y se puede encontrar en (http://www.cwp.mines.edu/data/oz.original/). El conjunto de datos consta de 60 trazas muestreadas con un intervalo de muestreo de $2 \mathrm{~ms}$ y $50 \mathrm{~m}$ de distancia entre receptores.

La dimensión del fractal variograma se exhibe en el panel (b) de la Figura 2.12. Se puede observar claramente el cambio abrupto en la dimensión fractal, y entonces es posible identificar claramente los primeros arribos a simple vista, incluso para los receptores que están lejos de la fuente (donde la relación $S N R$ es menor). Los artefactos numéricos que aparecen en los datos para tiempos menores a $0,3 \mathrm{~s}$ y a partir del receptor número 35 son generados por el control automático de ganancia (AGC) aplicado en el pre-procesamiento de los datos. Estos artefactos, que se observan como ruido de alta 
frecuencia en los datos, no se reflejan en la dimensión fractal del variograma en absoluto. Esto se debe a la propiedad de invarianza de la dimensión fractal del variograma ante cambios en la escala vertical descrita anteriormente, y por supuesto es visto como una ventaja de este método.

\subsection{Conclusiones del capítulo}

Hemos comparado dos técnicas de análisis de dimensión fractal utilizadas para identificar los primeros arribos en datos de prospección sísmica bajo diversas condiciones de ruido: el método del compás (CM) y el método de variograma (VM). Para determinar la llegada de la señal se utiliza la transición que exhibe la dimensión fractal entre el ruido y la señal con ruido. En este contexto, hemos encontrado que el VM brinda una transición bastante abrupta en la dimensión fractal calculada que permite identificar fácilmente los primeros arribos con un alto grado de precisión tanto en datos sintéticamente simulados como en datos reales. En general, la dimensión fractal del variograma del ruido alcanza valores altos $(1.7-2.1)$ y la dimensión fractal de la señal más el ruido presenta valores bajos $(1,2-1,5)$. Por el contrario, el CM arroja transiciones más suaves en la dimensión fractal que hacen más difícil determinar la aparición de la señal de forma precisa. Además, el CM requiere el ajuste cuidadoso de varios parámetros para obtener resultados aceptables. En particular, la escala utilizada para el eje $y$ debe ser correctamente elegida, pues la dimensión fractal del compás es muy sensible al valor a este parámetro. Esto es un serio inconveniente de este método por lo que se desaconseja su utilización.

Es importante señalar que para analizar la dimensión fractal de las trazas sísmicas se debe suponer que las mismas son auto-afines y no auto-similares. Por lo tanto, los algoritmos diseñados para calcular la dimensión fractal de curvas auto-similares (como es el caso del CM utilizado en Boschetti et al. [12]) no son adecuados para el procesamiento de trazas sísmicas debido a su fuerte dependencia con la escala vertical, como ya hemos mencionado. A pesar de ello, los parámetros se pueden ajustar para que el algoritmo brinde resultados razonables, pero sólo a un alto costo computacional y con una delicada selección de parámetros, lo que resulta en picados de primeros arribos de baja precisión y poca fiabilidad. Luego, cuando se analizan series de tiempo tales como trazas sísmicas, se recomienda que el método utilizado para calcular la dimensión fractal sea independiente de la escala vertical. Por el contrario, el VM, que está concebido para el análisis de 
curvas auto-afines, es completamente independiente de la escala vertical. El análisis del VM mostró que es un método robusto y proporciona resultados precisos y consistentes, incluso bajo condiciones de niveles de ruido considerables. El VM además arrojó muy buenos resultados cuando fue testeado con un registro de campo de sísmica marina. 


\section{Capítulo 3}

\section{Nuevos algoritmos y técnicas para detectar primeros arribos sísmicos}

En la Introducción General, enumeramos y describimos brevemente diferentes técnicas y métodos desarrollados en las últimas décadas para abordar el problema de picado automático de primeros arribos sísmicos, algunos de ellos "convencionales" y otros "no convencionales". Desafortunadamente, cuando la relación señal-ruido de los datos es pobre y su calidad no es buena, casi todos los métodos tienden a fallar. Por lo tanto, en gran parte de los trabajos de sísmica de exploración suele aún hoy día recurrirse al picado manual de los datos. Muchas veces, se intenta primero realizar el picado automático con algún método que se considere adecuado como primer paso, y en segunda instancia corregir manualmente los resultados obtenidos. Por ello, la etapa del picado de primeros arribos suele demandar un alto porcentaje del tiempo total de procesamiento. Si el volumen de los datos es grande, realizar esta tarea de forma eficiente resulta fundamental. Entonces, el problema de la detección automática de primeros arribos requiere aún de soluciones más eficaces, en especial a partir del aumento del volumen de datos a analizar impulsado por los equipos de registración modernos.

Asimismo, hemos mencionado también en la Introducción que dentro de los métodos convencionales uno de los métodos más sencillos y robustos para detectar primeros arribos sísmicos es aquel basado en la idea introducida por Coppens [19], en el que simplemente se compara la energía de la señal dentro dos ventanas de tiempo de tamaños diferentes. Entre los métodos no convencionales, en el Capítulo 2 hemos destacado en particular el método de la dimensión fractal. Motivados por algunos trabajos que utilizan un análisis fractal de la traza sísmica para detectar los arribos de la señal $[12,67,26]$, y por las diversas aplicaciones que se han desarrollado a partir de la teoría de los fractales en ciencias de la tierra en el último tiempo [30, 29, 69], hemos analizado algunos aspectos teóricos y prácticos del análisis de la dimensión fractal de la traza sísmica. Como resultado general, hemos encontrado que la dimensión fractal de la traza sísmica es un atributo adecuado para detectar la llegada de la señal en un entorno ruidoso si se tienen en cuenta ciertas consideraciones teóricas descritas en el capítulo anterior y que también 
se pueden encontrar en Sabbione y Velis (2008) [51]. Por otro parte, la entropía de una curva ya ha sido exitosamente utilizada para la segmentación de series espaciales y temporales [20], y recientemente fue aplicada para realizar el picado automático de primeros arribos sísmicos [54].

En este contexto, en este capítulo se proponen algunas mejoras útiles para el método de Coppens y para el método basado en la dimensión fractal que permiten incrementar significativamente su capacidad para detectar los primeros arribos de forma automática. También se presenta un nuevo algoritmo basado en la entropía de las curvas. En este caso, la entropía de la traza se utiliza como un nuevo atributo sísmico que cuantifica las propiedades estadísticas de la señal (la variabilidad y la estructura de la correlación). Se proponen entonces tres algoritmos que se basan en tres atributos sísmicos diferentes (relación de energías, dimensión fractal y entropía), que se calculan traza por traza dentro de ventanas que se mueven a lo largo del tiempo. La hipótesis fundamental de los métodos es que el atributo seleccionado se comporta de manera diferente si los datos en la ventana móvil contienen sólo ruido o si contienen señal más ruido, y que la transición entre estas dos regiones es detectable. Por lo tanto, la exactitud del método de picado estará claramente relacionada con la exactitud con la que se pueda detectar el cambio en el atributo utilizado. En este sentido, proponemos el uso de un filtro que suaviza los datos pero al mismo tiempo conserva los grandes cambios o bordes (EPS, "edgepreserving smoothing" [34]). Dicho filtro mejora significativamente esta transición, y como veremos en este capítulo, se convierte en una herramienta esencial que aumenta considerablemente la exactitud de los resultados.

Como una segunda instancia de proceso, y luego del análisis traza por traza, los algoritmos propuestos consideraran la organización aproximada de los primeros arribos según líneas rectas (dadas por el arribo del rayo directo y los rayos refractados), aprovechando de esta manera información extraíble de todo el conjunto de receptores de un registro de disparo común. Este procedimiento es llevado a cabo en un proceso de corrección de picados erróneos en cinco pasos, en donde se restringe la búsqueda de los primeros arribos a las proximidades de las rectas de refracción, que son obtenidas por mínimos cuadrados con los picados preliminares traza por traza. Como resultado, la consistencia y la coherencia espacial de los picados se mejoran significativamente. Más aún, los picados erróneos asociados a trazas malas o nulas, así como los que están relacionados con trazas 
que presentan primeros arribos a priori indistinguibles, son corregidos o descartados automáticamente mediante criterios estadísticos simples.

En este capítulo, en primer lugar ilustramos los tres algoritmos propuestos con una única traza (tomada de datos reales). A continuación, ponemos a prueba los tres métodos completos (incluyendo el procedimiento de corrección de picados erróneos) bajo diferentes relaciones de señal-ruido y tipos de fuentes utilizadas para generar los registros de campo. Para estas pruebas, hemos seleccionado tres datos ruidosos, uno generado a partir de fuente de dinamita y dos con Vibroseis. Los resultados muestran que los algoritmos propuestos son en general muy robustos y se obtienen picados precisos incluso cuando se utilizan datos con fuente Vibroseis, para los que la ubicación exacta del inicio de la señal no es fácilmente distinguible y suelen surgir los mayores problemas al utilizar algoritmos de picado automático. Asimismo, los métodos son muy eficientes en términos de costo computacional y fáciles de usar pues sólo dependen de un pequeño número de parámetros. Más aún, demostramos mediante un análisis de sensibilidad que la dependencia de los resultados no es crítica si los parámetros son restringidos a ciertos rangos. Para completar el capítulo, los métodos son adaptados y mejorados para realizar el picado automático de primeros arribos en datos reales de campo provistos por la industria correspondientes a un proyecto de sísmica 2D y a un proyecto de sísmica 3D con diversas complejidades.

\subsection{Análisis por traza}

En la metodología propuesta, el procedimiento de picado consta de dos etapas. La primera etapa es un proceso traza por traza destinado a identificar los cambios bruscos en cierto atributo de la traza sísmica (cociente de energías, entropía o dimensión fractal), que se calcula en función del tiempo a lo largo de ventanas que avanzan muestra por muestra. Para hacer más evidentes los cambios en los atributos, el atributo seleccionado se filtra con un filtro EPS (ver Apéndice A). Finalmente, se asigna el inicio del primer arribo a aquella muestra en la que la derivada del atributo filtrado sea máxima (o mínima en el caso del método de la dimensión fractal). En esta sección se describen, ilustran y comparan los tres algoritmos propuestos con la misma traza sísmica tomada de un registro de campo. La traza seleccionada es la número 14 de un registro obtenido mediante fuente de Vibroseis, y pertenece al ejemplo de registro de disparo común número 4 del libro de Yilmaz [75, p. 71], que fue adquirido con un intervalo de muestreo de $4 \mathrm{~ms}$. Por 
simplicidad, las amplitudes sísmicas son normalizadas a $(-1,1)$ antes del procesamiento.

La segunda etapa consiste en utilizar todo el conjunto de picados obtenidos en la etapa previa para cada traza del registro. Este procedimiento se basa en criterios estadísticos simples que ayudan a mejorar la coherencia espacial de los picados y automáticamente se detectan las trazas malas o nulas. El objetivo de este proceso es dar cuenta de la alineación aproximada esperada para los picados a lo largo de las líneas rectas dadas por el modelo de refracción. Los picados erróneos se pueden ajustar o eliminar en esta etapa.

\subsubsection{Método de Coppens modificado (MCM)}

La idea básica de esta estrategia es muy simple y sigue el método de Coppens [19]. El objetivo del método consiste en distinguir la señal del ruido de fondo (incoherente o coherente) a partir de sus diferencias de energía. Para ello, se calcula la energía de la traza sísmica $s_{t}$ dentro de dos ventanas anidadas:

$$
\begin{gathered}
E_{1}(t)=\sum_{i=t-n_{l}+1}^{t} s_{i}^{2}, \\
E_{2}(t)=\sum_{i=1}^{t} s_{i}^{2},
\end{gathered}
$$

donde $n_{l}$ es la longitud de la primera ventana ("ventana corta"), y representa un parámetro que debe seleccionarse a priori. Por el contrario, la longitud de la segunda ventana ("ventana larga") aumenta con el tiempo (ver Figura 3.1) y su longitud no es un parámetro del algoritmo. Luego, se calcula el cociente de energías entre ambas ventanas mediante:

$$
E R(t)=\frac{E_{1}(t)}{E_{2}(t)+\beta}
$$

donde $\beta$ es una constante de estabilización que ayuda a reducir las rápidas fluctuaciones de $E R(t)$ que podrían conducir a un picado de primer arribo falso, sobre todo cuando el ruido de fondo es de muy baja amplitud y el denominador de la ecuación 3.3 es muy cercano a 0 . El valor del atributo resultante se asigna a la última muestra de las ventanas. El esquema de ventanas anidadas garantiza que $E R(t)<1$, un resultado muy conveniente para controlar la magnitud del cociente de energías. 


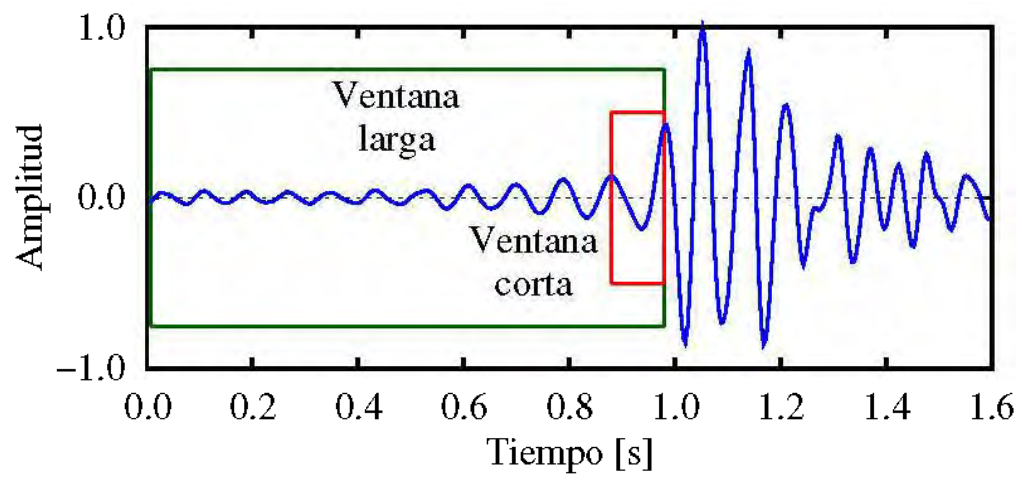

Figura 3.1: Esquema de ventanas utilizado en el MCM.

El atributo del cociente de energías, de la misma manera que los atributos de la dimensión fractal y la entropía descritos en las siguientes secciones, presenta una transición entre el ruido y el ruido más la señal. Uno de los aspectos más complicados de este tipo de algoritmo es determinar exactamente en qué muestra arriba la señal sísmica, puesto que a menudo la transición no es lo suficientemente clara. Para mitigar este problema, filtramos $E R(t)$ mediante la aplicación de un operador de suavizado con preservación de bordes (EPS), denominado "edge-preserving smoothing". El filtro EPS se puede entender como una simple modificación del método de promediación móvil, y fue ideado para reducir el ruido y conservar los cambios más notables de los datos (el EPS se describe en el Apéndice A). Por último, se asigna el inicio del primer arribo a la muestra en la que la derivada del atributo filtrado es máxima. Esta estrategia nos permite minimizar el retraso que generalmente ocurre entre el máximo del cociente de las energías y el verdadero inicio de la señal, mejorando así la exactitud de los resultados. Nos referiremos a este método como "método de Coppens modificado" (MCM).

Desde el punto de vista práctico, el MCM requiere que el usuario selecciones tres parámetros: la longitud de la ventana corta, $n_{l}$, la longitud del operador EPS, $n_{e}$, y la constante de estabilización, $\beta$. El objetivo de la ventana corta es capturar la energía del primer arribo, por lo que su longitud se establece igual a un período de la señal que se espera detectar. Este valor puede determinarse fácilmente analizando los datos a picar y midiendo la distancia temporal entre dos crestas o dos valles inmediatamente después de la llegada de la señal. Respecto de la longitud de la ventana del EPS, encontramos buenos resultados con valores entre uno y dos períodos de la señal, por lo que fijamos $n_{e}$ igual a un período y medio en todos los ejemplos que mostramos en este capítulo. 
a)

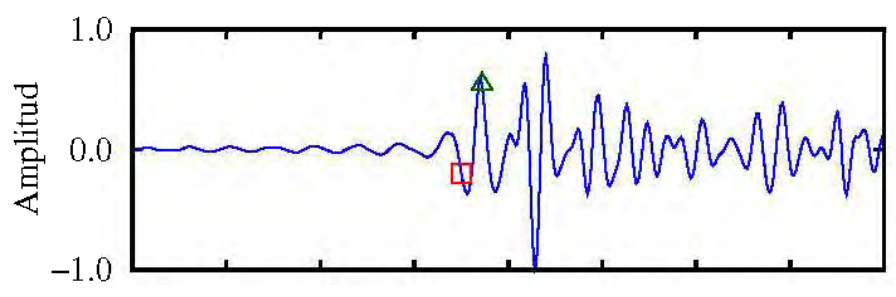

b)

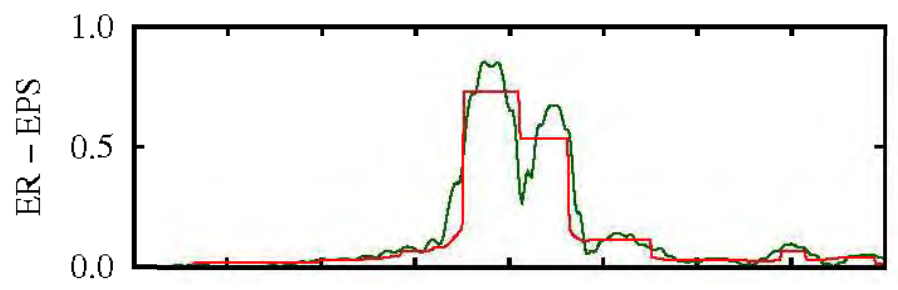

c)

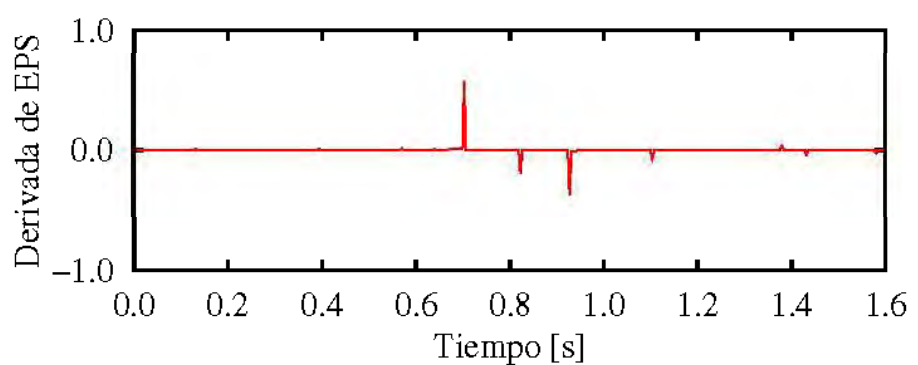

Figura 3.2: (a) Traza sísmica (azul) y primer arribo picado por el COP (triángulo verde) y por el MCM (cuadrado rojo). (b) Atributo del cociente de energías (verde) y el mismo atributo filtrado por EPS (rojo). (c) Derivada del atributo filtrado. Su máximo indica el primer arribo.

La selección de $\beta$ proporciona un mecanismo para controlar la sensibilidad del atributo de cociente de energías y ayuda a evitar picados falsos. En general, la selección de este parámetro no es crítica, y fue fijado en 0,2 (recordar que las amplitudes son previamente normalizadas a $(-1,1))$.

A pesar de no ser un método moderno, el método de Coppens (COP) es muy robusto cuando la relación señal-ruido de los datos es buena, es decir, cuando la amplitud el ruido es del orden el $10 \%$ de la de los datos o menor. Por ello, este método (o alguno similar en el que se calculen cocientes de energías) es muy utilizado para picar primeros arribos. Si el primer arribo es impulsivo (como ocurre generalmente cuando se cuenta con datos de dinamita o de sísmica marina) el desempeño del COP es muy bueno. Sin embargo, si el primer arribo no es muy abrupto (como suele ocurrir con datos generados con Vibroseis), por lo general $E R(t)$ alcanza su máximo en tiempos posteriores al primer arribo, lo que limita la capacidad del COP para detectar la ubicación exacta del comienzo 
de la señal. Con el objeto de ilustrar el MCM y compararlo con el COP, hemos testeado ambos métodos utilizando la traza que se muestra en la Figura 3.2. Por inspección visual, el período del primer arribo es de unos $80 \mathrm{~ms}$ (20 muestras), por lo que elegimos $n_{l}=20$ y $n_{e}=30$. Nótese cómo la determinación del primer arribo es mejorada por el uso del EPS. Si se hubiese utilizado el COP sin las modificaciones propuestas, el primer arribo habría sido picado unos 50 ms más tarde.

\subsubsection{Método de la entropía (EM)}

En esta subsección presentamos un nuevo método de análisis de la traza sísmica, que denominamos "método de la entropía" (EM), y está basado en la entropía de las curvas, un concepto utilizado por Denis y Crémoux [20] para realizar la segmentación de una serie espacial o temporal de datos. En su trabajo, la entropía de una curva se ve como una medida de la estructura de la variabilidad y la correlación de una serie de tiempo. Esto permite detectar cambios en las propiedades estadísticas de la señal y por lo tanto se la divide en segmentos localmente estacionarios. Aquí vamos a aplicar estos mismos conceptos al análisis de las trazas sísmicas, ya que ante la llegada del primer arribo se espera un rápido cambio en las propiedades estadísticas de los datos.

Denis y Crémoux [20] calculan la entropía de una serie de tiempo en función del tiempo (o del espacio) por medio de

$$
H(t)=\log (L(t) / t)
$$

donde $L(t)$ es la "longitud" de la serie de tiempo que es aproximada por la suma del valor absoluto de las primeras diferencias de la señal muestreada.

En el cálculo de la entropía como un atributo de la traza sísmica, se estima $H(t)$ en una ventana móvil de longitud fija, $n_{h}$, y se asigna su valor al último punto de la ventana. Por lo tanto, si $\Delta t$ es el intervalo de muestreo de los datos:

$$
H(t)=\log \left(\frac{1}{n_{h} \Delta t} \sum_{i=t-n_{h}+1}^{t-1}\left|s_{i+1}-s_{i}\right|\right) .
$$

En general, la entropía varía significativamente cuando la ventana móvil abarca solamente ruido o señal más ruido, y entonces la llegada de un primer arribo se puede identificar mediante la detección de cambios rápidos en este atributo. 
Vale la pena mencionar que si la ventana móvil fuera demasiado corta, la variabilidad de la entropía sería muy grande. Por otro lado, si fuera demasiado larga, podría disminuir la resolución temporal del cálculo. Además, y con el fin de capturar completamente las propiedades estadísticas del primer arribo, resulta razonable seleccionar $n_{h}$ como un múltiplo del período de la señal a detectar. En todas las trazas sísmicas analizadas en este capítulo encontramos buenos resultados ajustando $n_{h}$ igual al doble del período principal de la señal, que determinamos por inspección visual.

a)

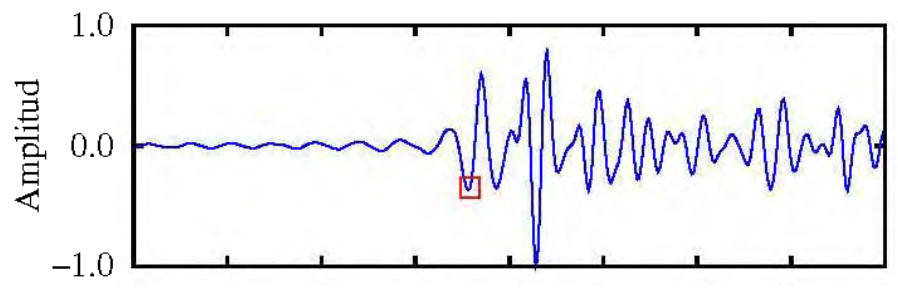

b)

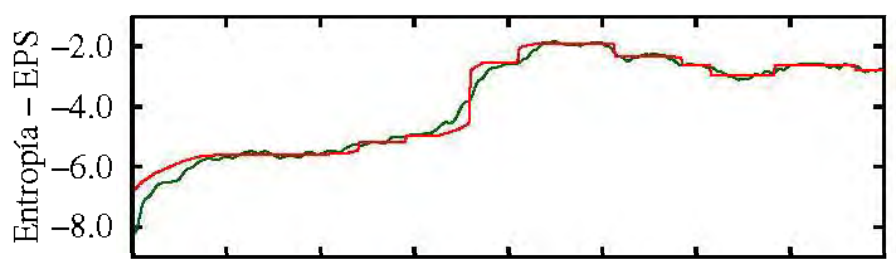

c)

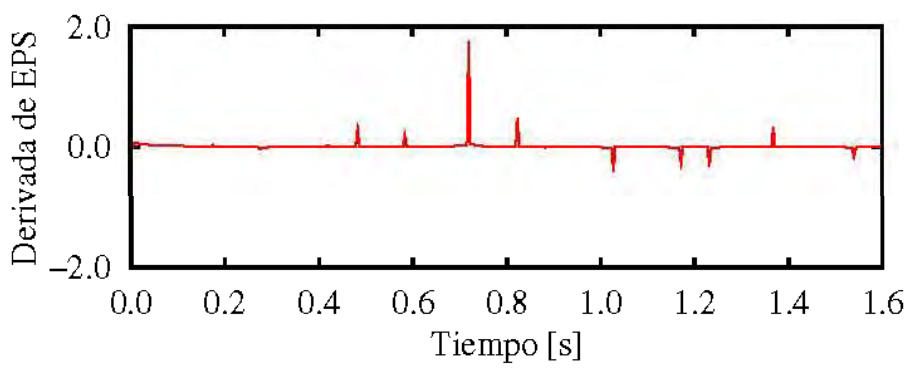

Figura 3.3: (a) Traza sísmica (azul) y primer arribo picado por el EM (cuadrado rojo). (b) Atributo de la entropía (verde) y el mismo atributo filtrado por EPS (rojo). (c) Derivada del atributo filtrado. Su máximo indica el primer arribo.

La Figura 3.3 muestra el comportamiento del EM cuando es aplicado a la misma traza utilizada para ejemplificar el MCM. Como el período del primer arribo es de 20 muestras, hemos seleccionado $n_{h}=40$. Se puede observar que el atributo de la entropía se incrementa significativamente en alrededor de $0,7 \mathrm{~s}$. Una vez más, este cambio es luego realzado aplicando el filtro EPS (Figura 3.3b). La longitud del operador EPS se fijó nuevamente igual a un período y medio (30 muestras) como en el caso del MCM. El máximo de la derivada del atributo filtrado indica claramente el inicio del primer arribo. 
Observar que el resultado es muy similar al picado obtenido con el MCM (Figura 3.2).

\subsubsection{Método de la dimensión fractal (FDM)}

En el capítulo anterior hemos indagado sobre diferentes métodos para obtener la dimensión fractal de la traza sísmica y analizado algunos aspectos teóricos. Vamos a aprovechar los resultados obtenidos para desarrollar este método. Utilizaremos el variograma para extraer la dimensión fractal, que ha probado ser un método robusto y confiable [51]. Para detallar el método, recordaremos algunos conceptos y fórmulas del capítulo anterior.

Para series de tiempo, una definición equivalente de un fractal auto-afín (ver sección 2.1 del capítulo anterior) es el requisito que su variograma $V(h)$ (o el semi-variograma, que es la mitad del variograma) se escale de manera que [69]:

$$
V(h) \propto h^{2 H_{a}},
$$

donde $H_{a}$ es la medida de Hausdorff, relacionada con la dimensión fractal mediante

$$
H_{a}=2-D
$$

De acuerdo con diversos autores $[67,26,51]$, y como hemos mencionado en el capítulo anterior, se encontró que las trazas sísmicas satisfacen este requisito y pueden ser clasificadas como fractales auto-afines. Si bien Boschetti et al. [12] desarrollaron un análisis basado en la dimensión fractal para la detección de los primeros arribos sísmicos utilizando el "método de la división" (que en el capítulo anterior hemos llamado "método del compás"), este método está concebido para analizar curvas auto-similares. Por lo tanto, hemos recomendado el uso de los métodos desarrollados para curvas auto-afines en el tratamiento de trazas sísmicas. En cambio, Jiao y Moon [26] utilizaron el "método de la varianza" para detectar señales de refracción, y Tosi et al. [67] utilizaron un análisis de variogramas para extraer la dimensión fractal de los sismogramas para detectar eventos en datos de terremotos. Estas dos técnicas resultan más adecuadas desde un enfoque teórico porque fueron concebidas para analizar fractales auto-afines.

El "método del variograma" es uno de los métodos más eficientes y robustos para el cálculo de la dimensión fractal de curvas auto-afines [30]. El método se basa en la 
relación exponencial entre el variograma y la separación $h$ con la que es calculado $V(h)$, que combinando la ecuación 3.6 con la ecuación 3.7 se puede escribir como:

$$
V(h) \propto h^{4-2 D}
$$

La ecuación 3.8, que también podríamos haber deducido de las ecuaciones 2.6 y 2.7, indica que si tomamos logaritmo en ambos miembros y calculamos el variograma para distintos valores de $h$ la dimensión fractal $D$ se obtiene a partir de la pendiente de la recta definida el dominio bilogarítmico (llamado gráfico de Mandelbrot-Richardson) mediante la ecuación 2.8, como ya hemos explicado en el capítulo anterior.

Hemos desarrollado entonces el "método de la dimensión fractal" (FDM) para picar los primeros arribos sísmicos a partir de lo estudiado en el capítulo anterior, y basándonos en el hecho que el ruido aleatorio presenta una dimensión fractal mayor que la señal. En este método, la dimensión fractal se calcula dentro de una ventana de tiempo de longitud $n_{f}$ que avanza muestra por muestra y el valor de $D$ hallado se asigna a la última muestra de la ventana. Nuevamente, debemos tener en cuenta que si $n_{f}$ es demasiado pequeño, el variograma (y la dimensión fractal obtenida) no puede ser estimado adecuadamente. Por otro lado, si $n_{f}$ es demasiado grande, no podremos detectar correctamente los cambios en la dimensión fractal, que es nuestro principal objetivo. Jiao y Moon [26] analizaron diferentes longitudes de ventanas y recomiendan el uso de una ventana de 48 muestras. Teniendo en cuenta esta información y los resultados obtenidos en el capítulo previo y considerando el período $T$ de la señal, equivalente a $n_{p e r}$ muestras, fijamos el tamaño de la ventana en $n_{f}=k n_{\text {per }}$, donde $k$ es el menor entero tal que $n_{f} \geq 48+n_{\text {per }} / 2$. Aclaremos que si bien $n_{p e r}$ es un entero que podría ser impar, el redondeo de $n_{p e r} / 2$ no nos preocupa pues como veremos más adelante en el análisis de sensibilidad de los métodos el efecto de este redondeo sobre los picados obtenidos es despreciable.

Además, siguiendo nuevamente los resultados mostrados en el capítulo anterior, añadimos sistemáticamente ruido blanco de baja amplitud a los datos antes de calcular su dimensión fractal. El ruido añadido (con una energía similar o menor a la del ruido de fondo para no enmascarar la señal) tiende a destruir la eventual correlación del ruido presente en la traza sísmica antes del primer arribo. Este efecto también fue hallado empíricamente por Jiao y Moon [26]. Por lo tanto, la cantidad de ruido añadido se debe calibrar de forma manual a partir del ruido de fondo de los datos a analizar. Esta simple estrategia mejora significativamente la capacidad del FDM de picar los primeros 
arribos, en especial cuando se están procesando datos de Vibroseis, para los que la fuente introduce ruido altamente correlacionado antes de la llegada de la señal.

Resumimos entonces el FDM de la siguiente manera. Estimamos el variograma $V(h, t)$ dentro de una ventana móvil de longitud $n_{f}$ que avanza muestra por muestra a lo largo de la traza sísmica $s_{t}$, a la que ya le hemos añadido ruido blanco de baja amplitud, mediante

$$
V(h, t)=\frac{1}{n_{f}-h} \sum_{i=t-n_{f}+1}^{t-h}\left(s_{i+h}-s_{i}\right)^{2},
$$

para cuatro separaciones diferentes $h=1,2,3$ y 4 , que resultan suficientes para captar la variabilidad de una traza sísmica ruidosa. Este rango de separaciones para $h$ está de acuerdo con el utilizado por Jiao y Moon [26]. Notar que la ecuación 3.9 es la misma ecuación que la 2.5 del capítulo anterior en donde hemos explicitado la dependencia del tiempo en el cálculo de $V(h)$ y la cantidad de pares de muestras separadas $h$ unidades de tiempo dentro de la ventana dada por $n(h)=n_{f}-h$. Luego de ajustar la línea recta en el gráfico de Mandelbrot-Richardson y obtener su pendiente $\beta$, calculamos la dimensión fractal con la ecuación 2.8 y asignamos su valor a la última muestra de la ventana. Posteriormente, aplicamos un operador EPS para mejorar la transición entre la dimensión fractal del ruido y la del ruido más la señal. Al igual que en el caso del MCM y el EM, la longitud del filtro $n_{e}$ fue fijada en un período y medio de la señal a detectar. Por último, y debido a que la dimensión fractal disminuye cuando la señal arriba, picamos el primer arribo en aquella muestra para la que la derivada de la dimensión fractal filtrada se hace mínima.

El FDM se ilustra en la Figura 3.4, utilizando nuevamente la misma traza utilizada para describir el MCM y el EM en las dos secciones anteriores. El ruido blanco fue añadido de modo que la relación señal-ruido sea $S N R=20$, donde $S N R$ es calculada como el cociente entre la energía de la traza y la energía del ruido. Dado que el período del primer arribo es de 20 muestras, seleccionamos $n_{f}=60$ y $n_{e}=30$ (es decir, $n_{e}$ lo elegimos igual que en el MCM y el EM).

En este punto hacemos hincapié en un detalle del algoritmo que no habíamos estudiado en el capítulo anterior. Nos interesa remarcar en qué muestra asignamos el primer arribo en el FDM y qué diferencias existen con las estrategias sugeridas por otros autores en otros métodos de picado de primeros arribos mediante el análisis de la dimensión fractal. Boschetti et al. [12] aplican el método de la división para calcular la dimensión fractal, 
a)

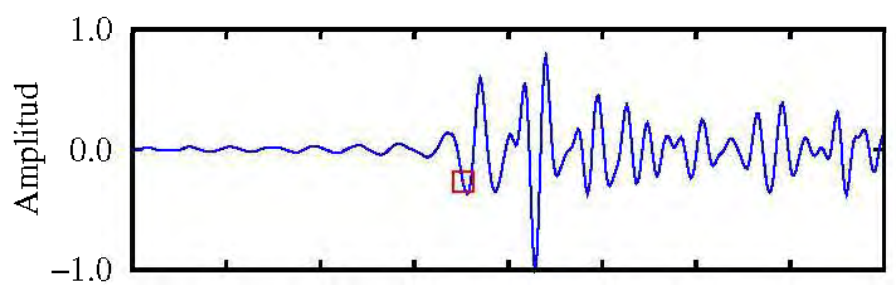

b)

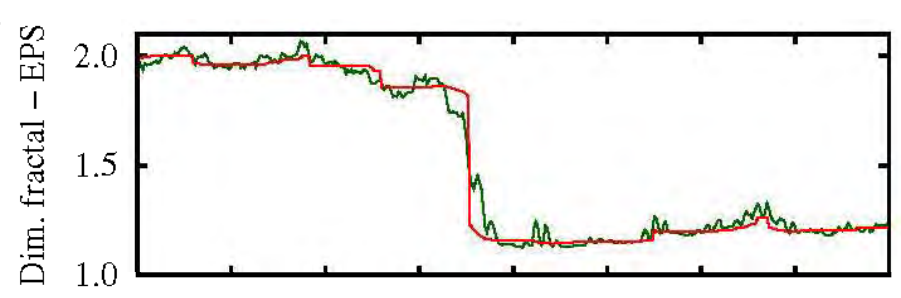

c)

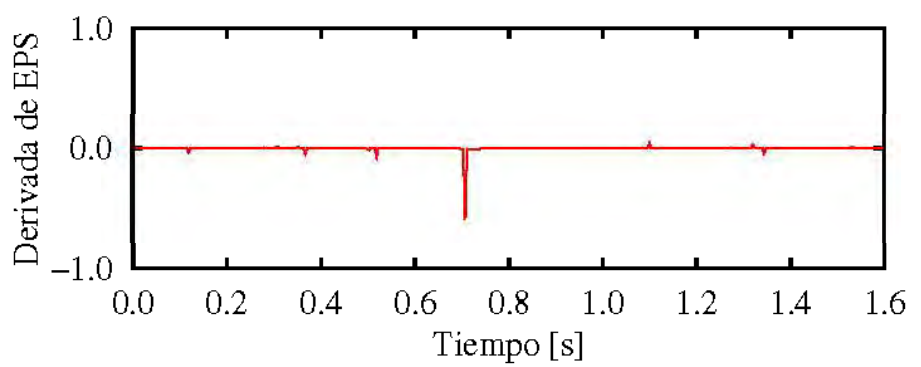

Figura 3.4: (a) Traza sísmica (azul) y primer arribo picado por el FDM (cuadrado rojo). (b) Atributo de la dimensión fractal (verde) y el mismo atributo filtrado por EPS (rojo). (c) Derivada del atributo filtrado. Su mínimo indica el primer arribo.

que produce una transición suave entre el ruido y la señal con ruido. Luego, utilizan un complicado esquema de tres segmentos para ajustar la dimensión fractal de la curva en las proximidades del primer arribo (esta región se selecciona manualmente). Finalmente, determinan el primer arribo unas pocas muestras antes de la intersección de dos de estas rectas. Por otro lado, Jiao y Moon [26] calculan la dimensión fractal mediante el método de la varianza, y obtienen transiciones bruscas, lo que hace que el picado del primer arribo sea más sencillo. Desafortunadamente, los autores no explican la forma en que realmente determinan la llegada de la señal. Es de suponer que se coloca en el punto donde comienza la transición (aunque este punto no se puede identificar fácilmente), como se observa en la Figura 12 de su artículo. En contraste, en el FDM el suavizado que preserva los saltos más importantes del atributo llevado a cabo por la implementación del EPS nos permite detectar fácilmente el inicio del primer arribo de forma automática. 


\begin{tabular}{|c|c|c|c|c|c|}
\hline Método & Parámetro & Criterio & $\begin{array}{c}\text { Registro } 1 \\
\Delta t=4 \\
n_{\text {per }}=13\end{array}$ & $\begin{array}{c}\text { Registro } 2 \\
\Delta t=2 \\
n_{\text {per }}=32\end{array}$ & $\begin{array}{c}\text { Registro } 3 \\
\Delta t=4 \\
n_{\text {per }}=20\end{array}$ \\
\hline $\mathrm{MCM}$ & $\begin{array}{l}n_{l} \\
n_{e} \\
\beta\end{array}$ & $\begin{array}{c}n_{\text {per }} \\
1.5 n_{\text {per }} \\
0.2\end{array}$ & $\begin{array}{l}13 \\
20 \\
0.2\end{array}$ & $\begin{array}{l}32 \\
48 \\
0.2\end{array}$ & $\begin{array}{l}20 \\
30 \\
0.2\end{array}$ \\
\hline EM & $\begin{array}{l}n_{h} \\
n_{e}\end{array}$ & $\begin{array}{c}2 n_{\text {per }} \\
1.5 n_{\text {per }}\end{array}$ & $\begin{array}{l}26 \\
20 \\
\end{array}$ & $\begin{array}{l}64 \\
48 \\
\end{array}$ & $\begin{array}{l}40 \\
30 \\
\end{array}$ \\
\hline FDM & $\begin{array}{c}n_{f} \\
n_{e} \\
S N R\end{array}$ & $\begin{array}{c}k n_{\text {per }} \\
1.5 n_{\text {per }} \\
\text { (fijar) }\end{array}$ & $\begin{array}{l}65 \\
20 \\
50\end{array}$ & $\begin{array}{l}64 \\
48 \\
70\end{array}$ & $\begin{array}{l}60 \\
30 \\
20\end{array}$ \\
\hline
\end{tabular}

Tabla 3.1: Los tres conjuntos de datos de campo utilizados para ilustrar los métodos de picado y los parámetros seleccionados para cada método. El intervalo de muestreo $\Delta t$ está dado en milisegundos. Todas las cantidades, excepto $\beta$ y $S N R$, están dadas en muestras. En el caso en que $n_{\text {per }}$ sea impar, redondeamos $1.5 n_{\text {per }}$ al entero siguiente.

\subsubsection{Selección de parámetros}

En la sección anterior recomendamos un conjunto de parámetros para cada método de picado. La Tabla 3.1 resume todos estos parámetros junto con los valores reales utilizados para la detección automática que se ilustra en la posterior sección con pruebas que utilizan datos de campo. Notar que la mayoría de los parámetros se definen en términos del período aproximado de los primero arribos, $T$, que se obtiene directamente a partir de los datos y equivale a $n_{\text {per }}$ muestras. Basta con considerar un único valor aproximado de $T$ para todo el registro de disparo común analizado. Por lo tanto, la selección de estos parámetros es bastante trivial. Cabe destacar también que la longitud de la ventana del EPS es la misma para los tres métodos y la constante de estabilización es la misma para todos los registros utilizados. Para poder tomar estos valores, por supuesto es fundamental que todas las trazas sean normalizadas como se describió anteriormente. En el caso particular de la longitud de la ventana móvil del FDM, el entero $k$ debe ser seleccionado con el fin de garantizar que $k n_{\text {per }}$ sea al menos $48+n_{\text {per }} / 2$ muestras. Luego, el parámetro $S N R$ es el único que hay que ajustar "manualmente" en el FDM. En 
general, cuanto menor sea $S N R$, más se retrasará el picado, por lo que este parámetro sí debe ser cuidadosamente elegido. A su vez, $S N R$ sirve como una variable de ajuste de la sensibilidad del método.

\subsection{Análisis por registro}

Los algoritmos descritos en las secciones anteriores buscan la llegada del primer arribo en una única traza. Sin embargo, un analista tendrá en cuenta el registro completo de disparo común para realizar los picados. Al hacerlo, prestará especial atención a factores de sentido común tales como retrasos de tiempo constante entre los trazas adyacentes, tiempos de picado en aumento con la distancia fuente-receptor, y especialmente en que los eventos se organicen aproximadamente según líneas rectas (las rectas de refracción). Cualquier picado que no cumpla con estos criterios, tendría que ser re-evaluado. Estos factores pueden ser incluidos en un algoritmo de selección automatizado mediante el uso de restricciones. Con este fin, hemos desarrollado una técnica de corrección de picados erróneos utilizando simples criterios estadísticos que restringe la búsqueda de los primeros arribos a las proximidades de estas rectas. Las rectas son construidas por mínimos cuadrados a partir de los picados traza por traza. Como resultado, los picados malos pueden ser corregidos o descartados (como se espera por ejemplo para aquellos asociados a trazas malas o nulas).

\subsubsection{Corrección de picados erróneos}

La corrección de picados erróneos se realiza a través de un proceso de cinco pasos. El primer paso consiste en el picado traza por traza utilizando uno de los tres algoritmos descritos en secciones previas (MCM, EM o FDM). Dependiendo de la calidad de los datos, algunos de los picados de este primer paso podría no ser correcto. Por ejemplo, en algunas trazas el primer arribo podría exhibir el segundo o el tercer mayor valor (o menor, en el caso FDM) de la derivada filtrada del atributo, en lugar del máximo absoluto de toda la traza (o el mínimo absoluto en el caso del FDM). Además, es posible que algunas de los receptores no hayan registrado correctamente, generando trazas malas o nulas, y el picado asociado sea naturalmente malo y deba ser rechazado. En un segundo paso, para evitar estos problemas de forma automática, ajustamos por mínimos cuadrados los picados obtenidos en el primer paso mediante todos los modelos posibles de dos rectas por flanco 
a)

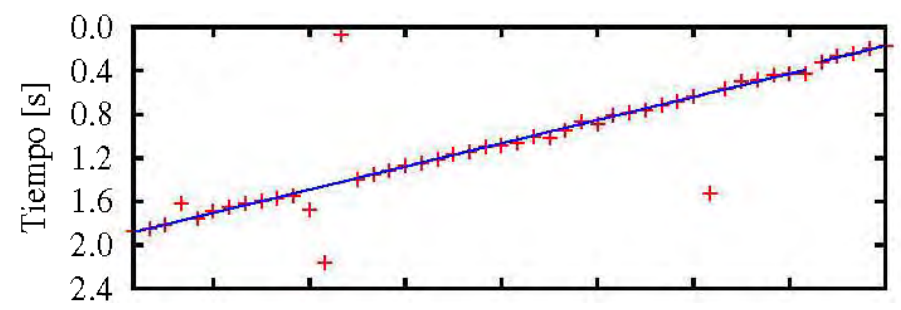

b)

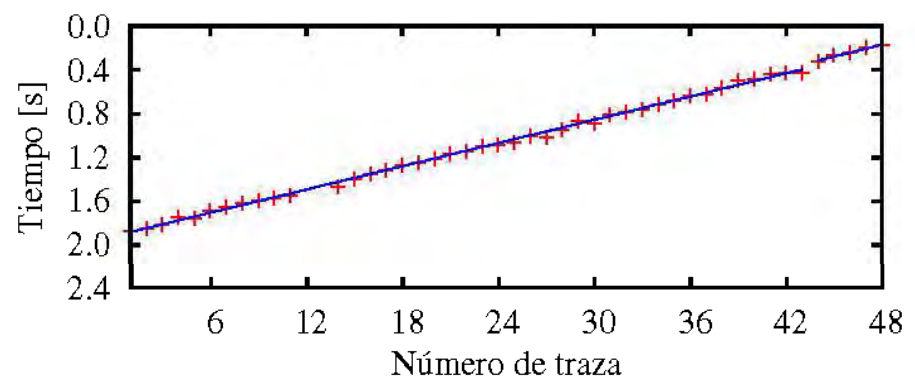

Figura 3.5: Procedimiento de corrección de picados errados. Los resultados corresponden al FDM aplicado a los datos de campo que se muestran en la Figura 3.7. (a) Picados traza por traza correspondientes al paso 1 (en rojo) y rectas ajustadas (azul) correspondientes al modelo de refracción preliminar (paso 2). (b) Picados corregidos (paso 3) y rectas ajustadas correspondientes al modelo de refracción final (paso 4). Los picados de las trazas 12 y 13 se asociaron con trazas malas o nulas y fueron rechazados (paso 5).

por registro. Este modelo intenta estimar las rectas esperadas correspondientes al rayo directo y al rayo refractado. Luego, se calcula el $\chi^{2}$ para evaluar la bondad del ajuste para cada modelo obtenido y seleccionamos aquel con el menor valor de $\chi^{2}$, considerado como el más probable. A continuación, si el error a posteriori del ajuste por mínimos cuadrados de cualquier punto (picado) es mayor que $3 \sigma$, donde $\sigma$ es la desviación estándar del ajuste, el picado es rechazado y las rectas son recalculadas. Este proceso se repite hasta que no haya puntos (picados) con errores superiores a $3 \sigma$ (en general, una o dos iteraciones son suficientes, y sólo pocos de los picados originales son rechazados). El resultado final de esta segunda etapa está dado por un modelo de refracción preliminar que consta de dos rectas por flanco por registro. A modo de ejemplo, la Figura 3.5a muestra los resultados del picado con el FDM (paso 1) y el modelo de refracción preliminar (paso 2) para los datos de campo que se muestran en la Figura 3.7 (próxima sección). Notar que en este caso particular, los picados correspondientes a las trazas 4, 12, 13, 14, y 37 no fueron considerados en el modelo de refracción preliminar debido a que no superaron el criterio de $3 \sigma$. Si bien no puede apreciarse en la Figura 3.5a, el picado de la traza 27 tampoco supero el test de $3 \sigma$ en esta instancia, a pesar de que aparenta ser correcto. 
En el tercer paso repetimos el proceso de picado, pero el análisis se limita ahora a una ventana de tolerancia de tamaño en tiempo $t_{t o l}$ que está centrada en las rectas del modelo preliminar de refracción obtenidas en el paso 2. Debemos pedir que $t_{t o l} / 4$ sea más grande que la mayor corrección estática que se puede esperar en los datos, como explicaremos más adelante al describir el paso 5. El objetivo de este nuevo proceso de picado restringido es la re-evaluación de aquellas trazas que podrían haber sido temporalmente descartadas durante el paso 2 (por causa del criterio de $3 \sigma$ ), y cuyo primer arribo correcto pudiera no corresponder al máximo global (o mínimo en el caso del FDM) de la derivada del atributo filtrado, sino a un máximo (o mínimo) local dentro de la ventana de tamaño $t_{t o l}$. Por lo tanto, algunos picados que podrían haber sido interpretados como errados en el paso 2 pueden ser re-evaluados y corregidos durante el paso 3. De esta manera, se logra un nuevo conjunto de picados para el registro analizado.

El siguiente paso (paso 4) consiste en el mismo procedimiento ideado para el paso 2, pero ahora con el nuevo conjunto de picados obtenidos luego del paso 3. Como resultado, obtenemos un modelo de refracción final. La Figura 3.5b muestra los resultados después de los pasos 3 y 4 . Los picados asociados con las trazas 4, 14 y 37 se han corregido y ahora se incluyen en el modelo de refracción final. Además, en este paso del algoritmo, en donde el modelo de refracción cambió levemente respecto del modelo de refracción preliminar, el picado correspondiente a la traza 27 no fue corregido ya que superó el criterio de $3 \sigma$ para el modelo de refracción final, a diferencia de lo que ocurrió en el paso 2 .

Finalmente, en el quinto y último paso, analizamos cada uno de los picados traza por traza y decidimos si volver a ajustar su tiempo de acuerdo con el modelo de refracción final o si debemos rechazarlo definitivamente. Los picados rechazados son asociados con trazas malas o nulas, o bien con trazas para las que el método seleccionado (MCM, EM, o FDM) no fue capaz de detectar correctamente el primer arribo. En este sentido, bajo la hipótesis que los primeros arribos deben seguir aproximadamente las líneas rectas obtenidas en el paso 4, se define una nueva ventana de tolerancia de la mitad de la longitud de la ventana anterior centrada en las rectas del modelo de refracción final. Luego, se busca el máximo local (o mínimo para el FDM) dentro de esta ventana de tolerancia más estrecha. Notar que el picado se realiza aún si el primer arribo no está muy claro, simulando así la forma en que un analista procede siguiendo las rectas de un hipotético modelo de refracción. Por otro lado, ya que el atributo filtrado es constante 
para aquellas trazas en las que el atributo sin filtrar no presenta cambios bruscos en la ventana de tolerancia corta, no habrá en estos casos un máximo o mínimo local para seleccionar, y por lo tanto, los picados de estas trazas serán rechazados.

Dicho de otro modo, los primeros arribos finales son picados dentro del intervalo dado por

$$
\left|t-t_{r}\right|<t_{t o l} / 4
$$

donde $t_{r}$ es el tiempo asociado con las rectas del modelo final de refracción obtenido en el paso 4. Por lo tanto, $t_{t o l}$ debe ser seleccionado con el fin de garantizar que $t_{t o l} / 4$ sea superior a la mayor corrección estática esperada en los datos, como habíamos adelantado. Observar que en los picados finales que se muestran en la Figura 3.5b, los receptores 12 y 13 se asociaron con trazas malas o nulas y sus tiempos picados fueron rechazados.

\subsubsection{Algoritmo final}

El algoritmo final de picado automático, que consta de cinco pasos, se puede resumir como sigue:

Paso 1. Para cada traza del registro de disparo común analizado se calcula la serie temporal correspondiente al atributo seleccionado (cociente de energías, entropía o dimensión fractal). Luego, el atributo se filtra mediante un operador EPS y se realizan los picados preliminares de los primeros arribos en el máximo de la derivada filtrada del atributo (o el mínimo en el caso del FDM).

Paso 2. Todos los picados del paso anterior se ajustan por el mejor modelo de dos rectas por flanco según el criterio de mínimos cuadrados. Luego, los picados con errores a posteriori del ajuste mayores que $3 \sigma$ son temporalmente rechazados y se calcula un nuevo modelo de dos rectas por flanco. El proceso se repite hasta que no haya picados con errores mayores a $3 \sigma$. Como resultado, se obtiene el modelo de refracción preliminar (véase la Figura 3.5a).

Paso 3. Los primeros arribos son ahora re-picados buscando el máximo (o mínimo en el FDM) de la derivada filtrada del atributo elegido dentro de una ventana de tamaño $t_{t o l}$ centrada en las rectas del modelo de refracción preliminar obtenido en el paso anterior. Este proceso por lo general conduce a la corrección de los picados de algunas trazas (trazas 4, 14 y 37 en el ejemplo de la Figura 3.5). 
Paso 4. Se repite el paso 2 con el conjunto actualizado de los picados obtenidos en el paso 3. En este paso se incluyen en el nuevo ajuste por mínimos cuadrados algunos de los picados erróneos que habían sido corregidos en el paso 3 (y temporalmente descartados en el paso 2) y se genera el modelo de refracción final. A modo de ejemplo, puede verse en la Figura 3.5b cómo ahora se han considerado en el modelo final los picados de los receptores 4, 14 y 37 que habían sido descartados en el paso 2.

Paso 5. Se fija una ventana de longitud $t_{t o l} / 2$ (es decir, la mitad de la longitud de la ventana del paso 3) centrada en el modelo de refracción final. Los tiempos finales son picados dentro de esta nueva ventana, o eventualmente los picados son rechazados si dentro de la ventana no existe un máximo local (o mínimo en el FDM). Las trazas sísmicas cuyos picados fueron rechazados se interpretan como trazas malas o nulas, o como trazas para las que el método elegido ha fallado. A modo de ejemplo, observar en la Figura 3.5b cómo han sido rechazados los picados de las trazas 12 y 13, con evidentes problemas.

Vale la pena mencionar que este proceso de cinco pasos, además de ser totalmente automático, es computacionalmente eficiente y rápido, puesto que el atributo sísmico se calcula por única vez en el paso 1. La simplicidad de este procedimiento de corrección le proporciona una gran robustez al algoritmo final. La etapa de corrección de los picados erróneos es consistente dentro de cada registro de disparo común. Así, los problemas relacionados con la falta de homogeneidad del subsuelo que pueden dar lugar a diferentes modelos de refracción en diferentes regiones del área prospectada no generan ningún inconveniente. Distintas pruebas con varios registros de campo muestran que esta estrategia es muy útil cuando los datos son de calidad pobre o simplemente difíciles de picar. Sin embargo, si un gran número de picados obtenidos en el paso 1 son malos (por encima de 30 o $35 \%$ ), no es posible obtener un modelo preliminar de refracción razonable, y el proceso de corrección de cinco paso descrito antes puede fallar.

\subsection{Resultados con datos reales}

En general, los datos marinos exhiben primeros arribos claros y fácilmente distinguibles, por lo tanto no suelen ofrecer ninguna dificultad para los algoritmos de picado automático propuestos. Por ejemplo, el registro de sísmica marina mostrado en el capítulo anterior para validar el uso de la dimensión fractal del variograma como detector de primeros 


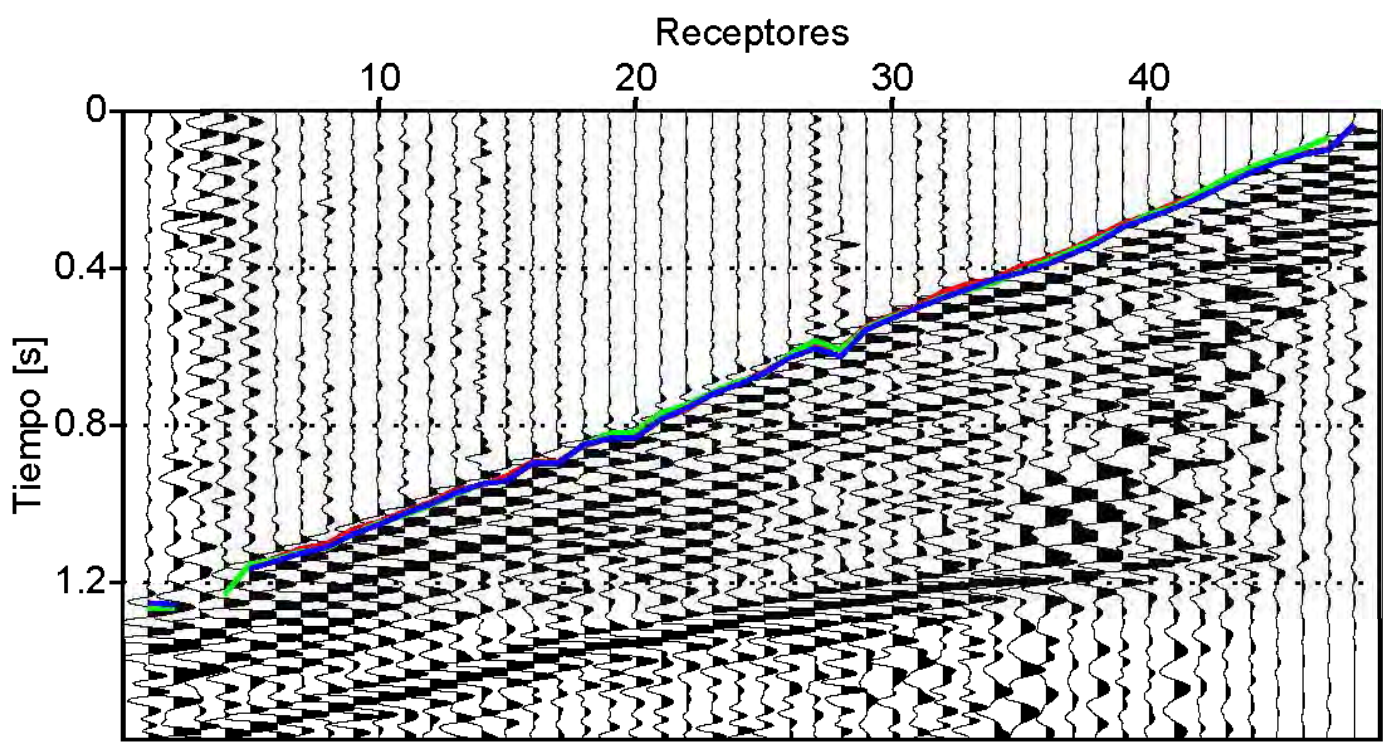

Figura 3.6: Resultado de los métodos de picado automático de primeros arribos aplicados al registro de disparo común con fuente dinamita (Registro 1 en la Tabla 3.1). En rojo los picados obtenidos mediante el MCM, en verde mediante el EM, y en azul mediante el FDM.

arribos (Figura 2.12) no representa mayor desafío para los algoritmos presentados en este capítulo. Por ello, vamos a ilustrar el comportamiento del MCM, del EM y del FDM, junto con la etapa de corrección de picados erróneos (es decir, utilizando el algoritmo final dado por los 5 pasos recién descritos) con datos terrestres de campo recolectados con fuente dinamita y con Vibroseis. Hemos seleccionado tres registros de disparo común con diferentes niveles de ruido de fondo, que no son fáciles de picar debido a la presencia de ruido correlacionado, trazas malas, cambios en las formas de onda, primeros arribos poco distinguibles, etc. Los datos de campo fueron tomados de Yilmaz [75], y están disponibles en http:/www.cwp.mines.edu/data/oz.original/). La Tabla 3.1 muestra el intervalo de muestreo y los períodos aproximados de la señal a detectar para cada conjunto de datos, junto con los parámetros que se utilizaron para los diferentes métodos de picado. En cuanto a la etapa de corrección de picados erróneos, seleccionamos $t_{t o l}$ igual a cuatro períodos para los tres registros y para los tres métodos (es decir, pasando a muestras, 52 para el registro 1, 128 para el registro 2, y 80 para el registro 3 ).

El primer dato seleccionado (Figura 3.6) es el registro de disparo común número 6 tomado de Yilmaz [75, p. 72]. El registro fue adquirido en el Lejano Oriente con una fuente de dinamita. Está compuesto por 48 trazas y la distancia entre receptores es de 


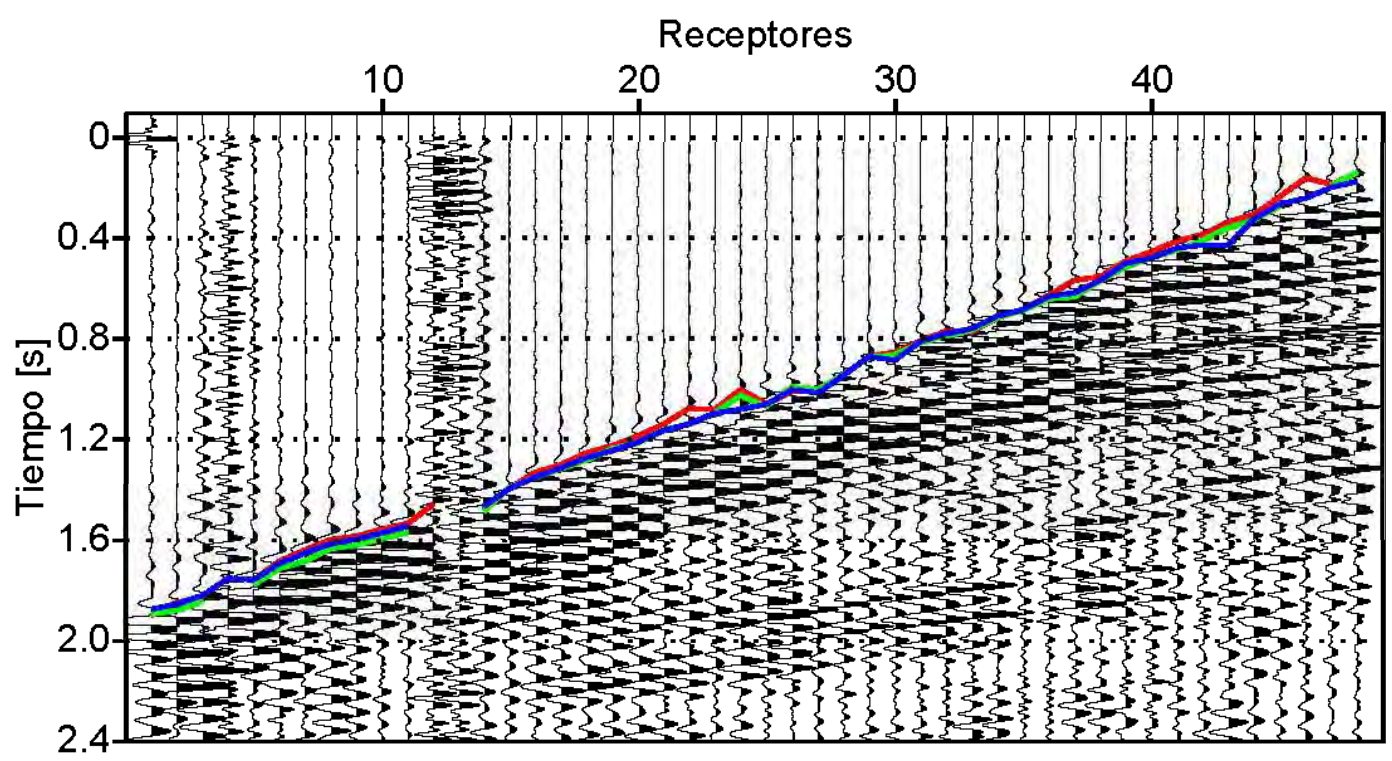

Figura 3.7: Resultado de los métodos de picado automático de primeros arribos aplicados al primero de los ejemplos de registro de disparo común con fuente Vibroseis (Registro 2 en la Tabla 3.1). En rojo los picados obtenidos mediante el MCM, en verde mediante el EM, y en azul mediante el FDM.

100 m. La Figura 3.6 muestra los resultados de los primeros arribos obtenidos mediante el MCM (rojo), el EM (verde) y el FDM (azul). Algunas trazas presentan primeros arribos poco claros. En particular, los receptores 2, 3, 4, 27 y 28 exhiben algunos problemas que dificultan su picado. En algunas de estas trazas, los métodos no pudieron encontrar un picado aceptable después del paso 5 , y por lo tanto las trazas fueron automáticamente interpretadas como trazas malas. A pesar de esto, los tres métodos automáticos picaron los primeros arribos correctamente en la mayoría de las trazas. La fuente de dinamita genera primeros arribos impulsivos, y aunque algunas trazas son bastante ruidosas y algunos primeros arribos no son fáciles de distinguir, los datos con dinamita no representan grandes dificultades para los métodos propuestos.

El siguiente dato utilizado (Figura 3.7) es un registro de campo de la Cuenca de San Joaquín (registro de disparo común número 23 de Yilmaz [75, p. 76]), que fue adquirido con una fuente de Vibroseis. Las 48 trazas están separadas por 220 pies. Este es el conjunto de datos utilizado para ilustrar el algoritmo de cinco pasos para la corrección automática de picados descrito en la sección anterior. El registro y los picados obtenidos mediante el MCM, el EM y el FDM se muestran en la Figura 3.7. Algunos receptores 


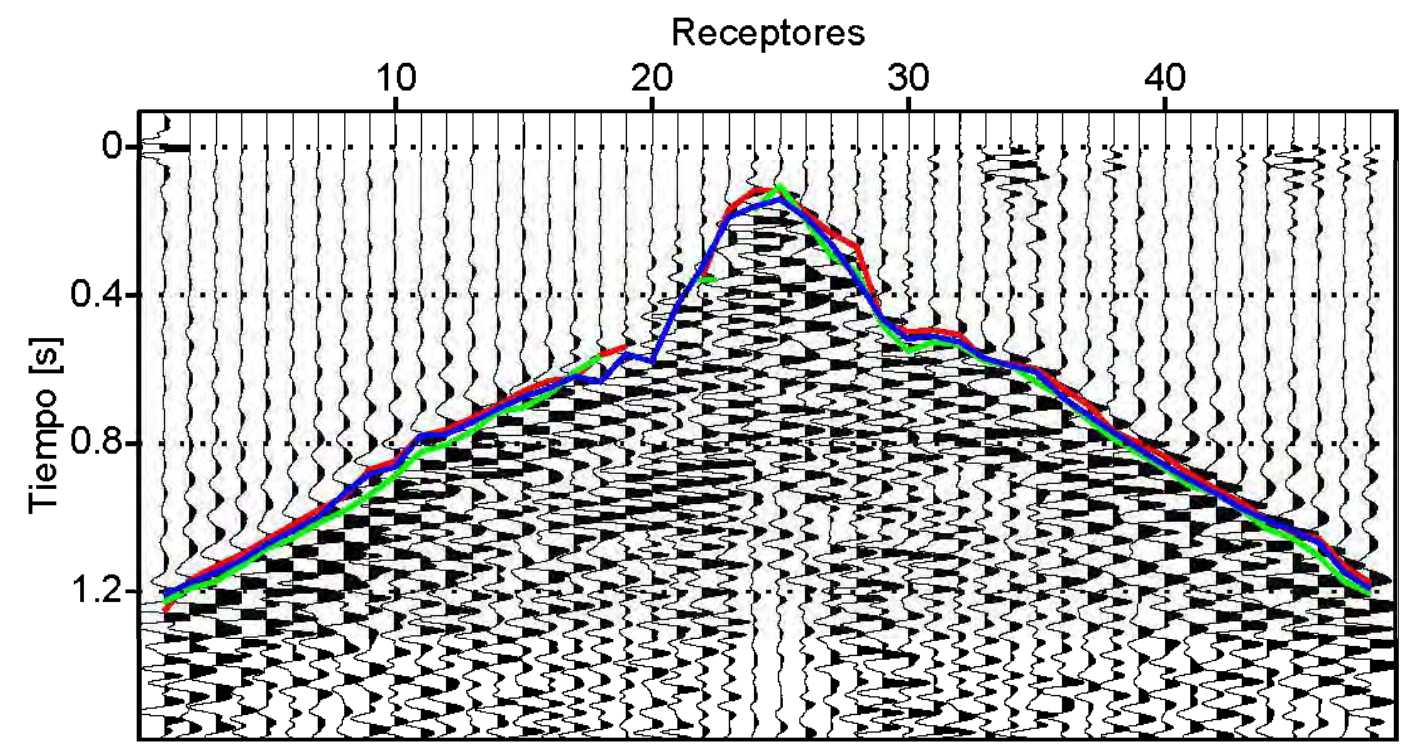

Figura 3.8: Resultado de los métodos de picado automático de primeros arribos aplicados al segundo de los ejemplos de registro de disparo común con fuente Vibroseis (Registro 3 en la Tabla 3.1). En rojo los picados obtenidos mediante el MCM, en verde mediante el EM, y en azul mediante el FDM.

presentan problemas para detectar la señal (ver las trazas 4, 12, 13 y 14). Para estos receptores, algunos métodos tienen éxito al picar los primeros arribos, y algunos métodos no, como se esperaba debido a la presencia de trazas malas. Además, los datos exhiben lóbulos antes de los primeros arribos (a causa de que la fuente es de fase cero) y los primeros arribos no son muy claros. Este es un problema común con los registros de Vibroseis. La complejidad de los datos hace que algunos de los métodos se "equivoquen" al determinar el primer arribo en aproximadamente un período para unas pocos trazas (ver receptores 22, 24, 43 y 46), pero los resultados son en general muy buenos teniendo en cuenta el dato considerado.

El último ejemplo, y tal vez el dato que presenta el mayor desafío, corresponde a un registro de campo de Vibroseis recogido en Turquía (registro de disparo común número 4 en Yilmaz [75, p. 71]). Está compuesto por 48 trazas equiespaciadas en $100 \mathrm{~m}$. Los datos y los picados resultantes se muestran en la Figura 3.8. En este ejemplo, los algoritmos de picado automático de primeros arribos convencionales tienden a fallar. Observar que para el ruido añadido al dato para el FDM se tomó $S N R=20$ (Tabla 3.1). Este valor, relativamente alto, tiene por objeto descorrelacionar la energía que precede al primer 
arribo cuando se utilizan datos de Vibroseis. Debido a la presencia de esta energía antes de los primeros arribos, que puede considerarse como un ruido monocromático, el inicio de la señal de interés es muy difícil de detectar. Incluso un analista con experiencia encontraría difícil decidir dónde ubicar los picados en algunas de las trazas (véase, por ejemplo, los receptores 29 a 33). Yilmaz [75] sugiere la presencia de irregularidades en el subsuelo cercanas a la superficie, que son evidentes si se inspecciona todo el registro a tiempos posteriores a $0.8 \mathrm{~s}$. A pesar de la complejidad de los datos, los resultados del picado automático son en general muy buenos. El EM tiende a retrasar el picado en algunas muestras.

\subsubsection{Análisis de sensibilidad}

En esta sección llevamos a cabo un análisis de sensibilidad de los métodos en función de los parámetros elegidos. Para ello, realizamos repetidas veces el picado de primeros arribos para cada registro con un gran número de conjuntos de parámetros diferentes. En este sentido, para cada traza en cada registro utilizado se calculó la desviación estándar de los picados, en donde cada picado se obtuvo mediante un conjunto diferente de parámetros. Se variaron la longitud de la ventana corta (para el MCM) o el tamaño de la ventana móvil (para el EM y el FDM) y la longitud del operador EPS en un rango de un período, centrado en los valores mostrados en la Tabla 3.1. Tanto $\beta$ para el MCM como $S N R$ para el FDM se mantuvieron fijos en los valores indicados en la misma tabla. Los rangos utilizados para el análisis de sensibilidad se muestran en la Tabla 3.2.

\begin{tabular}{|c|c|c|}
\hline Método & Parámetro & Rango \\
\hline MCM & $n_{l}$ & $0.5 n_{\text {per }}-1.5 n_{\text {per }}$ \\
& $n_{e}$ & $n_{\text {per }}-2 n_{\text {per }}$ \\
\hline EM & $n_{h}$ & $1.5 n_{p e r}-2.5 n_{p e r}$ \\
& $n_{e}$ & $n_{p e r}-2 n_{p e r}$ \\
\hline FDM & $n_{f}$ & $(k-0.5) n_{p e r}-(k+0.5) n_{p e r}$ \\
& $n_{e}$ & $n_{p e r}-2 n_{p e r}$ \\
\hline
\end{tabular}

Tabla 3.2: Rangos de variación de los parámetros de los diferentes métodos para realizar el análisis de sensibilidad. Todas las cantidades están dadas en muestras. En el caso en que $n_{p e r}$ sea impar, redondeamos $0.5 n_{p e r}, 1.5 n_{p e r}$ o $2.5 n_{p e r}$ al entero siguiente. 
Finalmente, se calculó una desviación estándar media (en ms) para cada registro promediando todas las desviaciones estándar de los picados asociados con cada traza individual. Esta cantidad se puede considerar como un indicador de la variabilidad de los picados de cada registro de disparo común. La Tabla 3.3 muestra la desviación estándar media para cada uno de los tres ejemplos ilustrados. Observar que la variabilidad de los picados es muy pequeña, lo que valida los criterios de selección de parámetros considerados. Por otra parte, también podemos concluir a partir de la Tabla 3.3 que la selección de parámetros no es crítica dentro de los rangos de variación utilizados.

\begin{tabular}{|c|c|c|c|}
\hline Método & Registro 1 & Registro 2 & Registro 3 \\
\hline MCM & 3.7 & 7.9 & 8.9 \\
EM & 4.8 & 7.0 & 12.2 \\
FDM & 4.1 & 7.6 & 12.8 \\
\hline
\end{tabular}

Tabla 3.3: Desviación estándar media (en ms) de los picados por registro calculadas para el análisis de sensibilidad.

\subsection{Mejoras y aplicación en datos de proyectos sísmicos $2 \mathrm{D}$ y $3 \mathrm{D}$}

Hasta aquí, en este capítulo presentamos tres métodos robustos y eficientes para picar de manera automática los tiempos de los primeros arribos en registros de disparo común. Para testear e ilustrar los métodos, los aplicamos a tres registros reales que presentan diversas complejidades. Además, dimos una guía sobre cómo elegir los parámetros de los que dependen y que validamos mediante un análisis de sensibilidad. Los principales resultados obtenidos fueron divulgados y presentados en diferentes congresos y publicaciones científicas $[52,53,54]$.

El buen desempeño logrado con los métodos propuestos, el gran interés que existe en la industria de exploración sísmica por este tema de investigación y la motivación de aplicar las estrategias propuestas a un mayor volumen de datos de campo dio lugar a un convenio de vinculación tecnológica con la compañía de servicios geofísicos Data Seismic. El objetivo principal de la interacción con la compañía fue adaptar y mejorar los métodos desarrollados para procesar registros de proyectos sísmicos completos intentando lograr resultados comparables a aquellos que se obtienen mediante el uso de software comercial. 
Se buscó entonces aplicar los algoritmos desarrollados a un gran volumen de datos y se incluyeron algunas mejoras que permitieron continuar con la puesta a punto de los métodos. Los datos reales analizados los podemos dividir en dos grupos: una línea de registración sísmica 2D y un cubo de datos de registración sísmica 3D. Cabe destacar que los algoritmos aquí presentados fueron programados poniendo énfasis en la optimización de los cálculos, de forma tal que puedan implementarse de forma rápida y sencilla, aprovechando también la simpleza en la selección de los parámetros descrita en secciones anteriores de este capítulo. Los programas que implementan los métodos y que utilizamos para procesar los datos están escritos en código FORTRAN. El objetivo principal de esta sección es comentar algunas mejoras introducidas en los métodos y presentar las situaciones que motivaron estos cambios.

\subsubsection{Ajuste de los picados}

En el algoritmo final que hemos descrito en la sección 3.2.2 la posición del primer arribo está determinada por la derivada del atributo filtrado por el operador EPS. Esta es una selección arbitraria en nuestros métodos que no contempla la forma de onda original de los datos. Luego, para lograr picados consistentes a lo largo de todos los registros del proyecto, se incluyó una subrutina para reposicionarlos en los máximos o mínimos locales de los datos, conforme cuál sea la polaridad esperada para el primer arribo. El ajuste se implementa después de cada picado en los pasos 1, 3 y 5 del algoritmo final (ver sección 3.2.2). Durante la explicación de este procedimiento denominaremos picados previos a aquellos obtenidos mediante la derivada del atributo filtrado por el operador EPS. A estos tiempos les asignamos la variable $t_{0}$.

Los únicos parámetros involucrados en el ajuste son la polaridad deseada para el lóbulo correspondiente al primer arribo y su período esperado $(T)$. El último ya había sido requerido como parámetro de entrada de los métodos. Supongamos, sin perder generalidad, que la polaridad deseada sea positiva, de modo que se quieren ajustar los picados a los máximos de los lóbulos positivos cercanos a los picados previos.

El ajuste de los picados se puede resumir como sigue. Primero, se buscan y almacenan el tiempo correspondiente al máximo local de la traza $s_{t}$ anterior a $t_{0} \mathrm{y}$ aquel posterior a $t_{0}$, dentro del intervalo:

$$
\left|t-t_{0}\right| \leq T / 4
$$


Asignamos los tiempos $t_{1}$ y $t_{2}$ a estos tiempos menores y mayores a $t_{0}$, respectivamente. Claramente, como la búsqueda está restringida, podrían no existir extremos locales dentro del intervalo $\left|t-t_{0}\right| \leq T / 4$. Es decir, se pueden obtener uno, dos o ningún máximo local con la polaridad deseada. Ante estas tres posibilidades:

(a) si existe $t_{1}$ pero no $t_{2}$, "adelantamos" el picado previo $t_{0}$ al tiempo $t_{1}$. Si, por el contrario, existe $t_{2}$ pero no $t_{1}$, "atrasamos" el picado previo $t_{0}$ al tiempo $t_{2}$.

(b) si existen $t_{1}$ y $t_{2}$, supongamos que son tales que

$$
\left|t_{1}-t_{0}\right| \leq\left|t_{2}-t_{0}\right|
$$

Entonces, corregimos el picado previo $t_{0}$ al tiempo $t_{1}$ solo si se cumple que

$$
s_{t_{1}}>0,3 s_{t_{2}}
$$

caso contrario, corregimos por $t_{2}$. Es decir, elegimos el tiempo más cercano disponible siempre y cuando este máximo local no sea relativamente chico respecto de aquel que corresponde al tiempo más alejado.

(c) si no existen máximos locales, no se obtiene ningún picado para la traza analizada.

Si ocurriera (c), procedemos de la misma manera que detallamos en el algoritmo final en la sección 3.2.2. Es decir, si no se obtuviera el picado para alguna traza en el paso 1 o 3 , dichas trazas no serán tenidas en cuenta para los modelos de refracción preliminar y final (paso 2 y 4, respectivamente). Si en cambio esto ocurriese en el paso 5, interpretamos las trazas para las que no podemos obtener un tiempo de arribo como malas o nulas. Esto completa la descripción del proceso de ajuste de picados.

\subsubsection{Restricción según el offset}

Hasta aquí, para procesar los datos en el paso 1 utilizamos cada traza sísmica desde tiempo 0 hasta un tiempo máximo (mayor al esperado para el primer arribo). Es decir, los cálculos fueron realizados a lo largo de toda la traza sísmica, y para todas las trazas del registro.

Esto supone una gran cantidad de cálculos si el volumen de datos a procesar es muy grande. Además, al no utilizar una ventana de trabajo con restricciones en tiempo en el paso 1 , se aumenta el riesgo de que los picados preliminares estén alejados del modelo de 
refracción real. Consecuentemente, el error del modelo preliminar de refracción del paso 2 podría ser grande. Si esta fuera la situación, los picados del paso 3 serían incorrectos y los métodos fallarían. Esto nos motiva a redefinir la ventana de trabajo de los algoritmos para el paso 1.

En primer término, vamos a introducir una restricción sobre el offset de las trazas a procesar. Para justificar esta restricción, recordemos algunos conceptos básicos de la sísmica de refracción. Los primeros arribos se utilizan, en primera instancia, para realizar las correcciones estáticas. En particular, interesan los arribos de aquellas ondas que se refractan en el límite entre las primeras capas del subsuelo. Si suponemos por ejemplo un modelo de tres capas, estos arribos brindan información sobre las velocidades $v_{2}$ y $v_{3}$ de la segunda y tercera capa, respectivamente, y sobre los espesores de la primera y de la segunda. Por el contrario, los arribos de ondas directas (que viajan con la velocidad $v_{1}$ de la primera capa) y los arribos para offsets muy grandes (que corresponden de refracciones profundas) no suelen ser de interés. Por todo esto, tiene sentido introducir una primera restricción en los métodos: sólo buscaremos picar los primeros arribos en aquellas trazas cuyo offset esté comprendido en el rango

$$
\text { of } f_{\min }<\text { offset }<\text { of } f_{\max }
$$

donde of $f_{\min }$ y of $f_{\max }$ son dos nuevos parámetros de entrada de los métodos. Según lo explicado, of $f_{\min }$ debe elegirse de forma tal que deje afuera a las trazas con primeros arribos de rayos directos. Por su parte, of $f_{\max }$ debe elegirse de forma que no incluya a las trazas con offsets mayores a los deseados para picar los primeros arribos.

\subsubsection{Restricción en tiempo por un modelo inicial de refracción}

Para realizar la restricción en tiempo, vamos a definir un modelo inicial de refracción. Este modelo formará parte de la entrada de los métodos. En el esquema del algoritmo final (sección 3.2.2), podemos entender la siguiente estrategia como un "paso 0" o inicial.

En una situación ideal, cada registro de disparo común podría contar con una estimación de los parámetros de las rectas de refracción obtenidas a partir de los datos, ya sea por inspección visual o mediante el uso de algún software de procesamiento. Sin embargo, en un proyecto sísmico grande donde deba procesarse una gran cantidad de registros de disparo común esto puede insumir mucho tiempo, situación que queremos 
evitar para automatizar todo el proceso. Veremos una técnica sencilla para obtener estos parámetros.

Para simplificar la explicación, consideremos un modelo de dos capas solamente. En dicho caso, se precisa la ordenada al origen y la pendiente de la recta de refracción para cada flanco de cada registro, donde la inversa multiplicativa de dicha pendiente representa la velocidad $v_{2}$ de la segunda capa. En general, en el área prospectada el modelo de refracción varía gradualmente de una posición de fuente a otra. Proponemos entonces la siguiente estrategia para generar el modelo inicial de refracción de entrada para todos los registros a procesar:

(1) Seleccionamos algunas posiciones de fuente distribuidas uniformemente a lo largo de la línea o área prospectada. Para cada una de estas posiciones de fuente, analizamos el registro de disparo común que corresponde a dicha fuente y obtenemos valores aproximados para la ordenada al origen y la pendiente de la recta de refracción. Llamemos $\left(a_{k}, b_{k}\right)$ a estos valores, donde $k=1,2, \ldots, N_{m}$ representa las distintas posiciones de fuente seleccionadas, cuyas coordenadas anotamos $\left(S x_{k}, S y_{k}\right)$.

(2) Para obtener los parámetros $(a, b)$ de las rectas para el resto de las posiciones de fuente, de coordenadas $(S x, S y)$, utilizamos la fórmula de interpolación de la inversa de la distancia de Shepard [58]:

$$
a=\frac{\sum_{k=1}^{N_{m}} w_{k} a_{k}}{\sum_{j=1}^{N_{m}} w_{j}}, \quad b=\frac{\sum_{k=1}^{N_{m}} w_{k} b_{k}}{\sum_{j=1}^{N_{m}} w_{j}},
$$

donde

$$
w_{k}=\frac{1}{\left(S x-S x_{k}\right)^{2}+\left(S y-S y_{k}\right)^{2}}
$$

es la función de peso de interpolación que depende del cuadrado de la distancia entre fuentes.

En la Figura 3.9 mostramos las posiciones de todas las fuentes utilizadas en el proyecto de sísmica 3D. Las coordenadas geográficas $\left(S_{x}, S_{y}\right)$ fueron trasladadas al origen para preservar la ubicación del área prospectada. El modelo inicial de refracción para toda el área se obtuvo eligiendo 14 posiciones de fuente para estimar los parámetros de las rectas de refracción. Estas fuentes se destacan en rojo en la Figura 3.9a. Con el conjunto de 
los 14 pares ordenados $\left(a_{k}, b_{k}\right)$ y las ecuaciones 3.15 y 3.16 se calcularon los pares $(a, b)$ para el resto de las fuentes. En la Figura $3.9 \mathrm{~b}$ se muestran los valores de velocidad de la capa 2 que se obtienen a partir de la inversa del parámetro de la pendiente de las rectas $(1 / b)$.

a)

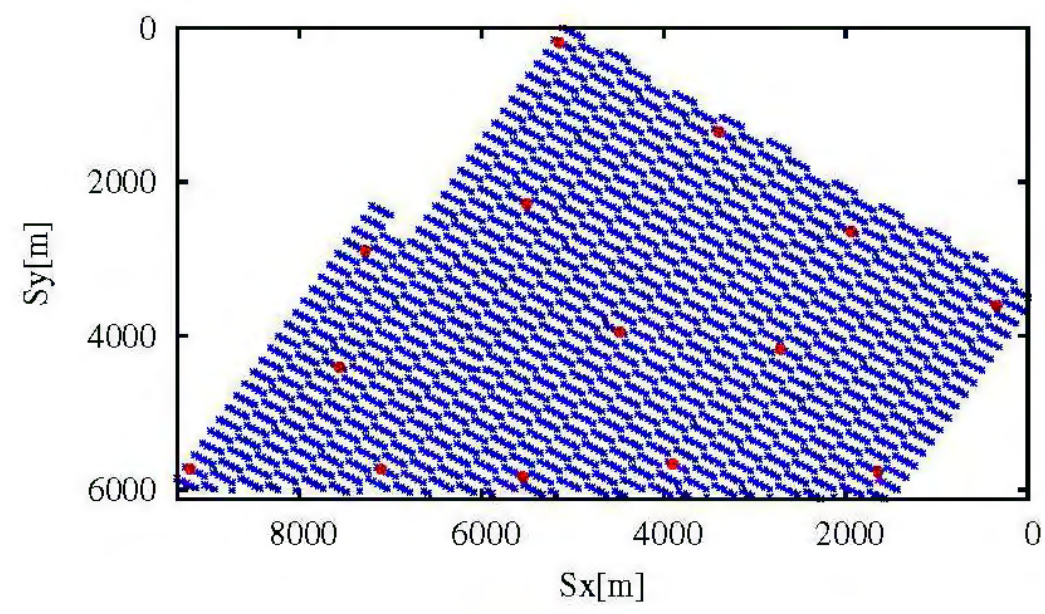

b)

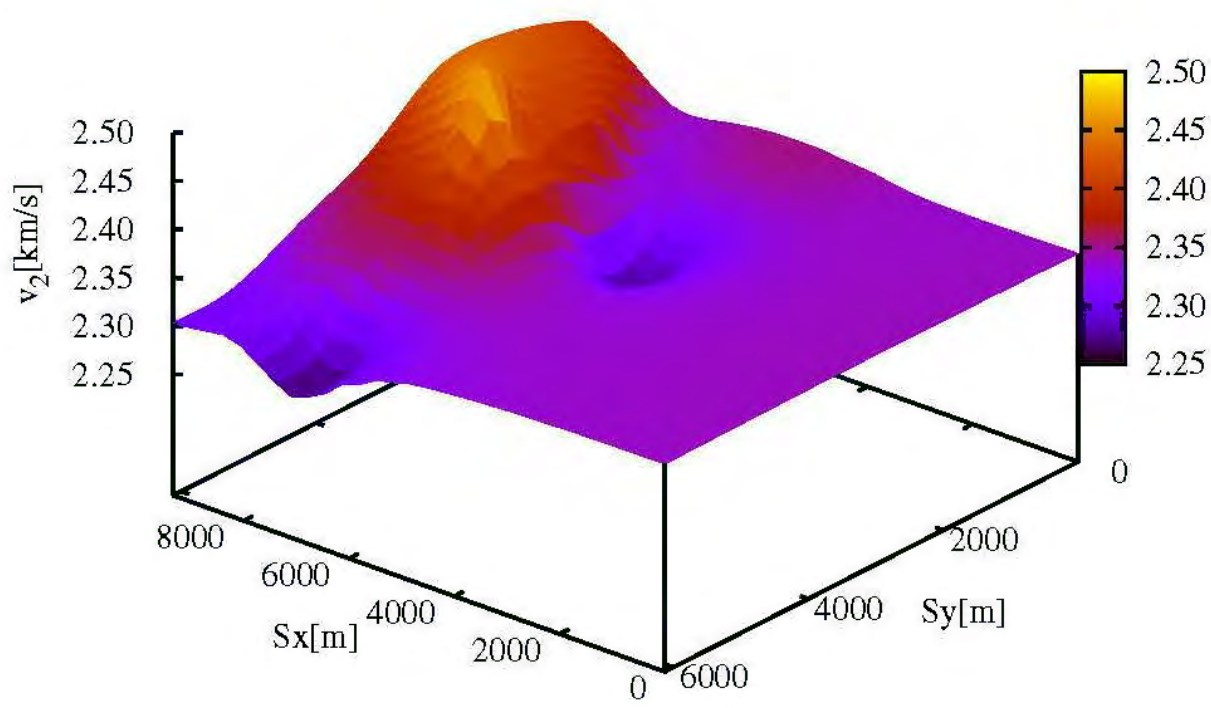

Figura 3.9: Modelo inicial de refracción. Las coordenadas geográficas $\left(S_{x}, S_{y}\right)$ fueron trasladadas al origen. (a) Fuentes utilizadas en el proyecto de sísmica 3D. En rojo se destacan las fuentes para las que se midieron los parámetros de entrada $(a, b)$. (b) Velocidad de la capa 2 según el modelo inicial de refracción.

Una vez obtenido el modelo inicial de refracción, restringimos en tiempo la búsqueda del primer arribo a una ventana centrada en las rectas del modelo. Elegimos el tamaño de dicha ventana de trabajo igual a 6 veces el período esperado del primero arribo. Dicho 
de otro modo, la ventana de trabajo se define vía:

$$
\left|t-t_{i}\right| \leq 3 t_{\text {per }}
$$

donde $t_{i}$ representa el tiempo del modelo inicial de refracción.

Con esta condición y la anteriormente explicada para el offset, hemos restringido la búsqueda de los primeros arribos según la distancia fuente-receptor y según el tiempo. De esta manera, la ventana de trabajo de los métodos se reduce considerablemente. A modo de ejemplo, en la Figura 3.10 se muestra la ventana de trabajo para uno de los registros de disparo común del proyecto de sísmica 3D. En sísmica tridimensional, la fuente no necesariamente se ubica sobre la línea de receptores. Por ello, y como ocurre en la Figura 3.10, al graficar las trazas equiespaciadas, los primeros arribos se presentan como hipérbolas y no como líneas rectas. Hacia los offsets chicos, la ventana se aplana para evitar los efectos de borde en los algoritmos que calculan los atributos.

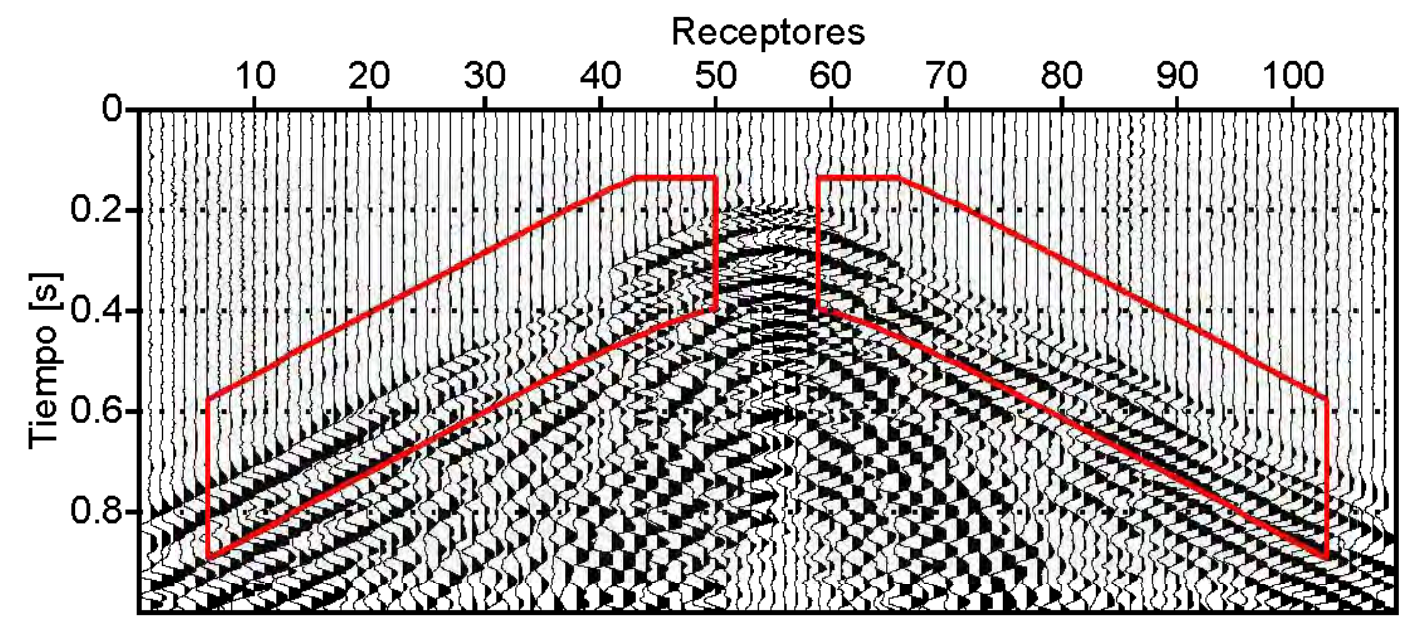

Figura 3.10: Ejemplo de la nueva ventana de trabajo para un registro de proyecto de sísmica 3D con las restricciones dadas para el offset y para el tiempo. La fuente se encuentra fuera de la línea de receptores. La ventana se aplana hacia offsets chicos para evitar los efectos de borde al calcular los atributos.

Claramente, estas restricciones no sólo disminuyen el tiempo de procesamiento de los datos, sino también ayudan considerablemente a definir el modelo preliminar de refracción que se obtiene en el paso 2. Asimismo, el ajuste de los picados también obra en el mismo sentido, puesto que se obtiene una mayor consistencia en todo el registro. 


\subsubsection{Corrección estática por elevación}

Al trabajar con datos reales, las rectas de refracción del modelo no son tales, y los primeros arribos se presentan apartados de dichas rectas. Esto ocurre por diversas razones. Entre ellas, destacamos dos causas principales: la elevación de los receptores y las inhomogeneidades laterales de velocidad. Justamente, estos apartamientos del modelo teórico representan el dato de interés en las correcciones estáticas. Como nuestros métodos definen las rectas de refracción mediante un ajuste por mínimos cuadrados (paso 2 y paso 4), para ayudar a ajustar dichas rectas pre-procesamos los datos aplicándoles una corrección estática por elevación. Para esta corrección, solamente se necesita la elevación de los receptores respecto de la fuente $(\Delta z)$ y la velocidad $v_{1}$ de la primera capa. En tiempo, la magnitud de la corrección estática por elevación $\Delta t_{e}$ se escribe:

$$
\Delta t_{e}=\Delta z / v_{1}
$$

La ecuación 3.18 implica que:

$$
\Delta z \stackrel{v_{1} \rightarrow \infty}{\longrightarrow} 0
$$

Luego, considerar un valor de $v_{1}$ excesivamente grande equivale a no realizar la corrección. Por el contrario, un valor de $v_{1}$ chico sobre-corrige los datos, lo que podría empeorar la alineación de los primeros arribos. Por ello, en los métodos utilizamos un valor de $v_{1}$ grande (1 a $1,5 \mathrm{~km} / \mathrm{s}$ ). Entonces, para remover el efecto de la elevación al procesar los datos, simplemente realizamos esta corrección previo a aplicar los métodos y luego implementamos los algoritmos para picar los primeros arribos de los datos corregidos. Por último, quitamos la corrección aplicada para obtener los verdaderos tiempos de arribo buscados.

\subsubsection{Ejemplos de los resultados obtenidos con las mejoras incorporadas}

Los métodos, con todas estas mejoras incorporadas, fueron utilizados para procesar dos conjuntos de datos: una línea de sísmica 2D formada por 350 registros de disparo común aproximadamente, con 96 canales por registro y un intervalo de muestreo de $2 \mathrm{~ms}$; y un proyecto de sísmica $3 \mathrm{D}$ constituido aproximadamente por 3300 registros, con cada registro 
formado por 5 líneas con 108 canales por línea (1.750.000 trazas aproximadamente) e intervalo de muestreo de $4 \mathrm{~ms}$.

Los resultados obtenidos están actualmente siendo comparados contra aquellos que se logran utilizando software comercial. En un primer análisis, pudimos observar que los picados obtenidos en general fueron consistentes y promisorios. No obstante, el análisis global de los resultados de los proyectos no es el objetivo primordial de esta sección y escapa a los contenidos de esta Tesis. A modo de ejemplo, y para analizar el efecto de las mejoras propuestas, mostraremos un registro picado para cada conjunto de datos.

En la Figura 3.11 se muestra uno de los registros de disparo común y los resultados para cada método. Los datos están normalizados por el rms de cada traza para facilitar su visualización, si bien para procesarlos no se les aplicó ningún tipo de ganancia. En este caso, se interpolaron linealmente los tiempos de primer arribo en las trazas no picadas utilizando los picados de las trazas contiguas. Esto se evidencia claramente en las trazas nulas 24 y 25. Como se puede observar en la figura, no se picaron trazas para offsets muy chicos ni para offsets muy grandes, conforme lo establece la restricción dada por la ecuación 3.14. Además, notar que los arribos fueron ajustados a los máximos de los lóbulos positivos de la forma de onda de los datos. Cuando esto no ocurre, es debido a que alguna traza no pudo ser picada y su primer arribo fue interpolado. Los resultados de los tres métodos son en general comparables en este ejemplo, y al igual que ocurrió con los datos reales analizados en la sección 3.3, el FDM tiende a atrasar algunos picados. En particular, los primeros arribos determinados por el FDM para las trazas 62, 63, $74,75,76,81,88$, y 89 están atrasados en un período. En cuanto al MCM, también para algunas trazas el picado está atrasado en un período (trazas 62, 63, 75 y 76) y en otros está adelantado en un período (trazas 7, 39, 64, 65, 87 y 88). El EM arroja los mejores resultados para este ejemplo. Sin embargo, mediante este análisis con un único ejemplo no podemos realizar una valoración relativa de los métodos, dado el gran volumen de datos procesados. No obstante, podemos sí afirmar que este ejemplo sugiere que la restricción en tiempo para el ajuste de los picados finales fue demasiado laxa, ya que en varios casos el primer arribo fue ajustado a un lóbulo incorrecto.

El procesamiento de los datos del proyecto sísmico 3D fue más trabajoso y requirió de una puesta a punto de los parámetros a utilizar por los métodos. El área prospectada es la que se muestra en la Figura 3.9a. Se utilizaron 3300 ubicaciones de fuente, y en promedio se registró en 5 líneas por cada posición de fuente, dando lugar a 16.500 
a)

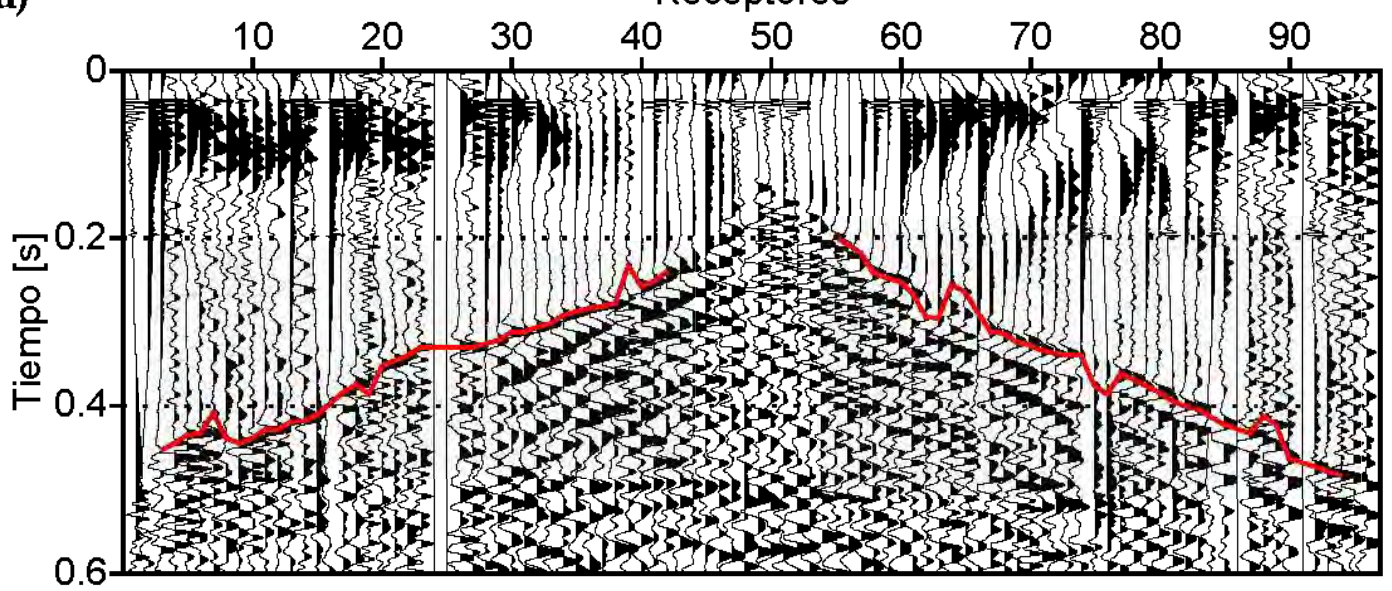

b)

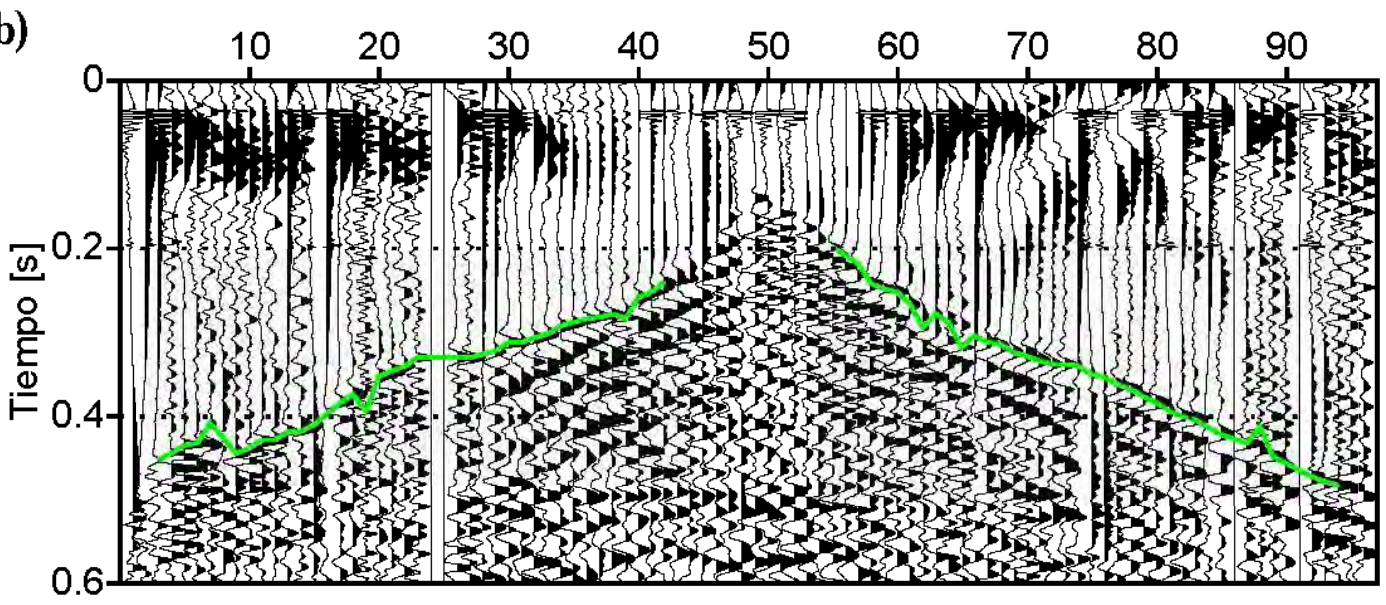

c)

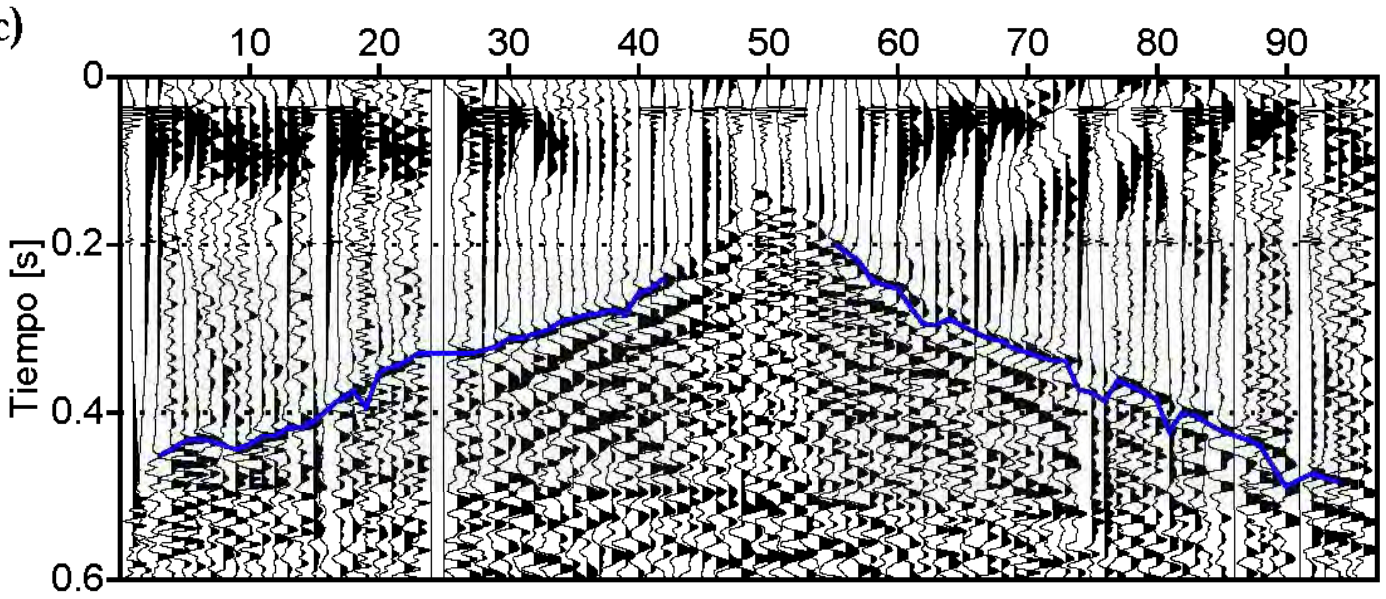

Figura 3.11: Ejemplo de los resultados obtenidos para uno de los registros de la línea sísmica 2D. Primeros arribos determinados mediante (a) MCM, (b) EM y (c) FDM. 

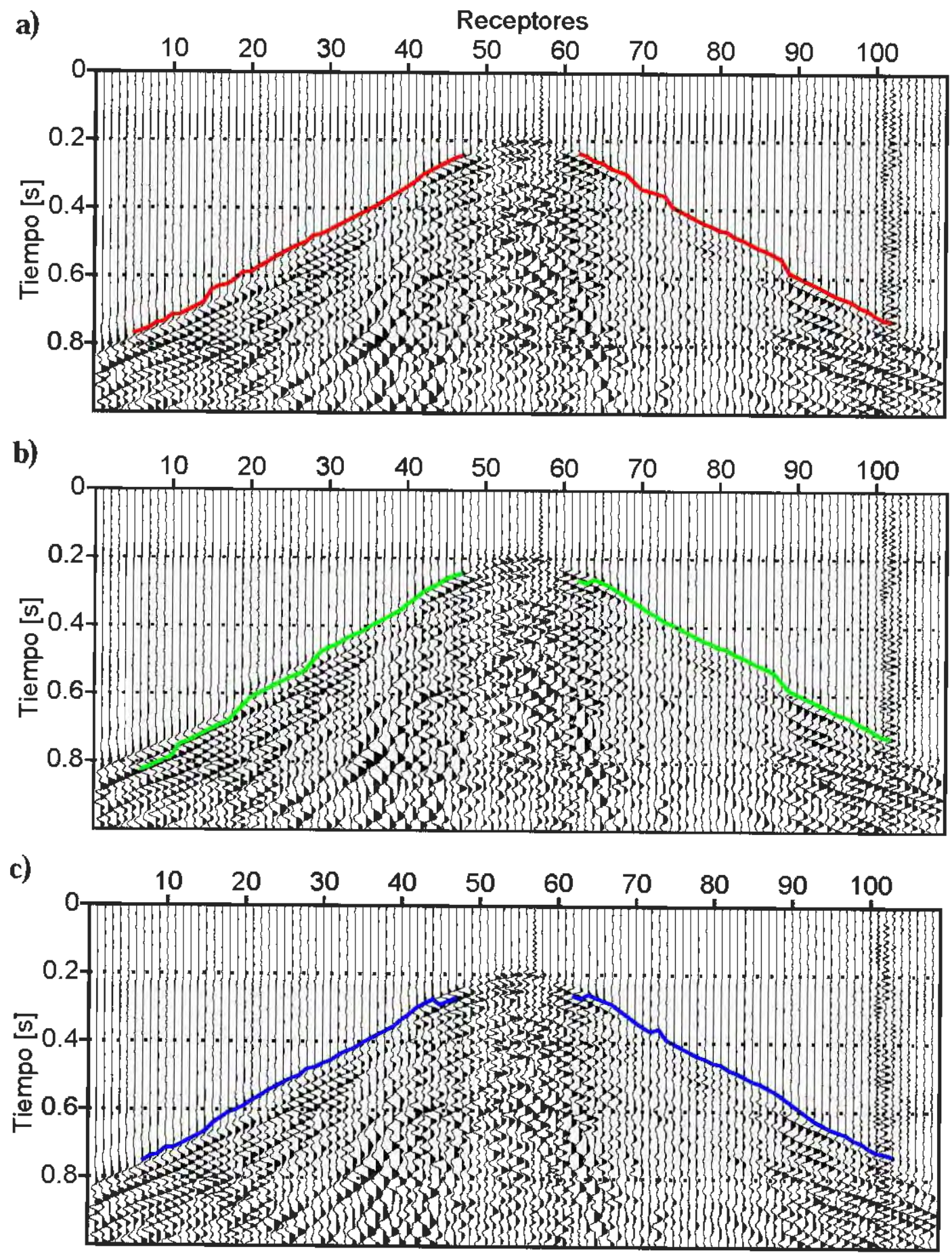

Figura 3.12: Ejemplo de los resultados obtenidos para una línea en uno de los registros del proyecto de sísmica 3D. Primeros arribos determinados mediante (a) MCM, (b) EM y (c) FDM. 
registros de línea y disparo común. En la Figura 3.12 se muestra un ejemplo en el que se intentan ilustrar dos situaciones. Por un lado, al igual que con la línea de sísmica 2D, el efecto de las mejoras introducidas. Por otro, las complejidades que presentaron los datos y que constituyen el mayor desafío para los métodos. Estos datos presentan uno de los principales inconvenientes en el problema de la determinación automática de los primeros arribos: el primer arribo, que se puede observar con claridad para cierto rango de offsets, se "pierde" partir de una dada distancia entre fuente y receptor. Esto suele estar relacionado con la presencia de capas someras de alta velocidad, como puede ser el caso de una colada basáltica, cuya anomalía de velocidad evita que se generen las refracciones.

Nuevamente, analizando la Figura 3.12, podemos apreciar los efectos del ajuste de los picados y la restricción por offset. En el ejemplo de la figura, los datos están escalados y se puede observar cómo los métodos corren el riesgo de atrasarse uno o más lóbulos a medida que el offset aumenta, pues a partir de cierta distancia entre fuente y receptor prácticamente no arriba energía de refracción. Esto se puede ver claramente para el flanco izquierdo en el panel (b) de la Figura 3.12, en donde el EM falla en la determinación del primer arribo. La misma situación se aprecia para el MCM y el EM en el flanco izquierdo del registro (paneles (a) y (b), respectivamente). Este es un inconveniente que aún hoy día no está resuelto en los distintos paquetes de software comercial disponible. En este ejemplo, debemos destacar el buen desempeño del FDM, que a excepción de unas pocas trazas para offsets cortos, determina el lóbulo del primer arribo correctamente.

\subsection{Conclusiones del capítulo}

En este capítulo hemos presentado tres nuevos métodos para determinar automáticamente los primeros arribos sísmicos, ya sea para datos marinos, o para datos de sísmica terrestre adquiridos con dinamita o Vibroseis. Los métodos, que llamamos método de Coppens modificado (MCM), método de la entropía (EM), y método de la dimensión fractal (FDM), se basan en el análisis de ciertos atributos de las trazas sísmicas que son especialmente sensibles a la llegada de una señal en medio del ruido de fondo. Los atributos incluyen un cociente de energías, la entropía, y la dimensión fractal, y son calculados a lo largo de la traza sísmica dentro de ventanas móviles. Para detectar la llegada de la señal, se buscan los mayores cambios que presentan los atributos. La transición entre 
el ruido y el ruido más la señal se mejora de forma significativa utilizando un filtro de suavizado que preserva los cambios más notables del atributo (EPS), dando lugar a una estrategia automática para detectar fácilmente el tiempo exacto en que aparece la señal (el máximo o mínimo de la derivada del atributo filtrado). El filtro EPS representa una herramienta muy útil para abordar el problema del picado automático de los primeros arribos sísmicos. Además, se propone un procedimiento para corregir los picados erróneos que nos permite aprovechar los beneficios de todo el registro analizado. Mediante este procedimiento se ajustan todos los picados traza por traza, y se pueden también descartar picados asociados con trazas malas o nulas. Como resultado, la precisión y la consistencia de los picados de primeros arribos se mejora significativamente.

Para mejorar el desempeño de los métodos cuando son aplicados a grandes volúmenes de datos y disminuir el tiempo de procesamiento, hemos introducido ciertas estrategias y mejoras. Estas mejoras incluyen: (1) el ajuste de los picados hacia el máximo (o mínimo) del lóbulo que se interpreta como primer arribo, (2) una restricción por distancia fuente-receptor para evitar procesar trazas fuera del rango de offsets de interés, (3) la propuesta de un modelo inicial de refracción para restringir en tiempo la búsqueda de los primeros arribos y favorecer la convergencia de los métodos hacia picados correctos, y (4) la corrección estática por elevación para mejorar la definición de las rectas que se ajustan en los distintos pasos de la técnica de corrección de picado erróneos.

Los métodos propuestos son robustos ante datos ruidosos y proveen picados precisos y coherentes, incluso en presencia de ruido correlacionado, trazas malas o nulas, cambios en la forma de onda, y primeros arribos poco distinguibles. Además, los métodos son computacionalmente eficientes y fáciles de aplicar, ya que el usuario tiene que seleccionar sólo dos o tres parámetros según el atributo utilizado. La mayoría de los parámetros se ajustan en función del período de la forma de onda de los primeros arribos, lo cual es fácil de determinar mediante una rápida inspección visual de los datos, por lo que su selección es muy sencilla. Por otra parte, el análisis de sensibilidad muestra que la variabilidad de los picados es muy pequeña cuando se utilizan distintos juegos de parámetros.

Los resultados muestran que el rendimiento del MCM supera considerablemente el rendimiento del tradicional método de Coppens (COP), debido principalmente a la utilización del filtro de suavizado con preservación de bordes (EPS). El EM, por su parte, es un nuevo enfoque para resolver el picado de primeros arribos que funciona exitosamente en la mayoría de las pruebas, si bien en algunos casos tiende a detectar la llegada de 
la señal algunas muestras antes o después de la llegada real. El FDM produce resultados muy consistentes y supera las debilidades de otros métodos basados en fractales anteriormente publicados.

En general, hemos observado que el MCM es muy eficaz para captar los primeros arribos cuando estos presentan características impulsivas con un fuerte aumento en la energía de la señal. Por otro lado, el FDM ofrece excelentes resultados cuando se lo aplica a datos de Vibroseis, donde los otros métodos tienden a ser menos eficaces. Sin embargo, dado que los tres métodos funcionan muy bien y que son computacionalmente eficientes, se recomienda aplicar los tres métodos y seleccionar aquel que otorgue los mejores resultados. 


\section{Capítulo 4}

\section{Detección automática de fases de terremotos}

Como hemos comentado en la Introducción General, existe cierta similitud entre el problema dado por el picado automático de primeros arribos en sísmica de exploración y la detección automática de fases de terremotos en sismología. En este capítulo, vamos a aprovechar los métodos y técnicas desarrolladas en el capítulo anterior y adaptar los algoritmos desarrollados para que sean aplicables a datos de terremotos. Además, vamos a analizar algunos de los métodos más reconocidos para realizar esta tarea, y sugerir algunas modificaciones a los mismos para poder contar así con una batería de métodos de detección de fases que puedan ser analizados y comparados mediante datos reales.

Uno de los mayores problemas de los métodos de picado automático de fases de terremotos es el de los picados falsos. En este trabajo vamos a diferenciar dos clases de picados falsos. Definimos como falsas alarmas a aquellas detecciones de algún evento que no están relacionadas a un sismo (por ejemplo, detecciones que ocurren antes de la llegada de las ondas primarias o mucho después de la coda), y llamaremos falsas fases a aquellas fases picadas luego de la llegada de las fases primarias de un sismo, pero que no logramos asociar a ninguna fase teórica. Esta distinción cobra importancia para aquellas estaciones donde se realizan estudios de sismicidad. En dichos estudios se intenta acotar el número de las falsas alarmas, procurando paralelamente no perder sensibilidad en la detección de eventos reales. Para definir entonces los picados falsos, dada una fase detectada mediante algún método automático que no se corresponda con el tiempo de alguna de las fases obtenidas mediante la lectura de bandas, se debe corroborar primero que el tiempo detectado no coincida (aproximadamente, con cierta tolerancia) con el tiempo de arribo de alguna fase teórica no distinguida por el analista al leer la banda. Si esto efectivamente no ocurre, dicha detección automática representa un picado falso.

La mayoría de los métodos nuevos que aparecen en la literatura suelen ser validados mediante la comparación contra métodos convencionales, pero no contra métodos menos difundidos o más recientes. Se han publicado también diversos trabajos en donde, además de presentar eventualmente nuevas estrategias, se realizan algunas recopilaciones 
y comparaciones de los métodos convencionales preexistentes [7, 72, 32].

Es claro que el desempeño de un dado método está ligado no sólo a la calidad de los datos (generalmente caracterizada por la relación señal-ruido), sino también a las diferentes características de los mismos. Desafortunadamente, resulta dificultoso hallar trabajos en los que se comparen y analicen diferentes métodos en función de las características del dato inspeccionado de manera de servir de guía a un sismólogo o analista a la hora de discernir qué método de picado automático utilizar para procesar los datos con los que cuenta.

Con la motivación de lo recién expuesto, hemos seleccionado once registros de terremotos adquiridos en la Estación Sismológica de La Plata (LPA). Los registros contienen terremotos regionales y telesísmicos con distancias epicentrales mayores a $1000 \mathrm{~km}$ y magnitudes mayores a $6(\mathrm{Mw})$. Hemos utilizado este conjunto de datos para analizar y comparar ocho métodos de picado de fases de terremotos, incluyendo métodos convencionales, no convencionales, y variaciones de métodos preexistentes propuestas en este trabajo. Entre ellos, testeamos tres métodos convencionales: el método presentado por Allen [6], aquel introducido por Baer y Kradolfer [9], y el método de Earle y Shearer [21]; dos métodos basados en modificaciones a estos mismos métodos (que llamaremos método de Allen modificado y método de Baer y Kradolfer modificado); y por último tres adaptaciones a los métodos presentados en el capítulo anterior que han resultado ser muy útiles en el picado de primeros arribos en exploración sísmica: el método de Coppens modificado, el método de la entropía, y el método de la dimensión fractal, todos ellos presentados por Sabbione y Velis [54].

Este estudio tiene también por objetivo brindar herramientas a la Estación Sismológica de La Plata que permitan la detección de fases de terremotos de manera automática. De esta manera, se pueden aprovechar la consistencia y la rapidez que se obtienen al realizar esta tarea de forma automática. Paralelamente, el conjunto de métodos de picado de fases generado podría utilizarse para realizar estudios de sismicidad en regiones de interés, que suelen involucrar un gran volumen de datos, y para los que la detección automática de eventos resulta primordial. En particular, este sería el caso del sistema de Fallas Magallanes-Fagnano en la Provincia de Tierra del Fuego, donde el Departamento de Sismología de La Plata cuenta con una serie de estaciones permanentes y personal que realiza monitoreo continuo de los registros de los mismas [55, 13].

Los resultados obtenidos con los ocho métodos de picado automático son analizados 
a partir de diferentes enfoques. Se estudia primero la capacidad de los métodos para detectar las fases leídas en las bandas. Uno de los resultados más interesantes que arroja la aplicación de los métodos es la detección de algunas fases reales originalmente omitidas por el analista. Además, para complementar el análisis de las detecciones, se calcula también el número de picados falsos obtenidos. Este análisis, junto con el estudio estadístico de los errores en los picados, nos permite recomendar cuáles de los métodos aquí presentados serían más aptos para realizar el picado automático de fases de terremotos de forma sistemática en estudios sismológicos de gran escala, o bien para realizar estudios continuos de sismicidad que requieren el procesamiento de un gran volumen de datos.

\subsection{Métodos utilizados}

En esta sección realizamos una muy breve descripción de los métodos utilizados en el presente trabajo. Para un análisis más minucioso de los mismos, se citan las referencias de aquellos artículos en donde los métodos fueron presentados. En algunos casos, describimos las mejoras propuestas en forma detallada.

Cualquier método de picado automático requiere que el usuario seleccione y fije un determinado número de parámetros para su aplicación. Esta selección representa un punto crucial en la detección de fases de eventos mediante algoritmos computacionales. Si los parámetros no son elegidos de manera adecuada, los métodos tenderán a fallar. Asimismo, si los resultados que se obtienen fueran muy dependientes de la selección de los parámetros, se deberá tener especial cuidado en su selección. Por ello, cabe resaltar que los métodos más robustos serán aquellos para los que se precise seleccionar el menor número de parámetros y cuyos resultados sean poco dependientes de dicha selección.

Para fijar los parámetros de los métodos se suelen considerar características de amplitud y tiempo de la señal, su contenido espectral, relación señal-ruido, etc. Por su parte, estas características están relacionadas con la distancia epicentral y profundidad del foco del terremoto, la magnitud, la geología local, el ruido de la estación, las características del instrumento, etc. Dado que la estación LPA está ubicada en una región con sismicidad local moderada a baja, los datos seleccionados corresponden a terremotos regionales y telesísmicos de diferentes características. Uno de los mayores desafíos en este trabajo se debe justamente a que al ser los datos tan disímiles, la selección de los parámetros para cada método resulta muy delicada. Al final de esta sección se incluye una tabla (Tabla 
1) donde se resumen los valores para los distintos parámetros de cada método descrito a continuación.

Antes de comenzar con la descripción particular de cada método, debemos mencionar que el primer paso de todos los algoritmos consiste en remover la componente continua de la señal y normalizar la amplitud de los registros a $(-1,1)$. De esta manera homogeneizamos la escala vertical del dato de entrada en todos los métodos y facilitamos la elección de los parámetros.

\subsubsection{Método de Allen (RAM)}

El método presentado por Allen [6], que llamaremos RAM (Rex Allen method), representó en su momento un gran avance en el picado de fases de terremotos mediante algoritmos computacionales. La función característica utilizada por Allen está dada por:

$$
C F_{i}=s_{i}^{2}+C_{i}\left(s_{i}-s_{i-1}\right)^{2}
$$

donde $s_{i}$ representa el sismograma, $i=1,2, \ldots, N$ es el número de muestra y $C_{i}$ es un factor de peso que vincula los dos términos que definen $C F_{i}$, el primero relacionado con la amplitud de la señal y el segundo indirectamente relacionado con su frecuencia. Tanto Baer y Kradolfer [9] como Küperkoch et al. [31] sugieren elegir

$$
C_{i}=\frac{\sum_{j=1}^{i}\left|s_{j}\right|}{\sum_{j=1}^{i}\left|s_{j}-s_{j-1}\right|},
$$

de manera de darle peso similar al término que depende de la amplitud y al que depende de la frecuencia.

A continuación, se calculan el short term average (STA) y el long term average (LTA) mediante:

$$
\begin{aligned}
& S T A_{i}=S T A_{i-1}+C_{3}\left(C F_{i}-S T A_{i-1}\right) \\
& L T A_{i}=L T A_{i-1}+C_{4}\left(C F_{i}-L T A_{i-1}\right)
\end{aligned},
$$

donde $C_{3}$ y $C_{4}$ son constantes que controlan el tamaño de las ventanas de los promedios $S T A$ y $L T A$. El algoritmo declara un evento cuando

$$
S T A_{i}>T H R L T A_{i}
$$


donde THR es una constante umbral (threshold) que determina la sensibilidad del método. Como hemos adelantado, luego de la descripción de los métodos, detallamos la elección de este y de los otros parámetros del RAM, como así también de los distintos parámetros de los otros métodos descritos a continuación (ver Tabla 4.1). Por último, en el RAM se define un "criterio de continuación" para determinar cuándo el evento ha finalizado [6].

\subsubsection{Método de Baer y Kradolfer (MBK)}

Baer y Kradolfer [9] introducen la función $E_{i}^{2}$, que es similar a la función característica utilizada en el RAM:

$$
E_{i}^{2}=s_{i}^{2}+\frac{\sum_{j=1}^{i} s_{j}^{2}}{\sum_{j=1}^{i}\left(s_{j}-s_{j-1}\right)^{2}}\left(s_{i}-s_{i-1}\right)^{2} .
$$

Además, exponen motivos para modificar el criterio STA/LTA y en su lugar realizan el picado a partir de la variable estadística normalizada de $E_{i}^{4}$

$$
B K_{i}=\frac{E_{i}{ }^{4}-\overline{E_{i}{ }^{4}}}{\sigma\left(E_{i}^{4}\right)} .
$$

Cabe mencionar aquí que en la expresión presentada por Baer y Kradolfer se utiliza la varianza de $E_{i}^{4}$ en el denominador de la ecuación 4.6 en lugar de su dispersión. Hemos introducido esta pequeña modificación en la expresión original pues obtuvimos mejores resultados con la inclusión de este cambio.

Finalmente, en el método de Baer y Kradolfer (BKM), los eventos se declaran si $B K_{i}$ supera el umbral $T H R$ y sólo son aceptados si esta situación se mantiene por un tiempo mayor a $T_{u p}$ y no se interrumpe por un tiempo mayor a $T_{\text {down }}$, caso contrario el evento se rechaza. El objetivo de $T_{u p}$ y $T_{\text {down }}$ es evitar tanto las falsas alarmas por cortos incrementos en $B K_{i}$ como el rechazo de eventos reales por breves disminuciones abruptas, respectivamente.

\subsubsection{Método de Earle y Shearer (ESM)}

En el tercer y último método "convencional" que presentamos, Earle y Shearer [21] utilizan la envolvente de la señal como función característica: 


$$
E_{i}=\sqrt{s_{i}^{2}+\widehat{s}_{i}^{2}}
$$

donde $\widetilde{s}_{i}$ es la transformada de Hilbert de $s_{i}$.

Luego, se definen dos ventanas de tiempo consecutivas de tamaño $T_{S T A}$ y $T_{L T A}$ para el cálculo de $S T A$ y $L T A$ y se calcula su cociente muestra a muestra, asignándolo a la primera muestra de la ventana más adelantada en tiempo, que corresponde a $S T A$. Para suavizar este cociente y así prevenir las rápidas fluctuaciones, en lugar de utilizar los parámetros $T_{u p}$ y $T_{\text {down }}$ como en el BKM, Earle y Shearer optaron por aplicar un filtro pasa-bajos de Hanning de longitud $T_{H a n}[21]$. Esta idea resulta muy útil y la utilizaremos más adelante en los nuevos métodos propuestos. En el método de Earle y Shearer (ESM) los eventos se declaran cuando el cociente suavizado supera un dado umbral THR. La fase es picada en el punto de inflexión inmediatamente anterior el máximo de este cociente suavizado.

\subsubsection{Método de Coppens modificado adaptado (MCM)}

En el método de Coppens modificado adaptado (MCM), que está basado en el método presentado en Sabbione y Velis [54] y que describimos extensamente en el capítulo previo, la función característica utilizada es la energía de la señal. Si bien no es estrictamente un método del tipo STA/LTA porque no se calculan promedios, el esquema es muy similar. Se definen dos ventanas móviles anidadas, una de longitud $T_{C_{1}}$ que intenta capturar el carácter presente de la señal, y una segunda ventana de longitud mayor a la primera, que a diferencia del trabajo original de Coppens [19] y al capítulo anterior hemos considerado de longitud fija $T_{C_{2}}$, y que pretende caracterizar el ruido de fondo del dato. Dicho cociente de energías, $E R_{i}$, es entonces calculado muestra a muestra mediante:

$$
E R_{i}=\frac{\sum_{j=i-N_{C_{1}}+1}^{i} s_{j}^{2}}{\sum_{j=i-N_{C_{2}}+1}^{i} s_{j}^{2}},
$$

donde $N_{C_{1}}$ y $N_{C_{2}}$ son el número de muestras que corresponden a las ventanas $T_{C_{1}}$ y $T_{C_{2}}$, respectivamente. El cociente de energías es asignado a la última muestra de las ventanas. Claramente, ante el arribo de una señal impulsiva, este cociente de energías presentará un rápido aumento que se acercará al valor 1 . 
De la misma manera que en Sabbione y Velis [54], aplicamos a $E R_{i}$ un filtro EPS (edge preserving smoothing) [34] de longitud en tiempo $T_{E P S}$ para resaltar los cambios bruscos. Finalmente, las fases son picadas en aquellas muestras donde el valor de la derivada de la resultante del filtro supera el umbral $T H R$.

\subsubsection{Método de la entropía adaptado (EM)}

En el método de la entropía (EM) se introduce la entropía de una serie de tiempo [20] como un atributo sísmico. Recordemos ahora las ecuaciones 3.4 y 3.5 del capítulo anterior, pero cambiando la notación para hacerla consistente con el resto del presente capítulo. La entropía se obtiene entonces mediante:

$$
H_{i}=\log \left(L_{i} / t_{i}\right)
$$

donde $L_{i}$ es la "longitud" de la curva al tiempo $t_{i}$. Dado que la entropía se calcula en una ventana de longitud temporal $T_{H}$ (equivalente, digamos, a $N_{H}$ muestras) que se mueve muestra a muestra a lo largo de la traza, la expresión que resulta para $H_{i}$ es:

$$
H_{i}=\log \left(\frac{1}{N_{H}} \sum_{j=i-N_{H}}^{i}\left|s_{j}-s_{j-1}\right|\right) .
$$

Este atributo tiende a aumentar rápidamente ante el advenimiento de la señal en un contexto ruidoso. En esta aplicación, hemos introducido una leve variación respecto del método publicado en Sabbione y Velis [54] y detallado en el capítulo anterior. Obtuvimos mejores resultados filtrando la entropía $H_{i}$ mediante la convolución con una ventana de Hanning de longitud $T_{H a n}$ de la misma manera que en el ESM. Luego, al igual que en el MCM, aplicamos un filtro EPS, y tomamos su derivada para picar las fases en aquellas muestras que superen un dado umbral THR.

\subsubsection{Método de la dimensión fractal adaptado (FDM)}

El método de la dimensión fractal (FDM) es otro método que resultó ser muy útil para picar primeros arribos sísmicos. Los detalles de la versión aquí usada del algoritmo pueden encontrarse en Sabbione y Velis [54] y fueron ampliamente discutidos en el capítulo previos. 
El método se basa en la idea de considerar la serie de tiempo del dato como una curva fractal en el plano [36]. Como tal, se puede extraer su dimensión fractal mediante diferentes métodos [69]. La dimensión fractal teórica de una serie de tiempo correspondiente a ruido blanco tiende al valor 2 , mientras que se aproxima a 1 en la presencia de señal. Aquí se calcula la dimensión fractal de la curva a partir del "método del variograma" [69, 51]. El método se resume brevemente a continuación.

El primer paso consiste en sumar ruido blanco de muy baja amplitud, definido por su relación señal-ruido $(S N R)$ a todo el dato. El objetivo de esto es descorrelacionar el ruido de baja amplitud presente en la estación para así diferenciar mejor su dimensión fractal de aquella que corresponde a la señal de interés. La selección de la relación señalruido $S N R$ sumada al dato es fundamental para que el método funcione correctamente. Este es un aspecto delicado del algoritmo cuyo efecto ya hemos analizado en los capítulos previos.

Una vez sumado el ruido, el variograma es calculado dentro de una ventana móvil de longitud $T_{F}$ y $N_{F}$ muestras mediante:

$$
V_{i}(h)=\frac{1}{N_{F}-h} \sum_{j=i-N_{F}+h+1}^{i}\left(s_{j}-s_{j-h}\right)^{2},
$$

para cuatro separaciones (o "retardos") diferentes $h=1,2,3,4$. Al igual que en el método anterior, cambiamos levemente la notación de la ecuación 3.9 para que sea consistente con el resto del capítulo. En esta notación, el subíndice $i$ hace alusión a la muestra en tiempo a la cual asignamos el valor del variograma.

Recordemos que la teoría de los fractales supone que existe una relación exponencial entre $h$ y $V_{i}(h)$ de la forma:

$$
V_{i}(h) \propto h^{4-2 D_{i}},
$$

donde $D_{i}$ es la dimensión fractal de la curva en la ventana considerada y asignada a la muestra $i$. Entonces, tomando logaritmo a ambos lado en la ecuación 4.12, la relación se vuelve lineal y $\operatorname{los}$ pares $\left(\log (h), \log \left[V_{i}(h)\right]\right)$ obtenidos para los 4 valores de $h$ se alinean (aproximadamente) en una recta. Ajustando dicha recta por mínimos cuadrados se obtiene su pendiente, que conforme la ecuación 4.12 será igual a $4-2 D_{i}$, y así se despeja finalmente la dimensión fractal $D_{i}$ de la ventana móvil considerada. Desplazando la ventana muestra a muestra, se obtiene $D_{i}$ punto a punto. 
Luego, al igual que en el MCM y el EM, se aplica el filtro EPS (en este caso a la dimensión fractal). Por último, teniendo en cuenta que se espera un decrecimiento en $D_{i}$ ante el arribo de la señal, se pican las fases en aquellas muestras en donde la derivada cambiada de signo de la resultante del filtro supere un dado umbral THR.

\subsubsection{Método de Allen modificado (MAM)}

A partir de haber hecho algunas pruebas con los distintos métodos aquí presentados hemos incorporado algunos cambios al algoritmo propuesto por Allen [6] y hemos desarrollado un método similar que denominamos método de Allen modificado (MAM).

La función característica elegida es la misma que en el método original, y está dada por las ecuaciones 4.1 y 4.2. En lugar de calcular los promedios $S T A$ y $L T A$ mediante las constantes $C_{3}$ y $C_{4}$ como en el método original de Allen (ver ecuaciones 4.3), aquí usamos ventanas móviles de longitud $T_{S T A}$ y $T_{L T A}$ (con $T_{S T A}>T_{L T A}$ ) para calcular $S T A$ y $L T A$, respectivamente. Dado un intervalo de muestreo constante estas longitudes equivalen a $N_{S T A}$ y $N_{L T A}$ muestras, respectivamente. Así, la función cociente $R F$ entre $S T A$ y $L T A$ se escribe, para la muestra $i$ :

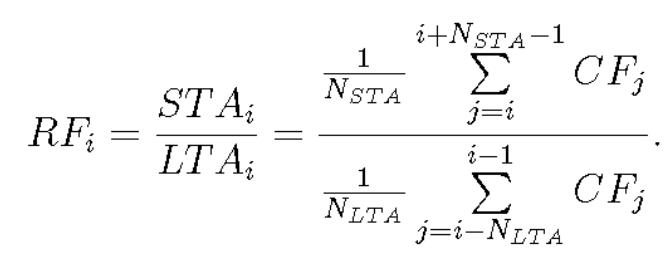

Este esquema de ventanas es el mismo al utilizado por Earle y Shearer [21] y se ilustra en la Figura 4.1b.

Diferenciándonos nuevamente del RAM, donde se utiliza un criterio de continuación para decir cuándo un determinado evento ha finalizado [6], en el MAM suavizamos la función cociente mediante una ventana de Hanning (Figura 4.1c). Luego, el evento es declarado cuando dicho cociente suavizado $(S R F)$ supera un dado umbral $T H R$, y se lo considera finalizado cuando esto deja de ocurrir. Las fases se pican en los máximos locales de $S R F$ donde el umbral es superado (Figura 4.1).

\subsubsection{Método de Baer y Kradolfer modificado (MBKM)}

El último método que presentamos aquí es el método de Baer y Kradolfer modificado (MBKM). Este método es esencialmente el mismo que el MBK, pero con una diferencia 
a)

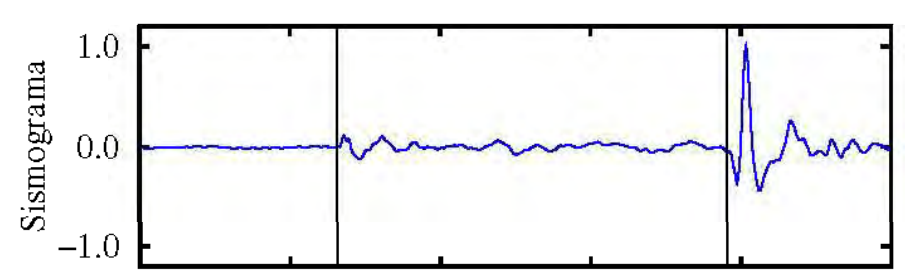

b)

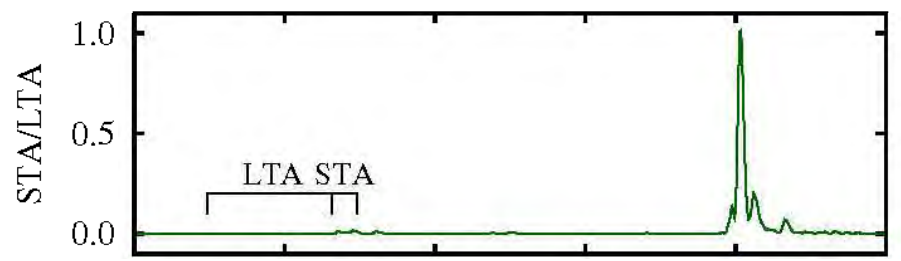

c)

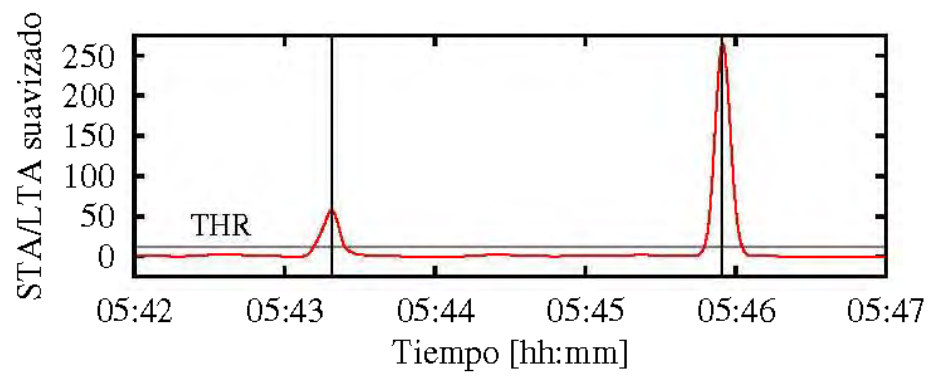

Figura 4.1: Método de Allen modificado (MAM). (a) Registro de la componente vertical de LPA. Los picados automáticos obtenidos mediante el MAM se muestran con líneas verticales negras. (b) Función característica $C F$ y esquema de ventanas para $S T A$ y $L T A$ del MAM. (c) STA/LTA suavizado por una ventana de Hanning y umbral THR (línea horizontal gris) utilizado para detectar las fases picadas (líneas verticales negras).

fundamental. En lugar de utilizar $T_{u p}$ y $T_{\text {down }}$ para evitar las rápidas fluctuaciones y así reducir las falsas alarmas y los falsos rechazos de eventos, suavizamos nuevamente con una ventana de Hanning de longitud $T_{H a n}$ (Figura 4.2). La gran ventaja de este cambio aparentemente menor, pero clave, es la reducción del número de parámetros a fijar para correr el método. De esta manera, sólo dos parámetros deben ser seleccionados para aplicar el MBKM (ver Tabla 4.1). Aclaramos por último que en el MBKM marcamos el arribo de las fases en la primera muestra para la cual se supera el umbral $T H R$, como se ve en la Figura 4.2c.

\subsubsection{Selección de parámetros}

Para completar la descripción de los métodos, enumeramos y describimos todos los parámetros utilizados en la Tabla 4.1. Los parámetros están enumerados en el orden en 
a)

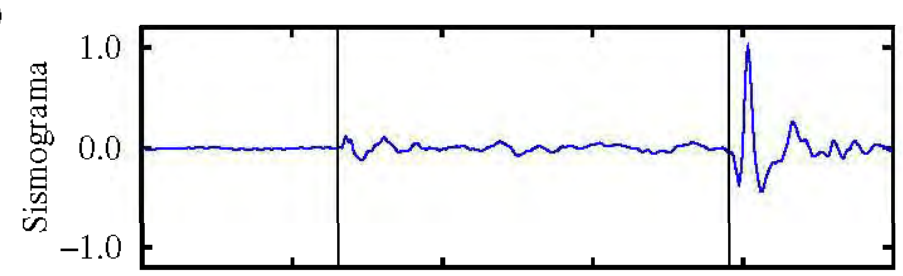

b)

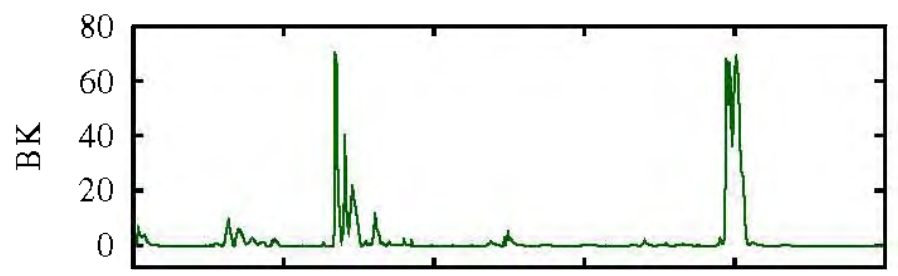

c)

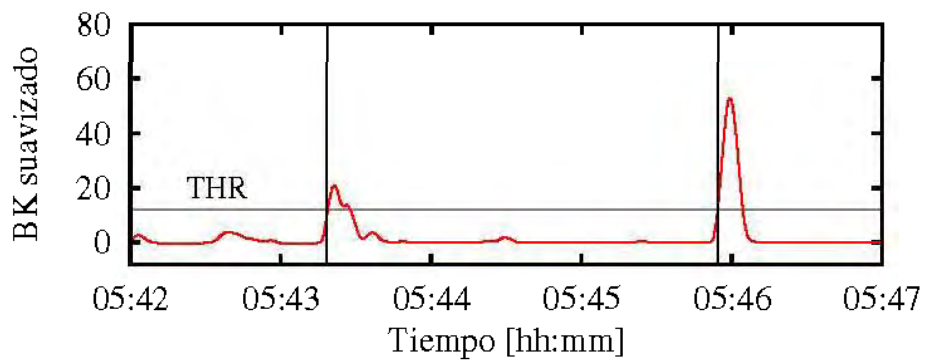

Figura 4.2: Método de Baer y Kradolfer modificado (MBKM). (a) Registro de la componente vertical de LPA. Los picados automáticos obtenidos mediante el MBKM se muestran con líneas verticales negras. (b) Función característica $C F$ del MBKM. (c) $C F$ suavizada por una ventana de Hanning y umbral THR (línea horizontal gris) utilizado para detectar las fases picadas (líneas verticales negras).

que son utilizados en el flujo de los algoritmos que implementan los distintos métodos. Las longitudes de las ventanas y de los filtros están en segundos. El resto de los parámetros, incluyendo los valores de los umbrales para declarar los eventos, son adimensionales. Notar que todos los algoritmos precisan de la elección del umbral THR, parámetro que controlará la sensibilidad del método. Por lo tanto, THR debe ser ajustado antes de procesar los datos procurando satisfacer la siguiente relación de compromiso: los algoritmos deben detectar el mayor número posible de los eventos de interés sin que se produzca un número significativo de falsas alarmas.

Debemos notar también en la Tabla 4.1 que algunos parámetros son requeridos no sólo en uno, sino en distintos algoritmos (por ejemplo, $T_{S T A}$ debe fijarse en ESM y en MAM). No obstante, esto no implica que sus valores deban ser necesariamente coincidentes, pues los mismos dependerán de las características particulares de cada algoritmo. Por último, observamos que el único parámetro que no fue fijado igual para todos los datos analizados 
es $S N R$ en el FDM, dado que este método requiere que dicho parámetro sea específica y cuidadosamente elegido para cada dato analizado.

\subsection{Datos de la Estación Sismológica de La Plata (LPA)}

En la Estación Sismológica de La Plata (LPA) se obtienen registros analógicos con un instrumento de largo período (Sprengnether) y registros digitales con un instrumento de banda intermedia (Guralp CMG 3ESPC). En la actualidad, un analista realiza la lectura de las bandas analógicas obtenidas con el instrumento Sprengnether para obtener los tiempos de arribos de las diferentes fases ante un dado evento. La información se transmite en forma codificada al ISC (International Seismological Centre, Gran Bretaña) y al NEIC-USGS (National Earthquake International Center - United States Geological Service, Estados Unidos). La Estación Sismológica de La Plata se caracteriza por realizar una exhaustiva lectura de fases secundarias. Las fases más importantes de estas lecturas correspondientes a once registros de terremotos fueron las utilizadas para poder evaluar los resultados del picado de los métodos aquí presentados. Los eventos utilizados para analizar los métodos corresponden a terremotos regionales y telesísmicos de magnitud mayor a $6(\mathrm{Mw})$ y con focos ubicados a diferentes distancias epicentrales y profundidades. Seleccionamos la componente vertical de los registros en donde a priori deberían observarse fases más claras y con mejor relación señal-ruido. Para poder contar con los registros digitales correspondientes a estas bandas se utilizaron los datos registrados en la componente vertical del sensor Guralp (CMG-3ESPC) y se los pre-procesó removiendo su respuesta de instrumento y agregando la respuesta del Sprengnether de manera de simular las bandas leídas. Este pre-proceso fue realizado mediante el Seismic Analysis Code (SAC). Teniendo en cuenta que el Sprengnether es un instrumento de largo período, el intervalo de muestro de los datos digitales generados fue fijado en 0,5 s.

Como se mencionó anteriormente, la amplitud de cada registro fue normalizada a $(-1,1)$ para preparar los datos de entrada para los métodos de picado automático. Hemos aislado registros horarios para cada sismo. Los once registros utilizados para el análisis de los métodos se observan en las Figuras 4.3 y 4.4. En estas figuras, y en la Tabla 4.2 que se presenta a continuación, puede apreciarse que los terremotos fueron seleccionados con diferente relación señal-ruido, como así también con distintas profundidades, distancias epicentrales, magnitudes, etc., como mencionamos anteriormente. 


\begin{tabular}{|c|c|c|c|}
\hline Método & Parámetro & Descripción & Valor \\
\hline RAM & $\begin{array}{c}C_{3} \\
C_{4} \\
T H R\end{array}$ & $\begin{array}{l}\text { Constante que controla } S T A \\
\text { Constante que controla } L T A \\
\text { Umbral de } S T A / L T A \text { para declarar un evento }\end{array}$ & $\begin{array}{r}0,05 \\
0,01 \\
3\end{array}$ \\
\hline BKM & $\begin{array}{c}\text { THR } \\
T_{u p} \\
T_{\text {down }}\end{array}$ & $\begin{array}{l}\text { Umbral de } C F \text { para declarar un posible evento } \\
\text { Tiempo mínimo para aceptar un evento } \\
\text { Tiempo mínimo para rechazar un evento }\end{array}$ & $\begin{array}{r}12 \\
2 \\
1\end{array}$ \\
\hline ESM & $\begin{array}{l}T_{S T A} \\
T_{L T A} \\
T_{H a n} \\
T H R\end{array}$ & $\begin{array}{l}\text { Longitud de la ventana del } S T A \\
\text { Longitud de la ventana del } L T A \\
\text { Longitud de la ventana de Hanning } \\
\text { Umbral de } S T A / L T A \text { para declarar un evento }\end{array}$ & $\begin{array}{r}5 \\
50 \\
10 \\
4\end{array}$ \\
\hline $\mathrm{MCM}$ & $\begin{array}{c}T_{C_{1}} \\
T_{C_{2}} \\
T_{H a n} \\
T H R\end{array}$ & $\begin{array}{l}\text { Longitud de la ventana } 1 \text { para de la energía } \\
\text { Longitud de la ventana } 2 \text { para la energía } \\
\text { Longitud de la ventana del filtro EPS } \\
\text { Umbral de } E R \text { para declarar un evento }\end{array}$ & $\begin{array}{r}5 \\
50 \\
10 \\
0,38\end{array}$ \\
\hline EM & $\begin{array}{c}T_{H} \\
T_{E P S} \\
T H R\end{array}$ & $\begin{array}{l}\text { Longitud de la ventana para la entropía } \\
\text { Longitud de la ventana del filtro EPS } \\
\text { Umbral de } H \text { declarar un evento }\end{array}$ & $\begin{array}{r}20 \\
5 \\
0,18\end{array}$ \\
\hline FDM & $\begin{array}{l}S N R \\
T_{F} \\
T_{E P S} \\
T H R\end{array}$ & $\begin{array}{l}\text { Relación señal-ruido del ruido sumado al dato } \\
\text { Longitud de la ventana para la dimensión fractal } \\
\text { Longitud de la ventana del filtro EPS } \\
\text { Umbral de } D \text { para declarar un evento }\end{array}$ & $\begin{array}{r}10 \circ 50 \\
50 \\
10 \\
0,20\end{array}$ \\
\hline MAM & $\begin{array}{l}T_{S T A} \\
T_{L T A} \\
T_{H a n} \\
T H R\end{array}$ & $\begin{array}{l}\text { Longitud de la ventana del } S T A \\
\text { Longitud de la ventana del } L T A \\
\text { Longitud de la ventana de Hanning } \\
\text { Umbral de } S T A / L T A \text { para declarar un evento }\end{array}$ & $\begin{array}{l}10 \\
50 \\
10 \\
12\end{array}$ \\
\hline MBKM & $\begin{array}{l}T_{\text {Han }} \\
\text { THR }\end{array}$ & $\begin{array}{l}\text { Longitud de la ventana de Hanning } \\
\text { Umbral de } C F \text { para declarar un evento }\end{array}$ & $\begin{array}{l}10 \\
12\end{array}$ \\
\hline
\end{tabular}

Tabla 4.1: Parámetros utilizados en la detección automática de fases. Las longitudes de las ventanas y de los filtros están dadas en segundos. El resto de los parámetros, incluyendo los valores de los umbrales para declarar los eventos, son adimensionales. 

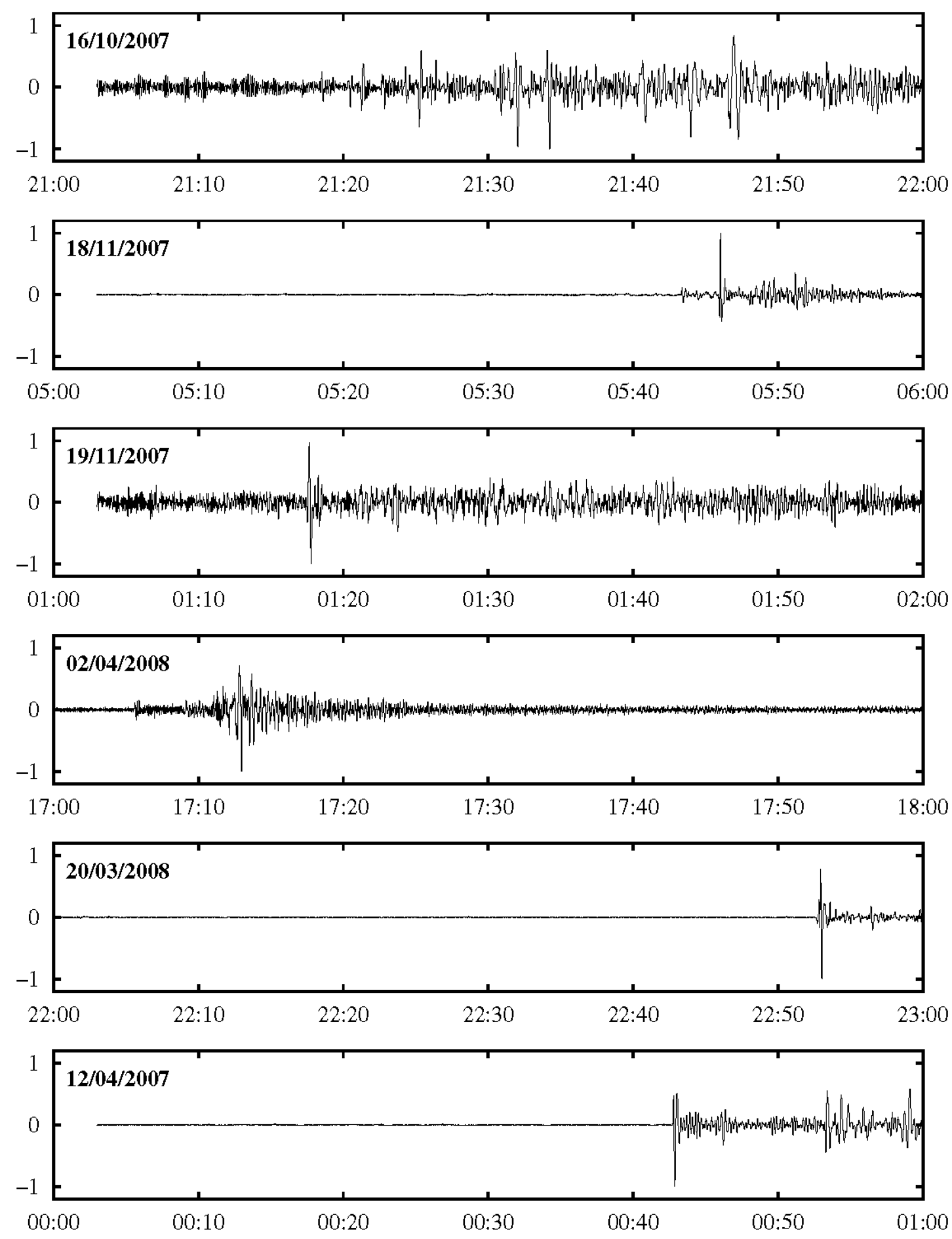

Figura 4.3: Registros de la componente vertical de LPA de los 6 primeros terremotos utilizados para analizar los métodos. En las abscisas se muestra el tiempo (UTC) y en las ordenadas la amplitud normalizada a $(-1,1)$. 

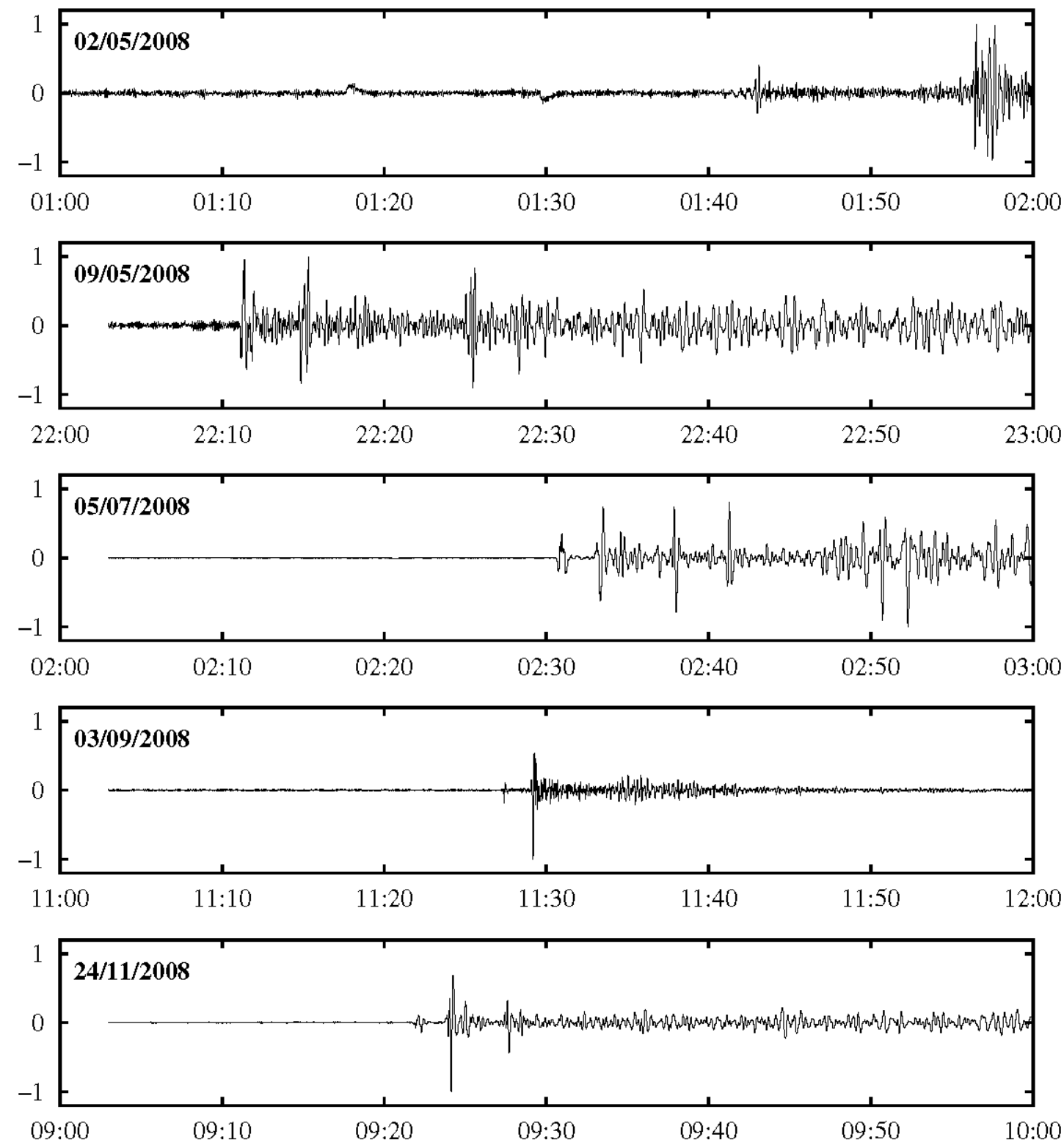

Figura 4.4: Registros de la componente vertical de LPA de los otros 5 terremotos utilizados para analizar los métodos. En las abscisas se muestra el tiempo (UTC) y en las ordenadas la amplitud normalizada a $(-1,1)$. 
En la Tabla 4.2 se resumen las características de los terremotos y las fases a picar por los métodos. El conjunto de las 30 fases que se muestran en la tabla, está compuesto por 25 fases picadas por el analista en la lectura de bandas y por otras 5 fases picadas por algunos de los métodos, pero que no fueron originalmente detectadas por el analista (en cursiva en la Tabla 4.2). Para comprobar que estas últimas fueran reales, se realizó el cálculo de los tiempos de arribo teórico utilizando el modelo de Tierra IASP91 [28]. Luego, una vez realizada esta comprobación, agregamos dichas fases originalmente no distinguidas al conjunto de fases utilizadas para analizar los métodos. Buscamos entonces picar de manera automática las 30 fases que se muestran en la Tabla 4.2. Notar que la gran mayoría de estas fases corresponden a ondas que arriban a la estación como ondas compresionales (ondas $\mathrm{P}$ ), que son aquellas que esperamos detectar con más claridad en la componente vertical de la estación, en especial para eventos regionales y telesísmicos como los estudiados.

\subsection{Análisis comparativo de los métodos}

Para evaluar los resultados de los métodos se consideraron las fases de la Tabla 4.2. No se realizó ningún tipo de restricción sobre el número de fases a picar. Esta última es una hipótesis bastante fuerte, ya que produce un mayor riesgo de picados falsos. Dado que los algoritmos no son complejos, los métodos corren muy rápido y una vez fijados los parámetros (Tabla 4.1) son muy simples de aplicar.

El primer resultado que se debe resaltar se refiere a las falsas alarmas (detección errónea de fases antes de la llegada de las ondas primarias, o posterior a la finalización de la coda). Se obtuvieron solamente un total de cuatro falsas alarmas con el método de Baer y Kradolfer (BKM) en dos registros diferentes, una falsa alarma con el método de la entropía (EM), y ninguna con los otros seis métodos analizados. Este bajo número de falsas alarmas muestra que los parámetros correspondientes fueron seleccionados de manera de no hacer los métodos demasiado sensibles, lo que a su vez brinda mayor confiabilidad respecto de los picados obtenidos.

Por otro lado, como puede apreciarse en las Figuras 4.3 y 4.4, las fases de los dos terremotos ocurridos en Argentina (los dos más cercanos), es decir, las fases P y S del terremoto de Jujuy del 18 de noviembre de 2007, y las fases P y sP del terremoto de Santiago del 3 de septiembre de 2008, son muy claras y fácilmente detectables. Para 


\begin{tabular}{|c|c|c|c|c|c|c|}
\hline Día & Región & $\Delta$ & $Z_{f}$ & $M_{w}$ & Fases & $t_{o b s} / t_{c a l}$ \\
\hline \multirow[t]{4}{*}{$16 / 10 / 2007$} & \multirow[t]{4}{*}{ Islas Fiji } & \multirow[t]{4}{*}{10982} & \multirow[t]{4}{*}{509} & \multirow[t]{4}{*}{6,6} & $\mathrm{pP}$ & $21: 20: 22$ \\
\hline & & & & & $\mathrm{PP}$ & $21: 22: 35$ \\
\hline & & & & & pPKiKP & $21: 25: 07$ \\
\hline & & & & & $P S$ & $21: 31: 50$ \\
\hline \multirow[t]{2}{*}{$18 / 11 / 2007$} & \multirow[t]{2}{*}{ Jujuy, Argentina } & \multirow[t]{2}{*}{1585} & \multirow[t]{2}{*}{246} & \multirow[t]{2}{*}{6,0} & $\mathrm{P}$ & $05: 43: 22$ \\
\hline & & & & & $\mathrm{S}$ & $05: 45: 54$ \\
\hline $19 / 11 / 2007$ & Islas Fiji & 11215 & 558 & 6,3 & $\mathrm{SP}$ & $01: 17: 29$ \\
\hline \multirow{2}{*}{$04 / 02 / 2008$} & \multirow[t]{2}{*}{ Tarapaca, Chile } & \multirow[t]{2}{*}{2020} & \multirow[t]{2}{*}{35} & \multirow[t]{2}{*}{6,3} & $\mathrm{P}$ & $17: 05: 34$ \\
\hline & & & & & $\mathrm{S}$ & $17: 09: 01$ \\
\hline \multirow[t]{3}{*}{$20 / 03 / 2008$} & \multirow[t]{3}{*}{ Xinjiang, China } & \multirow[t]{3}{*}{16344} & \multirow[t]{3}{*}{10} & \multirow[t]{3}{*}{7,2} & PKPdf & $22: 52: 38$ \\
\hline & & & & & pPKPbc & $22: 52: 49$ \\
\hline & & & & & $S K i K P$ & $22: 56: 20$ \\
\hline \multirow[t]{2}{*}{$12 / 04 / 2008$} & \multirow[t]{2}{*}{ Islas Macquire } & \multirow[t]{2}{*}{9405} & \multirow[t]{2}{*}{16} & \multirow[t]{2}{*}{7,1} & $\mathrm{P}$ & $00: 42: 45$ \\
\hline & & & & & SKSac & $00: 53: 08$ \\
\hline $02 / 05 / 2008$ & Islas Aleutianas & 14935 & 14 & 6,6 & $\mathrm{SKPbc}$ & $01: 56: 21$ \\
\hline \multirow[t]{2}{*}{$09 / 05 / 2008$} & \multirow[t]{2}{*}{ Islas Marianas } & \multirow[t]{2}{*}{16749} & \multirow[t]{2}{*}{76} & \multirow[t]{2}{*}{6,8} & PKPdf & $22: 11: 07$ \\
\hline & & & & & $\mathrm{PP}$ & $22: 14: 47$ \\
\hline $05 / 07 / 2008$ & Rusia & 16821 & 632 & 7,7 & PKPdf & $02: 30: 40$ \\
\hline & & & & & $\mathrm{pPKP}$ & $02: 32: 58$ \\
\hline & & & & & pPKiKP & $02: 33: 16$ \\
\hline & & & & & SKIKS & $02: 36: 48$ \\
\hline & & & & & $s P P$ & $02: 37: 57$ \\
\hline & & & & & sPPP & 02:41:05 \\
\hline $05 / 07 / 2008$ & Santiago, Argentina & 1036 & 569 & 6,3 & $\mathrm{P}$ & $11: 27: 26$ \\
\hline & & & & & $\mathrm{sP}$ & $11: 29: 06$ \\
\hline $05 / 07 / 2008$ & Rusia & 16722 & 492 & 7,3 & PKPdf & $09: 21: 47$ \\
\hline & & & & & PKP & $09: 21: 53$ \\
\hline & & & & & pPKP & $09: 23: 50$ \\
\hline & & & & & $p P K P$ & 09:23:54 \\
\hline & & & & & $p P K S$ & 09:27:28 \\
\hline
\end{tabular}

Tabla 4.2: Datos de los terremotos seleccionados y los tiempos observados (o calculados) de las 30 fases utilizadas para analizar los métodos. La distancia epicentral $\Delta$ y la profundidad de foco $Z_{f}$ están en $\mathrm{Km}$, la magnitud momento $M_{w}$ es adimensional y los tiempos están en hh:mm:ss. Las 5 fases que se muestran en cursiva son aquellas sólo detectadas por algunos de los métodos, y cuyos arribos teóricos fueron calculados mediante el modelo IASP91. 


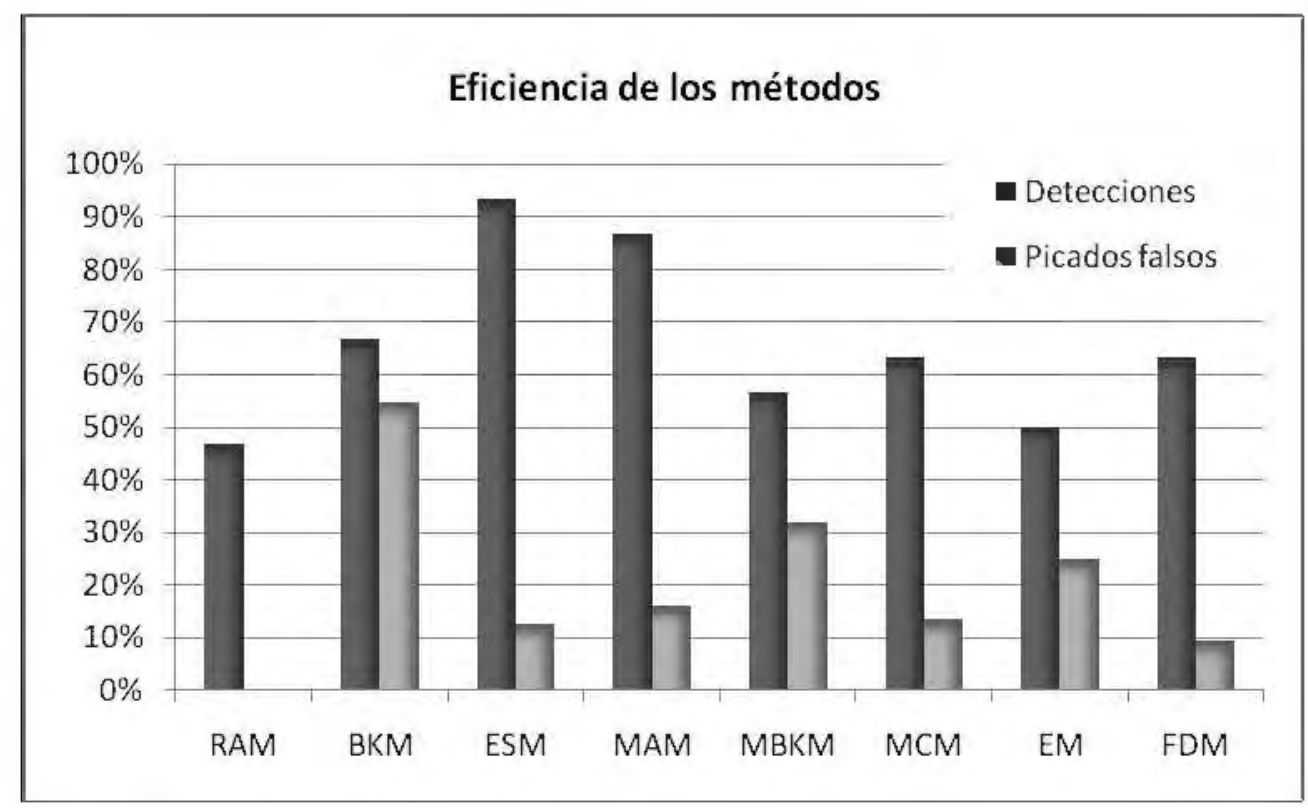

Figura 4.5: Eficiencia de los métodos. Las barras negras muestran el porcentaje de detecciones correctas y las barras grises el porcentaje de picados falsos para cada método.

estos dos eventos, como se esperaba, todos los métodos detectaron sus dos fases, sin ningún picado falso, con una sola excepción dada por el BKM, que en el terremoto de 2007 generó un único picado falso. Los resultados obtenidos para los registros de estos dos sismos muestran que los parámetros fueron seleccionados de manera tal de asegurar que se detecten correctamente las fases claras.

Para evaluar la eficiencia de los métodos calculamos el porcentaje de detecciones acertadas frente al total de las 30 fases a picar. Junto con este valor, calculamos también el porcentaje de picados falsos generados frente al total de picados realizados por cada método. Si bien debemos mencionar que el número total de fases analizadas no es muy grande, la muestra es suficiente para realizar el presente análisis cualitativo de los métodos. Estos resultados, resumidos en la Figura 4.5, nos indican la eficiencia de los métodos, puesto que brindan información sobre qué tan adecuados resultan para detectar fases reales sin generar picados falsos.

En primer lugar, vemos que a excepción del BKM, los métodos presentan un porcentaje de picados falsos que no supera el $32 \%$. Esta cota responde a que los parámetros fueron ajustados con el mismo criterio para todos los métodos: obtener un porcentaje alto de detecciones, pero intentando al mismo tiempo acotar los picados falsos.

Podemos ver también en la Figura 4.5 que el RAM no realiza ningún picado falso. 
Esto se debe principalmente a que la $C F$ que utiliza el método, dada por las ecuaciones 4.1 y 4.2 , es muy apropiada para detectar la llegada de señal, incluso en entornos ruidosos. El RAM resulta entonces un método muy fiable cuando detecta algún evento. No obstante, el porcentaje total de detecciones obtenido con este método es uno de los más bajos (menos del $50 \%$ de las fases a picar). Esto ocurre a causa del complicado "criterio de continuación" del método, ya que una vez detectado un evento, al algoritmo suele interpretar que continúa en la coda y no se pican fases posteriores a la P. El criterio de continuación del RAM debería ser eventualmente adaptado en diferentes estaciones sismológicas. Esta es la motivación por la cual aquí presentamos el método de Allen modificado (MAM).

Contrariamente al RAM, el BKM, que es el segundo método convencional aquí analizado, es el método que mayor porcentaje de picados falsos genera. Sin embargo, cabe destacar que presenta un porcentaje de detecciones relativamente bueno (cerca del 67\%). El elevado porcentaje de picados falsos se debe al criterio adoptado en Baer y Kradolfer [9] para decidir cuándo validar un evento y cuándo descartarlo (a partir de los parámetros $T_{u p}$ y $\left.T_{\text {down }}\right)$. Por esta razón es que intentamos en este trabajo mejorar dicho método e introducir el Método de Baer y Kradolfer modificado (MBKM), como ya fue mencionado.

Se destaca también en la Figura 4.5 el alto porcentaje de fases detectadas por el ESM y por el MAM, cercano al 90\% (en promedio pican 27 de las 30 fases analizadas). El ESM y el MAM resultan ser los más eficientes a la hora de detectar fases de terremotos. Además, los dos métodos generan un porcentaje relativamente pequeño de picados falsos (15\%, aproximadamente). Contrariamente, y a pesar del intento de mejora introducido, el desempeño del MBKM no se destaca por sobre la media de los otros métodos analizados.

Por último, y respecto de los tres métodos desarrollados originalmente para detectar primeros arribos en procesamiento de exploración sísmica (MCM, EM, y FDM) y que hemos adaptado para datos de sismología, observamos que el MCM y el FDM funcionan ligeramente mejor que el EM. Ambos pican algo más que el $60 \%$ de las fases, y además generan alrededor de $10 \%$ de picados falsos solamente. Sin embargo, este desempeño es inferior al del ESM y al del MAM, especialmente en cuanto al porcentaje de detecciones correctas. Interpretamos estos resultados como relativos a la dificultad de adaptar métodos de picado de primeros arribos sísmicos para detectar fases de terremotos.

Como ya hemos mencionado, algunos de los métodos arrojaron cinco tiempos de fases que no habían sido observadas por el analista, pero que mediante el uso del modelo 


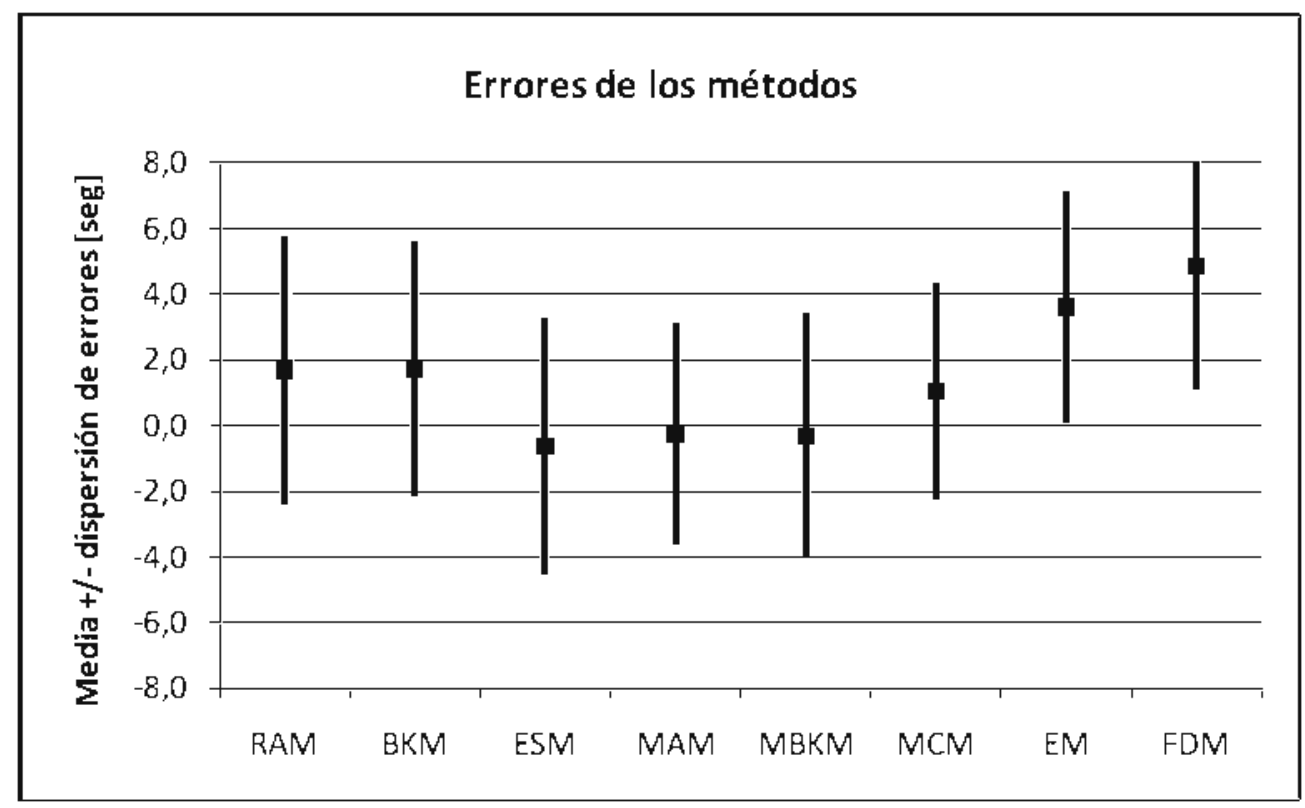

Figura 4.6: Errores de los diferentes métodos. Los cuadrados negros representan las medias de los errores: los valores positivos son retrasos en el picado y los negativos adelantos. Las barras representan las magnitudes de las respectivas dispersiones.

IASP91 corroboramos que se debían efectivamente a fases reales, y no a falsas alarmas. De este interesante resultado, debemos destacar que el ESM y el MAM son los métodos que reconocieron la mayoría de estas fases, ya que ambos detectaron cuatro de estos cinco casos.

Analicemos ahora los resultados desde un punto de vista estadístico a partir de los errores en los picados. Para estimar entonces la exactitud y la precisión de los métodos, se calcularon los errores en el picado de las 25 fases que fueron observadas por el anatista tomando como referencia los tiempos que se encuentran en la Tabla 4.1. En este análisis no se incluyeron las 5 fases que no habían sido observadas por el analista. Si bien sus errores se podrían haber calculado a partir de los tiempos de arribo obtenidos mediante el modelo IASP91, este modelo los contempla los efectos de sitio de la Estación Sismológica de La Plata, y esto habría sesgado los resultados.

Como es sabido, la media $\mu$ de los errores es un indicador de la exactitud de los métodos, y la dispersión $\sigma$ es un indicador de su precisión. En la Figura 4.6 se muestran las medias de los errores y el intervalo $(\mu-\sigma, \mu+\sigma)$ que ilustran el comportamiento estadístico de los errores.

Es notable la similitud de las dispersiones de los errores de todos los métodos, ya 
que para los ocho métodos analizados se encuentran dentro del intervalo $3,2-4,0 \mathrm{~s}$. $\mathrm{Si}$ bien estos valores son bastante altos, hay que tener en cuenta que estamos trabajando con dos muestras por segundo, y que además estamos considerando absolutamente todos los errores de las fases picadas en los cálculos, algunos de ellos bastante grandes, y que provocan un aumento significativo en la dispersión.

Respecto de la exactitud de los picados (dada por las medias de los errores), observamos que el EM y el FDM tienden a atrasarse en los picados cerca de $4 \mathrm{~s}$ (8 muestras), que es un valor demasiado alto. Como se ha propuesto en otros trabajos, esto es fácilmente solucionable incorporando un adelanto adecuado en los algoritmos para los tiempos picados. Sin embargo, para confiar en este procedimiento, resultaría necesario contar con un mayor volumen de datos.

El RAM y el BKM también tienden a atrasarse un poco en sus picados (algo más de $1,5 \mathrm{~s})$, que no obstante, es un error por demás aceptable. Por otro lado, el resto de los métodos (ESM, MAM, MBKM, y MCM), presentan una media de errores de picado muy pequeña, en general menor a 1 s en valor absoluto. Si tenemos en cuenta que esto equivale solamente a dos muestras, podemos afirmar que estos resultados son muy alentadores. En particular, el ESM y el MAM, además de ser métodos bastante eficientes a la hora de detectar eventos, son métodos bastante exactos para picar las fases.

\subsection{Conclusiones del capítulo}

Se presentaron y analizaron ocho métodos para realizar picado automático de fases internas de terremotos. Entre ellos, tres son convencionales y ya han sido ampliamente usados y estudiados: el método de Rex Allen (RAM), el método de Baer y Kradolfer (BKM), y el método de Earle y Shearer (ESM). Dos métodos fueron generados para este trabajo a partir de los métodos convencionales: el método de Rex Allen modificado (MAM), y el método de Baer y Kradolfer modificado (MBKM). Y por último, tres métodos que fueron originalmente desarrollados para detección de primeros arribos sísmicos, fueron adaptados en este trabajo para realizar picado de fases de terremotos: el método de Coppens modificado (MCM), el método de la entropía (EM), y el método de la dimensión fractal (FDM). Para analizar y comparar los métodos, se utilizaron once registros de una hora de duración adquiridos en la Estación Sismológica de La Plata (LPA). Estos registros corresponden a eventos de distancias epicentrales superiores a $1000 \mathrm{~km}$, magnitud mayor 
a $6(\mathrm{Mw})$, y diversas profundidades de foco.

La aplicación de los métodos es muy simple, y dado que son relativamente sencillos, los tiempos de procesamiento son muy pequeños. La única dificultad para implementar los métodos reside en seleccionar un número determinado de parámetros de forma adecuada, que dependiendo del método, oscila entre dos y cuatro solamente. Los resultados obtenidos con todos los métodos son los esperados en relación a las características de los datos picados, si bien algunos presentan un desempeño superior a otros.

Los picados falsos obtenidos se debieron en su gran mayoría a falsas fases en la coda de los eventos, y no así a falsas alarmas antes de que llegue la señal o luego de la coda, lo que indica que los métodos presentados son apropiados para realizar futuros estudios de sismicidad. Desde el punto de vista estadístico, si bien todos los métodos exhibieron precisiones muy similares y razonables teniendo en cuenta los datos utilizados, las dispersiones de los picados son algo mayores a lo deseado. Por ello, sería conveniente agregar un último paso a los algoritmos de picado para refinarlos y lograr así resultados más precisos. Este proceso podría incluir, por ejemplo, la búsqueda del punto de inflexión, o del máximo (o mínimo) de la señal más próximo al tiempo arrojado por el método de picado utilizado. Esto por supuesto dependerá del criterio que se adopte para definir el arribo de la fase.

Algunos de los métodos aquí presentados, en especial el método de Earle y Shearer (ESM) y el método de Allen modificado (MAM), detectaron fases internas teóricas que no habían sido observadas por el analista que originalmente realizó la lectura de las bandas. Más allá de las sabidas ventajas que ofrece el uso de métodos efectivos de picado automático en cuanto al ahorro de tiempo y recurso humano, este interesante resultado representa otro argumento a favor de su utilización en la estación sismológica LPA, donde se realiza una exhaustiva lectura de fases secundarias.

El MCM, el EM y el FDM, originalmente desarrollados para detectar un único evento (el primer arribo de los datos sísmicos), fueron correctamente adaptados para su aplicación en problemas de sismología. Sin embargo, esta adaptación resulta compleja para picar de manera exacta y precisa distintas fases y su desempeño no se destaca por sobre la media del resto de los métodos. En particular, el EM y el FDM tienden a realizar picados de fase demasiado retardados en tiempo.

El método de Allen (RAM) es un método cuyas detecciones son muy confiables puesto que no hemos observado que realice ningún picado falso. Por su parte, el ESM y el 
MAM resultan ser los más eficientes pues detectan con muy buena exactitud casi todas las fases de interés, y lo hacen generando un número muy pequeño de picados falsos. En base a estos resultados, recomendaríamos su uso en primer término para realizar el picado automático de un dado conjunto de datos. En el mismo sentido, el ESM y el MAM serían dos métodos apropiados para realizar un estudio de sismología global en la Estación Sismológica de La Plata utilizando una gran cantidad de registros. 


\section{Capítulo 5}

\section{Detección automática de eventos microsísmicos}

La detección de eventos microsísmicos es un tema de creciente interés dentro de la exploración geofísica [41]. El problema se encuentra actualmente en auge en la ingeniería de reservorios debido a su relevancia tanto en las fracturaciones por inyección hidráulica, como en producción primaria, recuperación secundaria, o en la inyección de residuos [38]. En general, podemos afirmar que los estudios de microsísmica se han establecido muy recientemente como parte de los procesos de rutina para monitorear la evolución de los reservorios. En Argentina, se ha comenzado en los últimos tiempos a realizar estudios de microsismicidad en los pozos de extracción.

El monitoreo microsísmico es usualmente llevado a cabo colocando un arreglo de geófonos multicomponentes (tri-axiales) ubicados, en general, en un pozo cercano al pozo de extracción a unos cientos de metros del mismo. Los arreglos suelen estar formados por 8 a 12 geófonos, dando lugar a registros de 24 a 36 canales, respectivamente, correspondientes a las componentes $x, y$ y $z$ de la señal polarizada. No obstante, en algunos casos se pueden usar también algunos sensores cercanos a la superficie [38]. Para realizar la localización precisa de los focos de los microsismos, es necesario conocer los tiempos de arribo de las ondas $\mathrm{P}$ y S, su polarización, y contar con modelos aproximados de velocidades que permitan resolver el problema directo con el fin de contrastar los tiempos picados con los tiempos dados por el modelo. El monitoreo de las imágenes microsísmicas a tiempo real permite además tomar decisiones en el campo mejorando el control y la efectividad de los efectos de la inyecciones hidráulicas.

En este capítulo, a partir de los resultados previos que hemos presentados en los dos capítulos anteriores $[54,50]$, testeamos y adaptamos algunos de los algoritmos desarrollados durante esta Tesis para utilizarlos para detectar señales de microsismos. Para ello, analizamos tres registros de campo cedidos por la industria y adoptamos nuevos criterios para proceder a la detección de los eventos. Los tres registros fueron seleccionados de manera que cada uno de ellos contenga un microsismo. En el primer registro, la relación señal-ruido del evento es buena, en el segundo la calidad del dato es regular, y en el 
último la relación señal-ruido es mala. De esta forma, el análisis permite realizar una valoración cualitativa de la capacidad de detección de los algoritmos frente a diferentes tipos de señales.

Aquí proponemos tres métodos de detección automática de microsismos basados en el método de Earle y Shearer (ESM), en el método de Allen modificado (MAM) y en el método de Baer y Kradolfer modificado (MBKM), todos ellos analizados y descritos en el capítulo anterior. La estrategia planteada se basa en aplicar en primer término los mencionados algoritmos para detectar eventos analizando los registros traza por traza. Como resultado de ello se obtiene cierto número de eventos para cada traza. Cada uno de estos eventos representa un potencial arribo de un microsismo en la traza analizada. Luego, se analizan los registros considerando simultáneamente la totalidad de los canales disponibles en el registro mediante una ventana móvil que avanza muestra a muestra. Atendiendo a la alineación aproximada según hipérbolas cuasi-horizontales que presentan los arribos de los eventos en los registros, los microsismos son declarados cuando dicha ventana de búsqueda contiene eventos en al menos la mitad de las trazas, en al menos una de las tres componentes. Finalmente, se determinan los tiempos de arribo correspondientes al microsismo en aquellas trazas donde fue detectado. Si bien este criterio multitraza utilizado es de gran utilidad para decidir si existe un microsismo o no, los resultados indican que es relevante generar algoritmos que detecten los eventos traza por traza con la mayor exactitud y precisión posible. Dicho de otro modo, si la detección unitraza es eficiente, un criterio multitraza sencillo que se base en los resultados del análisis traza por traza será suficiente para determinar las presencia de microsismos.

Los métodos son robustos y funcionan muy bien para el registro con datos de buena calidad; su desempeño es aceptable en el registro con relación señal-ruido moderada; y tienen dificultades para detectar el microsismo en el registro de mala calidad, lo que nos motiva para continuar en esta línea de investigación en trabajos futuros. Dos aspectos de los resultados deben destacarse. Por un lado, los tiempos de arribo obtenidos mediante el análisis traza por traza para los microsismos declarados son por lo general muy precisos. Y por otro lado, con la estrategia propuesta, debemos también remarcar que no se declaran falsos microsismos en los ejemplos analizados, lo que determina una alta fiabilidad en los microsismos detectados. 


\subsection{Datos}

Los tres registros de microsísmica que vamos a estudiar fueron adquiridos en un pozo ubicado a unos $500 \mathrm{~m}$ del pozo de extracción mediante una riestra vertical de 8 receptores con tres componentes cada uno, espaciados entre sí $30 \mathrm{~m}$. Las frecuencias esperadas en microsísmica son mayores que aquellas usualmente registradas en la sísmica convencional [41]. Por ello, los intervalos de muestreo son menores. Claramente, esto está relacionado con la menor distancia entre fuente y receptor y con las características de la fuente. Como es bien sabido, el medio funciona como un filtro pasa-bajos, y las altas frecuencias se atenúan a distancias menores que las bajas frecuencias, que pueden entonces viajar distancias mayores. De acuerdo con Shemeta y Anderson [57], considerando un valor de corte arbitrario de $5 \%$ de la máxima energía, una onda de $500 \mathrm{~Hz}$ puede observarse hasta los $572 \mathrm{~m}$. Para adquirir los datos que analizaremos, el intervalo de muestreo utilizado fue de $1 \mathrm{~ms}$, por lo que de acuerdo al criterio de Nyquist, se pueden registrar señales de hasta $500 \mathrm{~Hz}$, un valor que es coherente con la distancia entre fuente y receptor del experimento.

Si bien las velocidades en los primeros metros del subsuelo suelen ser, en general, altamente heterogéneas, supongamos por un momento que los rayos atraviesan una capa de velocidad constante. Claramente, dada la disposición espacial de la fuente de los microsismos y de los receptores, al graficar una traza al lado de la otra como se acostumbra en la sísmica de pozo, los arribos de microsísmica se deben alinear aproximadamente como una hipérbola. Es decir, en el dominio de tiempo vs. profundidad de receptor, los eventos que se alejan de esta hipérbola teórica corresponden a dispersiones y reflexiones múltiples causadas por las inhomogeneidades de velocidad en el camino del rayo. Teniendo en cuenta además que la separación entre los pozos es de un orden de magnitud mayor que el espaciamiento entre receptores, dicha hipérbola debe ser aproximadamente lineal (esto es, con alineación horizontal en los registros). A pesar de que estas consideraciones son triviales, es importante enfatizarlas porque justifican la estrategia de detección de microsismos que explicaremos más adelante.

Los registros de microsísmica son adquiridos de forma continua a partir del momento en que se realiza la inyección hidráulica y la registración puede durar hasta algunas horas. No obstante, los datos se suelen almacenar en períodos de tiempo pequeños, del orden de $10 \mathrm{~s}$, por ejemplo. Esto es, para intervalos de muestreo de $1 \mathrm{~ms}$ como los de la campaña 
en la que se adquirieron los datos utilizados en este capítulo, cada traza por cada registro tendrá del orden de mil muestras. Para testear los métodos desarrollados en esta Tesis, se separaron registros de $1 \mathrm{~s}$ solamente, lo que facilita la visualización de los eventos.

El primer registro utilizado se exhibe en la Figura 5.1. Se muestran las componentes $x, y$ y $z$ en tres paneles independientes con el objeto de poder apreciar las hipérbolas correspondientes a los eventos con mayor claridad. Se puede apreciar en la figura el arribo de un microsismo para tiempos comprendidos entre 270 y $330 \mathrm{~ms}$ aproximadamente. Observemos que la hipérbola que corresponde a la llegada del microsismo se aprecia con gran claridad en la componente $z$ (Figura 5.1c), y también se puede detectar la mayoría de los canales de las componentes $x$ e $y$ (Figura 5.1a y Figura 5.1b, respectivamente). El quinto canal de la componente $x$ parece tener algún tipo de problema, y el dato recolectado no es de utilidad. Además, la hipérbola se presenta con poca inclinación, como habíamos predicho.

En la Figura 5.2 presentamos el segundo ejemplo considerado. Nuevamente, analizando globalmente el registro, se distingue un evento entre 240 y $300 \mathrm{~ms}$. Vale aclarar que si bien estos tiempos son similares a los del evento anterior, los dos eventos no están relacionados y esto es una simple coincidencia. A diferencia del registro previo, aquí es muy complicado apreciar el microsismo en la componente $z$ (Figura 5.2c); sólo un observador muy experto sería capaz de detectarlo. Sin embargo, podemos distinguir la hipérbola en la componente $x$ (Figura 5.2a) y en especial en la componente $y$ (Figura 5.2b) para tiempos comprendidos entre 240 y $300 \mathrm{~ms}$. Nuevamente, el canal 5 de la componente $x$ presenta problemas. No debe sorprendernos que un evento se aprecie con claridad en cierta componente y sea indistinguible en otra, porque esto dependerá de la polarización con la que arriba la onda a los geófonos.

El último registro que estudiaremos se muestra en la Figura 5.3. En este caso, es realmente muy difícil detectar un microsismo mediante inspección visual. Quizás tanto en la componente $x$ como en la componente $y$ (Figura 5.1 a y Figura 5.1b, respectivamente) pueda notarse el arribo de la señal entre 270 y 320 ms. Sin embargo, la mala relación señal-ruido de los datos hace prácticamente imposible la detección. Una vez más, el canal 5 de la componente $x$ presenta problemas, que interpretamos entonces como una falla instrumental. 
a)

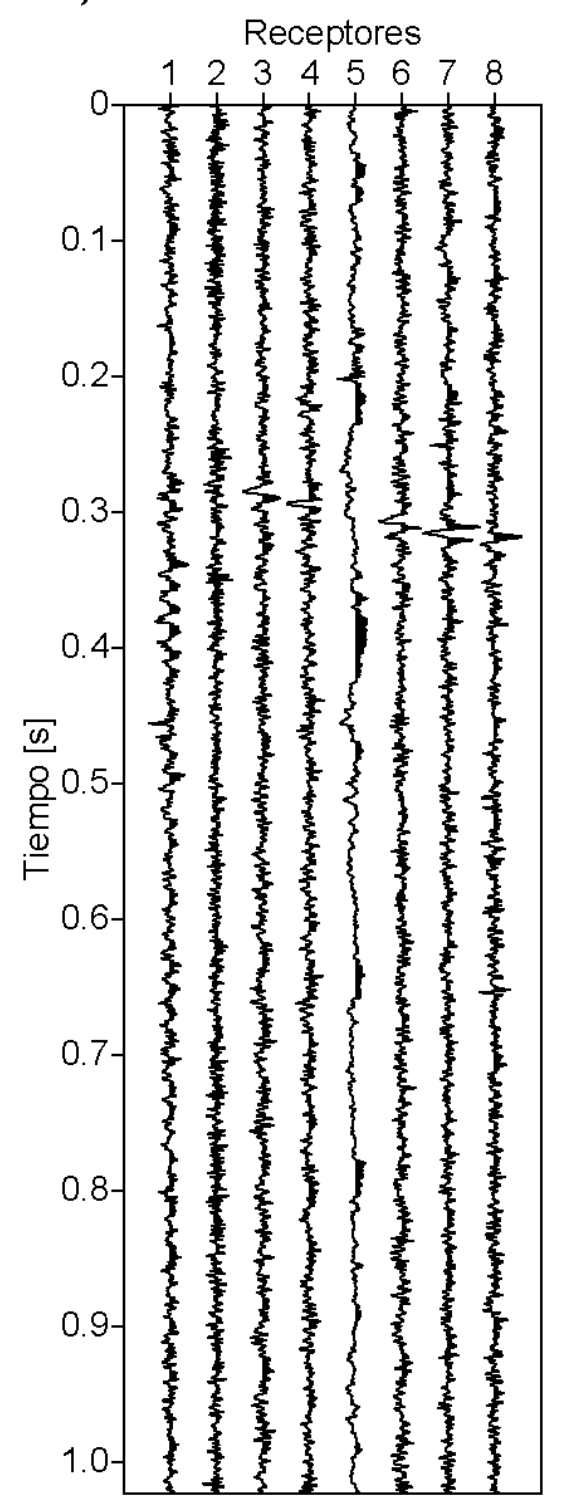

b)

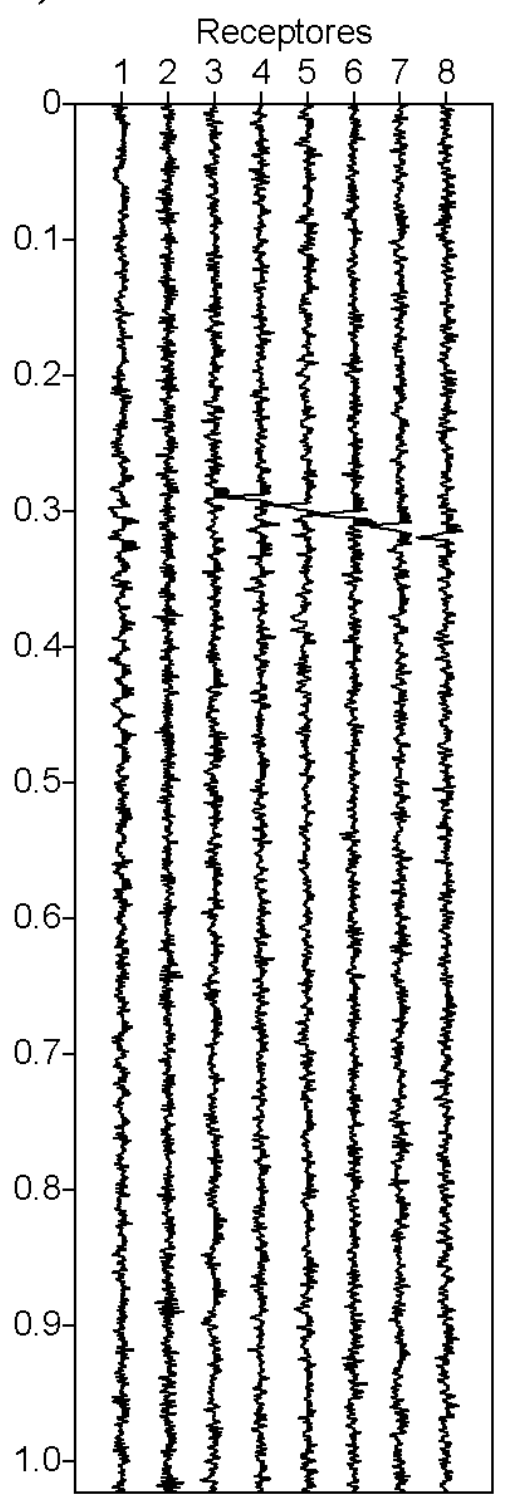

c)

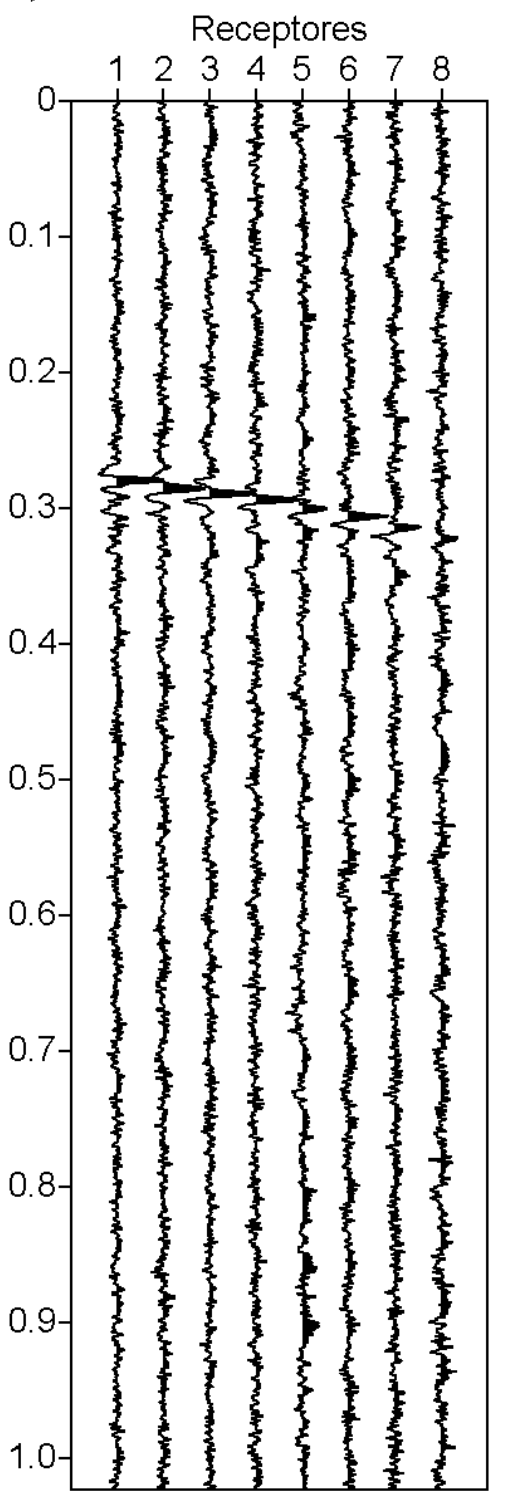

Figura 5.1: Registro de microsísmica número 1. La relación señal-ruido del evento es buena. (a) Componente $x$. (b) Componente $y$. (c) Componente $z$. 
a)

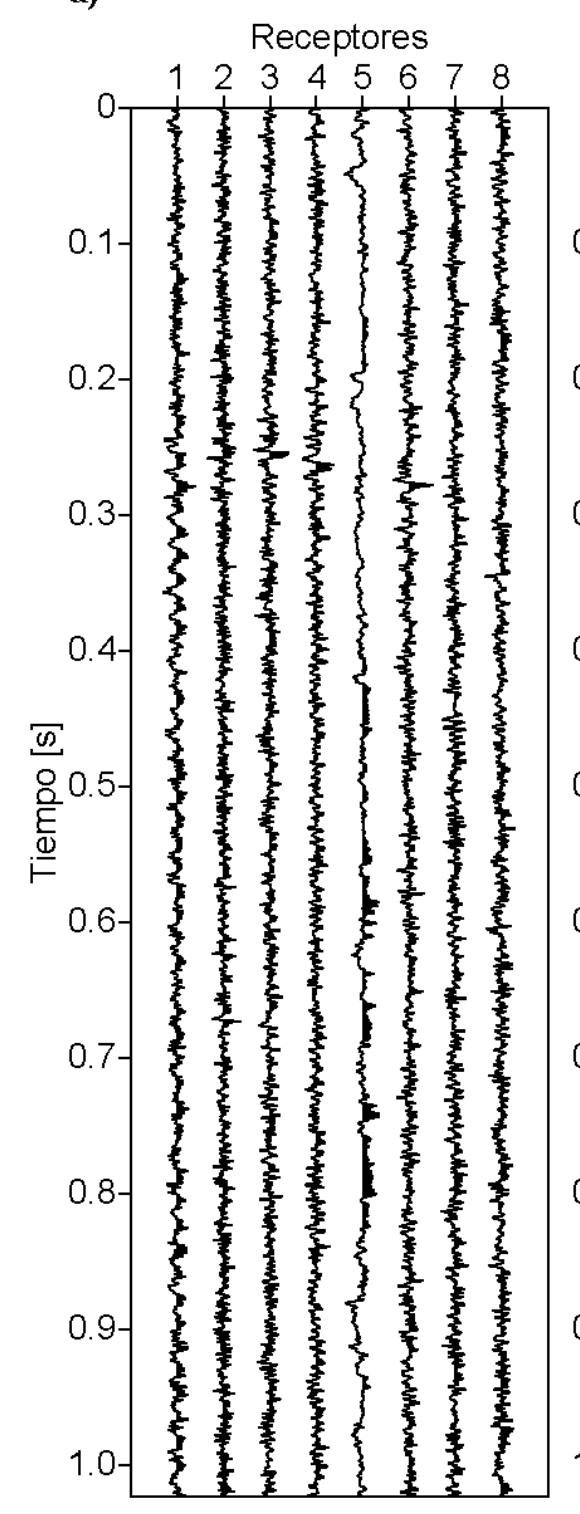

b)

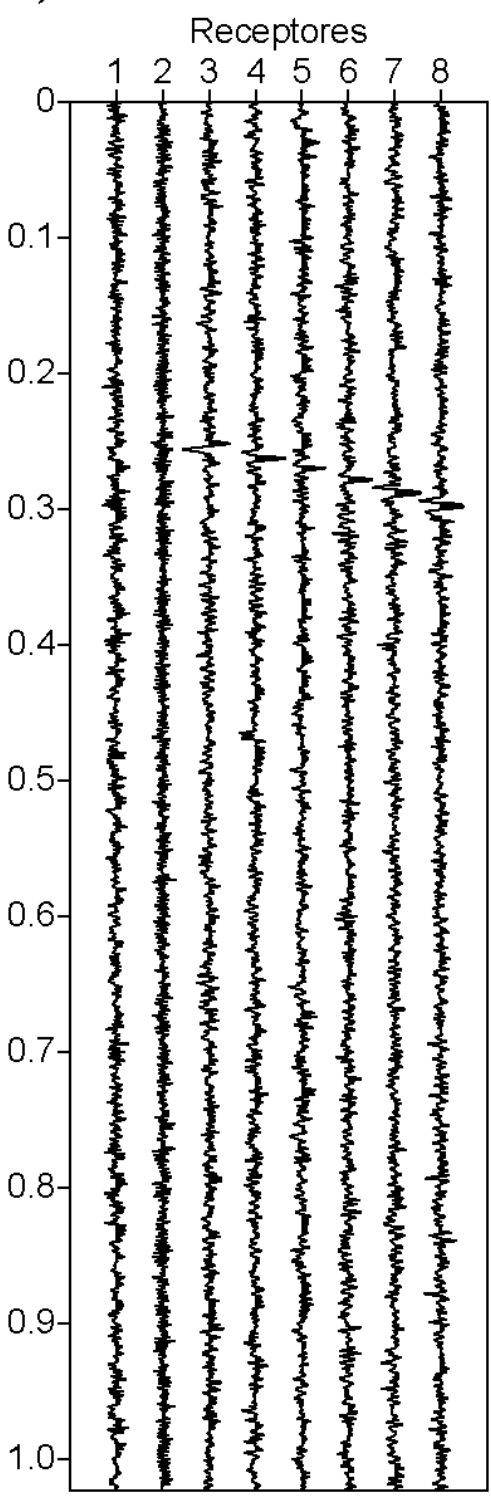

c)

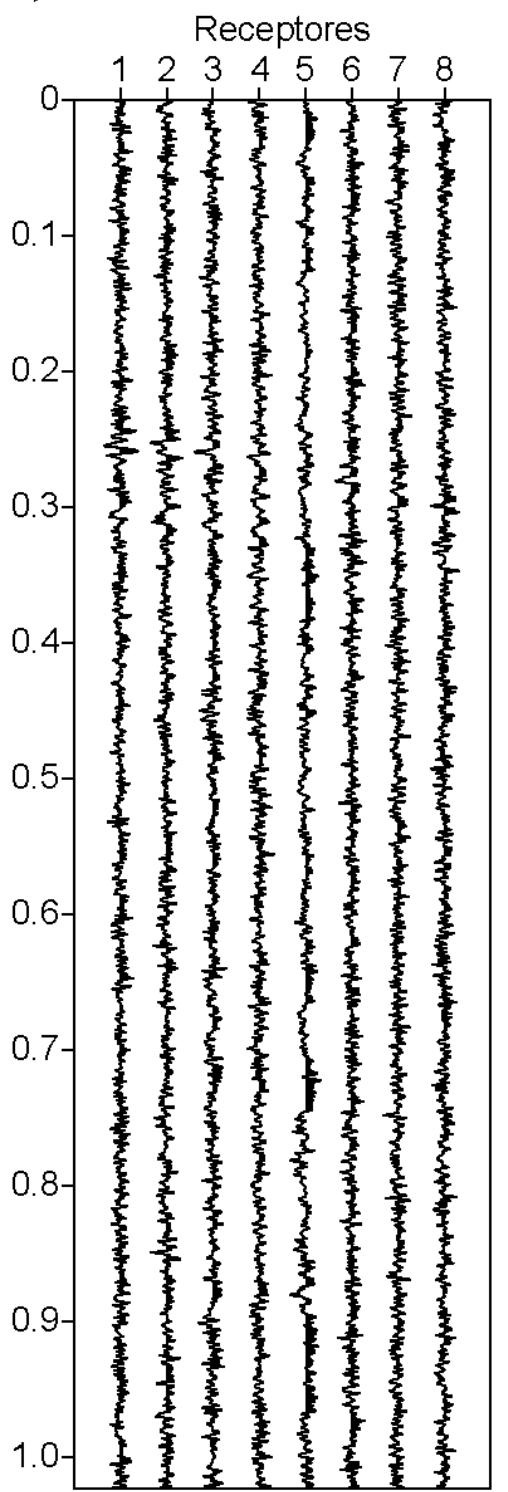

Figura 5.2: Registro de microsísmica número 2. La relación señal-ruido del evento es regular. (a) Componente $x$. (b) Componente $y$. (c) Componente $z$. 
a)

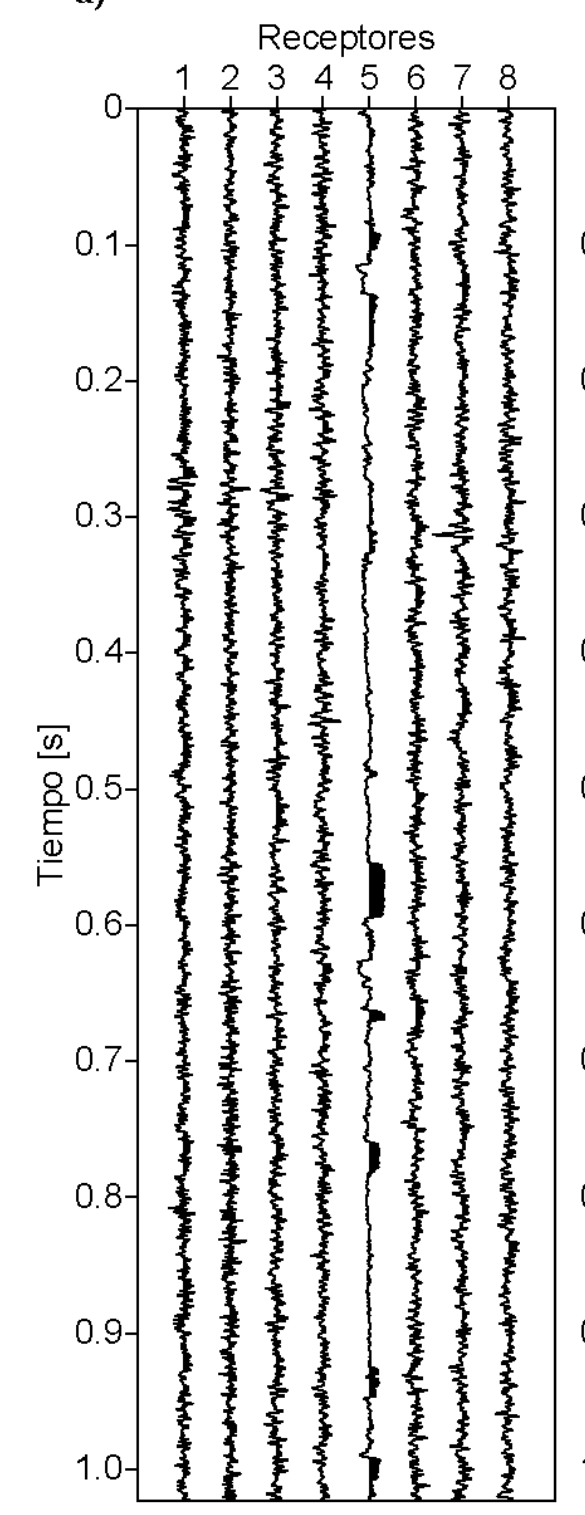

b)

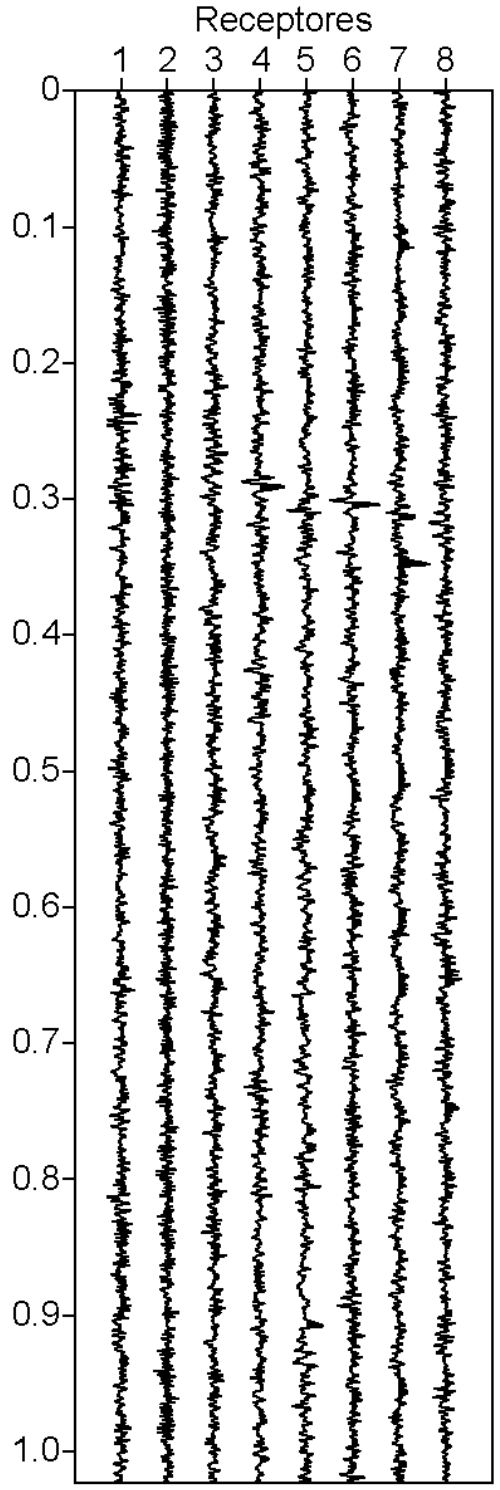

c)

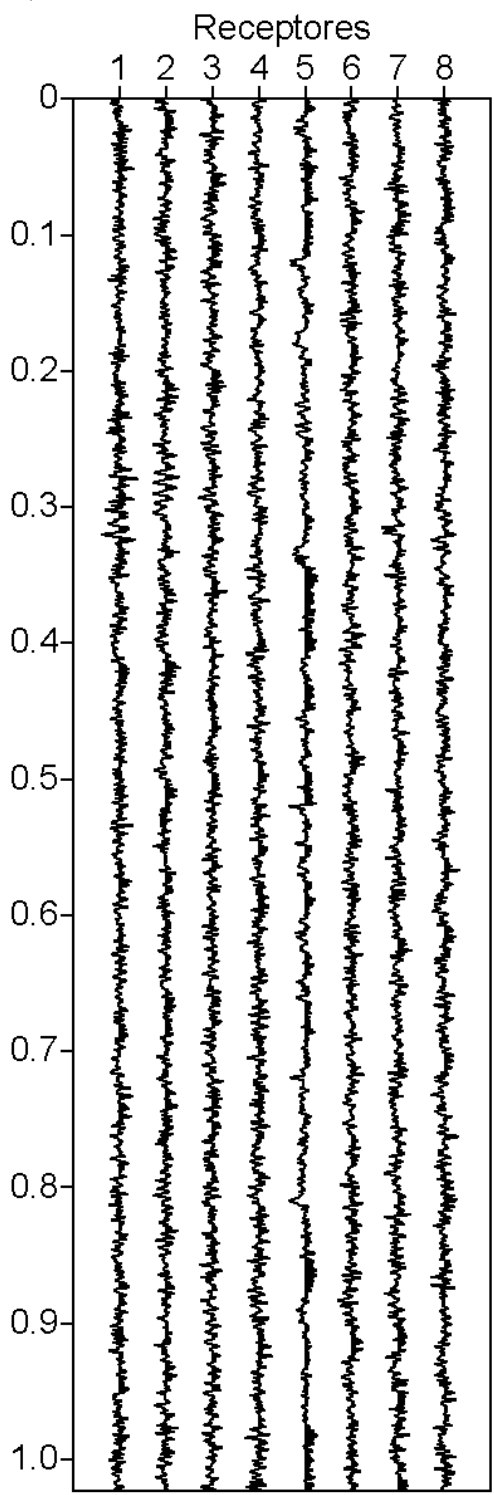

Figura 5.3: Registro de microsísmica número 3. La relación señal-ruido del evento es mala. (a) Componente $x$. (b) Componente $y$. (c) Componente $z$. 


\subsection{Metodología propuesta y resultados}

En el capítulo anterior comparamos ocho métodos para detectar y picar fases de terremotos. Ahora bien, a diferencia de lo que ocurre en sismología, donde se utilizan en general estaciones aisladas (cuando no se trabaja con arreglos, claro), en los registros microsísmicos se cuenta con riestras de receptores ubicados en un pozo. Esto representa una ventaja sustancial al momento de diseñar estrategias para detectar los eventos, puesto que se puede explotar la información extra que brinda la coherencia en el arribo de las señales en todo el registro. En este sentido, claramente la situación es equivalente a la que se tiene en el problema de picado de primeros arribos en sísmica convencional, que comentamos en el Capítulo 3, donde hemos propuesto una técnica que contempla la alineación aproximada de los arribos siguiendo las rectas de refracción para mejorar los tiempos de picado y detectar y descartar los picados falsos. No obstante, como primer paso, analizaremos los datos en busca de microsismos traza por traza y luego propondremos un criterio muy sencillo para determinar la presencia de eventos considerando la información de todos los canales en forma simultánea.

Como no existe restricción en el número de eventos a picar en cada método, podría ocurrir que se detecten varios eventos en cada traza, y que sólo uno o incluso ninguno corresponda al microsismo buscado. Para descartar estos eventos falsos, y al mismo tiempo decidir si los picados corresponden o no a un microsismo, utilizaremos una ventana móvil que avance en tiempo buscando eventos con una alineación aproximadamente horizontal. Detallaremos esta estrategia más adelante.

\subsubsection{Detección de eventos traza por traza}

Para el análisis traza por traza, seleccionamos tres de los ocho métodos presentados en el capítulo anterior, basándonos en el análisis comparativo entre ellos. Utilizaremos los dos métodos con los que obtuvimos mejores resultados: el método de Earle y Shearer (ESM) y el método de Allen modificado (MAM). Utilizaremos también el método de Baer y Kradolfer modificado (MBKM) para completar el análisis. Entonces, no vamos a considerar el método de Allen (RAM) ni el método de Baer y Kradolfer (BKM), pero sí los métodos basados en estos mismos con mejoras introducidas. Tampoco vamos a utilizar la adaptación de los métodos propuestos en el Capítulo 4: el método de Coppens modificado (MCM), el método de la entropía (EM), y el método de la dimensión fractal 
(FDM), puesto que su desempeño al aplicarlos para detectar fases de terremotos no ha sido destacada.

En esta sección obviaremos la descripción de los tres métodos utilizados ya que la misma puede encontrarse en las secciones 4.1.3, 4.1.7 y 4.1.8 del capítulo anterior. De la misma manera que en los dos capítulos previos, para el análisis traza por traza se precisa seleccionar cuidadosamente los parámetros para cada método. Como hemos adelantado, las frecuencias en microsísmica son mayores que en sísmica convencional y mucho mayores que en sismología. Entonces, teniendo en cuenta que para seleccionar el tamaño de las ventanas de los métodos nos basamos en los períodos de la señal de interés, los tamaños de las ventanas serán lógicamente mucho menores que los elegidos en el capítulo anterior.

Los parámetros seleccionados para cada método se resumen en la Tabla 5.1. Los parámetros están enumerados en el orden en que son utilizados en el flujo de los algoritmos que implementan los distintos métodos. Las longitudes de las ventanas y de los filtros están dadas en milisegundos. El resto de los parámetros, incluyendo los valores de los umbrales para declarar los eventos, son adimensionales. Recordemos que el esquema de ventanas del MAM es el mismo que el del ESM, y se muestra en la Figura 4.1b. Por ello, tiene sentido considerar los mismos tamaños de ventanas y filtros para estos dos métodos, como se puede ver en la Tabla 5.1. El valor del umbral THR utilizado para declarar un evento depende de qué tan sensible sea el atributo utilizado. La función característica del MAM, dada por las ecuaciones 4.1 y 4.2, responde de forma más abrupta e intensa ante la llegada de una señal que la envolvente utilizada en el ESM, por lo que el valor de THR debe ser mayor que para el caso del ESM. De aquí que los valores elegidos para THR para el ESM y para el MAM son 2.5 y 6, respectivamente. Respecto de los parámetros para el MBKM, el único parámetro de ventanas es el de la longitud de la ventana de Hanning, que fue fijado en $10 \mathrm{~ms}$ para los tres métodos. Por último, para este método se consideró un valor $T H R=5$, algo menos que el umbral utilizado en el MAM.

Una vez fijados los parámetros, implementamos los tres métodos elegidos para las 24 trazas y para cada registro en los tres ejemplos. Teniendo en cuenta que los datos seleccionados contienen un único microsismo, la situación óptima sería que cada método pique un único evento por cada traza. Cabe resaltar que si bien es importante en primer término elegir de forma coherente las longitudes de las ventanas y de los filtros, el valor del umbral THR es el parámetro que controlará el número de eventos picados por traza: mientras menor sea $T H R$, más eventos se picarán y viceversa. Para simplificar la forma 


\begin{tabular}{|c|c|l|r|}
\hline Método & Parámetro & Descripción & Valor \\
\hline \multirow{2}{*}{ ESM } & $T_{S T A}$ & Longitud de la ventana del $S T A$ & 5 \\
& $T_{L T A}$ & Longitud de la ventana del $L T A$ & 50 \\
& $T_{H a n}$ & Longitud de la ventana de Hanning & 10 \\
& $T H R$ & Umbral de $S T A / L T A$ para declarar un evento & 2.5 \\
\hline MAM & $T_{S T A}$ & Longitud de la ventana del $S T A$ & 5 \\
& $T_{L T A}$ & Longitud de la ventana del $L T A$ & 50 \\
& $T_{H a n}$ & Longitud de la ventana de Hanning & 10 \\
& $T H R$ & Umbral de $S T A / L T A$ para declarar un evento & 6 \\
\hline MBKM & $T_{H a n}$ & Longitud de la ventana de Hanning & 10 \\
& $T H R$ & Umbral de $C F$ para declarar un evento & 5 \\
\hline
\end{tabular}

Tabla 5.1: Parámetros utilizados en la detección automática de eventos de microsismos en el análisis traza por traza. Las longitudes de las ventanas y de los filtros están dadas en milisegundos. El resto de los parámetros, incluyendo los valores de los umbrales para declarar los eventos, son adimensionales.

en la que presentamos las tablas, figuras y resultados, mostraremos de ahora en más las tres componentes de los registros en conjunto, numerando las trazas de la componente $x$ de 1 a 8, las de la componente $y$ de 9 a 16, y las de la componente $z$ de 17 a 24. En la Tabla 5.2 se resumen la cantidad de eventos picados para cada método y para cada traza en cada registro.

En la Tabla 5.2, notamos primero que los métodos devuelven en algunos casos varios eventos para la componente $x$ del quinto geófono. Recordemos que la situación deseada es un único evento por canal. Lo que ocurre es que estos eventos no son correctos debido a que los datos recolectados por esta traza no son fidedignos puesto que el canal presenta problemas, como ya habíamos mencionado. Este tipo de situación complica el criterio multitraza a adoptarse a continuación para declarar los microsismos.

Por otro, a partir de analizar la Tabla 5.2 por registro, observamos que para el registro 1 la situación se acerca mucho a la óptima, como era de esperarse dada la buena relación señal-ruido de los datos. En este registro, los métodos detectan sólo un evento en la mayoría de las trazas, y este evento casi siempre corresponde justamente a la llegada del microsismo de interés, como veremos más adelante. Sin embargo, en los otros dos 


\begin{tabular}{|c|c|c|c|c|c|c|c|c|c|}
\hline \multirow[b]{2}{*}{ Traza } & \multicolumn{3}{|c|}{ Registro 1} & \multicolumn{3}{|c|}{ Registro 2} & \multicolumn{3}{|c|}{ Registro 3} \\
\hline & ESM & MAM & MBKM & ESM & MAM & MBKM & ESM & MAM & MBKM \\
\hline 1 & 0 & 0 & 1 & 0 & 0 & 0 & 0 & 0 & 0 \\
\hline 2 & 0 & 0 & 0 & 0 & 0 & 0 & 0 & 0 & 0 \\
\hline 3 & 1 & 1 & 1 & 1 & 1 & 1 & 0 & 0 & 0 \\
\hline 4 & 1 & 1 & 1 & 0 & 0 & 0 & 0 & 0 & 0 \\
\hline 5 & 0 & 0 & 1 & 2 & 3 & 1 & 6 & 4 & 1 \\
\hline 6 & 0 & 0 & 1 & 1 & 0 & 1 & 0 & 0 & 0 \\
\hline 7 & 1 & 1 & 1 & 0 & 0 & 0 & 1 & 0 & 1 \\
\hline 8 & 1 & 1 & 1 & 0 & 0 & 0 & 0 & 0 & 0 \\
\hline 9 & 0 & 0 & 0 & 0 & 0 & 0 & 0 & 0 & 0 \\
\hline 10 & 0 & 0 & 0 & 0 & 0 & 0 & 0 & 0 & 0 \\
\hline 11 & 0 & 0 & 0 & 1 & 1 & 1 & 0 & 0 & 0 \\
\hline 12 & 1 & 1 & 1 & 1 & 1 & 1 & 1 & 1 & 1 \\
\hline 13 & 1 & 1 & 1 & 0 & 0 & 0 & 1 & 1 & 1 \\
\hline 14 & 1 & 2 & 1 & 1 & 0 & 1 & 1 & 1 & 1 \\
\hline 15 & 1 & 1 & 1 & 1 & 1 & 1 & 1 & 0 & 2 \\
\hline 16 & 1 & 1 & 1 & 1 & 1 & 1 & 0 & 0 & 0 \\
\hline 17 & 1 & 1 & 1 & 0 & 1 & 0 & 0 & 0 & 0 \\
\hline 18 & 1 & 1 & 1 & 1 & 0 & 0 & 0 & 0 & 0 \\
\hline 19 & 1 & 1 & 1 & 0 & 0 & 0 & 0 & 0 & 0 \\
\hline 20 & 1 & 1 & 1 & 0 & 0 & 0 & 0 & 0 & 0 \\
\hline 21 & 1 & 2 & 1 & 0 & 0 & 0 & 2 & 0 & 1 \\
\hline 22 & 1 & 1 & 1 & 0 & 0 & 0 & 0 & 0 & 0 \\
\hline 23 & 1 & 1 & 1 & 0 & 0 & 0 & 0 & 0 & 0 \\
\hline 24 & 1 & 0 & 1 & 0 & 0 & 0 & 0 & 0 & 0 \\
\hline
\end{tabular}

Tabla 5.2: Picado "preliminar": cantidad de eventos picados por traza y por registro para cada método. 
registros, sólo en la componente $y$ (canales 9 a 16) la situación se asemeja a la deseada, mientras que para las componentes $x$ y $z$ (canales 1 a 8 y 17 a 24 , respectivamente) el microsismo es escasamente detectado por alguno de los métodos propuestos. Esto se debe principalmente a dos factores: la pobre relación señal-ruido y polarización de la señal.

\subsubsection{Declaración de microsismos mediante un criterio multitraza}

Hasta aquí obtuvimos entonces cierto número de picados "preliminares" para cada una de las 24 trazas de cada registro. En esta primera instancia, no conocemos la posición de la fractura que origina el microsismo. Además, a priori no se tiene tampoco información respecto de si existen microsismos o no en los registros analizados. Por tanto, aún si conociéramos con precisión el modelo de velocidades, no podríamos calcular los parámetros de la hipérbola que representa la llegada de los microsismos. No obstante, como hemos mencionado, podemos afirmar que dicha hipérbola se va a presentar en el dominio de la profundidad del geófono vs. tiempo con poca curvatura (con alineación cuasi horizontal en este dominio). Por ello, podemos pensar que una ventana de tiempo bastante corta pero de duración suficiente deberá alcanzar para abarcar la llegada de los eventos en todos los canales. Nuestro criterio de detección de eventos se basa en esta idea sencilla.

Luego, definimos una ventana de cierta duración fija (digamos, entre 40 y $120 \mathrm{~ms}$ ) que avanza en tiempo muestra a muestra y "cuenta" los eventos que contiene que fueron picados traza por traza para determinar la presencia de un microsismo. La longitud de la ventana de búsqueda de microsismos fue fijada en $50 \mathrm{~ms}$ para los tres registros. En la Figura 5.4 esquematizamos el funcionamiento de esta ventana móvil cuyo objetivo es "buscar" los microsismos. Debemos aclarar que, con el fin facilitar la interpretación de la figura, la ventana mostrada es de mayor longitud que la ventana efectivamente utilizada para procesar los datos. Los datos mostrados en la Figura 5.4 corresponden a la Figura 5.1 y los eventos picados corresponden a los obtenidos mediante el MAM. Notemos que para las trazas 1, 2, 5, 6, 9, 10, 11 y 24 no se detectó ningún evento, mientras que para las trazas 14 y 21 se detectaron dos. En estos dos últimos casos, uno de los eventos picados corresponde al microsismo buscado, y el otro es un picado falso. En el resto de las trazas, el evento detectado corresponde efectivamente al microsismo presente en el registro.

Ahora bien, nos falta definir un criterio que determine cuándo declarar un microsismo. 


\section{Trazas}

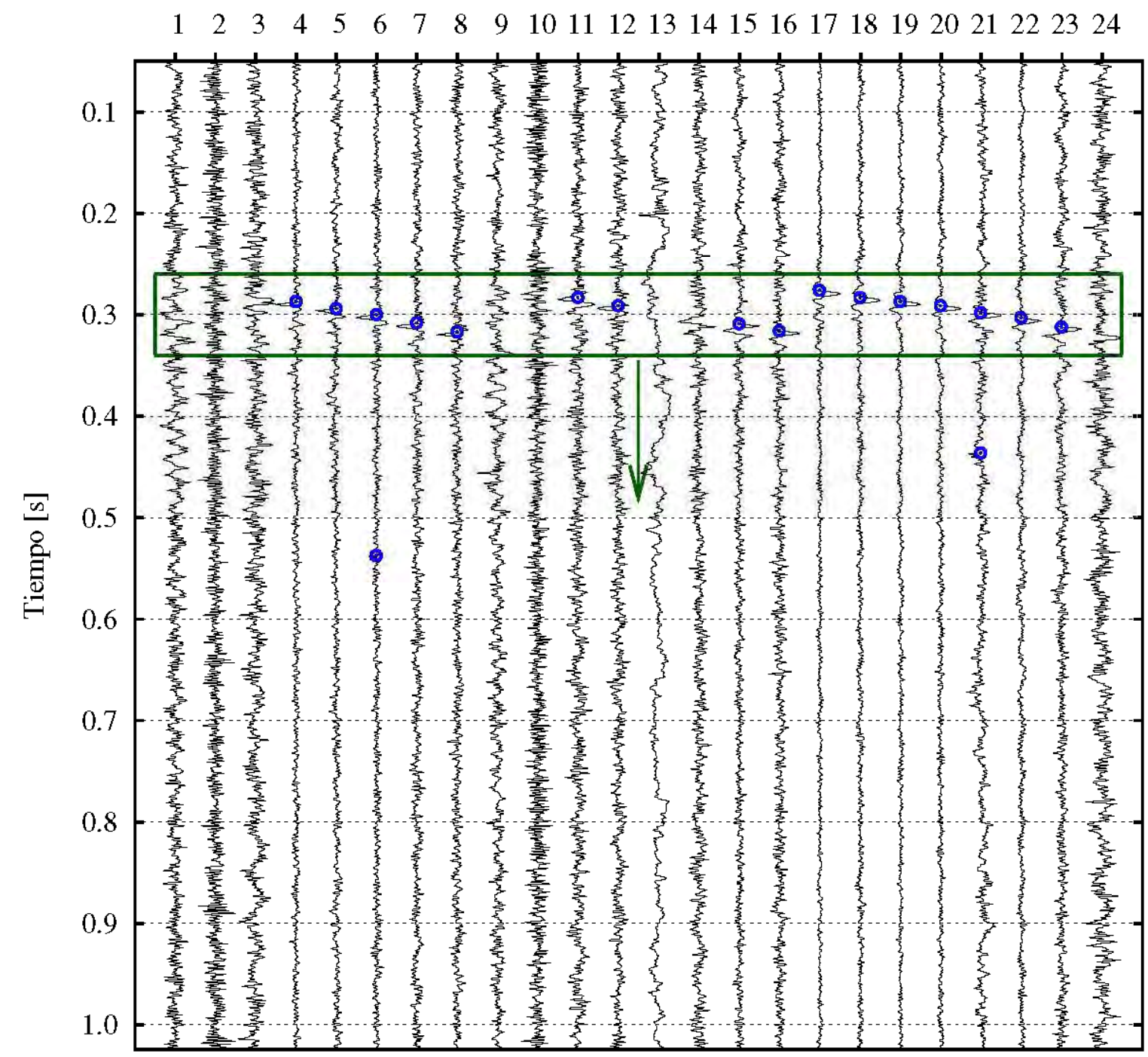

Figura 5.4: Ventana móvil utilizada para detectar los microsismos (en verde). La ventana avanza en tiempo muestra a muestra y cuenta el número de eventos contenidos en ella. Los datos corresponden a la Figura 5.1 y los picados corresponden a los obtenidos mediante el MAM. 
Recordemos que dependiendo de la polarización de la señal, un microsismo podría detectarse perfectamente en una de las tres componentes de los geófonos y no registrarse señal alguna en las otras dos componentes. Luego, el criterio de declaración de microsismos debe tener indefectiblemente esto en cuenta. Bajo estas hipótesis, analizamos cada componente por separado, y si en alguna de ellas se registra una cantidad mínima de eventos sobre el total de geófonos (8, en este caso), declaramos el evento. Adoptamos finalmente el siguiente criterio: declarar un microsismo si en alguna componente la ventana de búsqueda encuentra al menos un evento en al menos la mitad de las trazas (4, para nuestros ejemplos). Notemos que con este criterio en el ejemplo mostrado en la Figura 5.4 el microsismo se podría declarar según las tres componentes, pues en cada una de ellas hay el menos 4 eventos picados.

Nos resta por último determinar cómo aislar el microsismo, o dicho de otra manera, cómo determinar la ventana mínima que lo contiene. Si bien este es un aspecto bastante técnico de la metodología propuesta, daremos algunas precisiones al respecto. Como podemos apreciar en la Figura 5.4, en general no existirá una, sino varias ventanas que contengan el microsismo. Es decir, dado que la ventana avanza muestra a muestra, no sólo la ventana de la figura contiene el microsismo, también lo harán varias ventanas previas y varias posteriores. Entonces, ante la primera ventana en la que se declara un microsismo, nuestro algoritmo de detección procede de la siguiente manera:

(1) Se consideran todas las ventanas contiguas que cumplen con el mencionado requisito para declarar un microsismo. En la Figura 5.5a se muestran en verde la primera y la última de todas estas ventanas para el ejemplo ilustrado en la Figura 5.4. Mientras que en la primera el microsismo se detecta debido a los 4 eventos en la componente $z$ (canales $17,18,19$ y 20), en la última se detecta debido a 4 eventos en la componente $y$ (canales 13 , 14, 15 y 16). Observar que todas las ventanas contiguas intermedias también detectarán el microsismo. Nuevamente, para facilitar la comprensión de la figura, las ventanas mostradas son de longitud algo mayor que la efectivamente utilizada para procesar los datos.

(2) Luego, se genera una ventana mayor a partir de la unión de todas las ventanas contiguas que detectan el microsismo. Dicha ventana grande se exhibe en verde en la Figura 5.5b.

(3) Finalmente, la ventana grande es acortada todo lo posible para definir así la menor 
ventana que contiene el microsismo, que se muestra en la Figura 5.5b en rojo.

El algoritmo contempla también que exista más de un microsismo dentro de la ventana grande, pero la descripción de este caso es por demás engorrosa y la obviaremos. Así, el resultado final del método propuesto está dado por la detección del microsismo, su ventana final, y todos los eventos picados contenidos en ella.

Debemos mencionar también que podría ocurrir que dentro de la ventana final haya más de un evento picado para cierta traza, y que algunos de estos eventos representen un picado falso (o incluso todos). Sin embargo, esa situación no debe preocuparnos en demasía en esta instancia, pues el objetivo fundamental de nuestro método es detectar microsismos, que es la tarea más demandante y compleja para una analista. No obstante, como salida de los métodos obtendremos los tiempos picados del microsismo dentro de la ventana final para cada traza del registro en donde fue detectado. Esta ventana deberá ser luego inspeccionada traza por traza por un analista para decidir corregir los picados en caso que fuera necesario. Claramente, esta es una tarea menor frente al análisis de todo un registro completo de microsismicidad de dos o tres horas de duración, en dónde suelen encontrarse solamente algunas decenas de microsismos.

Es importante remarcar que si bien se han seleccionado 3 registros de 1 s de duración aproximadamente conteniendo un evento cada uno de ellos, la metodología propuesta es válida para sacar conclusiones respecto de la declaración de microsismos falsos. Podemos afirmar esto puesto que la ventana móvil no guarda memoria de ventanas anteriores, ya que una vez que la ventana ha atravesado completamente un microsismo y deja de abarcarlo, se analiza el resto del registro buscando nuevos eventos sin importar qué ocurrió en muestras previas. Observemos en los datos utilizados (Figuras 5.1, 5.2 y 5.3) que más del $60 \%$ de los registros (a partir de $400 \mathrm{~ms}$ ) no contienen microsismo alguno si consideramos una ventana móvil de $50 \mathrm{~ms}$.

\subsubsection{Indicador de confianza para los microsismos declarados}

Por último, para completar la descripción de la metodología propuesta, debemos generar algún tipo de indicador de confianza para los microsismos declarados. Recordando lo ya discutido, la situación óptima es que se haya picado un evento dentro de la ventana final del microsismo en cada traza (Figura 5.5b), lo que sólo ocurre siempre y cuando la onda arribe con la polarización adecuada. En el otro caso extremo, de acuerdo al criterio que hemos propuesto, el microsismo declarado menos confiable será aquel para el cual 
(a)

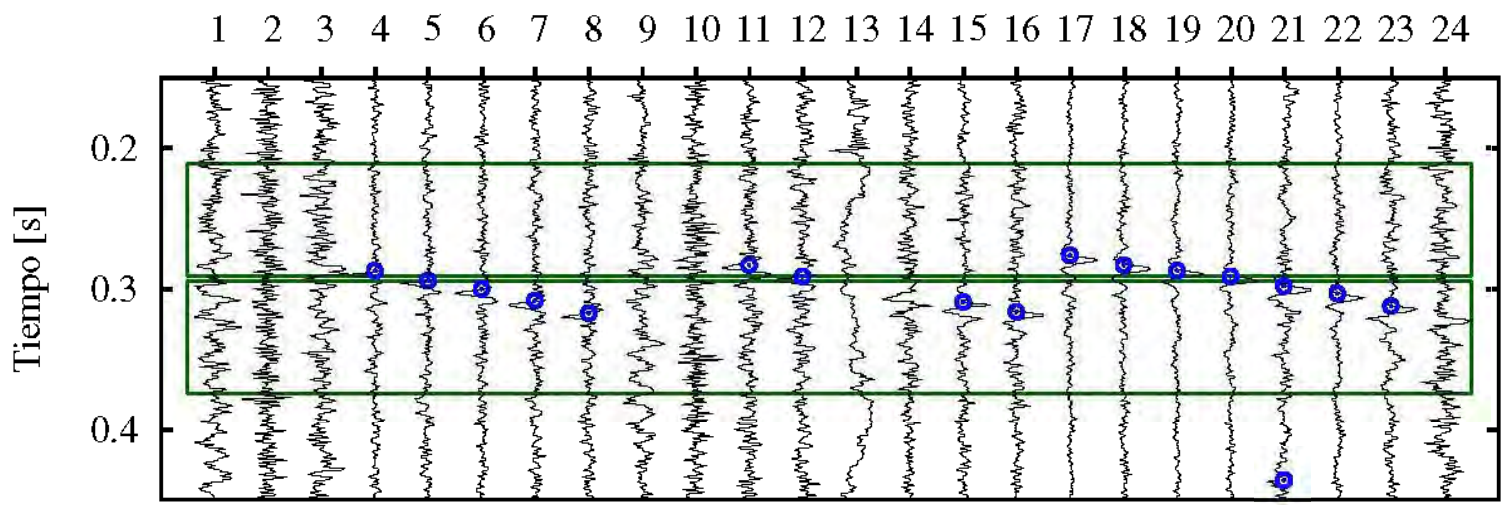

(b)

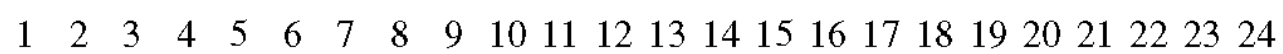

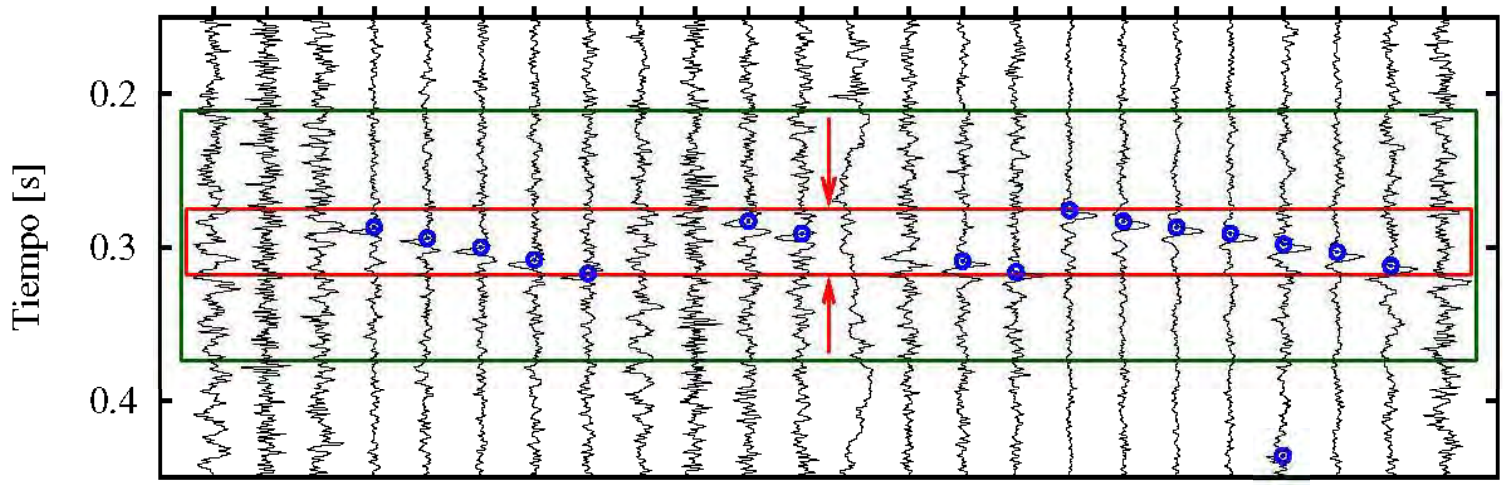

Figura 5.5: Estrategia para determinar la mínima ventana que contiene el microsismo. (a) La primera y la última de las ventanas que detectan un microsismo (en verde). (b) La unión de todas las ventanas móviles contiguas que detectan un microsismo forma una ventana grande (en verde). La ventana grande se acorta todo lo posible para definir una ventana final más pequeña que delimita el microsismo (en rojo). Al igual que en la Figura 5.4, los datos corresponden al registro 1 y los picados corresponden a los obtenidos mediante el MAM. 
sólo se detectaron eventos en la mitad los receptores para cierta componente. Entonces, definida la mínima ventana que contiene al microsismo, podemos definir un indicador de confianza sencillo $P$ vía:

$$
P[\%]=\frac{N_{\text {eve }}}{N_{\text {tot }}} 100 \%
$$

donde $N_{\text {eve }}$ es el número de trazas con eventos y $N_{\text {tot }}$ es el total de canales disponibles. Si en cada traza hubiera un evento dentro de la ventana del microsismo detectado, $P$ tomará un valor de $100 \%$. Si, por el contrario, el microsismo hubiese sido detectado por la condición mínima, es decir, solamente en la mitad de canales de una de las tres componentes, $P$ valdrá 16,6\%, ya que sólo un sexto del total de los canales disponibles habría detectado un evento en este caso. Ante esta última situación, corresponderá a un analista prestar especial atención respecto de si el microsismo detectado es correcto o no. Mencionemos también el caso en que un microsismo arribe a la riestra de geófono en el pozo con una polarización tal que se observe perfectamente en una componente pero no en las otras dos. En esta situación, el valor del indicador de confianza $P$ será 33,3\%, más allá de que eventualmente la relación señal-ruido sea excelente. A modo de ejemplo, observemos que para el caso de la Figura 5.4 se detecta un evento en 16 de los 24 canales, y por tanto tendremos $P=(16 / 24) 100 \%=66,6 \%$.

\subsection{Análisis global de los resultados}

Para introducir el análisis del desempeño de las estrategias de detección automática de microsismos propuestas, mostramos primero en la Tabla 5.3 los indicadores de confianza para los microsismos detectados para cada registro según el criterio recién explicado. El microsismo del registro 1 fue detectado en la mayoría de las trazas con todos los métodos, lo que se refleja en los altos valores de confianza de la Tabla 5.3. Por su parte, el microsismo del registro 2 también fue detectado por los tres métodos, pero con niveles de confianza moderados a bajos, algo esperable considerando la calidad de los datos (ver Figura 5.2). Por último, el ESM y el MAM no detectan el microsismo en el último registro. Sólo el MBKM detecta el evento en este caso, y lo hace lógicamente con un nivel de confianza bajo.

Analicemos ahora los resultados con mayor detalle. En la Figura 5.6 mostramos las ventanas finales y los picados obtenidos con cada uno de los tres métodos para el caso 


\begin{tabular}{|c|c|c|c|}
\hline & ESM & MAM & MBKM \\
\hline Registro 1 & $70,8 \%$ & $66,6 \%$ & $70,8 \%$ \\
\hline Registro 2 & $33,3 \%$ & $20,8 \%$ & $29,2 \%$ \\
\hline Registro 3 & - & - & $20,8 \%$ \\
\hline
\end{tabular}

Tabla 5.3: Indicadores de confianza de los microsismos detectados por los métodos para los tres registros utilizados.

del registro 1 (Figura 5.1). Los altos porcentajes de confianza reflejados en la Tabla 5.3 se deben a que dentro de la ventana final el ESM detecta eventos en 17 de las 24 trazas del registro (Figura 5.6a), el MAM en 16 (Figura 5.6b), y el MBKM el 17 (Figura 5.6c). Observar que los resultados de los tres métodos son muy similares, ya que los tres detectan eventos en al menos las trazas 3, 4, 7, 8, y de 12 a 23 (es decir, en un total de 16 trazas). Sin embargo, no debemos dejar de remarcar que a pesar de que la relación señal-ruido de los datos es relativamente buena, los mismos contienen un nivel de ruido de fondo no despreciable, y en algunas trazas es muy difícil (si no imposible) detectar la llegada de los microsismos aún ante una rigurosa inspección visual (ver trazas 1, 2, 9 y 10).

Claramente, la detección automática del microsismo del registro 2 (Figura 5.2) representa un desafío mucho mayor para los métodos. En la componente $z$ (trazas 17 a 24) el arribo de la señal está totalmente enmascarado por el ruido. Además de los problemas en el canal 5, las trazas 1 y 2 correspondientes a la componente $x$ y la traza 10 correspondiente a la componente $y$ son también muy ruidosas. Luego, como se puede observar en la Figura 5.7, el evento sólo puede detectarse en unas pocas trazas. Aún así, los tres métodos propuestos logran detectar los eventos según el criterio de búsqueda establecido mediante la ventana móvil. Si bien los valores de confianza son bajos porque el microsismo sólo es detectado en unas pocas trazas (8 para el ESM, 5 para el MAM y 7 para el MBKM), los métodos funcionan con éxito.

El registro 3 (Figura 5.3) es indudablemente el más complejo de los tres ejemplos analizados. Al implementar los métodos de detección automática con una ventana de búsqueda de microsismos de $50 \mathrm{~ms}$ (al igual que en los otros dos ejemplos), solamente el MBKM detecta el microsismo (Figura 5.8c), y lo hace con un nivel de confianza bajo $(20,8 \%)$. Contrariamente, tanto en el ESM como el MAM, ninguna ventana de búsqueda 
(a)

$\begin{array}{llllllllllllllllllllllll}1 & 2 & 3 & 4 & 5 & 6 & 7 & 8 & 9 & 10 & 11 & 12 & 13 & 14 & 15 & 16 & 17 & 18 & 19 & 20 & 21 & 22 & 23 & 24\end{array}$

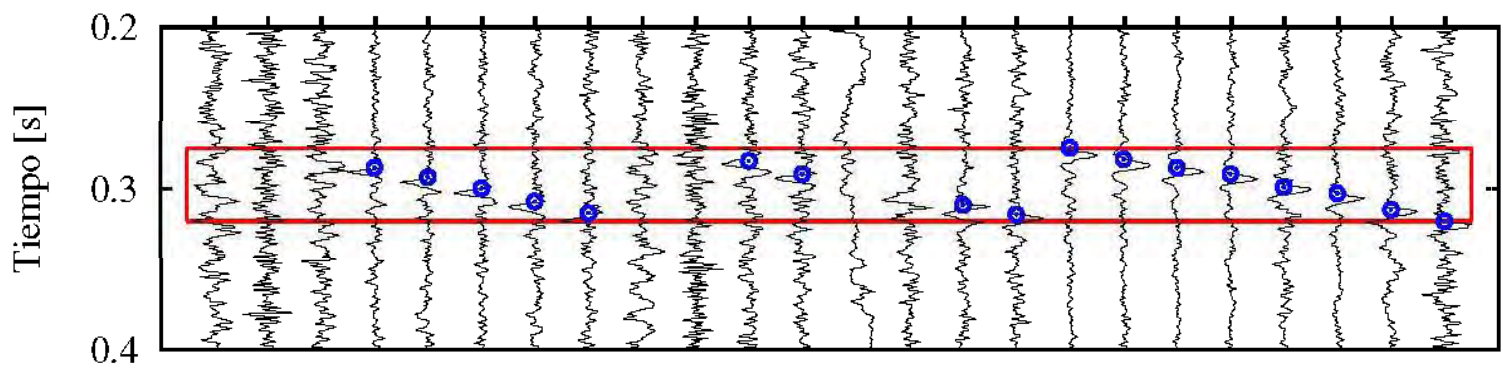

(b)

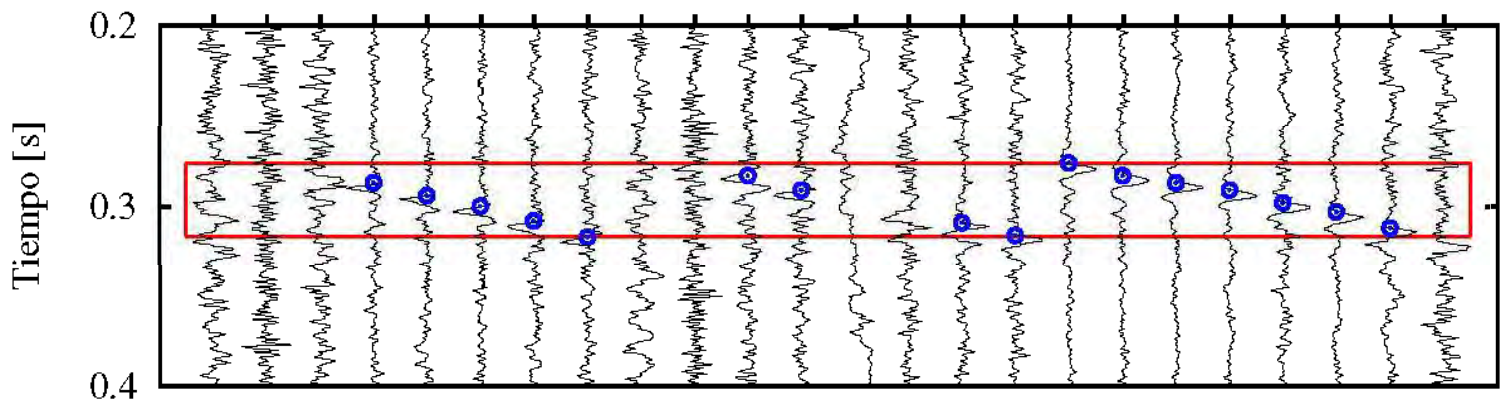

(c)

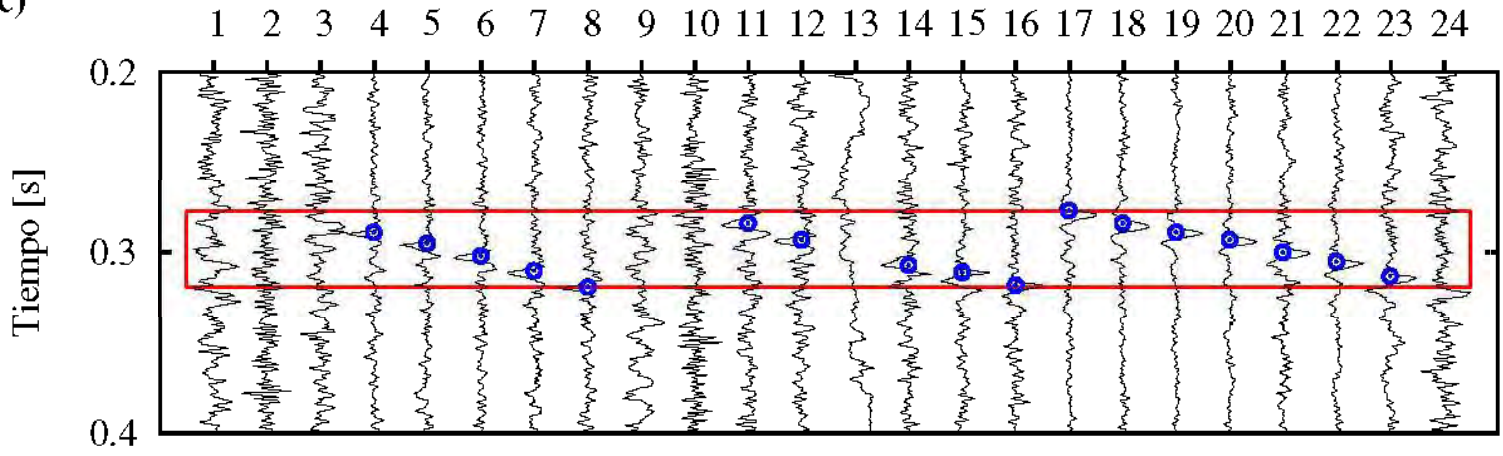

Figura 5.6: Ventana final con el microsismo detectado y los eventos picados para el registro 1. (a) ESM, (b) MAM y (c) MBKM. 
(a) Trazas

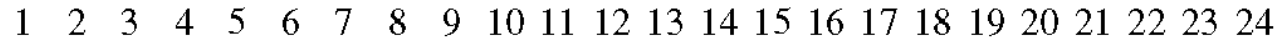

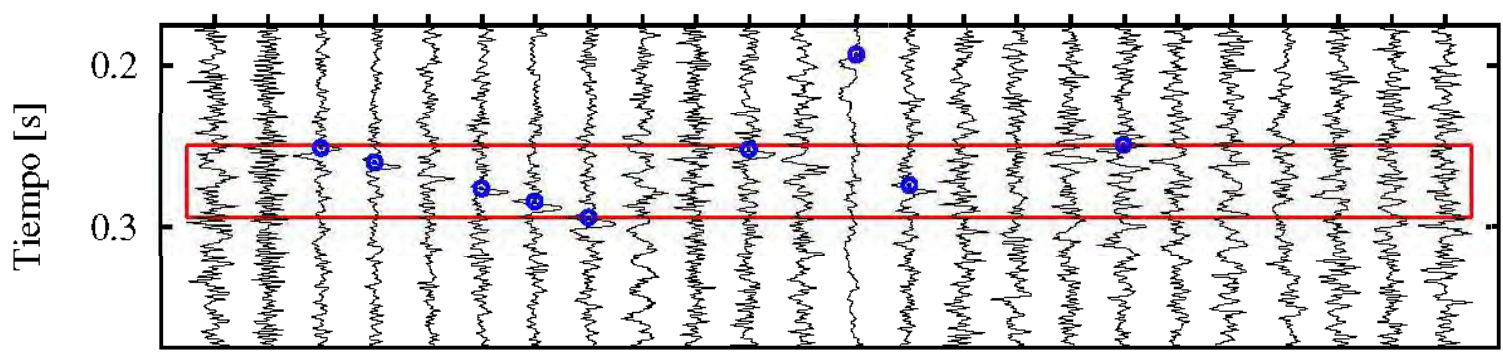

(b)

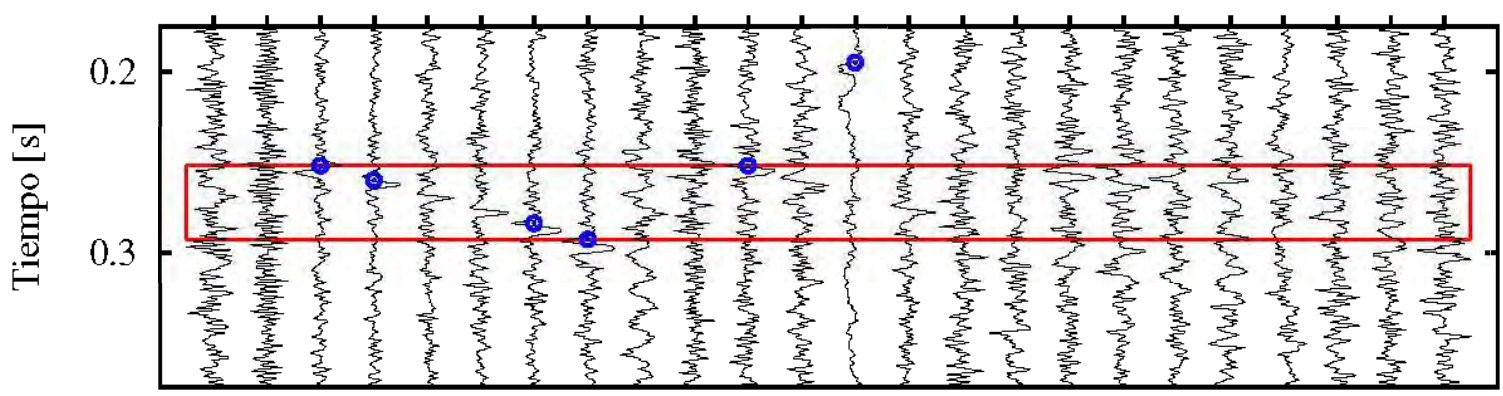

(c)

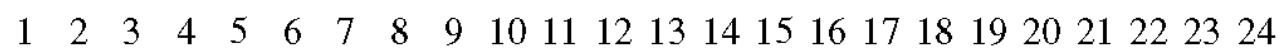

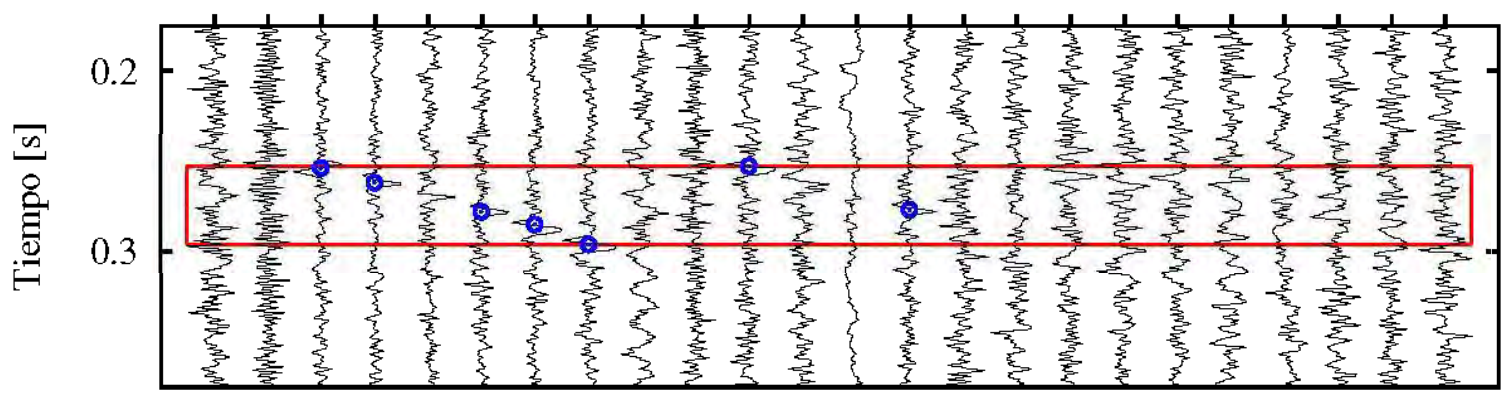

Figura 5.7: Ventana final con el microsismo detectado y los eventos picados para el registro 2. (a) ESM, (b) MAM y (c) MBKM. 
contiene al menos 4 eventos en 8 de las trazas de una dada componente (véanse las Figuras 5.8a y 5.8b, respectivamente), y por ello el microsismo no es detectado y no se muestra la ventana final en la figura. Además, ningún método logra picar evento alguno para las trazas correspondientes a la componente $z$, ya sea por la polarización de la señal, por el alto nivel de ruido de fondo presente en esta componente, o por ambas razones.

El resultado final de los métodos no sólo está dado por la detección de los microsismos y por su ubicación en los registros (marcado con la ventana final), sino también por los tiempos picados en las trazas para los eventos correspondientes. Es de destacar en todos los casos que todos los eventos fueron picados automáticamente con notable precisión, como puede verse en las figuras. Si bien no utilizamos un criterio homogéneo para definir el tiempo exacto de los picados en cada traza, en los tres registros se obtuvieron tiempos que corresponden aproximadamente al arribo del lóbulo central de la señal, como se puede ver en las Figuras 5.6, 5.7 y 5.8 .

Por último, analicemos los eventos detectados por el ESM y por el MBKM para la traza 15 del registro 3 (Figura 5.8). Ambos métodos detectan un evento en esta traza cercano a $350 \mathrm{~ms}$, pero aparentemente este evento no tiene que ver con el arribo del microsismo, puesto que no está cercano a la hipérbola a lo largo de la cual se deben alinear los eventos. Si bien no se muestra en los resultados ni en las figuras, hemos encontrado que con una ventana de búsqueda de $60 \mathrm{~ms}$, es decir apenas más larga que la ventana de $50 \mathrm{~ms}$ utilizada, el ESM detecta el microsismo en el registro. Esto ocurre porque existe al menos una ventana de $60 \mathrm{~ms}$ que contiene el mencionado evento de la traza 15 junto con los tres eventos picados para las trazas 12, 13 y 14, todas correspondientes a la componente $y$ de los datos, como se puede ver en la Figura 5.8a. Sin embargo, el picado de la traza 15 que ayuda a reunir los 4 eventos necesarios para declarar el microsismo, no es correcto. Más aún, para una ventana de búsqueda de $60 \mathrm{~ms}$, el MBKM también contendría este picado en una misma ventana, y habría que decidir entre éste y el picado correcto detectado para la traza 15 en tiempos menores, cerca de $310 \mathrm{~ms}$ (ver Figura 5.8c). Esta situación ilustra que ventanas de búsqueda mayores tienden a detectar más microsismos, pero aumentan el riesgo de incluir eventos falsos dentro de las ventanas finales. Más aún, en un caso extremo, ventanas demasiado grandes podrían entonces aumentar el riesgo de detectar microsismos falsos formados solamente por falsos picados. Luego, el tamaño de la ventana de búsqueda es un parámetro crítico en estos métodos que debe ser cuidadosamente seleccionado. 
(a) Trazas

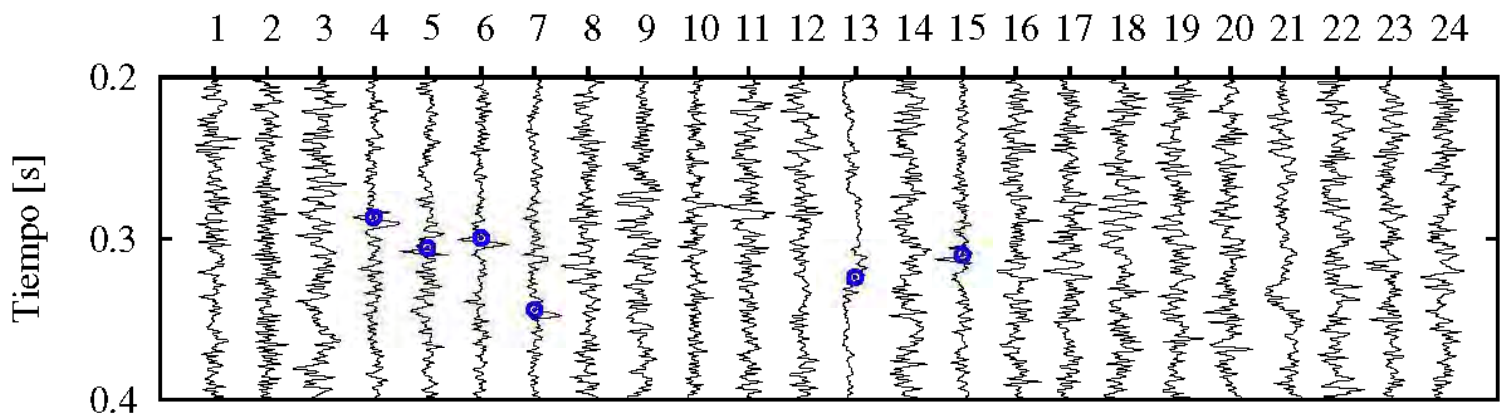

(b)

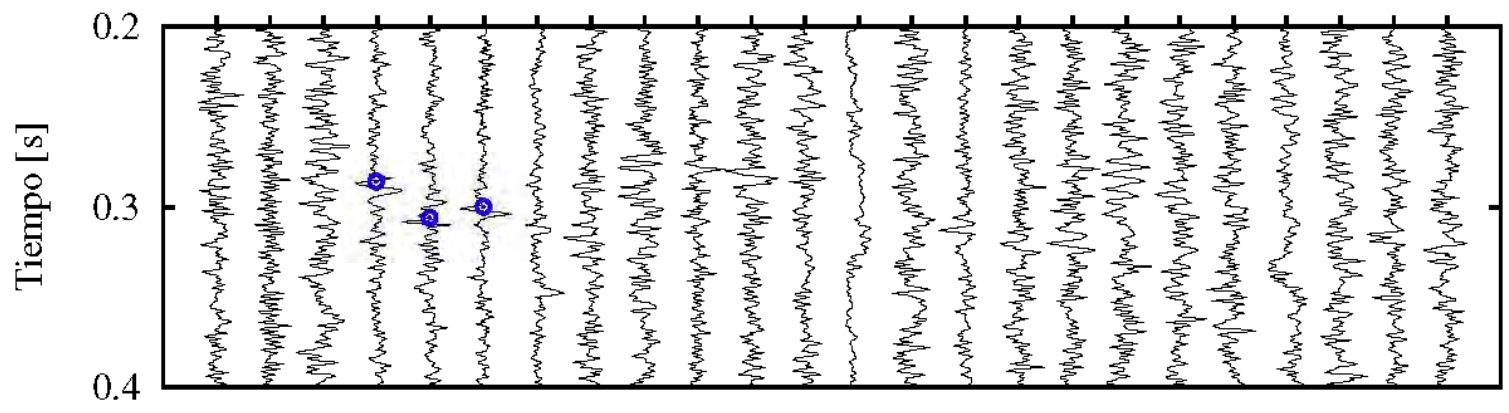

(c)

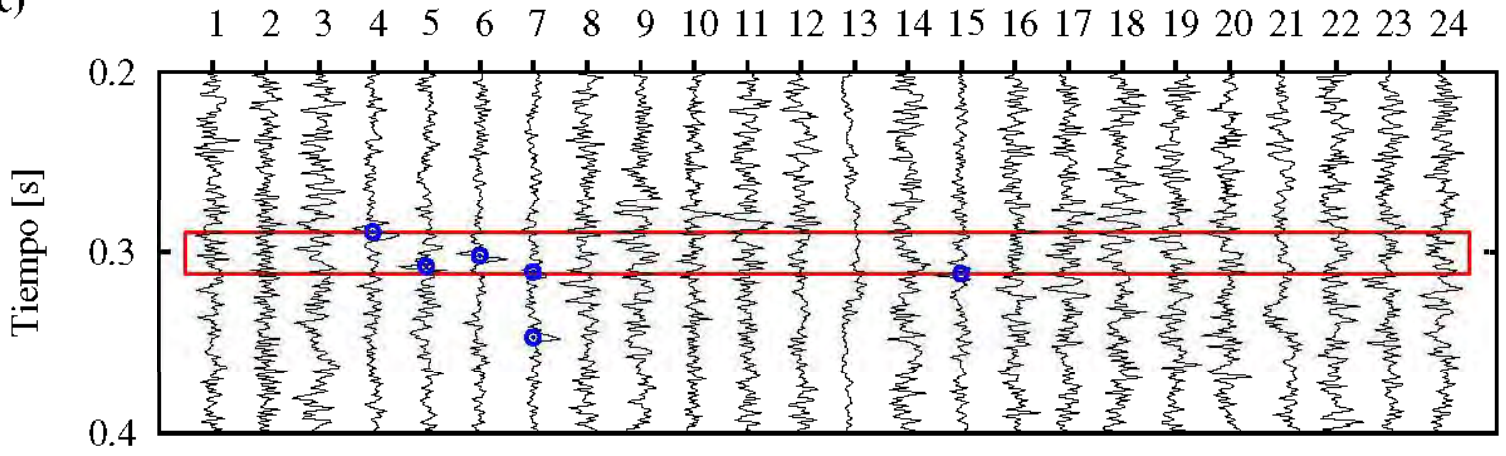

Figura 5.8: Ventana final con el microsismo detectado y los eventos picados para el registro 3. (a) ESM, (b) MAM y (c) MBKM. 
Para concluir con el análisis de los resultados, debemos mencionar que ante registros ruidosos como lo son especialmente los registros 2 y 3 , sería provechoso para mejorar la detección preprocesar los datos intentando mitigar el ruido de fondo de los mismos. Por ejemplo, antes de implementar los algoritmos aquí propuestos, se podría aplicar la técnica de atenuación de ruido presentada por Han et al. [24] o la transformada tiempofrecuencia con restricciones propuesta por Vera Rodriguez et al. [71], lo que sin dudas contribuiría a mejorar la efectividad de los métodos de picado automático propuestos en esta Tesis.

\subsection{Conclusiones del capítulo}

Hemos seleccionado tres de los ocho métodos analizados en el capítulo anterior a partir de los cuales desarrollamos nuevas estrategias de detección automática de microsismos. Los métodos utilizados son el método de Earle y Shearer (ESM), el método de Allen modificado (MAM), y el método de Baer y Kradolfer modificado (MBKM). La técnica propuesta puede dividirse en dos etapas. En un primer paso, se utilizan estos métodos para picar potenciales arribos de microsismos a lo largo de todas las trazas que comprenden un registro de microsísmica. En un segundo paso, se recorre el registro considerando todas las trazas con una ventana de búsqueda de algunas decenas de milisegundos de duración cuyo objetivo es declarar un microsismo cuando contiene al menos la mitad de trazas de una dada componente con eventos picados dentro de ella. La salida de los métodos está dada por una ventana final que abarca el microsismo detectado, si lo hubiera, y con los tiempo de arribo correspondientes dentro de dicha ventana. Además, se brinda un nivel de confianza para cada microsismo detectado, lo que contribuye a determinar la existencia o no de un evento dado.

La aplicación de los métodos es muy simple, y de la misma manera que en los dos capítulos anteriores, una elección adecuada de los parámetros que intervienen en los algoritmos que analizan las trazas en forma individual en el primer paso resulta crucial para el buen funcionamiento de los mismos. Dicha elección es sencilla ya que depende de características de la señal que pueden ser fácilmente extraídas de los datos mediante una inspección visual preliminar de los mismos. La sensibilidad de los métodos depende fundamentalmente de dos parámetros. En la instancia en la que se analizan los datos traza por traza, la sensibilidad está dada por la elección de un valor de umbral THR que 
determina cuándo picar un evento y cuándo no. Luego, en la etapa del análisis global de los registros, y considerando que se ha fijado previamente el número mínimo de trazas con eventos picados para declarar un microsismo, la sensibilidad en la declaración de los microsismos depende de la elección del tamaño de la ventana de búsqueda. Ventanas grandes reducen el riesgo de obviar involuntariamente la detección de un microsismo, pero generan mayor riesgo de declaración de microsismos falsos.

Los métodos fueron testeados con tres registros de microsísmica de 1 s de duración aproximadamente conteniendo un microsismo cada uno de ellos. Los registros se seleccionaron de forma tal que el nivel de dificultad en la detección del microsismo sea bajo, medio, y alto, respectivamente. Los tres métodos utilizados detectaron el microsismo del primer registro con un alto nivel de confianza. El microsismo presente en el segundo registro también fue detectado con éxito, con un indicador de confianza de moderado a bajo. Por último, ante la implementación de los métodos frente al dato más complejo, el ESM y el MAM fallaron en la detección, en tanto que el MBKM detectó el microsismo con un bajo nivel de confianza. Si bien el desempeño del ESM y del MAM fue superior al del MBKM en la aplicación del capítulo anterior para detectar fases de terremotos, en este caso el MBKM resultó una de las mejores alternativas. No obstante, evaluando los eventos picados traza por traza en el registro de mala calidad, podemos afirmar que los desempeños de los tres métodos fueron muy similares. Por último, debemos remarcar que ningún método, en ninguno de los ejemplos considerados, declaró un microsismo falso, un rasgo destacable del desempeño logrado con la metodología propuesta.

Los tiempos de arribo picados para los eventos detectados fueron significativamente precisos, si bien no se adoptó un criterio de refinado de picados consistente para cada traza a lo largo del registro. En todos los casos, los tiempos picados corresponden al arribo impulsivo del lóbulo central del evento, o se encuentran muy próximos al mismo.

Entendemos que los buenos resultados que hemos obtenido en este capítulo están asociados principalmente a dos razones. La primera tiene que ver con el aporte que representa en este problema el extenso estudio de métodos de detección de terremotos llevado a cabo en el capítulo anterior, que fue fundamental para comprender el funcionamiento, debilidades y fortalezas de varios algoritmos. La segunda está dada por la experiencia alcanzada para saber definir y elegir los parámetros a utilizar de forma adecuada en cada uno de lo algoritmos.

El estudio realizado indica que los métodos propuestos funcionan muy bien si la 
relación señal-ruido de los datos es buena. Por otro lado, ante los resultados obtenidos frente a registros con relación señal-ruido moderada o mala, si bien el microsismo de interés en general fue detectado, debemos concluir que sería provechoso preprocesar los datos para atenuar el ruido de fondo y facilitar el desempeño de los métodos.

Esta aplicación del presente trabajo de Tesis es muy reciente, y debemos finalmente mencionar que los métodos podrían mejorarse incluyendo algunos complementos. Por ejemplo, declarado un microsismo, restaría implementar una estrategia para ajustar los tiempos de arribo a una hipérbola. Hecho esto, se podría agregar un tercer paso de procesamiento en el que se restrinja la búsqueda del arribo de los eventos a una ventana centrada en dicha hipérbola. De esta manera, se podría intentar detectar el microsismo en aquellas trazas en las que no se habían picado eventos y corregir los eventos del primer paso. Esta estrategia sería similar a la adoptada para la detección de primeros arribos descrita en el Capítulo 3, en donde se ajustan las rectas de refracción para restringir la búsqueda de los arribos y se corrigen los picados preliminares. Por último, y como trabajo futuro, se pretende agregar también un análisis de polarización de los eventos a partir de la confección de hodogramas. Este es un paso fundamental para realizar la localización de las fracturas que originan los microsismos a detectar, que representa el objetivo final de los estudios de microsismicidad. 


\section{Capítulo 6}

\section{Conclusiones generales y trabajos futuros}

El objetivo principal de este trabajo de Tesis consistió en estudiar las estrategias actuales para realizar la detección automática de señales sísmicas en problemas con aplicación de alto interés e impacto tanto en el ámbito científico-académico como tecnológico y generar nuevos algoritmos y métodos para llevar a cabo esta tarea de forma automática, precisa y eficiente. Las principales aplicaciones de los métodos desarrollados incluyen el picado de los tiempos de los primeros arribos en registros de exploración sísmica, la detección y determinación de los tiempos de llegada de fases de terremotos en registros de estaciones sismológicas, y la detección y picado de señales producidas por microfracturas en registros adquiridos en estudios de microsismicidad.

En el caso del picado automático de los primeros arribos en exploración sísmica, los principales resultados de estas investigaciones constituyen aportes originales para resolver un problema de alto interés en la prospección de recursos naturales. En particular, se estudió con gran detalle el uso de la teoría de los fractales para analizar la traza sísmica, y se aclararon algunos aspectos teóricos que deben ser tenidos en cuenta en el cálculo de la dimensión fractal de la traza. Luego, se presentaron tres nuevos métodos para el picado automático de primeros arribos que pueden ser utilizados para analizar registros marinos, registros de fuente dinamita, o registros de Vibroseis. Dichos métodos introducen estrategias innovadoras para detectar los primeros arribos de forma automática, y ofrecen una alternativa muy viable ante datos complejos ya que los resultados muestran que los métodos son robustos, eficientes en términos computacionales, y fáciles de implementar. En el caso de la detección y picado de fases en registros sismológicos, se programaron ocho métodos diferentes de detección automática de fases de terremotos, y se los analizó comparativamente aplicándolos a datos registrados en la Estación Sismológica de La Plata (LPA). Las conclusiones obtenidas clarifican la decisión respecto de qué algoritmo utilizar para analizar los datos. De esta manera, se aportaron nuevos desarrollos computacionales para ser utilizados en futuros estudios de sismología global 
y de sismicidad. En cuanto a la aplicación para detectar señales asociadas con microsismos, se seleccionaron tres de los ocho métodos analizados en el caso anterior en base al desempeño logrado con cada uno de ellos. Estos tres métodos se adaptaron e implementaron con datos obtenidos en registros de estudios de microsismicidad. A partir de ellos, y utilizando una nueva metodología para declarar microsismos, se propuso una técnica de detección automática de microsismos y determinación de sus tiempos de arribo en las trazas en las que son detectados.

A lo largo de esta Tesis, la información sísmica es analizada bajo la suposición de que se pueden detectar los comienzos de las señales buscadas, que se encuentran inmersas en el ruido de fondo de los datos, calculando ciertos atributos específicamente sensibles a la llegada de los eventos de interés. En este sentido, en la Introducción General se enumeran y comentan una serie de estrategias que, basadas en diferentes atributos convencionales y no convencionales, y a partir diversos criterios, buscan detectar las señales en forma automática. Además, se remarcan en algunos casos las ventajas y desventajas de estas estrategias previas, y se brinda también el marco teórico de los problemas y de los métodos que se investigan en los capítulos subsiguientes.

En el marco del análisis de los atributos sísmicos no convencionales, en el Capítulo 2 se puso énfasis en el estudio de la dimensión fractal de las trazas sísmicas. En este sentido, se compararon dos técnicas para extraer la dimensión fractal de las curvas: el método de compás (CM) y el método del variograma (VM), basadas cada una de ellas en diferentes hipótesis. En el CM, la traza sísmica se debe considerar un curva fractal autosimilar, y en el VM, como un fractal auto-afín. Para poder implementar y comparar las dos técnicas, se generaron datos sintéticos que simulan un experimento de refracción con distintos niveles de ruido. Como primer resultado, se mostró que el VM es teóricamente más adecuado para determinar la dimensión fractal de los datos sísmicos, y es además más sencillo de utilizar que el CM, para el que hay que ajustar un mayor número de parámetros. Entonces, la traza sísmica no debe ser considerada como una curva fractal auto-similar, si bien esto puede lograrse ajustando cuidadosamente la escala en la que se representa la amplitud que se mide en una traza sísmica. A pesar de que con ambos métodos se evidenció una transición en la dimensión fractal frente a la llegada de la señal, los cambios exhibidos por la dimensión fractal cuando fue calculada mediante el VM fueron más abruptos y claros. Se demostró también que el efecto de sumar ruido aleatorio de baja amplitud contribuye a descorrelacionar el ruido de los datos previo 
al arribo de la señal. Esto a su vez produce que se incremente la diferencia entre la dimensión fractal de la primera fracción de la traza (que sólo contiene ruido) y aquella correspondiente al resto del dato (que incluye a la señal buscada). De esta manera, se mejora el desempeño del método. La aplicación del VM en un registro real de prospección marina demuestra que la dimensión fractal de la traza sísmica puede ser utilizada para detectar automáticamente los tiempos de los primeros arribos en exploración sísmica. Eventualmente, otros métodos distintos del variograma son factibles de ser utilizados bajo la condición de que hayan sido diseñados para calcular la dimensión fractal de curvas auto-afines.

En el Capítulo 3 se propusieron tres nuevos métodos para picar los tiempos de los primeros arribos de registros sísmicos de disparo común de forma automática. Los métodos fueron implementados mediante un algoritmo que consta de cinco pasos de procesamiento. En el primer paso se analiza cada traza individualmente y se pican los primeros arribos basándose en ciertos atributos especialmente diseñados para detectar el inicio de la señal. Estos atributos corresponden a un cociente de energías por ventanas, la entropía de la traza, y su dimensión fractal obtenida mediante el VM, aprovechando los resultados del capítulo anterior. Los atributos son filtrados mediante un operador de suavizado que preserva los bordes (EPS), realzando drásticamente los cambios buscados, y definiendo el tiempo exacto de la llegada de la señal. Esta es una técnica innovadora para resolver este problema y que puede adoptarse en muchos otros métodos. El filtrado de los datos recién mencionado completa el primer paso de los algoritmos, en el que se define el atributo a utilizar y se obtiene el conjunto (preliminar) de tiempos picados para todo el registro traza por traza. En los otros pasos del método se corrigen los picados de la primera etapa, considerando la alineación aproximada dada por el modelo de refracción de todo del conjunto de los tiempos picados del registro. Esta novedosa pero simple estrategia genera consistencia en los tiempos de arribo de los registros y además permite detectar y descartar automáticamente aquellas trazas malas o nulas. Para completar el estudio de los nuevos métodos, se realizó un estudio de sensibilidad utilizando registros reales con datos de diferentes complejidades, para los que se obtuvieron resultados que dan cuenta de la robustez de los métodos. Luego, se incorporaron una serie de mejoras en los métodos para aplicarlos a un gran volumen de datos recientemente adquiridos provistos por la industria: una línea de símica 2D y un cubo de un proyecto de sísmica 3D. Entre las mejoras, se agregó un ajuste de los picados para corregirlo al máximo (o 
mínimo) del primer arribo. Además, se incluyeron restricciones en offset y en tiempo, reduciendo así la ventana de trabajo para disminuir el tiempo de procesamiento y facilitar la convergencia de los métodos hacia los modelos de refracción. Se incorporó también un paso de pre-procesamiento para remover los efectos de topografía (correcciones estáticas por elevación) y facilitar la determinación de las rectas de refracción. Con todas estas mejoras, los resultados obtenidos demuestran que los métodos propuestos funcionan con éxito aún en algunos casos en los que los métodos incluidos en paquetes de procesamiento tienden a fallar.

Teniendo en cuenta la analogía que existe entre el picado automático de primeros arribos en datos de prospección sísmica y la detección automática de fases de terremotos con datos de sismología, el Capítulo 4 estuvo focalizado en realizar un análisis comparativo de métodos de detección de fases de terremotos utilizando datos registrados en la Estación Sismológica de La Plata. Para ello, se consideraron los tres algoritmos propuestos en el capítulo anterior para el análisis de trazas individuales, se programaron tres de los métodos tradicionales de mayor relevancia en el tema, y se propusieron otros dos métodos que suponen algunas mejoras a métodos previos. Este conjunto de ocho métodos fue analizado desde el punto de vista de su capacidad para detectar fases y de la exactitud de las detecciones. En particular, el método de Earle y Shearer (ESM) y el método de Allen modificado (MAM) arrojaron los mejores resultados, por lo que se recomienda su uso frente a un problema en el que se quiera detectar eventos utilizando un gran volumen de datos, como puede ser el caso de estudios de sismología global en la Estación Sismológica de La Plata, o estudios de sismicidad en otras estaciones nacionales. La Facultad de Ciencias Astronómicas y Geofísicas de la Universidad Nacional de la Plata cuenta con una estación de registración continua en Río Grande, Tierra del Fuego, en donde se planea realizar un trabajo de investigación en el que se adapten e implementen los métodos aquí desarrollados.

El análisis comparativo de los métodos para detectar y picar fases de terremotos realizado en el Capítulo 4 brindó las herramientas computacionales y la experiencia suficiente para generar una nueva aplicación de los métodos de detección automática de señales de esta Tesis utilizando registros de microsísmica. En este caso, las señales buscadas son generadas por las fracturas que se inducen por inyección hidráulica en las inmediaciones de un reservorio. Estas perturbaciones se manifiestan como pequeños terremotos (microsismos) que son registrados en pozos de monitoreo cercanos al pozo de extracción. 
En el Capítulo 5 se propuso entonces una nueva metodología para detectar microsismos de forma automática que consta de dos pasos. El primer paso se basa en aplicar el método de Earle y Shearer (ESM), el método de Allen modificado (MAM), o el método de Baer y Kradolfer modificado (MBKM) para picar eventos en las trazas que conforman un registro de microsísmica, de manera similar a la que se los utilizó para detectar terremotos. Se obtiene así un conjunto de tiempos picados que representan potenciales arribos de microsismos en cada traza. En el segundo paso, se examinan los registros analizados en busca de la presencia de microsismos. Para ello, se utiliza una ventana que avanza muestra a muestra considerando la alineación hiperbólica aproximada con la que arriban los microsismos a los registros. La salida de esta nueva estrategia está dada por el número de microsismos detectados en cada registro, un indicador de confianza asociado a cada detección, y los tiempos de los arribos de los microsismos en aquellas trazas en las que pudo ser detectado. Para testear la metodología propuesta se utilizaron tres registros de un estudio de microsismicidad de diferente complejidad en cuanto a su relación señal-ruido. Los métodos funcionan muy bien cuando la relación señal-ruido de los datos es buena, y de forma muy aceptable cuando la calidad de la señal es regular o mala. La detección es confiable pues en ningún caso ningún método detectó la presencia de microsismos erróneamente. Además, los comienzos de las señales fueron obtenidos con una exactitud significativamente alta. No obstante, esta aplicación es reciente y se pretende continuar desarrollando los métodos e incluir algunos complementos para mejorar su desempeño. En particular, a futuro se planea agregar un análisis de pola-rización de la llegada de las ondas mediante la confección de hodogramas, una técnica fundamental para la localización de las microfracturas que representan el objetivo de los estudios de microsismicidad. Asimismo, restan estudiarse otras técnicas para declarar los microsismos a partir de los resultados que brindan los atributos utilizados, y consolidar la vinculación con la industria para continuar con esta línea de investigación. Por otro lado, dado que los datos de microsísmica se caracterizan por su mala relación señal-ruido, debe también evaluarse la posibilidad de adoptar algún pre-proceso de atenuación de ruido que, según se espera, mejoraría los resultados obtenidos.

Dado el crecimiento exponencial del volumen de datos registrados en exploración sísmica, la constante aparición de nuevas redes sismológicas, y el desarrollo de nuevas tecnologías como es el caso de los estudios de microsísmica (actualmente en auge), persiste la necesidad de contar con nuevas y mejores técnicas de detección automática de señales 
sísmicas que realicen la tarea de forma eficiente, precisa, y efectiva. Más aún, estos desarrollos podrían aplicarse también a otras áreas no abordadas en esta Tesis, como ser el monitoreo de actividad volcánica, señales de otras ramas de la prospección geofísica, o en general, cualquier tipo de datos de otras ciencias donde sea necesario determinar el advenimiento de cierta señal de interés en un contexto de baja relación señal-ruido. 


\section{Apéndice A}

\section{El filtro EPS}

El suavizado con preservación de bordes (EPS) es un proceso de filtrado basado en consideraciones estadísticas que está diseñado para reducir el ruido de la señal, pero al mismo tiempo preservar los cambios más abruptos de los datos, es decir, los "bordes" [34]. En este apéndice describimos el algoritmo EPS en una dimensión, si bien se puede generalizar fácilmente para 2 o 3 dimensiones [4].

El EPS puede ser considerado como una simple modificación del método de suavizado por promediación móvil. Al igual que este método, el único parámetro del que depende el algoritmo del EPS es la longitud de la ventana móvil. Veamos cómo funciona este filtro por medio de un ejemplo.

Consideremos un operador EPS de cinco puntos. Dada una muestra arbitraria de una función muestreada, digamos $s_{i}, i=1,2, \ldots, N$, habrá cinco ventanas desplazadas en una muestra una de otra que incluyen a la muestra $s_{i}$ :

$$
\begin{aligned}
& \text { Ventana 1: }\left(s_{i-4}, s_{i-3}, s_{i-2}, s_{i-1}, s_{i}\right) \\
& \text { Ventana 2: }\left(s_{i-3}, s_{i-2}, s_{i-1}, s_{i}, s_{i+1}\right) \\
& \text { Ventana 3: }\left(s_{i-2}, s_{i-1}, s_{i}, s_{i+1}, s_{i+2}\right) \\
& \text { Ventana 4: }\left(s_{i-1}, s_{i}, s_{i+1}, s_{i+2}, s_{i+3}\right) \\
& \text { Ventana 5: }\left(s_{i}, s_{i+1}, s_{i+2}, s_{i+3}, s_{i+4}\right)
\end{aligned}
$$

En la salida del filtro EPS, la muestra $s_{i}$ se sustituye por el valor medio de aquella ventana con la menor desviación estándar. Este proceso se repite para todas las muestras de los datos. Como resultado, el proceso de filtrado asigna a la muestra $i$-ésima la media de la ventana que abarca los datos más homogéneos en torno a dicha muestra. Por lo tanto, si una ventana contiene un cambio brusco (borde), la desviación estándar será alta y la media de esta ventana no será la seleccionada para la salida del EPS. En consecuencia, el ruido se filtra mediante el promedio mientras que los cambios más 
a)

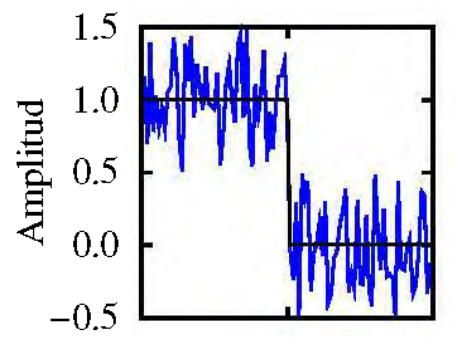

b)

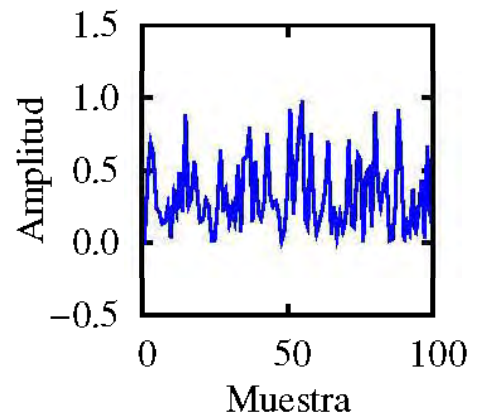

c)

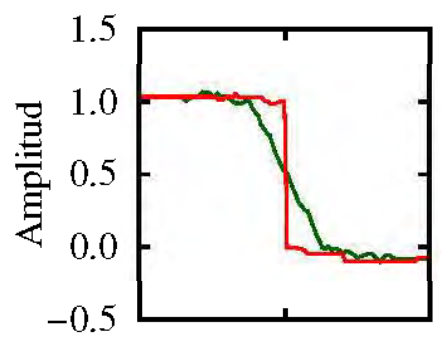

d)

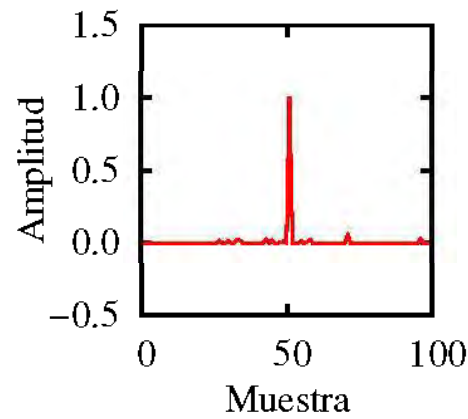

Figura A.1: (a) Función escalón (negro) y función escalón contaminada con ruido (azul). (b) Valor absoluto de la derivada de la función escalón contaminada con ruido. (c) Función escalón con ruido luego de ser suavizada por promediación móvil (verde) y por EPS (rojo) utilizando un operador de 25 muestras. (d) Valor absoluto de la derivada la función filtrada por EPS en (c).

abruptos se conservan. Notar la diferencia con la promediación móvil, en donde sólo se calcula la ventana centrada en la muestra $i$-ésima (y la salida resulta entonces suavizada) pero los cambios bruscos no se conservan ya que también son suavizados por el promedio.

El EPS es ilustrado en la Figura A.1 y comparado con el suavizado por promediación móvil. En el panel (a) se muestra una función escalón (en negro) que es contaminada con ruido aleatorio (en azul). El panel (b) muestra el valor absoluto de la derivada de la función contaminada. El escalón es enmascarado por el ruido y no se puede identificar fácilmente mediante esta derivada. Comparemos ahora el efecto de filtrar la señal por promediación móvil y por EPS utilizando ventanas de 25 muestras. Al suavizar por promediación móvil, se detecta el cambio de la señal (curva verde en la Figura A.1c), pero la posición exacta del escalón no se puede determinar. Por otro lado, luego de la aplicación del filtro EPS, la ubicación del escalón es claramente visible (en rojo en la Figura A.1c). Más aún, su posición exacta se puede identificar fácilmente mediante el valor absoluto de la derivada de la función filtrada (Figura A.1d). Este ejemplo ilustra el filtrado por EPS y demuestra sus virtudes. 


\section{Referencias}

[1] Akaike, H. Autoregressive model fitting for control. Annals of the Institute of Statistical Mathematics, 23:163-180, 1971.

[2] Akaike, H. Markovian representation of stochastic processes and its application to the analysis of autoregressive moving average processes. Annals of the Institute of Statistical Mathematics, 26:363-387, 1974.

[3] Akram, J. Automatic P-wave Arrival Time Picking Method for Seismic and Microseismic Data. CSPG CSEG CWLS Convention, convention abstracts, 2011.

[4] AlBinHassan, N.M., Y. Luo, and M.N. Al-Faraj. 3D edge-preserving smoothing and applications. Geophysics, 71(4):P5-P11, 2006.

[5] Aldersons, F. Toward three-dimensional crustal structure of the Dead Sea region from local earthquake tomography. PhD thesis, Tel Aviv University, Israel, 2004.

[6] Allen, R.E. Automatic earthquake recognition and timing from single traces. Bulletin of the Seismological Society of America, 68(5):1521-1532, 1978.

[7] Allen, R.E. Automatic phase pickers: their present use and future prospects. Bulletin of the Seismological Society of America, 72(6):S225-S242, 1982.

[8] Anstey, N. Attributes in color: the early years. CSEG Recorder, 30:12-15, 2005.

[9] Baer, M. and U. Kradolfer. An automatic phase picker for local and teleseismic events. Bulletin of the Seismological Society of America, 77(4):1437-1445, 1987.

[10] Bai, C.Y. and B.L.N. Kennett. Automatic phase-detection and identification by full use of a single three-component broadband seismogram. Bulletin of the Seismological Society of America, 90(1):187-198, 2000.

[11] Balch, A.H. Color sonograms: a new dimension in seismic data interpretation. Geophysics, 36:1074-1098, 1971.

[12] Boschetti, F., M.D. Dentith, and R.D. List. A fractal-based algorithm for detecting first arrivals on seismic traces. Geophysics, 61:1095-1102, 1996. 
[13] Buffoni, C., N.C. Sabbione, G. Connon, and J.L. Hormaechea. Localización de hipocentros y determinación de su magnitud en Tierra del Fuego y zonas aledañas. Geoacta, 34:75-85, 2009.

[14] Burrough, P.A. Multiscale sources of spatial variation in soil. I. The application of fractal concepts to nested levels of soil variation. European Journal of Soil Science, 34:577-597, 1983.

[15] Carr, J.R. and W.B. Benzer. On the practice of estimating fractal dimension. Mathematical Geology, 23(7):945-958, 1991.

[16] Chen, Z. and R.R. Stewart. A multi-window algorithm for real-time automatic detection and picking of p-phases of seismic events. CREWES Research Report, $18: 15.1-15.9,2006$.

[17] Chopra, S. and K.J. Marfurt. Seismic Attributes for Prospect Identification and Reservoir Characterization. Geophysical Developments No. 11. SEG, 1st. edition, 2007.

[18] Cohen, J.K. and J.M. Stockwell. CWP/SU: Seismic Unix Release No. 4.0: an open source software package for seismic research and processing. Center for Wave Phenomena, Colorado School of Mines, 2007.

[19] Coppens, F. First arrivals picking on common-offset trace collections for automatic estimation of static corrections. Geophysical Prospecting, 33:1212-1231, 1985.

[20] Denis, A. and F. Crémoux. Using the entropy of curves to segment a time or spatial series. Mathematical Geology, 34(8):899-914, 2002.

[21] Earle, P.S. and P.M. Shearer. Characterization of global seismograms using an automatic-picking algorithm. Bulletin of the Seismological Society of America, 84(2):366-376, 1994 .

[22] Feder, J. Fractals. Plenum, New York, 1988.

[23] Gelchinsky, B. and V. Shtivelman. Automatic picking of first arrivals and parametrization of traveltime curves. Geophysical Prospecting, 31:915-928, 1983.

[24] Han, L., J. Wong, and J.C. Bancroft. Time picking and random noise reduction on microseismic data. CREWES Research Report, 21:30.1-30.13, 2009. 
[25] Hatherly, P.J. A computer method for determining seismic first arrival times. Geophysics, 47(10):1431-1436, 1982.

[26] Jiao, L. and W.M. Moon. Detection of seismic refraction signals using a variance fractal dimension technique. Geophysics, 65(1):286-292, 2000.

[27] Johnson, C.E., A. Bittenbinder, B. Bogaert, L. Dietz, and W. Kohler. Earthworm: a flexible approach to seismic network processing. Incorporated Research Institute for Seismology Newsletters, 14(2):1-4, 1995.

[28] Kennett, B.L.N. IASPEI 1991 Seismological tables. Research School of Earth Sciences, Australian National University, 1991.

[29] Klinkenberg, B. A review of methods used to determine the fractal dimension of linear features. Mathematical Geology, 26(1):23-46, 1994.

[30] Korvin, G. Fractal models in the Earth Sciences. Elsevier, Amsterdam, 1992.

[31] Küperkoch, L., T. Meier, J. Lee, W. Friederich, and EGELADOS Working Group. Automated determination of P-phase arrival times at regional and local distances using higher order statistics. Geophysical Joumal International, 181:1159-1170, 2010 .

[32] Leonard, M. Comparison of manual and automatic onset time picking. Bulletin of the Seismological Society of America, 90(6):1384-1390, 2000.

[33] Leonard, M. and B.L.N. Kennett. Multi-component autoregressive techniques for the analysis of seismograms. Physics of the Earth and Planetary Interiors, 113:247$263,1999$.

[34] Luo, Y., M. Marhoon, S. Al Dossary, and M. Alfaraj. Edge-preserving smoothing and applications. The Leading Edge, 21(2):136-158, 2002.

[35] Malinverno, A. Testing linear models of sea-floor topography. Pure and Applied Geophysics, 131:139-155, 1989.

[36] Mandelbrot, B.B. The fractal geometry of Nature. W. H. Freeman and Company, New York, 1983.

[37] Mandelbrot, B.B. Self-affine fractal sets i, ii, iii. In L. Pietronero and E. Tosatti, editors, Fractals in Physics, B. V., 1986. Elsevier Science Publishers. 
[38] Maxwell, S.C. A Brief Guide to Passive Seismic Monitoring. CSEG National Convention, convention abstracts, pages 177-178, 2005.

[39] Maxwell, S.C. Confidence and Accuracy of Microseismic Images. CSPG CSEG CWLS Convention, convention abstracts, pages 480-483, 2009.

[40] Maxwell, S.C. What Does Microseismic Tell Us About Hydraulic Fractures? SEG Expanded Abstracts, pages 1565-1569, 2011.

[41] Maxwell, S.C. and T.I. Urbancic. The role of passive microseismic monitoring in the instrumented oil field. The Leading Edge, 20(6):636-639, 2001.

[42] Molyneux, J.B. and D.R. Schmitt. First-break timing: arrival onset times by direct correlation. Geophysics, 64:1492-1501, 1999.

[43] Munro, K. Automatic event detection and picking of p-wave arrivals. CREWES Research Report, 16:12.1-12.10, 2004.

[44] Murat, M.E. and A.J. Rudman. Automated first arrival picking: A neural network approach. Geophysical Prospecting, 40:587-604, 1992.

[45] Nams, V.O. Improving accuracy and precision in estimating fractal dimension of animal movement paths. Acta Biotheoretica, 54:1-11, 2006.

[46] Peitgen, H.O., H. Jurgens, and D. Saupe. Fractals for the classroom. Part one: Introduction to fractals and chaos. Springer-Verlag, New York, 1992.

[47] Peraldi, R. and A. Clement. Digital processing of refraction data: study of first arrivals. Geophysical Prospecting, 20:529-548, 1972.

[48] Ruud, B.O. and E.S. Husebye. A new three-component detector and automatic single-station bulletin production. Bulletin of the Seismological Society of America, $82(1): 221-237,1992$.

[49] Sabbione, J.I., M.L. Rosa, D.R. Velis, and N.C. Sabbione. Detección semiautomática de fases de terremotos registrados en la Estación sismológica de La Plata (LPA). In XXIV Reunión Científica de la Asociación Argentina de Geofísicos y Geodestas, Mendoza, Argentina, 2009.

[50] Sabbione, J.I., M.L. Rosa, D.R. Velis, and N.C. Sabbione. Análisis comparativo de diferentes métodos de picado automático de fases de terremotos registrados en la Estación Sismológica de La Plata (LPA). Geoacta, 36(2):189-209, 2011. 
[51] Sabbione, J.I. and D.R. Velis. First arrivals picking using fractal dimension analysis. In VII Congreso de Exploración y Desarrollo de Hidrocarburos. La Geofísica: integradora del conocimiento del subsuelo, pages 187-200, Mar del Plata, Argentina, 2008 .

[52] Sabbione, J.I. and D.R. Velis. Nuevas técnicas y algoritmos para el picado automático de primeros arribos sísmicos. In III Convención Cubana de Ciencias de La Tierra, La Habana, Cuba, 2009.

[53] Sabbione, J.I. and D.R. Velis. Nuevas técnicas y algoritmos para el picado automático de primeros arribos sísmicos. In $2^{o}$ Workshop sobre Inversión y Procesamiento de Señales en Exploración Sísmica (IPSES'09), Facultad de Ciencias Astronómicas y Geofísicas, Universidad Nacional de La Plata, Argentina, 2009.

[54] Sabbione, J.I. and D.R. Velis. Automatic first breaks picking: new strategies and algorithms. Geophysics, 75:V67-V76, 2010.

[55] Sabbione, N.C., G. Connon, J.L. Hormaechea, and M.L. Rosa. Estudio de sismicidad en la provincia de Tierra del Fuego. Geoacta, 32:41-50, 2007.

[56] Saragiotis, C.D., L.J. Hadjileontiadis, I.T. Rekanos, and S.M. Panas. Automatic P-phase picking using maximum kurtosis and k-statistics criteria. IEEE Geoscience and Remote Sensing Letters, 1(3):147-151, 2004.

[57] Shemeta, J. and P. Anderson. It's a matter of size: Magnitude and moment estimates for microseismic data. The Leading Edge, 29(3):296-302, 2010.

[58] Shepard, D. A two-dimensional interpolation function for irregularly-spaced data. ACM '68 Proceedings of the 1968 23rd ACM national conference, 1968.

[59] Sheriff, R.E. Encyclopedic Dictionary of Exploration Geophysics. Geophysical Reference Series No. 13. SEG, 4rd. edition, 2002.

[60] Sleeman, R. and T. van Eck. Robust automatic P-phase picking: an online implementation in the analysis of broadband seismogram recordings. Physics of the Earth and Planetary Interiors, 113:265-275, 1999.

[61] Spagnolini, U. Adaptive picking of refracted first arrivals. Geophysical Prospecting, 39:293-312, 1991. 
[62] St-Onge, A. Akaike Information Criterion Applied to Detecting First Arrival Times on Microseismic Data. SEG Expanded Abstracts, pages 1658-1662, 2011.

[63] Taner, M.T., F. Koehler, and R.E. Sheriff. Complex seismic trace analysis. Geophysics, 44(6):1041-1063, 1979.

[64] Taner, M.T. and R.E. Sheriff. Application of amplitude, frequency, and other attributes to stratigraphic and hydrocarbon determination. In Payton, G.E., editor, Application to hydrocarbon exploration, pages 352-359, 1977.

[65] Tarantola, A. Inverse Problem Theory, Methods for Data Fitting and Model Parameter Estimation. Elsevier Science Publishing Co., 1987.

[66] Tibuleac, I.M., E.T. Herrin, J.M. Britton, R. Shumway, and A.C. Rosca. Automatic secondary seismic phase picking using wavelet transform. In Nuclear Explosion Monitoring: Building the Knowledge Base, pages 352-359, Tucson, Arizona, 2003.

[67] Tosi, P., S. Barba, V. De Rubeis, and F. Di Luccio. Seismic signal detection by fractal dimension analysis. Bulletin of the Seismological Society of America, 89(4):970-977, 1999 .

[68] Tselentis, G., N. Martakis, P. Parakevopoulus adn A. Lois, and E. Sokos. A method for microseismic event detection and p-phase picking. SEG Expanded Abstracts, pages 1638-1642, 2011.

[69] Turcotte, D.L. Fractals and chaos in Geology and Gephysics. Cambridge University Press, Cambridge, second edition, 1997.

[70] Vera Rodriguez, I. Automatic Time-picking of Microseismic Data Combining STA/LTA and the Stationary Discrete Wavelet Transform. CSPG CSEG CWLS Convention, convention abstracts, 2011.

[71] Vera Rodriguez, I., D. Bonar, and M.D. Sacchi. Microseismic record de-noising using a sparse time-frequency transform. SEG Expanded Abstracts, pages 1693-1698, 2011.

[72] Whiters, M., R.A. Aster, C. Young, J. Beiriger, M. Harris, S.Moore, and J. Trujillo. A comparison of select trigger algorithms for automated global seismic phase and event detection. Bulletin of the Seismological Society of America, 88(1):95-106, 1998. 
[73] Wilson, T.H. Some distinctions between self-similar and self-affine estimates of fractal dimension with case history. Mathematical Geology, 32(3):319-335, 2000.

[74] Wong, J., L. Han, J.C. Bancroft, and R.R. Stewart. Automatic time-picking of first arrivals on noisy microseismic data. CSEG Conference Abstracts, 2009.

[75] Yilmaz, Ö. Seismic Data Analysis: processing, inversion, and interpretation of seismic data. Investigations in Geophysics. SEG, 2001.

[76] Yung, S.K. and L.T. Ikelle. An example of seismic time picking by third-order bicoherence. Geophysics, 62(6):1947-1951, 1997. Short Note.

[77] Zhang, H., C. Thurber, and C. Rowe. Automatic P-wave arrival detection and picking with multiscale wavelet analysis for single-component recordings. Bulletin of the Seismological Society of America, 93(5):1904-1912, 2003.

[78] Zhu, X., D.P. Sixta, and B.G. Angstman. Tomostatics: Tourning ray tomography + static corrections. The Leading Edge, 11:15-23, 1992. 